Daniel Prata Vieira

Estudo Experimental das Vibrações Induzidas pela Emissão de Vórtices em Cilindros Flexíveis Inclinados em Relação à Correnteza 
DANIEL PRATA VIEIRA

\section{Estudo Experimental das Vibrações Induzidas pela Emissão de Vórtices em Cilindros Flexíveis Inclinados em Relação à Correnteza}

Tese apresentada à Escola Politécnica da Universidade de São Paulo para obtenção do título de Doutor em Ciências. 
DANiEL Prata Vieira

\section{Estudo Experimental das Vibrações Induzidas pela Emissão de Vórtices em Cilindros Flexíveis Inclinados em Relação à Correnteza}

Tese apresentada à Escola Politécnica da Universidade de São Paulo para obtenção do título de Doutor em Ciências.

Área de Concentração:

Engenharia Naval e Oceânica

Orientador:

Prof. Dr. André Luis Condino Fujarra 
Este exemplar foi revisado e corrigido em relação à versão original, sob responsabilidade única do autor e com a anuência de seu orientador.

São Paulo, de de

Assinatura do autor:

Assinatura do orientador:

Catalogação-na-publicação

Vieira, Daniel Prata

Estudo experimental das vibrações induzidas pela emissão de vórtices em cilindros flexíveis inclinados em relação à correnteza / D. P. Vieira -- versão corr. São Paulo, 2017.

$188 \mathrm{p}$.

Tese (Doutorado) - Escola Politécnica da Universidade de São Paulo. Departamento de Engenharia Naval e Oceânica.

1.Vórtices dos Fluidos (Experimentação e Experimentos) 2.Vibrações 3.Tubos Flexíveis I.Universidade de São Paulo. Escola Politécnica.

Departamento de Engenharia Naval e Oceânica II.t. 
Ao meu filho Bernardo, pela sua inabalável vontade de viver. 


\section{Agradecimentos}

Esta tese, como qualquer outra, é fruto de um trabalho conjunto de muitas pessoas. Pessoas estas que plantaram, desde os primeiros anos de vida, uma curiosidade necessária ao caminho da pesquisa. As que relaciono aqui são apenas algumas.

Primeiramente, gostaria de agradecer minha falecida vó Emília, primeira pessoa a me incentivar ao caminho do estudo. Ao suor da minha mãe Lourdes, a quem devo praticamente tudo que conquistei. Aos ensinamentos das minhas tias Margarete e Sandra que abriram os caminhos da leitura que hoje culminaram com este texto. Agradeço minha irmã Andréia por colocar as vírgulas no lugar durante o inestimável trabalho de revisão do texto. Agradeço também as pessoas mais próximas da minha família: meu pai Reinaldo, meu primo Junior, minha tia Ana Fátima, meu tio Jorge, meus falecidos vô Zé e vô Tó, e minha vó Helena. Com certeza vocês formaram a base da minha educação.

À minha esposa e companheira Natasha faltariam páginas para descrever o quanto seu apoio e incentivo foram fundamentais à conclusão deste trabalho. Uma parceria tão grande quanto a nossa que já dura seus oito anos e os recentes cuidados extraordinários que nosso filho Bernardo demanda e que você exerce com extrema dedicação e carinho, são apenas um pequeno exemplo de como um amor verdadeiro pode fazer diferença na vida de uma pessoa.

Agradeço infinitamente os profissionais de saúde (médicos, enfermeiros, técnicos, fisioterapeutas, fonoaudiólogos, limpeza e alimentação) dos Hospitais São Luiz e Santa Catarina que cuidaram do meu filho Bernardo possibilitando sua recuperação e reabilitação enquanto eu desenvolvia diversas atividades desta pesquisa. Somente com a confiança que vocês passaram isso foi possível. Em especial, gostaria de agradecer aos cuidados dos excepcionais Dr. Vinícius Scaramuzzi e Dr. Uenis Tannuri, vocês fizeram a diferença.

Agradeço também à família que me acolheu: minha sogra Magda, minha irmã Charlotte, meu sobrinho Kayque, tia Cleire, tio Geraldo e minha prima Simone. Vocês sempre estão por perto para o que eu precisar.

Na minha vida profissional, agradeço ao Professor Kazuo Nishimoto que há quase dez anos me encoraja a desenvolver meu potencial nas mais diversas áreas da Engenharia Naval, através de toda estrutura conquistada com o Tanque de Provas Numérico. Agradeço também a parceria desde a iniciação científica do meu amigo e orientador Professor André Fujarra, que me impulsionou a elaborar este texto através de um programa de doutorado direto logo ao fim da graduação. 
Agradeço aos meu amigos Edgard Borges Malta e Fabiano Rampazzo por me apoiarem tanto no aspecto profissional como do pessoal, através da Technomar Engenharia Oceânica e de seus sócios Felipe Rateiro, Carlos Fucatu e Marcelo Cyrillo, assim como os colegas de trabalho Felipe Masetti, Fernando Luz, Lázaro Moratelli Jr., Gustavo Pimentel, Rodrigo Sant'Anna e Vinícius Vaguetti.

Aos companheiros de TPN, agradeço em destaque a ajuda fundamental do meu amigo Pedro Cardozo, sem a qual nenhum dos experimentos que realizei até hoje teriam saído do papel. Agradeço aos companheiros de jornada Raul Dotta, Thiago Peternella, André Gallina, Rodrigo Schiller, Rafael Máximo, Oygres Siqueira, José Roberto, Amin Assad, Dênnis Maluf, Felipe Pierrobom e Fábio Amorim, além dos Professores GuiIherme Franzini, Rodolfo Gonçalves e Rodrigo Amarante. Aos amigos da Argonáutica Rafael Watai, Rodrigo Lavieri, Felipe Ruggieri e Guilherme Feitosa. Aos Professores Eduardo Tannuri, Cláudio Mueller, Liang-Yee Cheng e Alexandre Simos.

Aos profissionais do Departamento de Engenharia Naval e Oceânica, agradeço à dedicação da Lânia Camilo e dos Professores André Bergsten, Bernardo Andrade e Gustavo Assi.

Agradeço aos Professores Celso Pesce e Clóvis Martins por possibilitar a utilização do recursos do Laboratório de Mecânica Offshore, assim como a ajuda do colega Eduardo Malta.

Agradeço ao Instituto de Pesquisas Tecnológicas, principalmente ao Dr. André Mitsuo Kogishi, que desde as primeiras discussões acerca do experimento me apoiou incondicionalmente com os mais variados recursos, assim como todo corpo técnico: David, Fidel, Bruno e Gustavo que "carregaram" o experimento nas costas.

Agradeço à Agência Nacional do Petróleo pelo financiamento deste trabalho, através de seu Programa de Recursos Humanos, PRH-19, na oportunidade coordenado pelos Professores Hernani Brinati, Marcelo Ramos e Jairson de Lima. 
Ogni uomo semplice, porta in cuore un sogno, con amore ed umiltà potrà costruirlo Se con fede tu saprai vivere umilmente più felice tu sarai anche senza niente. Se vorrai ogni giorno con il tuo sudore una pietra dopo l'altra alto arriverai Nella vita semplice troverai la strada che la calma donerà al tuo cuore puro

E le gioie semplici sono le più belle sono quelle che alla fine sono le più grandi Dai e dai ogni giorno con il tuo sudore una pietra dopo l'altra in alto arriverai

La canzone de San Damiano, San Francesco de Assisi 


\section{Resumo}

O problema das vibrações induzidas por vórtices em cilindros flexíveis inclinados em relação ao perfil de correnteza incidente é estudado através de uma abordagem experimental. Este tema se mostra de grande importância e aplicação na Engenharia Naval e Oceânica uma vez que são diversas as estruturas que se encaixam nesta descrição, como são o casos dos risers e linhas de amarração. Apesar de extensa, a literatura técnica especializada no assunto é focada em simplificações, tais como os estudos de cilindros rígidos fixos, cilindros rígidos montados em base elástica e cilindros flexíveis verticais ou lançados em catenária livre. A questão da inclinação é abordada em termos do Principio da Independência que diz que as forças e a frequência de emissão de vórtices em um cilindro inclinado são iguais as de um cilindro vertical se considerada apenas a parcela da correnteza normal à direção de inclinação. Estudos anteriores mostraram que este princípio é válido somente em algumas condições específicas e poucos deles apresentam resultados para cilindros flexíveis. Com base nisso, um ensaio em escala reduzida em tanque de reboque foi realizado com um modelo de linha composto por um tubo de silicone preenchido com microesferas de aço e condições de contorno articuladas em suas extremidades, o que conferiu características inerciais e geométricas ideais para a obtenção do fenômeno. Além da configuração vertical $\left(\theta=0^{\circ}\right)$, que é o caso de referência, o modelo foi estudado em outras quatro inclinações com a vertical: $\theta=10^{\circ}, 20^{\circ}, 30^{\circ} \mathrm{e} 45^{\circ}$. Estas inclinações foram ensaiadas para cinco diferentes azimute: $\beta=0^{\circ}, 45^{\circ}, 90^{\circ}, 135^{\circ} \mathrm{e} 180^{\circ}$, resultando em vinte e uma configurações de inclinação. Os resultados são analisados em termos da decomposição modal da vibração da linha, ou seja, são apresentadas amplitudes e frequências de oscilação ocorridas em cada um dos modos de vibrar. Além disso são realizadas análises espectrais, gráficos de evolução espaço-temporal, trajetórias de pontos ao longo do modelo flexível, entre outros. Frequências naturais, coeficientes de amortecimento e trações no topo são apresentados, complementarmente, como resultados de caracterização do modelo. Os estudos apontaram para uma validade do PI com algumas ressalvas, principalmente influenciadas pela diferença nas frequências do primeiro e segundo modo que é crescente com o aumento da inclinação. Além disso conclusões importantes sobre a coexistência modal, em regiões de ressonância e/ou de transição da dominância modal, foram obtidas.

Palavras-chave: Vibrações induzidas pela emissão de vórtices, cilindros flexíveis, princípio da independência, decomposição modal, investigação experimental 


\section{Abstract}

The vortex-induced vibration problem in flexible cylinders yawed in relation to the incident current profile is studied through an experimental approach. This topic has great importance and application on Naval and Oceanic Engineering once there are multiple structures that fit into this description, such as risers and mooring lines. Though extensive, technical literature specialized on this topic is focused on simplifications such as the study of fixed rigid cylinders, elastic base rigid cylinders and flexible cylinders assembled vertically or launched in free hanging catenary. The inclination issue is addressed in the terms of the Principle of Independence which states that the forces and frequency shedding in an inclined cylinder are equal to those of a vertical cylinder if only considered the current component normal to the inclination plane. Previous studies showed that this principle is valid only on some specific conditions and few of them showed results to flexible systems. Based on this, a scaled tow tank test was performed with a line model composed of a silicone tube filled with steel microspheres and articulated end conditions, which offered the ideal inertial and geometrical conditions to obtaining the phenomenon. Besides the vertical configuration $\left(\theta=0^{\circ}\right)$, which is the reference case, the model was studied in other four inclinations with the vertical: $\theta=10^{\circ}$, $20^{\circ}, 30^{\circ}$ and $45^{\circ}$. These inclinations were tested for five different azimuth directions: $\beta=0^{\circ}, 45^{\circ}, 90^{\circ}, 135^{\circ}$ and $180^{\circ}$, resulting in 21 configurations. The results are analyzed on terms of the modal decomposition of the line motions, that is, amplitudes and oscillation frequencies are presented for each one of the vibration modes. Furthermore other analyzes are made, as spectral graphs, spatio-temporal evolution graphs, line points trajectories, among others. Natural frequencies, damping coefficients and tensions at the top are presented, complementarly, as results of the model characterization. The studies pointed to a validity of the IP with some reservations, mainly influenced by the difference in of the first and second mode frequencies that is increasing with the yaw increase. In addition, important conclusions about modal coexistence in regions of resonance and / or transition of modal dominance were obtained.

Keywords: Vortex-induced vibration, flexible circular cylinders, principle of independence, modal decomposition, experimental investigation 


\section{Lista de Figuras}

1.1 Tipos de configuração geométrica para a instalação de risers . . . . . 29

1.2 Desenho esquemático comparando a configuração geométrica de uma linha de amarração lançada em taut-leg e uma linha lançada em catenária. 30

1.3 Plataforma do tipo jaqueta Fulmar (Chakrabarti, 2005). . . . . . . . 30

1.4 Arranjo esquemático com os sistemas de coordenadas adotados no problema estudado na presente tese. . . . . . . . . . . . . 31

2.1 Variação do número de Strouhal em função do número de Reynolds. Extraído de Blevins (1990) . . . . . . . . . . . . . . . . . 35

2.2 Esteira de von Karmán formada a partir do escoamento ao redor de cilindro. Extraído de Williamson \& Govardhan (2004). . . . . . . . . 36

2.3 Modelo de formação de vórtices. Extraído de Gerrard (1966). . . . . . . 37

2.4 Sequência da distribuição de pressão na superfície de um cilindro em $1 / 3$ de ciclo de emissão de vórtice $\left(R e=1.12 \cdot 10^{5}\right)$. Extraído de Blevins (1990). . . . . . . . . . . . . . . . . . .

2.5 Exemplo esquemático da variação da frequência de emissão de vórtices em função da velocidade de escoamento. . . . . . . . . . . . . . . 38

2.6 (a) Configuração geométrica do modelo isolado e os parâmetros de definição dos strakes. (b) Arranjo do ensaio para a configuração de quatro cilindros flexíveis instalados em série. Fonte: Vickery \& Watkins (1964).

2.7 Amplitude modal máxima para diversos cilindros flexíveis em função de $S_{G}$. Adaptado de Skop \& Griffin (1975) . . . . . . . . . . . . . .

2.8 R.M.S. da amplitude adimensionalizada versus a velocidade reduzida, para cilindros flexíveis com diferentes razões de massa (Chung, 1987).

2.9 Arranjo esquemático de ensaio para excitação de comportamento multimodal. Extraído de Lyons \& Patel (1986). . . . . . . . . . . . . . . . 
2.10 Regiões suscetíveis ao fenômeno de VIV em função da forma como a extremidade superior do modelo é movimentada. Extraído de Lyons \& Patel (1986). . . . . . . . . . . . . . . . . . .

2.11 Amplitude modal normalizada versus a velocidade reduzida para o $1^{\circ} \mathrm{M}$ (Pesce \& Fujarra, 2000). . . . . . . . . . . . . . . . . . . .

2.12 Amplitude e frequência versus a velocidade reduzida: $\square$ - velocidades crescentes, $\mathbf{\square}$ - velocidades decrescentes. Extraído de Fujarra et al. (2001) . . . . . . . . . . . . . . . . . . .

2.13 Aplicação da transformada de Hilbert-Huang para o estudo do fenômeno de "salto". (Esq.) Velocidade reduzida e oscilação transversal do cilindro; (Dir.) Espectro de Hibert-Huang. Extraído de Pesce et al. (2006) . . . . . . . . . . . . . . . . . . . . .

2.14 Arranjo esquemático do experimento realizado por Chaplin et al. (2005) 50

2.15 (a) Frequências de resposta do movimento transversal, (b-h) desviopadrão da amplitude modal do $1^{\circ} \mathcal{M}$ ao $7^{\circ} \mathcal{M}$. Ambos gráficos em função da velocidade reduzida calculada com a frequência do $1^{\circ} \mathcal{M}$. Adaptado de Chaplin et al. (2005).

2.16 Variação das Amplitudes Modais versus a velocidade reduzida baseada na frequência natural de cada modo de vibrar (Malta, 2014). . . . . . .

2.17 (a) Visualização do escoamento apresentando dois modos de emissão de vórtice para $R e=160$. Extraído de Ramberg (1983). (b) Esquematização da esteira obtida por Ramberg para cilindros inclinados de comprimento finito. Adaptado de Marshall (2003). . . . . . . . . . . .

2.18 Esquematização da emissão de vórtice axial e da esteira de von Karmán em cilindros inclinados. Adaptado de Matsumoto et al. (2001). . .

2.19 Visualização tridimensional da esteira formada por escoamento inclinado ao redor de cilindro (a) fixo e (b) livre para oscilar. As setas representam a incidência do escoamento $\left(\theta=70^{\circ}\right)$. Adaptado de Lucor \& Karniadakis (2003). . . . . . . . . . . . . . . . . . . . .

2.20 Iso-superfícies instantâneas da vorticidade à jusante do cilindro flexível para as configurações (a) inclinada $\theta=60^{\circ} \mathrm{e}$ (b) vertical. As setas representam o fluxo incidente. Extraído de Bourguet et al. (2015) . . . . 
2.21 Arranjo esquemático apresentando os principais ângulos envolvidos para a consideração das componentes normais local e global. A posição do cilindro na ausência de velocidade é denotado pela linha cinza tracejada. Extraído de Bourguet et al. (2015) . . . . . . . . . . . . 58 58

3.1 Fluxo de dados da metodologia empregada. . . . . . . . . . 62

3.2 Visão geral da montagem do experimento. . . . . . . . . . . . . 64

3.3 Ensaios de caracterização para determinação de rigidez axial (a) e flexional (b) do modelo desenvolvido anteriormente e utilizado na presente pesquisa. Adaptado de Rateiro (2014). . . . . . . . . . . . . .

3.4 (a) Rolamento apoiado em mancal de flange. (b) Eixo Universal. (c) Detalhe da montagem da articulação na extremidade do modelo. . . . . 65

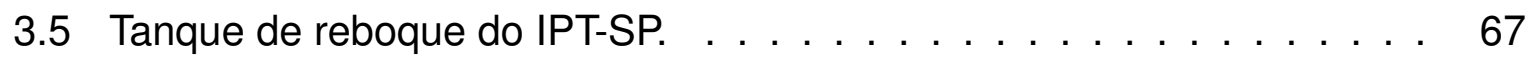

3.6 Dimensões principais da seção transversal do tanque de reboque do IPT-SP (Unidades: $\mathrm{m}$ ). . . . . . . . . . . . . . . . . . . . 67

3.7 Carro de reboque utilizado no tanque do IPT-SP. . . . . . . . . . 68

3.8 Exemplo de aquisição velocidade de reboque - Corrida 22 - Velocidade Nominal $=492.00 \mathrm{~mm} / \mathrm{s} \ldots \ldots \ldots \ldots$

3.9 Comparação entre a instalação do experimento e maquete digital. . . . 70

3.10 Vistas frontal (esq.) e lateral (dir.) da instalação do fundo falso (Unida-

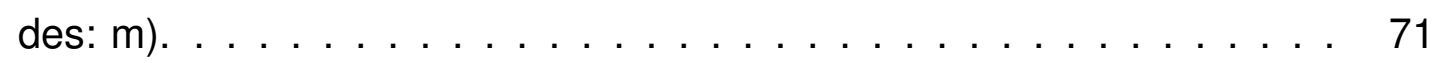

3.11 Vista explodida do arranjo utilizado como âncora para a extremidade

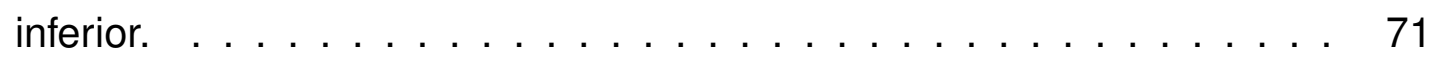

3.12 Dimensões principais da âncora (Unidades: $\mathrm{mm})$. . . . . . . . . . 72

3.13 Vista lateral do arranjo esquemático do posicionamento do modelo e do fundo falso no carro auxiliar para cada uma das inclinações estudadas (Unidades: $\mathrm{m}$ ). . . . . . . . . . . . . . . . . .

3.14 Vista superior do arranjo esquemático da estrutura circular localizada no carro auxiliar (Unidades: $\mathrm{m}$ ). . . . . . . . . . . . . . . . 74

3.15 Arranjo esquemático da mudança de azimute do modelo $-\beta=0^{\circ} \mathrm{e}$ $\beta=180^{\circ} \ldots \ldots \ldots \ldots \ldots \ldots \ldots \ldots \ldots \ldots \ldots \ldots \ldots \ldots \ldots \ldots$

3.16 Arranjo esquemático da mudança de azimute do modelo $-\beta=45^{\circ} \mathrm{e}$

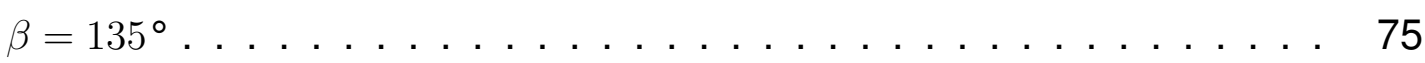

3.17 Arranjo esquemático da mudança de azimute do modelo $-\beta=90^{\circ} \ldots 75$ 
3.18 (a) Atuadores montados para fornecer um sistema com dois graus de liberdade: $800 \mathrm{~mm}$ na horizontal e $280 \mathrm{~mm}$ na vertical. (b) Drivers PLC utilizados para o controle dos atuadores. . . . . . . . . . .

3.19 (a) Célula de carga modelo Mini 85 da ATI Industrial Automation. (b) Definição dos eixos da célula de carga para medição das forças e momentos nos 6 graus de liberdade. Extraído de ATI Industrial Automation (2010) . . . . . . . . . . . . . . . . . . . .

3.20 Detalhes da câmera submersa "Oqus Underwater" da Qualisys ${ }^{\circledR}$. Fonte:

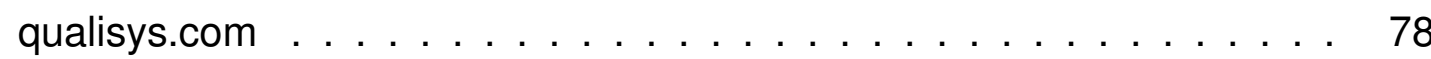

3.21 Alvos refletivos aderidos ao modelo de cilindro flexível. . . . . . . . . 79

3.22 Vista superior da instalação das câmeras submersas da Qualisys ${ }^{\circledR}$ no Carro Auxiliar do Tanque de Reboque do IPT-SP . . . . . . . . . . 79

3.23 Imagens processadas em cada uma das câmeras submersas. . . . . . 80

3.24 Posicionamento da câmera de vídeo no carro auxiliar. . . . . . . . . . 81

3.25 Visualização do movimento tridimensional dos alvos e da posição relativa das câmeras submersas. . . . . . . . . . . . . . . . . 82

3.26 Vista superior do sistema QTM mostrando a distância de aproximadamente 1.5 metros entre o modelo e as câmeras submersas. . . . . . . .

3.27 Arranjo esquemático com os sistemas de coordenadas adotados no problema estudado na presente tese. . . . . . . . . . . . . . 84

3.28 Exemplo de interpolação dos alvos medidos pelo sistema QTM para obtenção da linha elástica do modelo ensaiado. . . . . . . . . . . . 86

3.29 Exemplo de análise de decomposição modal . . . . . . . . . . . 87

3.30 Exemplo da avaliação das amplitudes para um sinal do $1^{\circ} \mathcal{M}$ obtido em um ensaio de VIV. . . . . . . . . . . . . . . . . 89

3.31 Definição dos parâmetros utilizados no modelo numérico do Orcaflex. . 92

3.32 Exemplo de análise modal de linha inclinada realizada no OrcaFlex®. . 93

3.33 Configurações estáticas do modelo lançado em ar. . . . . . . . . . . . 94

3.34 Componentes locais dos modos de vibrar do modelo em ar - Inclin.

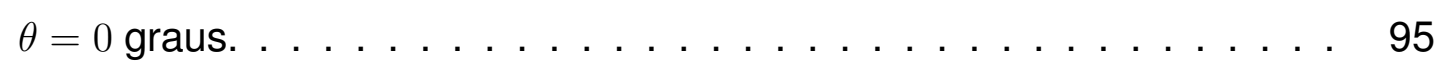

3.35 Configurações estáticas do modelo submerso em água. . . . . . . . . 96

3.36 Série temporal típica de uma análise de decaimento. . . . . . . . . . 97 
3.37 Instalação em ar do modelo flexível para realização dos ensaios de decaimento - (Esq.) $\theta=0^{\circ}$, (Dir.) $\theta=45^{\circ} \ldots \ldots \ldots \ldots$. . . . . 100

3.38 Realização do ensaio de decaimento em água - $\theta=0^{\circ}$ - Repetição 01 . 101

3.39 Análise de Fourier para os sinais calculado a partir das amplitudes modais obtidas em ensaio de decaimento: (a) Sinal Original; (b) Sinal Filtrado.

3.40 Mapeamento das velocidades reduzidas $V r_{i}$ função dos ângulos $\theta$ e $\beta$ e da velocidade de reboque $U$.

4.1 Mapeamento da amplitude modal em função dos ângulos $\theta, \beta$ e de $V r_{i}$ considerando a análise do desvio padrão do sinal.

4.2 Rotação das direções dos modos de vibrar da configuração vertical para obtenção dos mapas de referência. . . . . . . . . . . . . . . . . . . . 113

4.3 Amplitude modais agrupadas por ângulo $\theta$ para cada modo $i$ em função do ângulo $\beta$ e de $V r_{i}$

4.4 "Griffin Plot" relacionando a amplitude adimensional máxima observada em função do parâmetro $S_{G}$ (eixo vertical escala logarítmica) para diferentes azimutes ( $\beta$ ). Adpatado de Skop \& Balasubramanian (1997). . .

4.5 "Griffin Plot" relacionando a amplitude adimensional máxima observada em função do parâmetro $S_{G}$ (eixo vertical escala linear) para diferentes azimutes ( $\beta$ ). Adaptado de Khalak \& Williamson (1999). . . . . . . . . .

4.6 Mapeamento das frequências de vibração em função dos ângulos $\theta, \beta$ e de $V r_{i}$.

4.7 Amplitudes Modais e Frequências de Resposta para $V r_{1}=12.11-\theta=$ $10^{\circ}$ e $\beta=0^{\circ}$.

4.8 Mapeamento das amplitudes modais em função dos ângulos $\theta, \beta$ e de $V r$

4.9 Comparação da avaliação das amplitudes modais para $\overline{V r}_{1}=9.80 \mathrm{e}$ $\overline{V r}_{1}=10.32-\theta=30^{\circ}$ e $\beta=180^{\circ} \ldots \ldots \ldots \ldots \ldots \ldots$

4.10 Comparação da evolução temporal da componente binormal entre $\overline{V r}_{1}=$ 9.80 e $\overline{V r}_{1}=10.32-\theta=30^{\circ}$ e $\beta=180^{\circ}$.

4.11 Amplitudes Modais e Frequências de Resposta para $\overline{V r}_{1}=14.11-\theta=$ $20^{\circ}$ e $\beta=45^{\circ} \ldots \ldots \ldots \ldots \ldots \ldots \ldots \ldots \ldots$ 
4.12 Evolução temporal das componentes normal e binormal para $\overline{V r}_{1}=$ $14.11-\theta=20^{\circ}$ e $\beta=45^{\circ} \ldots \ldots \ldots \ldots \ldots \ldots$

4.13 Amplitudes modais em função do tempo e da frequência (Espectro de Hilbert-Huang) para $\overline{V r}_{1}=14.11-\theta=20^{\circ} \mathrm{e} \beta=45^{\circ} \ldots \ldots \ldots \ldots$

4.14 Comparação entre os resultados para diferentes $\overline{V r}_{1}$ das trajetórias obtidas nas velocidades que apresentaram a amplitude máxima de vibração para o $1^{\circ} \mathcal{M}, 3^{\circ} \mathcal{M}, 5^{\circ} \mathcal{M}$ e $7^{\circ} \mathcal{M}-\beta=0^{\circ}$ e $\theta=0^{\circ} \ldots \ldots \ldots \ldots$

4.15 Amplitudes modais referentes aos ângulos de inclinação e velocidades reduzidas apresentados na Tabela $4.5-\beta=0^{\circ}$. . . . . . . . .

4.16 Densidades espectrais referentes aos ângulos de inclinação e velocidades reduzidas apresentados na Tabela $4.5-\beta=0^{\circ}$. . . . . . . . . 129

4.17 Evoluções espaço-temporais referentes aos ângulos de inclinação e velocidades reduzidas apresentados na Tabela $4.5-\beta=0^{\circ} . \ldots \ldots$. .

4.18 Amplitudes modais referentes aos ângulos de inclinação e velocidades reduzidas apresentados na Tabela $4.6-\beta=135^{\circ} \ldots \ldots \ldots \ldots 132$

4.19 Comparação de um trecho das séries temporais de amplitude para os pares: $1^{\circ} \mathcal{M} / 2^{\circ} \mathcal{M}$ e $3^{\circ} \mathcal{M} / 4^{\circ} \mathcal{M}-\beta=135^{\circ}$ e $\theta=10^{\circ} \ldots \ldots \ldots \ldots \ldots 133$

4.20 Amplitudes modais referentes aos ângulos de inclinação e velocidades reduzidas apresentados na Tabela $4.7-\beta=135^{\circ} \ldots \ldots \ldots \ldots$

4.21 Densidades espectrais referentes aos ângulos de inclinação e velocidades reduzidas apresentados na Tabela $4.7-\beta=135^{\circ} \ldots \ldots \ldots \ldots 136$

4.22 Comparação de um trecho das séries temporais de amplitude para os pares: $1^{\circ} \mathcal{M} / 2^{\circ} \mathcal{M}-\beta=135^{\circ}$.

4.23 Evoluções espaço-temporais referentes aos ângulos de inclinação e velocidades reduzidas apresentados na Tabela $4.7-\beta=135^{\circ} . \ldots \ldots 138$

4.24 Trajetórias dos alvos fixados no modelo referentes aos ângulos de inclinação e velocidades reduzidas apresentados na Tabela $4.7-\beta=135^{\circ}$.

B.1 Componentes locais dos modos de vibrar do modelo em ar - Inclin.

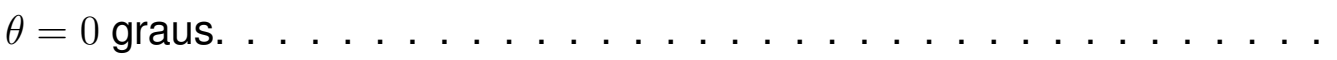

B.2 Componentes locais dos modos de vibrar do modelo em ar - Inclin. $\theta=10$ graus.

B.3 Componentes locais dos modos de vibrar do modelo em ar - Inclin. $\theta=20$ graus 
B.4 Componentes locais dos modos de vibrar do modelo em ar - Inclin. $\theta=30$ graus.

B.5 Componentes locais dos modos de vibrar do modelo em ar - Inclin. $\theta=45$ graus.

B.6 Componentes locais dos modos de vibrar do modelo em água - Inclin. $\theta=0$ graus.

B.7 Componentes locais dos modos de vibrar do modelo em água - Inclin. $\theta=10$ graus.

B.8 Componentes locais dos modos de vibrar do modelo em água - Inclin. $\theta=20$ graus.

B.9 Componentes locais dos modos de vibrar do modelo em água - Inclin. $\theta=30$ graus.

B.10 Componentes locais dos modos de vibrar do modelo em água - Inclin. $\theta=45$ graus.

C.1 Mapeamento da amplitude modal em função dos ângulos $\theta, \beta$ e de $V r_{i}$ considerando a análise da média dos extremos entre zeros ascendentes do sinal.

C.2 Mapeamento da amplitude modal em função dos ângulos $\theta, \beta$ e de $V r_{i}$ considerando a análise da média dos $10 \%$ maiores extremos entre zeros ascendentes do sinal

C.3 Amplitudes Modais em função de $\overline{V r}_{1}-\theta=0^{\circ}$ e $\beta=0^{\circ}$. . . . . . . 174

C.4 Amplitudes Modais em função de $\overline{V r}_{1}-\theta=0^{\circ} \mathrm{e} \beta=45^{\circ}$. . . . . . . 175

C.5 Amplitudes Modais em função de $\overline{V r}_{1}-\theta=0^{\circ} \mathrm{e} \beta=90^{\circ}$. . . . . . 175

C.6 Amplitudes Modais em função de $\overline{V r}_{1}-\theta=0^{\circ} \mathrm{e} \beta=135^{\circ}$. . . . . . . 176

C.7 Amplitudes Modais em função de $\overline{V r}_{1}-\theta=0^{\circ}$ e $\beta=180^{\circ} \ldots \ldots \ldots \ldots$

C.8 Amplitudes Modais em função de $\overline{V r}_{1}-\theta=10^{\circ} \mathrm{e} \beta=0^{\circ}$. . . . . . . 177

C.9 Amplitudes Modais em função de $\overline{V r}_{1}-\theta=10^{\circ} \mathrm{e} \beta=45^{\circ} \ldots \ldots \ldots . .178$

C.10 Amplitudes Modais em função de $\overline{V r}_{1}-\theta=10^{\circ} \mathrm{e} \beta=90^{\circ} \ldots \ldots \ldots . .178$

C.11 Amplitudes Modais em função de $\overline{V r}_{1}-\theta=10^{\circ} \mathrm{e} \beta=135^{\circ}$. . . . . . . 179

C.12 Amplitudes Modais em função de $\overline{V r}_{1}-\theta=10^{\circ} \mathrm{e} \beta=180^{\circ}$. . . . . . . 179

C.13 Amplitudes Modais em função de $\overline{V r}_{1}-\theta=20^{\circ} \mathrm{e} \beta=0^{\circ}$. . . . . . . 180

C.14 Amplitudes Modais em função de $\overline{V r}_{1}-\theta=20^{\circ} \mathrm{e} \beta=45^{\circ} \ldots \ldots \ldots . .181$ 
C.15 Amplitudes Modais em função de $\overline{V r}_{1}-\theta=20^{\circ}$ e $\beta=90^{\circ}$. . . . . . . . . 181

C.16 Amplitudes Modais em função de $\overline{V r}_{1}-\theta=20^{\circ}$ e $\beta=135^{\circ}$. . . . . . . . 182

C.17 Amplitudes Modais em função de $\overline{V r}_{1}-\theta=20^{\circ}$ e $\beta=180^{\circ}$. . . . . . . . 182

C.18 Amplitudes Modais em função de $\overline{V r}_{1}-\theta=30^{\circ}$ e $\beta=0^{\circ}$. . . . . . . . 183

C.19 Amplitudes Modais em função de $\overline{V r}_{1}-\theta=30^{\circ}$ e $\beta=45^{\circ}$. . . . . . . . 184

C.20 Amplitudes Modais em função de $\overline{V r}_{1}-\theta=30^{\circ}$ e $\beta=90^{\circ}$. . . . . . . . . 184

C.21 Amplitudes Modais em função de $\overline{V r}_{1}-\theta=30^{\circ}$ e $\beta=135^{\circ}$. . . . . . . . 185

C.22 Amplitudes Modais em função de $\overline{V r}_{1}-\theta=30^{\circ}$ e $\beta=180^{\circ}$. . . . . . . . 185

C.23 Amplitudes Modais em função de $\overline{V r}_{1}-\theta=45^{\circ}$ e $\beta=0^{\circ}$. . . . . . . . . 186

C.24 Amplitudes Modais em função de $\overline{V r}_{1}-\theta=45^{\circ}$ e $\beta=45^{\circ}$. . . . . . . . . 187

C.25 Amplitudes Modais em função de $\overline{V r}_{1}-\theta=45^{\circ}$ e $\beta=90^{\circ}$. . . . . . . . . 187

C.26 Amplitudes Modais em função de $\overline{V r}_{1}-\theta=45^{\circ}$ e $\beta=135^{\circ}$. . . . . . . 188

C.27 Amplitudes Modais em função de $\overline{V r}_{1}-\theta=45^{\circ}$ e $\beta=180^{\circ}$. . . . . . . . 188 


\section{Lista de Tabelas}

2.1 Categorias principais dos estudos empíricos e numéricos de escoamento ao redor de cilindros. . . . . . . . . . . . . . . . . 39

2.2 Parâmetros adimensionais envolvidos no fenômeno de VIV. Adaptado de Khalak \& Williamson (1999). . . . . . . . . . . . . . . . . . . 40

3.1 Principais parâmetros e características do modelo utilizado nos ensaios. 66

3.2 Impacto na velocidade reduzida com base na flutuação da velocidade do carro de reboque - Corrida $22 \ldots \ldots$. . . . . . . . . 69

3.3 Características físicas da célula de carga modelo Mini 85 da ATI Industrial Automation. . . . . . . . . . . . . . . . . . . . 77

3.4 Características operacionais da célula de carga modelo Mini 85 da ATI Industrial Automation. . . . . . . . . . . . . . . . . . . 77

3.5 Propriedades da câmera submersa "Oqus Underwater" da Qualisys ${ }^{\circledR}$.

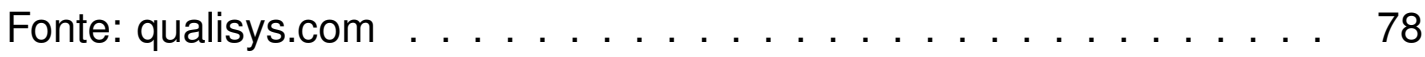

3.6 Propriedades da câmera aérea "Oqus 500" da Qualisys ${ }^{\circledR}$. Fonte: qua-

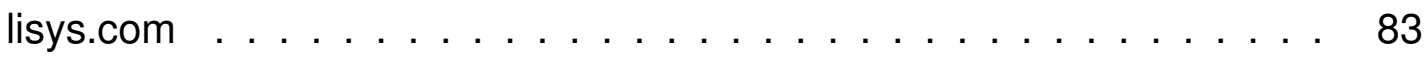

3.7 Resumo dos parâmetros das configurações estáticas do modelo lançado em ar. . . . . . . . . . . . . . . . . . . . . . . 94

3.8 Resumo dos parâmetros de configurações estáticas do modelo sub-

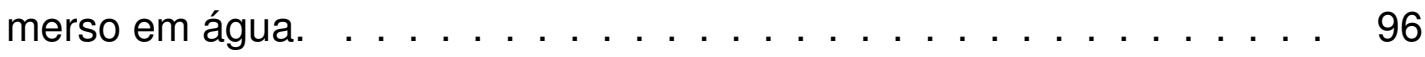

3.9 Matriz completa dos Ensaios de VIV . . . . . . . . . . . . . . 103

3.10 Número de Reynolds e Velocidades Reduzidas para o ensaio da configuração de referência $-\theta=0^{\circ} \ldots \ldots \ldots \ldots \ldots$

4.1 Comparação entre as frequências naturais em ar $\left(f_{n_{i}}^{a r}\right)$ obtidas pelos ensaios de decaimento (Exp.) e pelo modelo Orcaflex® (Num.) . . . . . 108 
4.2 Coeficientes de amortecimento linear obtidos através de ensaio de decaimento com o modelo em ar e parâmetros $\alpha$ e $S_{G}$ calculados para cada ângulo de inclinação . . . . . . . . . . . . . . . . . .

4.3 Comparação entre as frequências naturais em água $\left(f_{n_{i}}\right)$ obtidas pelos ensaios de decaimento (Exp.) e pelo modelo Orcaflex® (Num.) . . . . . 109

4.4 Coeficientes de amortecimento linear obtidos através de ensaio de decaimento com o modelo submerso em água . . . . . . . . . . . . . 110

4.5 Velocidades reduzidas, $\overline{V r}_{1}$, estudadas na seção $4.3 .1-\beta=0^{\circ}$. . . . 126

4.6 Velocidades reduzidas, $\overline{V r}_{1}$, estudadas na seção $4.3 .2-\beta=135^{\circ}$. . . 131

4.7 Velocidades reduzidas, $\overline{V r}_{1}$, estudadas na seção $4.3 .3-\beta=135^{\circ} . \ldots 134$

B.1 Frequências naturais dos modos de vibrar obtidas através de ensaios de decaimento realizados em ar - $f_{n_{i}}^{a r}(\mathrm{~Hz})$ - e Coeficiente de Amortecimento $-\zeta_{s}\left(\theta=0^{\circ}\right) \ldots \ldots \ldots \ldots \ldots \ldots \ldots$

B.2 Frequências naturais dos modos de vibrar obtidas através de ensaios de decaimento realizados em ar - $f_{n_{i}}^{a r}(\mathrm{~Hz})$ - e Coeficiente de Amortecimento $-\zeta_{s}\left(\theta=10^{\circ}\right) \ldots \ldots \ldots \ldots \ldots \ldots \ldots$

B.3 Frequências naturais dos modos de vibrar obtidas através de ensaios de decaimento realizados em ar - $f_{n_{i}}^{a r}(\mathrm{~Hz})$ - e Coeficiente de Amorteci-

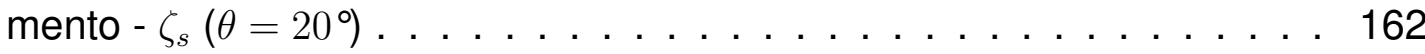

B.4 Frequências naturais dos modos de vibrar obtidas através de ensaios de decaimento realizados em ar - $f_{n_{i}}^{a r}(\mathrm{~Hz})$ - e Coeficiente de Amortecimento $-\zeta_{s}\left(\theta=30^{\circ}\right) \ldots \ldots \ldots \ldots \ldots \ldots \ldots \ldots$

B.5 Frequências naturais dos modos de vibrar obtidas através de ensaios de decaimento realizados em ar $-f_{n_{i}}^{a r}(\mathrm{~Hz})$ - e Coeficiente de Amortecimento $-\zeta_{s}\left(\theta=45^{\circ}\right) \ldots \ldots \ldots \ldots \ldots$. . . . . . . . . 164

B.6 Frequências naturais dos modos de vibrar obtidas através de ensaios de decaimento realizados em água - $f_{n_{i}}(\mathrm{~Hz})$ - e Coeficiente de Amortecimento $-\bar{\zeta}\left(\theta=0^{\circ}\right) \ldots \ldots \ldots \ldots \ldots \ldots \ldots \ldots$

B.7 Frequências naturais dos modos de vibrar obtidas através de ensaios de decaimento realizados em água - $f_{n_{i}}(\mathrm{~Hz})$ - e Coeficiente de Amortecimento $-\bar{\zeta}\left(\theta=10^{\circ}\right) \ldots \ldots \ldots \ldots$. . . . . . . . . . 167

B.8 Frequências naturais dos modos de vibrar obtidas através de ensaios de decaimento realizados em água - $f_{n_{i}}(\mathrm{~Hz})$ - e Coeficiente de Amortecimento $-\bar{\zeta}\left(\theta=20^{\circ}\right) \ldots \ldots \ldots \ldots \ldots$ 
B.9 Frequências naturais dos modos de vibrar obtidas através de ensaios de decaimento realizados em água - $f_{n_{i}}(\mathrm{~Hz})$ - e Coeficiente de Amortecimento $-\bar{\zeta}\left(\theta=30^{\circ}\right) \ldots \ldots \ldots \ldots$. . . . . . . . . 169

B.10 Frequências naturais dos modos de vibrar obtidas através de ensaios de decaimento realizados em água - $f_{n_{i}}(\mathrm{~Hz})$ - e Coeficiente de Amortecimento $-\bar{\zeta}\left(\theta=45^{\circ}\right) \ldots \ldots \ldots \ldots \ldots$ 


\section{Lista de Abreviações}

CFD Dinâmica de Fluidos Computacional, ou Computational Fluid Dynamics.

EP-USP Escola Politécnica da Universidade de São Paulo.

IPT-SP Instituto de Pesquisas Técnológicas do Estado de São Paulo.

LDA Lâmina D'água.

LMO Laboratório de Mecânica Offshore.

MEF Método dos Elementos Finitos.

MMQ Método dos Mínimos Quadrados.

NDF Núcleo de Dinâmica e Fluidos.

PI Princípio da Independência.

PSD Densidade Espectral de Potência, ou Power Spectral Density.

QTM Qualysis Tracker Manager.

TDP Touch Down Point.

TLP Tension-Leg Platform.

TPN Tanque de Provas Numérico.

VIM Movimento Induzido pela Emissão de Vórtices.

VIV Vibração Induzida pela Emissão de Vórtices. 


\section{Lista de Símbolos}

\section{Alfabeto Grego}

$\alpha \quad$ Parâmetro de massa e de amortecimento

$\beta \quad$ Azimute da linha em relação ao plano da correnteza

$\gamma \quad$ Peso linear da linha na água

$\gamma^{a r} \quad$ Peso linear da linha no ar

$\delta \quad$ Decremento logarítmico

$\bar{\zeta} \quad$ Coeficiente de amortecimento linear obtido a partir dos ensaios em água

$\zeta \quad$ Coeficiente de amortecimento segundo Khalak \& Williamson (1999)

$\zeta_{s} \quad$ Coeficiente de amortecimento linear estrutural

$\zeta_{\text {visc }} \quad$ Coeficiente de amortecimento linear viscoso

$\bar{\theta} \quad$ Ângulo local da linha em relação à vertical

$\theta \quad$ Ângulo de inclinação da reta que liga as duas extremidades da linha em relação à vertical

$\theta_{0} \quad$ Ângulo com a vertical da extremidade inferior da linha

$\theta_{\text {topo }} \quad$ Ângulo com a vertical da extremidade superior da linha

$\lambda_{i} \quad$ Fator modal referente ao $i$-ésimo modo natural

$\mu \quad$ Viscosidade dinâmica

$\nu \quad$ Viscosidade cinemática

$\omega_{d} \quad$ Frequência angular natural amortecida

$\omega_{n} \quad$ Frequência angular natural 

$\rho \quad$ Densidade
$\rho_{f} \quad$ Densidade do fluido no qual o sistema está imerso
$\sigma \quad$ Desvio padrão da série temporal
$\phi_{i} \quad$ Função que descreve o $i$-ésimo modo de vibrar
$\varphi \quad$ Ângulo local da linha em relação à horizontal

\section{Alfabeto Romano}

A Área da seção indeformada da linha

$A^{*} \quad$ Amplitude adimensional

$A_{m_{i}} \quad$ Amplitude modal do $i$-ésimo modo natural de vibrar

$A_{m_{i}}^{\max } \quad$ Amplitude modal máxima do $i$-ésimo modo natural de vibrar

a Razão de massa adicional

b Componente binormal do movimento

$C_{a}^{P O T} \quad$ Coeficiente de massa adicional potencial

$C_{D} \quad$ Coeficiente de arrasto

$C_{L} \quad$ Coeficiente de sustentação

D Diâmetro

$D_{\text {int }} \quad$ Diâmetro interno do modelo

E $\quad$ Módulo de Young

$F_{D} \quad$ Força de arrasto

$F_{L} \quad$ Força de sustentação

$f_{i} \quad$ Frequência de oscilação no $i$-ésimo modo de vibrar

$f_{n_{i}} \quad$ Frequência natural do $i$-ésimo modo de vibrar, calculada com o modelo em água

$f_{n_{i}}^{a r} \quad$ Frequência natural do $i$-ésimo modo de vibrar, calculada com o modelo em ar

$f_{S} \quad$ Frequência de emissão de vórtices 
$f_{S_{i}} \quad$ Frequência de emissão de vórtices do $i$-ésimo modo de vibrar

$h \quad$ Profundidade ou lâmina d'água

I Inércia da seção não deformada da linha

$L_{0} \quad$ Comprimento não deformado da linha

$L_{h} \quad$ Comprimento submerso

M Massa total do modelo

$M_{a}^{P O T} \quad$ Massa adicional potencial total do modelo

$\mathcal{M} \quad$ Modo de vibrar

$i^{\circ} \mathcal{M}\left\langle f_{j}\right\rangle$ Modo de vibrar $i$ oscilando na frequência do modo $j$

$m \quad$ Massa estrutural por unidade de comprimento

$m^{*} \quad$ Razão entre massa estrutural e massa de fluido deslocado

$m_{a}^{P O T} \quad$ Massa adicional potencial por unidade de comprimento

$N \quad$ Número de elementos utilizados para a discretização da linha

$N_{t} \quad$ Número de amostras de tempo entre $t_{0}$ e $t_{f}$

$n \quad$ Componente normal do movimento

$O^{\prime} n b t \quad$ Sistema de coordenadas de Frenet-Serret

$O X Y Z$ Sistema de coordenadas global

Oxyz Sistema de coordenadas rotacionado no plano da linha

$q \quad$ Posição da linha no sistema de Frenet-Serret

Re Número de Reynolds

$S_{G} \quad$ Parâmetro de Skop-Griffin

St Número de Strouhal

$s \quad$ Coordenada curvilínea

$\bar{T} \quad$ Tração adimensional

T Tração axial 
$T_{0} \quad$ Tração axial na extremidade imersa

$T_{H} \quad$ Componente horizontal da tração

$T_{\text {topo }} \quad$ Tração axial no topo

$t \quad$ Componente tangencial do movimento

$t \quad$ Tempo

$t_{0} \quad$ Instante de tempo inicial

$t_{f} \quad$ Instante de tempo final

U Velocidade de correnteza/reboque

$U_{n} \quad$ Componente normal da velocidade de correnteza/reboque

$\overline{V r}_{1} \quad$ Velocidade reduzida do $1^{\circ}$ modo natural de vibrar considerando a velocidade de correnteza total

$V r \quad$ Velocidade reduzida

$V r_{i} \quad$ Velocidade reduzida calculada com base $i$-ésimo modo natural de vibrar e no Princípio da Independência 


\section{Sumário}

1 Introdução $\quad 28$

1.1 Descrição do problema . . . . . . . . . . . . . . 28

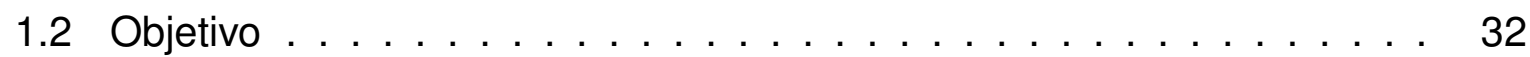

1.3 Objetivos Secundários e Organização do Texto . . . . . . . . . . . 32

2 Revisão bibliográfica $\quad 34$

2.1 Vibrações induzidas pela emissão de vórtices . . . . . . . . . . . . 34

2.2 VIV em cilindros flexíveis . . . . . . . . . . . . . . . . 41

2.3 A questão da inclinação em relação ao perfil de correnteza: Cilindros Flexíveis . . . . . . . . . . . . . . . . . . . . 53

3 Metodologia $\quad 60$

3.1 Materiais \& Infraestrutura $\ldots \ldots \ldots \ldots \ldots \ldots$

3.1.1 Modelo de cilindro flexível . . . . . . . . . . . . . . . . 64

3.1.2 Tanque de reboque $\ldots \ldots \ldots \ldots 6 \ldots$

3.1 .3 Sistema de Reboque . . . . . . . . . . . . . . . 68

3.1.4 Sistema de ajuste da tração . . . . . . . . . . . . . . . 75

3.1.5 Sistema de monitoração da Qualisys ${ }^{\circledR} \ldots \ldots \ldots \ldots$. . . . . . 78

3.2 Métodos de Análise de Dados . . . . . . . . . . . . . . . 83

3.2.1 Método da Decomposição Modal . . . . . . . . . . . . . . . 83

3.2.2 Avaliação das amplitudes e frequências . . . . . . . . . . 87

3.2.3 Cálculo da Velocidade Reduzida . . . . . . . . . . . . . . 89

3.3 Métodos Numéricos . . . . . . . . . . . . . . . . . . . . . . . . . 91 
3.3.1 Configurações em ar . . . . . . . . . . . . . . . . . 9 93

3.3.2 Configurações submersas em água . . . . . . . . . . . . 95

3.4 Métodos Experimentais . . . . . . . . . . . . . . . . . . . 97

3.4.1 Ensaio de Decaimento . . . . . . . . . . . . . . . . . 97

3.4 .2 Ensaios de VIV . . . . . . . . . . . . . . . . . . . . 102

4 Apresentação e Discussão dos Resultados Obtidos 107

4.1 Frequências naturais e coeficientes de amortecimento . . . . . . . . 107

4.2 Amplitudes modais e frequências de resposta . . . . . . . . . . 110

4.3 Análises aprofundada em regiões de interesse . . . . . . . . . . . 125

4.3.1 Amplitudes Máximas para $\beta=0^{\circ} \ldots \ldots \ldots \ldots \ldots$

4.3.2 Região de transição para $\beta=135^{\circ} \ldots \ldots \ldots \ldots \ldots \ldots$

4.3.3 Amplitudes máximas do $1^{\circ} \mathcal{M}$ e do $2^{\circ} \mathcal{M}$ para $\beta=135^{\circ} \ldots \ldots 134$

5 Conclusões e Considerações Finais $\quad 140$

Bibliografia 144

\section{Apêndices}

A Subsídios Teóricos 152

A.1 Configuração Estática da Catenária Elástica . . . . . . . . . . . . 153

A.2 Cálculo das frequências naturais . . . . . . . . . . . . . . 155

A.2.1 Configuração Vertical . . . . . . . . . . . . . . . . . 155

A.2.2 Configuração Inclinada . . . . . . . . . . . . . . . 156

B Frequências, modos naturais e coeficientes de amortecimento 159

B.1 Ensaios de decaimento no ar . . . . . . . . . . . . . . . . . . 159

B.2 Ensaios de decaimento em água . . . . . . . . . . . . . . . 165

C Resultados complementares do ensaio de VIV 171

C.1 Amplitudes modais em função de $V r_{i} \ldots \ldots \ldots \ldots \ldots \ldots$ 
C.2 Amplitudes modais em função de $\overline{V r}_{1} \ldots \ldots \ldots$. . . . . . . . . 174

C.2.1 Inclinação 0 graus . . . . . . . . . . . . . . . . . . . . 174

C.2.2 Inclinação 10 graus . . . . . . . . . . . . . . . . 177

C.2.3 Inclinação 20 graus . . . . . . . . . . . . . . . . . . . . . 180

C.2.4 Inclinação 30 graus . . . . . . . . . . . . . . . . . . . 183

C.2.5 Inclinação 45 graus . . . . . . . . . . . . . . . . 186 


\section{Capítulo 1}

\section{Introdução}

\subsection{Descrição do problema}

A exploração de hidrocarbonetos em águas ultra profundas é um ramo no qual a indústria brasileira tem se destacado no cenário mundial. Nas últimas décadas o país se viu defronte de um imenso potencial energético encontrado há alguns quilômetros sob o leito do oceano. Consequentemente, para quebrar as barreiras tecnológicas impostas por uma atividade de tamanha complexidade, é necessário entender a fundo os fenômenos físicos a que estão submetidos os diversos sistemas oceânicos.

Sob a superfície oceânica, há uma infinidade de sistemas que são fundamentais para a operação de extração do petróleo. Como exemplo temos: linhas de amarração, risers, manifolds, boias, árvores de natal, estruturas tubulares de plataformas fixas, entre outros. Uma vez submerso, estes sistemas estão diariamente sujeitos à incidência de correntes marinhas. Consequentemente, as forças impostas nestas estruturas implicam em diferentes tipos de interações.

Neste trabalho pretende-se estudar um problema específico de interação fluido-estrutura comum à engenharia Oceânica que é o problema de Vibração Induzida pela Emissão de Vórtices (VIV), ou seja, movimentos oscilatórios causados pela interação entre o fluido em movimento que ao incindir sobre à estrutura desprende vórtices alterando o campo de pressões.

Dada a ampla ocorrência desse fenômeno, muitos estudos já foram realizados e com o advento dos fatores abordados acima o estudo deste fenômeno se intensificou nos últimos anos. Por se tratar de um problema de dinâmica dos fluidos não linear, apesar dos grandes avanços realizados até o momento, existem áreas específicas que ainda demandam estudos mais completos.

Esta tese se insere neste cenário ao pretender estudar o fenômeno de VIV agindo 
sobre uma classe específica de estruturas: cilindros flexíveis inclinados em relação ao perfil de correnteza incidente. Esta classe se aproxima principalmente das estruturas tubulares ou de seção circular, tais quais são os risers e as linhas de amarração.

Na Figura 1.1 estão apresentadas as configurações mais comuns para a instalação de risers. Cada uma dessas configurações tem suas particularidades que as tornam mais vantajosas que as outras dependendo do cenário. No entanto, podemos perceber que todas elas possuem trechos que estão inclinados em relação à direção paralela ao fundo do mar.

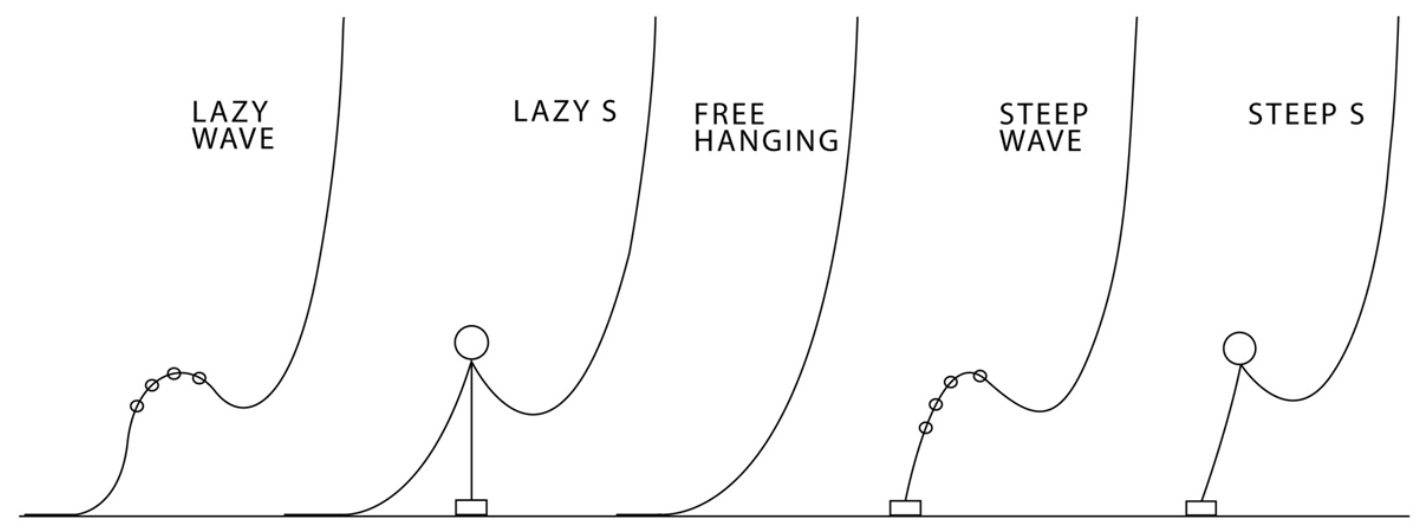

Figura 1.1 - Tipos de configuração geométrica para a instalação de risers

Além dos risers, outro sistema que fica suscetível à incidência das correntes são as linhas de amarração. A Figura 1.2 apresenta uma comparação entre duas configurações comuns para linhas de amarração: linhas lançadas em catenária ou linhas lançadas em taut-leg. Ambas possuem longos trechos inclinados e se diferenciam basicamente pelo seu comprimento e nível de tração aplicado.

Adicionalmente, o fenômeno de VIV pode ocorrer para outros tipos de estruturas, como é o caso das estruturas tubulares utilizadas nas treliças que sustentam plataformas fixas, tais quais as plataformas do tipo jaqueta ou plataformas do tipo auto-elevatórias. Na Figura 1.3 é apresentado um desenho esquemático do arranjo geral da plataforma Fulmar, localizada no Mar do Norte, no qual é possível observar o grande número de estruturas tubulares que eventualmente fiquem inclinadas em relação às correntes marinhas. 


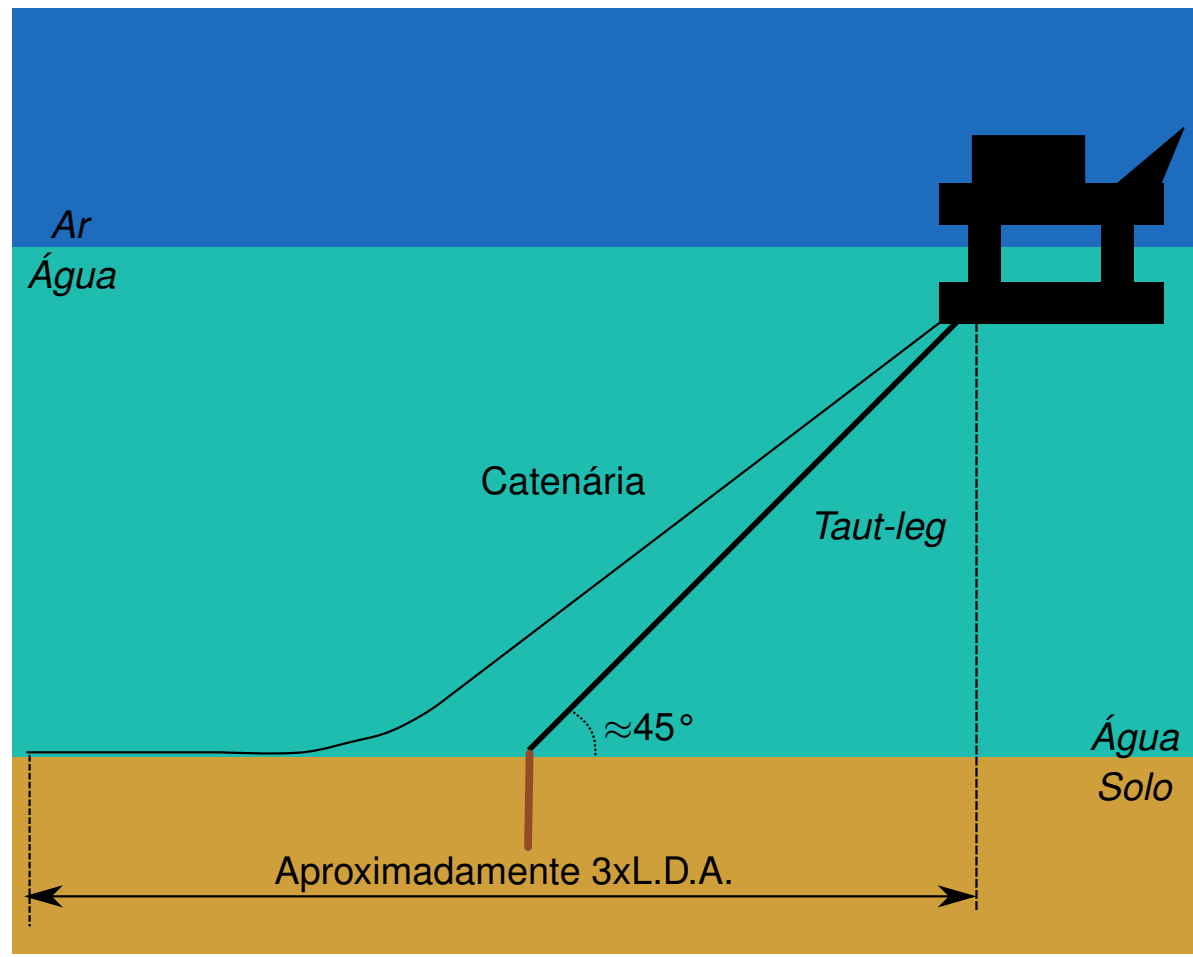

Figura 1.2 - Desenho esquemático comparando a configuração geométrica de uma linha de amarração lançada em taut-leg e uma linha lançada em catenária.

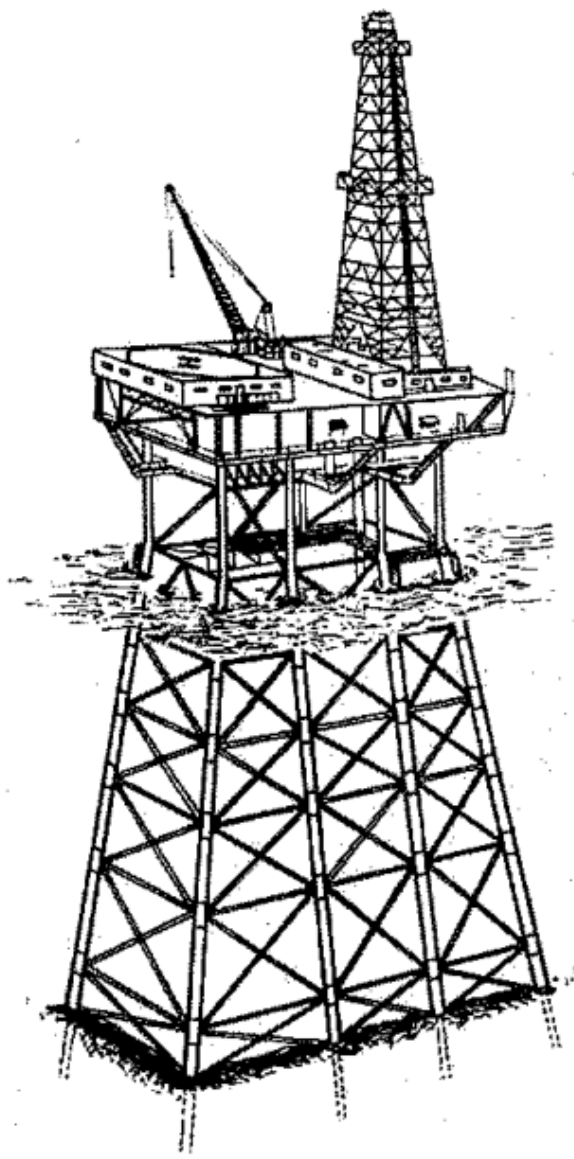

Figura 1.3 - Plataforma do tipo jaqueta Fulmar (Chakrabarti, 2005). 
Levando em conta os exemplos apresentados acima podemos generalizar o problema através do arranjo esquemático apresentado na Figura 1.4. Nesta figura, a linha vermelha representa a elástica (configuração de referência) do cilindro flexível montado em articulações. $U$ é a velocidade do perfil de correnteza que, por ora, será tratada como uniforme (velocidade constante no decorrer do tempo e perfil constante ao longo da profundidade).

Os ângulos $\theta$ e $\beta$ representam a inclinação em relação à vertical da reta que liga os dois extremos do cilindro flexível e o azimute em relação ao plano da correnteza, respectivamente.

$O X Y Z$ é o sistema de coordenadas global tal que o eixo $X$ esteja contido no plano da correnteza e possua sentido oposto ao desta. Oxyz é o sistema de coordenadas obtido rotacionando-se o sistema global ao redor de $Z$ de um ângulo $\beta$. A catenária formada pela deformação do cilindro flexível devido ao seu peso próprio está contida no plano $O x z$.

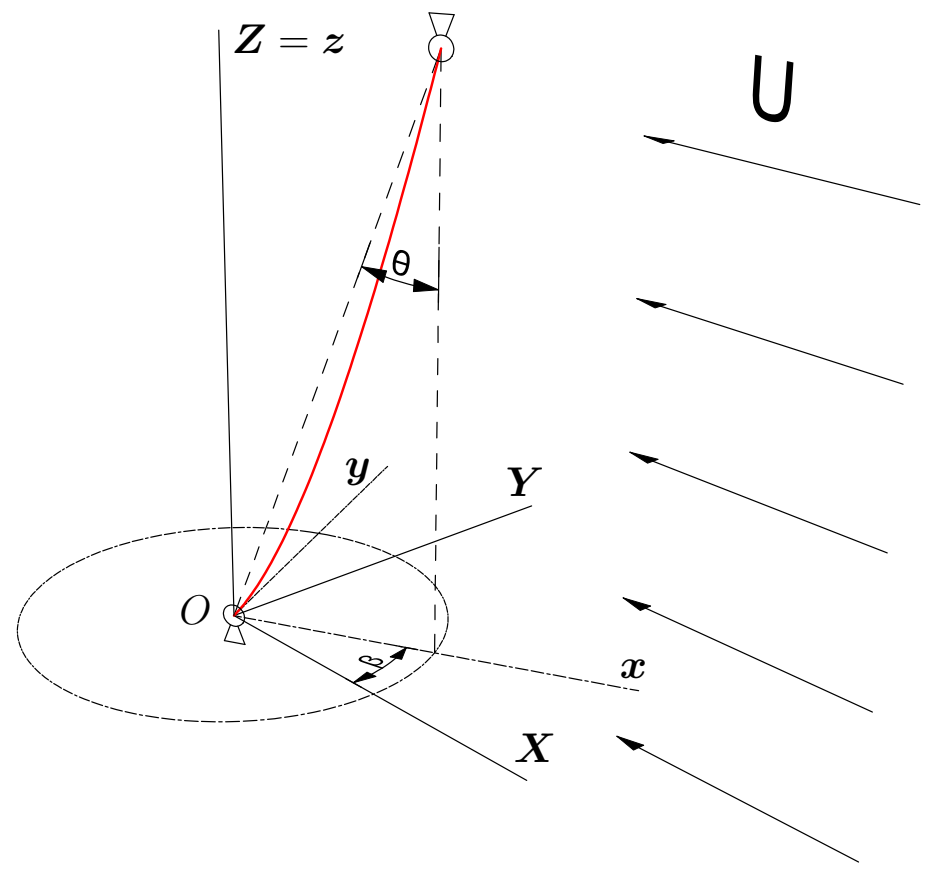

Figura 1.4- Arranjo esquemático com os sistemas de coordenadas adotados no problema estudado na presente tese. 


\subsection{Objetivo}

Conforme a natureza do problema apresentada acima, podemos destacar nesta seção o objetivo principal do trabalho que é Investigar experimentalmente a influência da inclinação com a vertical e a mudança de azimute no comportamento dinâmico de cilindros flexíveis suscetíveis às vibrações induzidas pela emissão de vórtices.

Essa investigação será pautada no comportamento multimodal das linhas flexíveis, utilizando métodos e processos bem difundidos e amplamente utilizados pela comunidade científica. Para tal, uma série de objetivos secundários devem ser alcançados. Esses objetivos e a forma como são organizados no texto são apresentados a seguir.

\subsection{Objetivos Secundários e Organização do Texto}

Baseando-se na literatura abrangente sobre VIV e nas pesquisas recentes realizadas no âmbito da Escola Politécnica da Universidade de São Paulo (EP-USP), principalmente os trabalhos que foram desenvolvidos nos laboratórios Laboratório de Mecânica Offshore (LMO), Núcleo de Dinâmica e Fluidos (NDF) e Tanque de Provas Numérico (TPN), pretende-se obter os fundamentos teóricos do fenômeno de VIV em tubulações flexíveis e inclinadas em relação ao perfil de correnteza incidente, determinando onde atualmente se encontra o estado-da-arte. Estes pontos estão abordados no Capítulo 2 - Revisão bibliográfica.

Com base nestes levantamentos teóricos, o presente trabalho tem por objetivo projetar experimentos em escala reduzida capazes de obter de forma controlada o fenômeno de VIV agindo sobre uma estrutura tubular flexível e inclinada, conforme o diagrama apresentado anteriormente na Figura 1.4. As técnicas e processos utilizados para se alcançar tal objetivo são descritos no Capítulo 3 - Metodologia.

Com base nos dados obtidos com os experimentos é feita uma apresentação comparativa entre as diversas configurações estudadas e uma análise crítica e descritiva dos principais resultados, sempre que possível fazendo uma correlação com aquilo que foi apresentado na fundamentação teórica. As comparações e discussões acerca destes pontos estão detalhadas no Capítulo 4 - Apresentação e Discussão dos Resultados Obtidos.

Por fim, como conclusão de um trabalho de pesquisa, este trabalho tem o intuito de apresentar um resumo dos principais tópicos levantando as considerações importantes, baseado naquilo que foi discutido como resultado. Quando possível, elaborar estes tópicos com foco nos pontos que precisam ser trabalhados em pesquisas futu- 
ras, propondo temas que venham a contribuir com o desenvolvimento dos problemas aqui discutidos. Tais ponderações estão apresentadas no Capítulo 5 - Conclusões e Considerações Finais.

Adicionalmente, foi proposta a apresentação de alguns apêndices que contém temas correlatos à pesquisa, bem como resultados complementares. A derivação de equações importantes aos estudo de cilindros flexíveis inclinados é apresentada no Apêndice $A$ - Subsídios Teóricos. A complementação dos resultados referentes à caracterização do modelo é apresentada no Apêndice $B$ - Frequências, modos naturais $e$ coeficientes de amortecimento. Já a complementação dos resultados referentes aos gráficos de amplitude contidos no texto principal são apresentados no Apêndice $C$ Resultados complementares do ensaio de VIV. 


\section{Capítulo 2}

\section{Revisão bibliográfica}

\subsection{Vibrações induzidas pela emissão de vórtices}

O estudo do VIV é um ramo da mecânica dos fluidos que estuda a vibração de corpos rombudos causada pela incidência de escoamentos externos. Corpos rombudos são aqueles que provocam separação em uma significativa parte de sua superfície (Bearman, 1984).

A aplicação deste estudo é muito abrangente: na engenharia em geral, temos aplicações do estudo de VIV em projeto de pontes, torres de exaustão, turbinas termoelétricas, linhas de transmissão, motores etc; mais especificamente, na engenharia naval e oceânica, temos aplicações do estudo no projeto de sistemas de amarração de unidade flutuantes, sistemas de tubulações de prospecção de petróleo e gás, projeto de plataformas do tipo Spar ou Monocolunas ${ }^{1}$, elementos estruturais de plataformas do tipo jaqueta, tendões de plataformas Tension-Leg Platform (TLP) e no projeto de inúmeros subsistemas que estão sujeitos à incidência de correntes oceânicas.

Apesar de as primeiras observações empíricas da emissão de vórtices em escoamentos serem datadas da Grécia antiga, apenas recentemente os primeiros estudos científicos sobre o tema foram realizados por Strouhal (1878) que, em suas investigações, notou a relação entre a frequência de emissão de vórtices $\left(f_{S}\right)$, o diâmetro do corpo imerso $(D)$ e a velocidade do escoamento incidente $(U)$ e chegou ao primeiro valor aproximado:

$$
f_{S}=0.185 \frac{U}{D}
$$

${ }^{1} \mathrm{~A}$ nomenclatura utilizada atualmente para a vibração induzida em unidades flutuantes é Movimento Induzido pela Emissão de Vórtices (VIM) ou, em inglês, Vortex-Induced Motion 
Na sequência, Rayleigh (1896) em um estudo mais completo, notou que este valor não era fixo como afirmou Strouhal, porém variável e dependente do número de Reynolds, dado por:

$$
R e=\frac{U D}{\nu}
$$

onde $U$ e $D$ são a velocidade e o comprimento característicos do sistema analisado e $\nu$ é a viscosidade cinemática dada por:

$$
\nu=\frac{\mu}{\rho_{f}}
$$

onde $\mu$ é a viscosidade dinâmica do fluido e $\rho_{f}$ sua densidade.

Desta forma, Rayleigh definiu o número de Strouhal $(S t)$ que relaciona a frequência de emissão de vórtices, a velocidade do escoamento e a dimensão característica do corpo imerso:

$$
f_{S}=S t \frac{U}{D}
$$

Abaixo, na Figura 2.1, tem-se a variação do número de Strouhal em função do número de Reynolds e da rugosidade do cilindro. Estes dados são válidos apenas para escoamentos subsônicos.

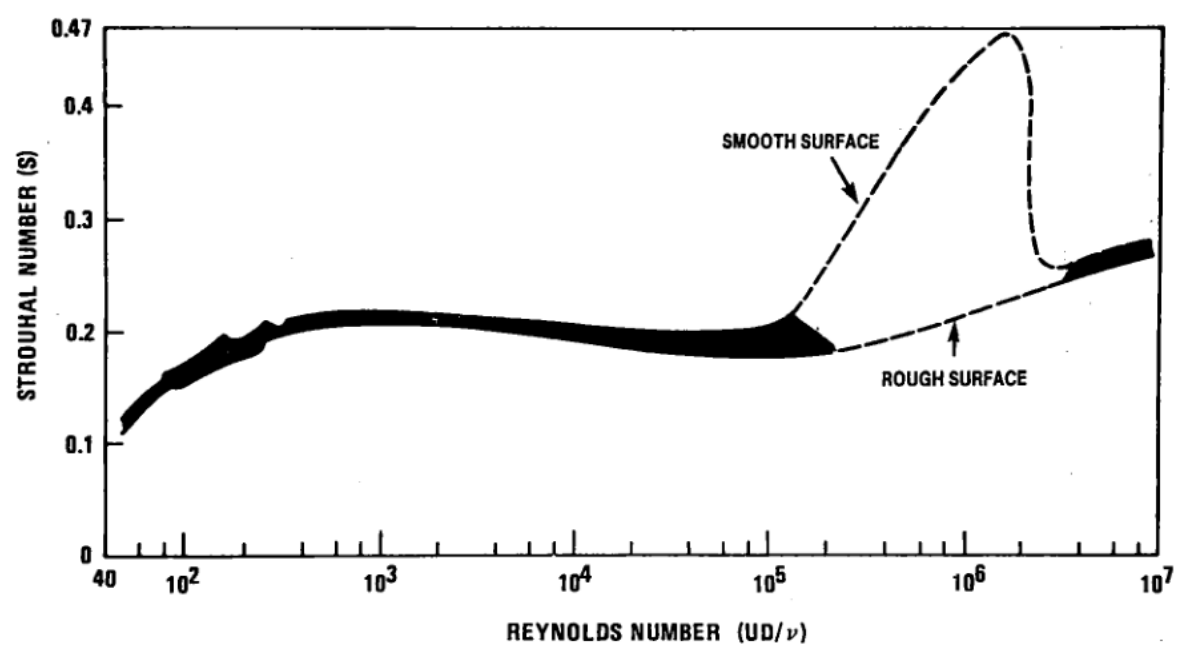

Figura 2.1 - Variação do número de Strouhal em função do número de Reynolds. Extraído de Blevins (1990).

Quanto menor for o Re maior é o domínio das forças viscosas e, quanto maior for o Re maior é o domínio das forças de caráter inercial. Como não poderia ser diferente, em problemas de liberação de vórtices em um cilindro circular liso, sujeito a um escoamento em regime permanente, o adimensional utilizado é o número de Reynolds, cuja 
variação influi significativamente na porção de fluido denominada camada limite. A camada limite é uma porção do escoamento onde ocorre uma variação no gradiente de velocidade, desde velocidade nula na superfície do corpo fixo, até onde a velocidade é assintoticamente igual à velocidade do escoamento à montante.

As definições do cilindro descrito acima fazem com que o ponto de separação da camada limite varie na superfície do cilindro de montante à jusante conforme o Re aumenta. Na região de incidência do escoamento, a camada limite corresponde à uma faixa estreita bem aderida ao cilindro. Conforme o fluido percorre a superfície do cilindro aparece um aumento da pressão no sentido contrário até o ponto onde ocorre a separação da camada limite do corpo.

A Figura 2.2 apresenta a esteira alternada de vórtices, que é formada quando se tem um determinado escoamento ao redor de um cilindro. Esta esteira é conhecida como Esteira de von Karmán. $O$ cilindro está localizado à direita na imagem e o escoamento tem direção da direita para a esquerda. É possível observar a alternância na formação desses vórtices.

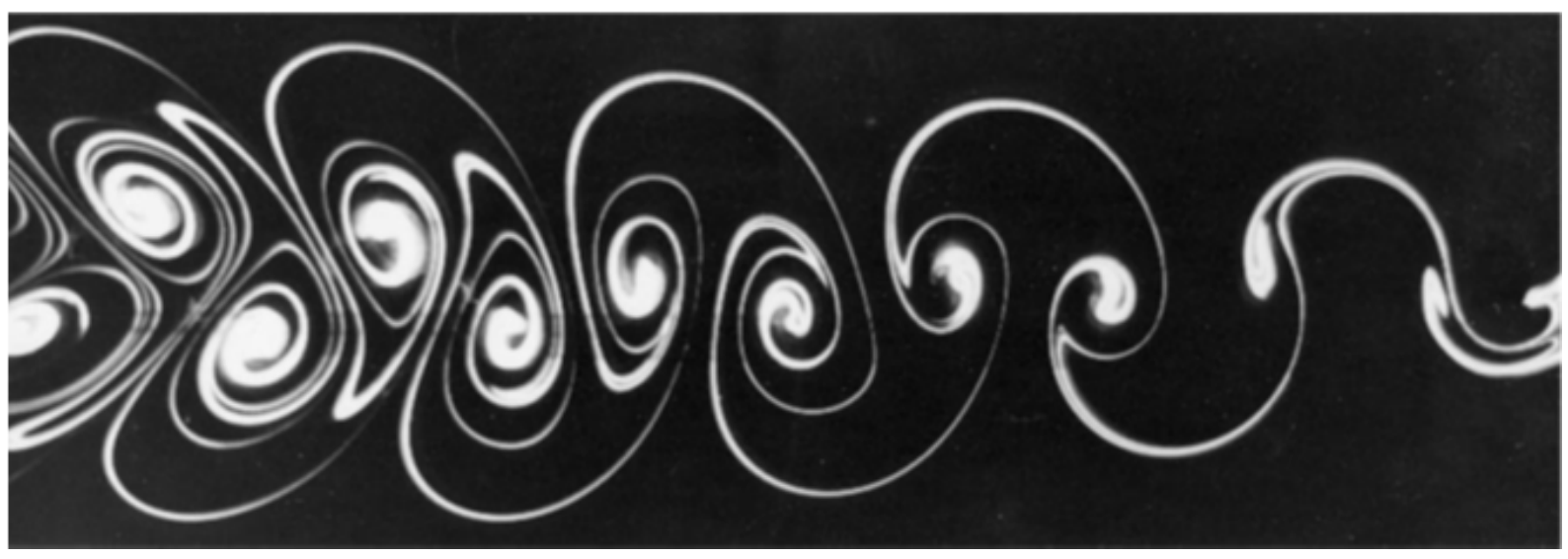

Figura 2.2 - Esteira de von Karmán formada a partir do escoamento ao redor de cilindro. Extraído de Williamson \& Govardhan (2004).

Bearman (1984) salienta que a interação entre as camadas limites liberadas em cada lado do cilindro é o que gera a esteira de vórtices observada. O padrão da formação destes vórtices depende de fatores como a localização dos pontos de separação e se o cilindro está livre para vibrar ou não. Este padrão de formação de vórtices não é uma tarefa simples de se prever, porém alguns mecanismos como o apresentado em Gerrard (1966) explicam melhor a interação entre as camadas limites.

Após o ponto de separação, a camada limite ainda possui um gradiente de velocidade menor na porção interna que antes estava em contato com a parede do cilindro e maior na região externa em contato com o escoamento. Segundo Assi (2009), a camada limite após o ponto de separação é uma região concentrada de vorticidade. Na Figura 2.3 podemos observar esquematicamente que a camada limite inferior apresenta um 
movimento de subida no qual parte dela é engolfada pela vorticidade da camada limite superior (a), parte executa um movimento de corte da camada limite superior (b) e parte realimenta a vorticidade da esteira na região próxima ao cilindro (c). Este processo ocorre alternadamente em cada uma das camadas limites, desprendendo vórtices de sentidos opostos de rotação a cada ciclo.

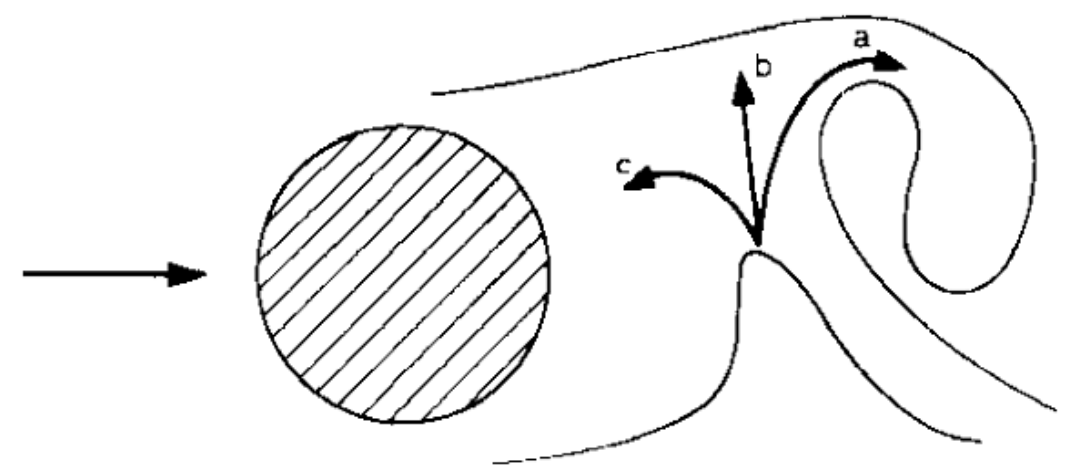

Figura 2.3 - Modelo de formação de vórtices. Extraído de Gerrard (1966).

A Figura 2.4 apresenta a sequência de distribuição do coeficiente de pressão na superfície de um cilindro durante aproximadamente um terço de ciclo de emissão de vórtices.

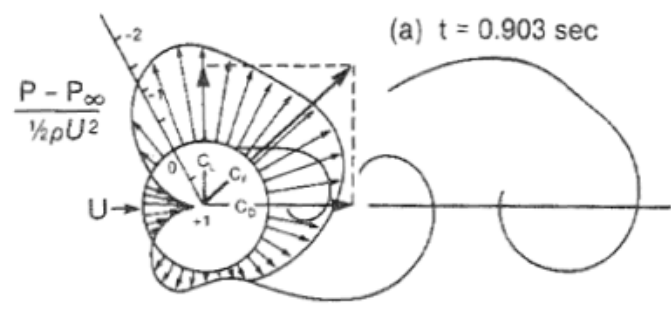

(b) $t=0.935 \mathrm{sec}$

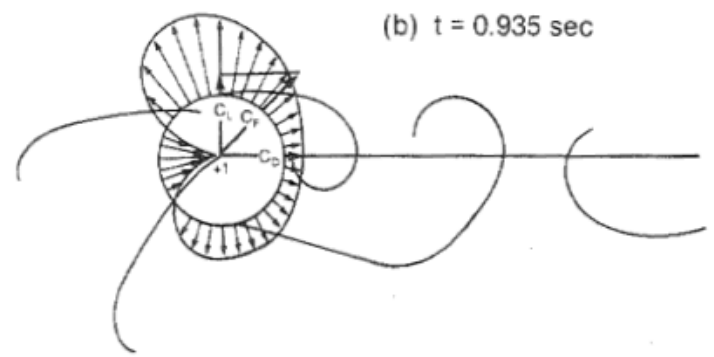

(c) $t=0.968 \mathrm{sec}$

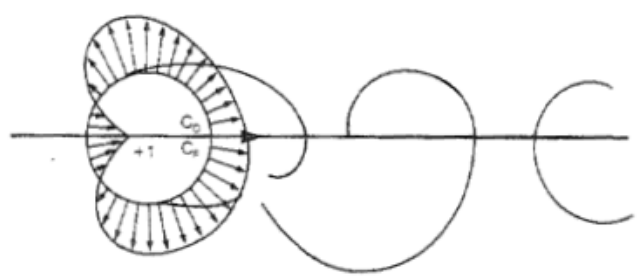

(d) $\mathrm{t}=1.000 \mathrm{sec}$

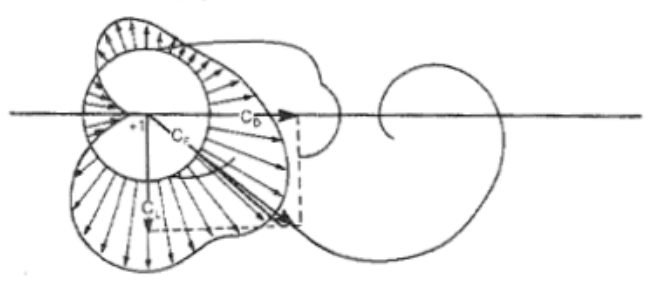

Figura 2.4 - Sequência da distribuição de pressão na superfície de um cilindro em 1/3 de ciclo de emissão de vórtice $\left(R e=1.12 \cdot 10^{5}\right)$. Extraído de Blevins (1990).

Devido à variação de pressão ao longo do tempo na superfície do cilindro, a liberação alternada de vórtices induz forças alternadas, tanto na direção do escoamento quanto na direção perpendicular à este. Se o cilindro for flexível ou rígido montado em 
uma base elástica, estas forças alternadas resultam em um fenômeno essencialmente ressonante com duas principais características:

- autoexcitação

- autocontrole

Segundo Bearman (1984), o mecanismo que resulta nestas características é o seguinte: ao passo que as velocidades vão aumentando, a frequência de emissão de vórtices também aumenta de acordo com a relação (2.4). Ao passo que a frequência de emissão de vórtices se aproxima da frequência de ressonância do sistema, há um aumento significativo na amplitude de oscilação do sistema. Essa amplitude altera o escoamento de tal forma que a própria oscilação começa a induzir a frequência na qual os vórtices são liberados e assim, mesmo aumentando-se a velocidade, a frequência de emissão permanece próxima da frequência natural. Esta manutenção do sistema oscilando em sua frequência natural é a chamada sincronização.

Esta faixa de velocidades na qual $f_{S} \approx f_{n}$ é denominada região de sincronização ou região de lock-in. Na Figura 2.5 podemos ter uma ideia do comportamento do mecanismo relatado acima.

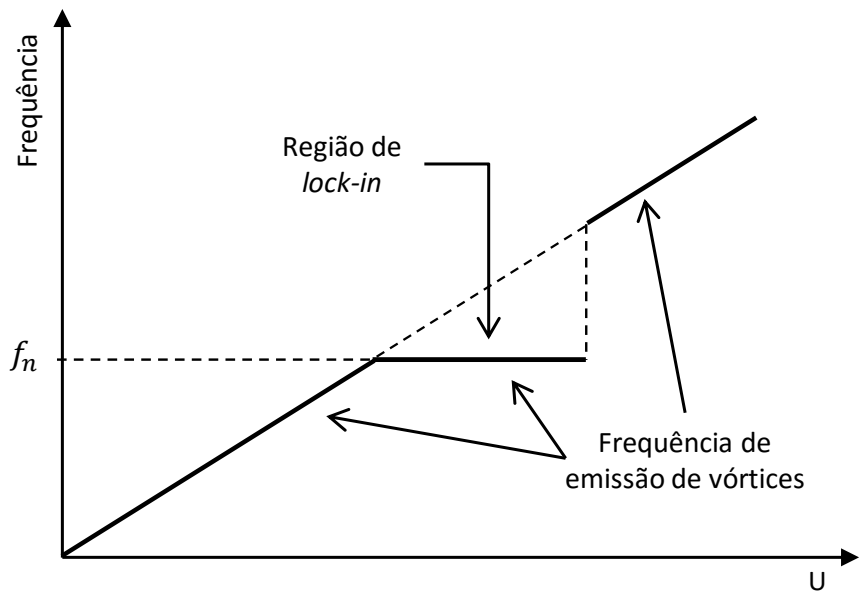

Figura 2.5 - Exemplo esquemático da variação da frequência de emissão de vórtices em função da velocidade de escoamento.

Aumentando-se ainda mais velocidade, esse mecanismo de autoexcitação se torna instável e a esteira de vórtices é desfeita. Quando isso ocorre há uma dessincronização entre a emissão de vórtices e a oscilação do cilindro, a amplitude de vibração reduz-se significativamente e a frequência de emissão de vórtices obedece novamente a relação (2.4). A este processo de dessincronização é que atribuímos a característica de autocontrole. 
As maiores amplitudes obtidas através de observações feitas em laboratório estão sempre direcionadas transversalmente ao escoamento e dificilmente foram encontrados valores máximos maiores que 1.5 vezes o diâmetro do cilindro, independente das particularidades de cada experimento.

De acordo com as principais revisões e compêndios sobre VIV (Bearman, 1984; Williamson \& Govardhan, 2004; Sarpkaya, 2004), os estudos empíricos e numéricos acerca de escoamentos ao redor de cilindros podem ser categorizados, em ordem de complexidade dos fenômenos observáveis, conforme a Tabela 2.1.

Tabela 2.1 - Categorias principais dos estudos empíricos e numéricos de escoamento ao redor de cilindros.

Tipo de estudo Principais Características

Fixos

Medição das forças de arrasto e sustentação; visualização dos diferentes padrões de emissão de vórtices.

Forçados

Imposição de movimento em uma ou mais frequências; visualização do desprendimento da esteira de vórtices em função da amplitude e frequência de oscilação; observação das flutuações nas forças.

Rígidos com 1 grau Simplificação de casos complexos restringindo a mode liberdade vimentação em apenas uma direção; medição da amplitude e frequência de movimento em apenas uma direção isolada; influência de parâmetros como massa, amortecimento e restauração, observação do mecanismos de autoexcitação e autocontrole.

Rígidos com 2 graus Possibilidade de movimentação nas direções alinhada de liberdade e transversal ao escoamento; medição dos movimentos acoplados: trajetórias, relação entre frequências.

Flexíveis

Sistema mais próximo da aplicação prática, interação entre os diversos modos de vibrar: convivência modal, mudanças abruptas ou saltos entre modos, efeito da geometria da estrutura, propagação de ondas, perfis de correnteza estratificados. 
Para a realização destes estudos, além dos números de Strouhal, eq. (2.4), e de Reynolds, eq. (2.2), já abordados neste texto, a definição de outros parâmetros adimensionais se faz necessária. Estes parâmetros estão apresentados na Tabela 2.2.

Tabela 2.2 - Parâmetros adimensionais envolvidos no fenômeno de VIV. Adaptado de Khalak \& Williamson (1999).

\begin{tabular}{ccc}
\hline Parâmetro & Símbolo & Expressão \\
\hline Razão de massa & $m^{*}$ & $\frac{M}{\pi \rho_{f} D^{2} L_{h} / 4}$ \\
Coeficiente de amortecimento & $\zeta$ & $\frac{c}{2 \sqrt{k\left(M+M_{a}^{P O T}\right)}}$ \\
Velocidade reduzida & $V r$ & $\frac{U}{f_{n} D}$ \\
Amplitude adimensional & $A^{*}$ & $\frac{A_{y}}{D}$ \\
Frequência adimensional & $f^{*}$ & $\frac{f}{f_{n}}$ \\
Coeficiente de arrasto & $C_{D}$ & $\frac{F_{D}}{\frac{1}{2} \rho_{f} D L_{h} U^{2}}$ \\
Coeficiente de sustentação & $C_{L}$ & $\frac{F_{L}}{\frac{1}{2} \rho_{f} D L_{h} U^{2}}$ \\
\hline
\end{tabular}

Além dos artigos citados acima é importante salientar os grandes avanços e fundamentais contribuições dos estudos de: Lyons \& Patel (1986), Meneghini (1993), Jauvtis \& Williamson (2004).

Por outro lado, uma abordagem já clássica em VIV é a que trata da dinâmica da esteira de vórtices através de modelos de ordem reduzida, emulando-a através de osciladores não lineares, do tipo van der Pol ou Rayleigh. Esta linha de modelagem é conhecida como wake oscillators. Exemplos clássicos desta abordagem são discutidos em Hartlen \& Currie (1970), Iwan \& Blevins (1974), Skop \& Balasubramanian (1997), Fujarra \& Pesce (2002), Facchinetti et al. (2004). Esta linha de pesquisa tem sido muito bem explorada no âmbito da EP-USP, ver por exemplo: Parra (1996), Fujarra (2002), Silveira et al. (2007), Franzini et al. (2009), Silveira (2009). Um estudo comparativo destes modelos pode ser visto na dissertação de mestrado de Cunha (2005). Outro, de caráter mais aprofundado, sob o ponto de vista da Mecânica Analítica, pode ser encontrado em Benaroya \& Gabbai (2008). 
Assim, foram apresentados alguns dos principais trabalhos que tratam os aspectos fenomenológicos centrais do VIV. Com a base fornecida por estes estudos é possível, na próxima seção, entrar nos aspectos particulares das estruturas flexíveis, ponto central do presente estudo.

\subsection{VIV em cilindros flexíveis}

Ao passo que os estudos de VIV foram se desenvolvendo, um caminho natural a se percorrer foi o entendimento e a formulação de problemas que envolvessem estruturas flexíveis, mais próximas daquelas encontradas em problemas reais de engenharia, tais quais aqueles apresentados na Introdução deste trabalho.

A possibilidade de oscilar em diversos modos e de apresentar amplitudes diferentes de vibração ao longo do comprimento da estrutura inserem no problema diversos aspectos que tornam o estudo das estruturas flexíveis uma área bem específica do VIV e de muito interesse, tanto acadêmico como industrial.

Os cilindros flexíveis são caracterizados por possuírem infinitas frequências naturais associadas aos respectivos modos de vibrar. Como visto na seção anterior, à medida em que a velocidade de escoamento ao redor aumenta, a frequência de emissão de vórtices aumenta proporcionalmente. Uma vez que se tenha uma velocidade suficiente para excitar o primeiro modo de vibrar, qualquer velocidade acima desta pode liberar vórtices numa frequência que coincidi com uma frequência de um modo mais alto.

Sendo assim, diferentemente dos cilindros rígidos montados em base elástica, para os cilindros flexíveis é esperado que com o aumento da velocidade uma sucessão de sincronizações ocorra, de forma a se obter amplitudes de vibração expressivas para um intervalo muito maior de velocidades.

Um problema consequente desse fato é que vibrações em frequências altas causam curvaturas cada vez maiores, devido ao aumento do número de nós dos modos de vibrar. Este conjunto de frequências e curvaturas altas favorecem a fadiga do material, sendo potencialmente prejudicial aos sistemas oceânicos.

O ponto central, quanto à fluido-dinâmica, que separa os cilindros flexíveis verticais dos sistemas com cilindros rígidos fixos ou montados em base elástica é a natureza tridimensional do problema. Os cilindros rígidos, que possuem razões de aspecto suficientemente grandes para que os efeitos de borda sejam desprezíveis, possuem uma correlação de formação de vórtices ao longo do comprimento, tal que o problema possa ser estudado de forma bidimensional. 
No tema VIV em cilindros flexíveis existem trabalhos teóricos, experimentais e mais recentemente trabalhos numéricos. Dada a complexidade relatada acima, é natural que os primeiros estudos tenham adotado o método experimental como ponto de partida para a obtenção dos fundamentos teóricos e fenomenológicos que existem até o momento.

Um dos experimentos de VIV em cilindros flexíveis que firmou as bases para a execução deste tipo de ensaios foi o de Vickery \& Watkins (1964). Os experimentos foram executados em túnel de vento com modelos feitos com tubos de PVC, instalados na forma de cantilever ${ }^{2}$. A matriz de ensaio, compreendeu testes com um cilindro único e com quatro cilindros idênticos alinhados na direção do vento (Figura 2.6a), além da utilização de strakes $^{3}$ usados para mitigação da vibração (Figura 2.6b).

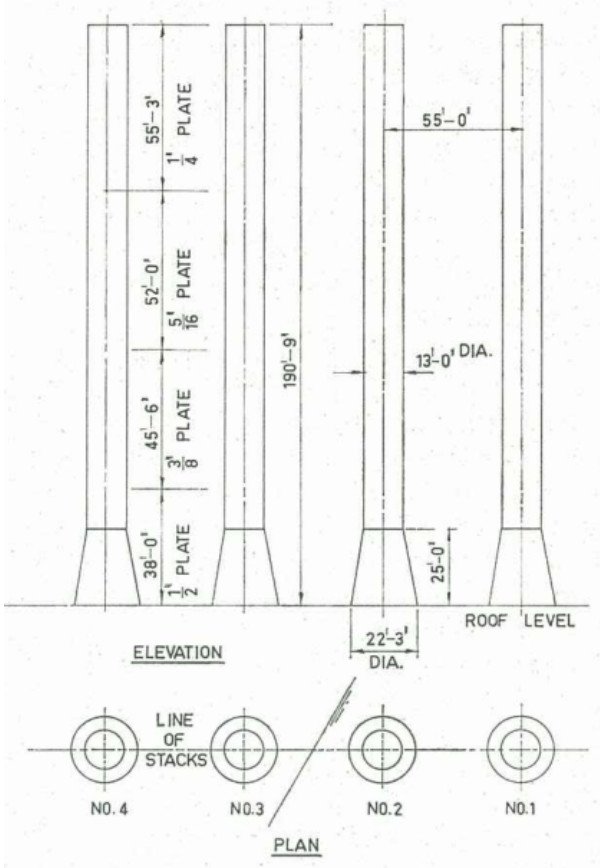

(a)

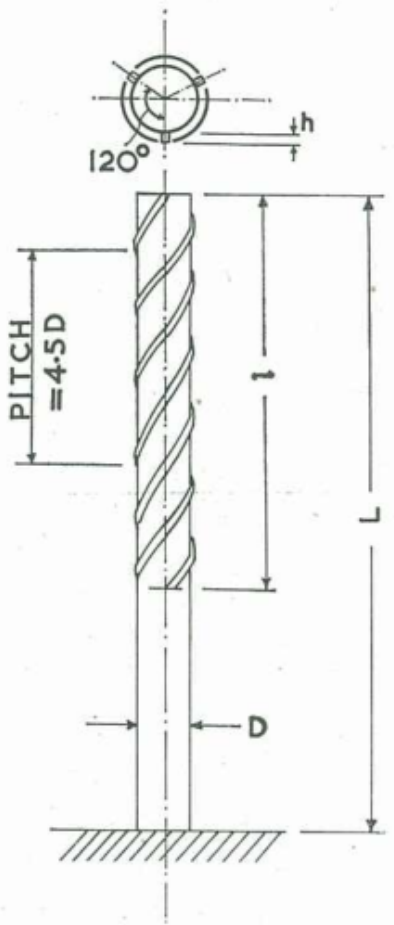

(b)

Figura 2.6 - (a) Configuração geométrica do modelo isolado e os parâmetros de definição dos strakes. (b) Arranjo do ensaio para a configuração de quatro cilindros flexíveis instalados em série. Fonte: Vickery \& Watkins (1964).

Essa configuração estudada visava entender a resposta de estruturas comuns à engenharia civil tais quais a passagem de vento através de chaminés implantadas em

\footnotetext{
${ }^{2}$ Cantilever é o nome dado à condição de contorno na qual o cilindro está engastado em uma extremidade, enquanto a outra permanece livre.

${ }^{3}$ Strakes são estruturas helicoidais colocadas ao longo do comprimento do cilindro para modificar a tridimensionalidade do escoamento e, por consequência, suprimir a vibração.
} 
diferentes tipos de parques industriais, muitas vezes construídas em relativa proximidade umas das outras.

Suas principais conclusões foram a de que strakes colocados em $1 / 4$ do comprimento, a partir da extremidade livre, são capazes de suprimir as vibrações. Já para os cilindros arranjados em série, a utilização dos strakes perde eficiência. Neste caso também foi possível notar a dependência da amplitude de vibração com a direção de incidência do vento e com o espaçamento entre os cilindros.

Os avanços no campo da previsão do fenômeno ressonante começaram com a fundamentação teórica apresentada em Skop et al. (1973) e Skop \& Griffin (1975), na qual o modelo fenomenológico que utiliza a equação de van der Pol foi modificado de forma a estender os estudos prévios feitos com cilindros rígidos (Skop \& Griffin, 1973; Griffin et al., 1973; Iwan \& Blevins, 1974) para o estudo de sistemas com cilindros flexíveis.

Uma das principais contribuições foi a definição da curva de amplitude modal máxima $\left(A_{m_{i}}^{\max }\right)$ em função do parâmetro de Skop-Griffin $\left(S_{G}\right)$, apresentada na Figura 2.7 e comparada com diversos estudos experimentais.

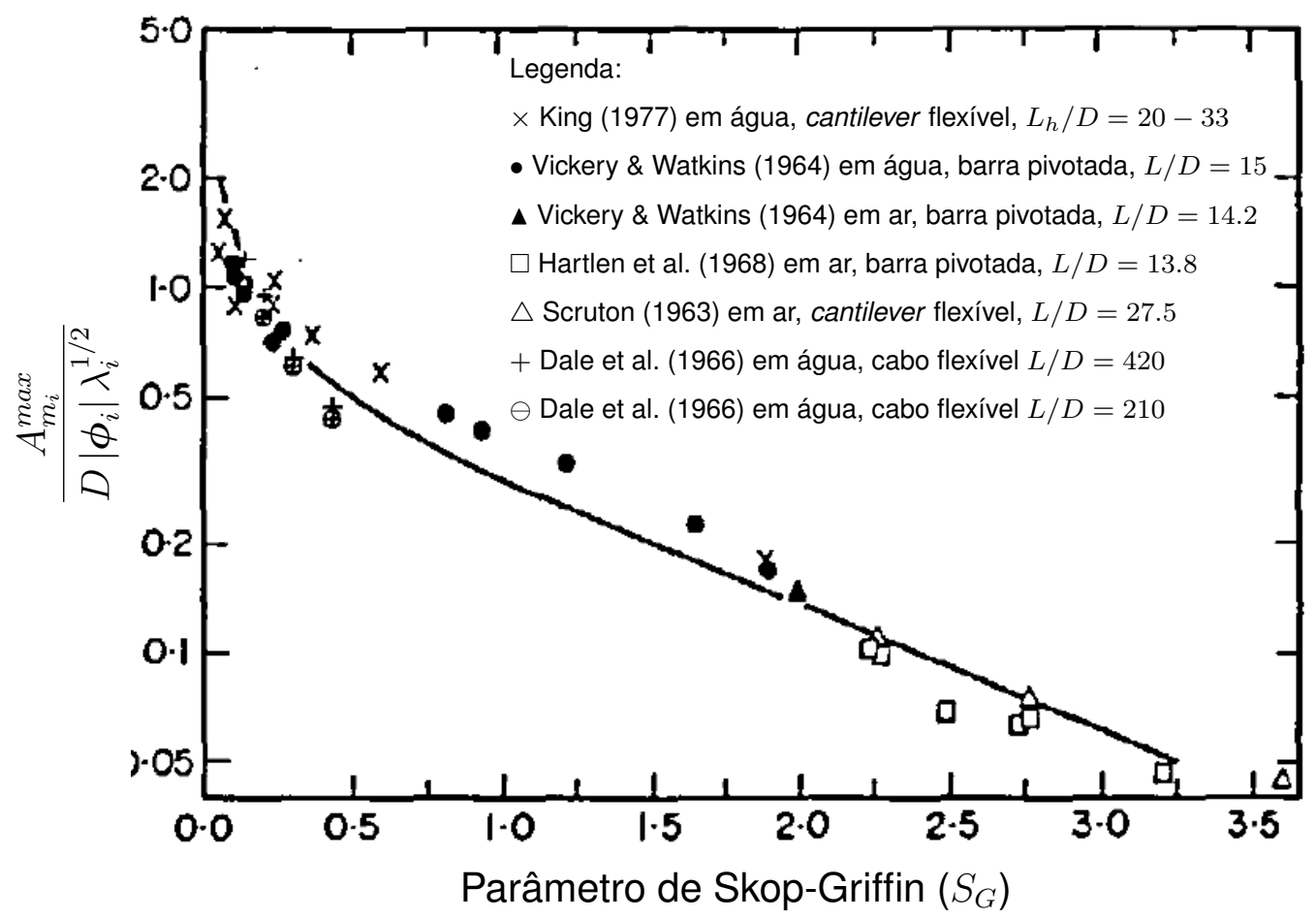

Figura 2.7 - Amplitude modal máxima para diversos cilindros flexíveis em função de $S_{G}$. Adaptado de Skop \& Griffin (1975)

O parâmetro de Skop-Griffin é dado, para sistemas com massa constante ao longo do comprimento, por:

$$
S_{G}=2 \pi^{3} S_{t}^{2}\left(m^{*} \bar{\zeta}\right)
$$


onde $\bar{\zeta}$ é o amortecimento medido no mesmo fluido do escoamento ${ }^{4}$, porém na ausência deste, e $\lambda_{i}$ é o fator modal calculado, segundo Blevins (1990), como:

$$
\lambda_{i}=\frac{\int_{0}^{1} \phi_{i}^{2}(s) d s}{\int_{0}^{1} \phi_{i}^{4}(s) d s}
$$

Estudos seguintes, apresentados em Ramberg \& Griffin (1974) e Ramberg \& Griffin (1976), buscaram entender experimentalmente a formação da esteira em cabos flexíveis realizando ensaios com oscilação forçada. Eles chegaram as clássicas conclusões de que o padrão da esteira depende da amplitude e frequência da vibração e de que, apesar de sua natureza tridimensional, "a esteira próxima de qualquer ponto ao longo do cabo pode ser representada pela esteira próxima de um cilindro fixo vibrando sobre as mesmas condições de frequência, amplitude e $R e$ ".

A seguir, os estudos de Vandiver (1993) destacaram cuidadosamente diversas conclusões importantes. Neste trabalho teórico-experimental alguns pontos-chave da dinâmica de VIV em cilindros flexíveis são listados, tais como a variação da massa adicional, o fato de que cilindros flexíveis com baixos valores de razão de massa possuem faixas de lock-in mais largas que aqueles com maiores valores de razão de massa (Figura 2.8) e que grandes amplitudes de vibração auto-excitadas ocorrem se, e somente se, houver uma sincronização entre a frequência de formação dos vórtices e a frequência de algum modo de vibrar da estrutura flexível.

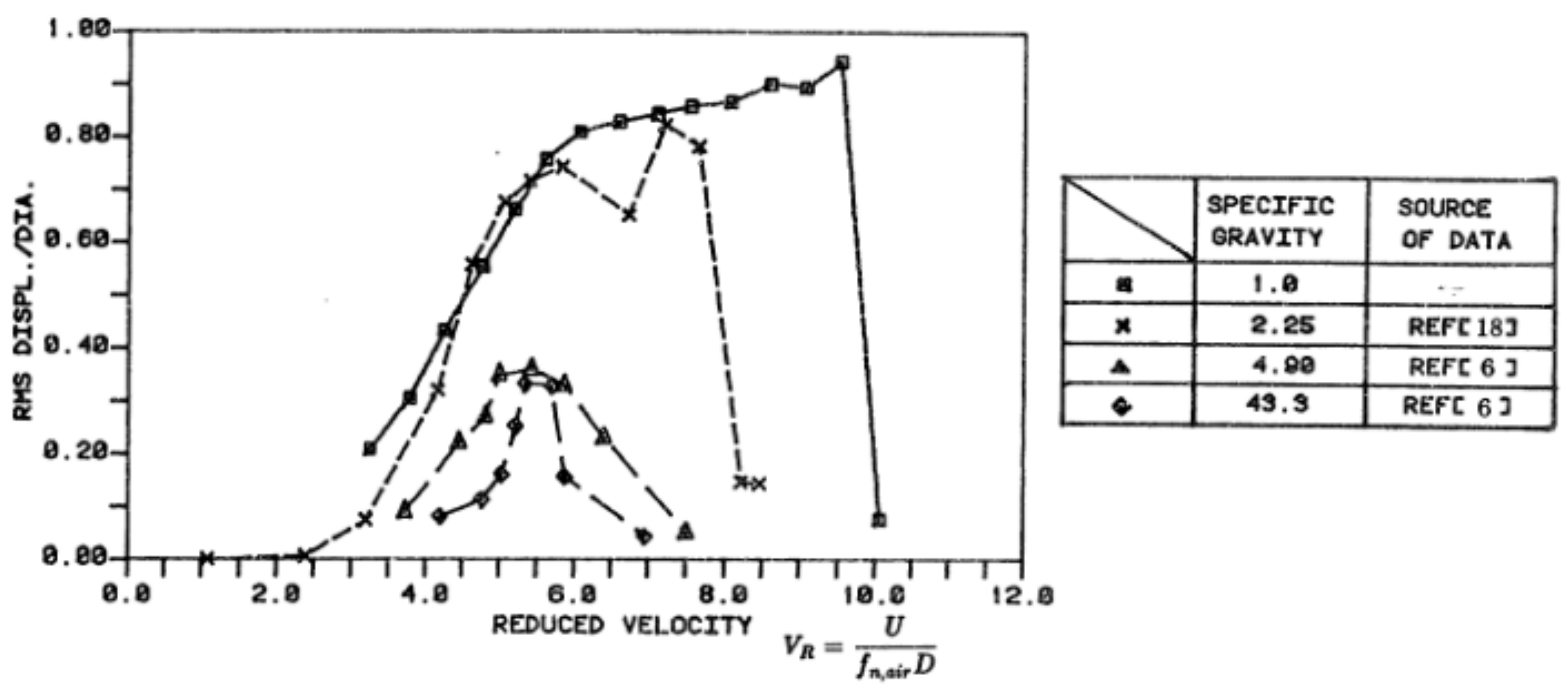

Figura 2.8 - R.M.S. da amplitude adimensionalizada versus a velocidade reduzida, para cilindros flexíveis com diferentes razões de massa (Chung, 1987).

\footnotetext{
${ }^{4}$ Esse fato deve ser bem evidenciado, pois as pesquisas mais recentes usam o valor de $\zeta$ como 0 amortecimento estrutural medido no ar, conforme considerações que serão feitas na seção 3.4.1.
} 
A determinação da faixa de lock-in depende do amortecimento e da tolerância do processo de formação da esteira às variações na velocidade reduzida. Porém, sua determinação precisa depende ainda do número de Reynolds, da intensidade da turbulência, da rugosidade e da amplitude de vibração do cilindro.

Além disso, foram apresentadas conclusões acerca da coexistência de modos na faixa de lock-in. Ou seja, apesar do lock-in ocorrer para velocidades em que a frequência de emissão de vórtices se aproxima de uma das frequências naturais do sistema, diversos modos podem ser excitados mesmo que sua frequência natural seja distante.

Para os modelos de viga tracionadas, conforme os modos de vibrar aumentam, os efeitos da rigidez flexional se tornam mais importantes devido à razão com que as frequências naturais crescem.

O fato é que o comportamento do VIV coexistindo em diversos modos simultaneamente é uma recorrente nas observações de campo para risers, cabos de amarração e tendões.

Trabalhos como os de Lyons \& Patel (1986) utilizaram estes fatores através de modelos semi-empíricos para estimar a vibração multimodal com base na velocidade reduzida calculada para cada um dos modos de vibrar e compararam com experimentos projetados de forma a fornecer um perfil linear de velocidades, induzindo o comportamento de VIV em apenas algumas regiões do cilindro.

Nesse trabalho o modelo foi pivotado em sua extremidade inferior e sujeito a um movimento forçado na extremidade superior conforme apresentado na Figura 2.9.

$Y=$ function $(x, t$, top amplitude and period)

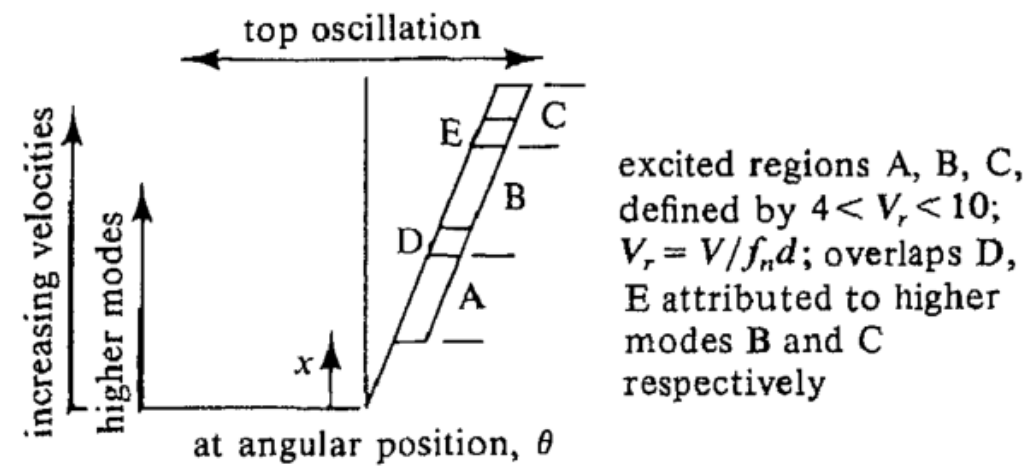

Figura 2.9 - Arranjo esquemático de ensaio para excitação de comportamento multimodal. Extraído de Lyons \& Patel (1986).

Dependendo da movimentação imposta na extremidade superior foi possível a obtenção de diversas combinações de regiões suscetíveis ao fenômeno de lock-in, como podemos ver na Figura 2.10. 


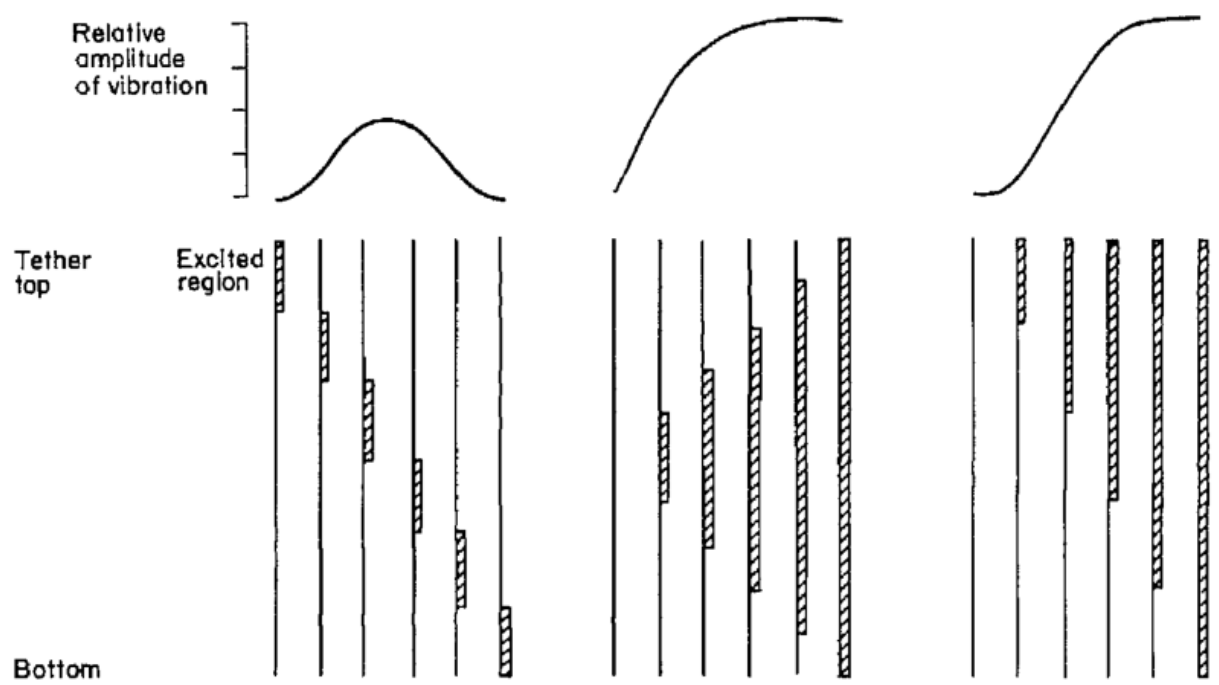

Figura 2.10 - Regiões suscetíveis ao fenômeno de VIV em função da forma como a extremidade superior do modelo é movimentada. Extraído de Lyons \& Patel (1986).

Este estudo forneceu muitas das bases que são utilizadas hoje em dia para a predição da ocorrência de VIV com a utilização de códigos computacionais que são amplamente utilizados na estimativa da vida útil dos sistemas oceânicos.

No final da década de 90, os modelos de predição de amplitude máxima de VIV em cilindros flexíveis sofreu uma pequena mudança. O trabalho de Skop \& Balasubramanian (1997) revisitou as equações do modelo de oscilador anteriormente apresentadas em Skop \& Griffin (1975) e, com base nos estudos mais recentes, redefiniu a maneira como as predições de amplitude seriam realizadas. A partir deste trabalho e o de Khalak \& Williamson (1999) o parâmetro mais aceito para a avaliação da amplitude máxima de resposta foi $\left(m^{*}+C_{a}^{P O T}\right) \zeta$ (calculado de acordo com a Tabela 2.2).

Desta forma, o parâmetro de Skop-Griffin $S_{G}$ foi redefinido para a equação (2.7):

$$
S_{G}=2 \pi^{3} S_{t}^{2}\left(m^{*}+C_{a}^{P O T}\right) \zeta
$$

Este parâmetro será utilizado, mais adiante, para comparação com os resultados experimentais da presente tese.

Mesmo com a evolução e implementação de novos efeitos e novos modelos de predição nos códigos numéricos, a utilização do método experimental se fez imprescindível e, neste quesito, é possível citar as contribuições realizadas no âmbito da EP-USP, desenvolvendo metodologias diversas para o estudo de cilindros flexíveis seja em tanques de reboque ou mesmo em tanques oceânicos. Além das contribuições do estudo de VIV, é possível apontar os avanços realizados no projeto de modelos em escala reduzida, nos métodos de aquisição de dados através de câmeras submersas, entre 
outros.

Neste contexto, têm-se os avanços feitos por Pesce \& Fujarra (2000), no qual são apresentados os resultados do ensaio em tanque de reboque de um modelo de alumínio instalado em cantilever. A medição da amplitude foi realizada indiretamente através da utilização de strain gauges ${ }^{5}$ instalados internamente ao modelo.

Abaixo, na Figura 2.11, é apresentado o resultado da medição da amplitude modal como função da velocidade reduzida para o primeiro modo de vibrar.

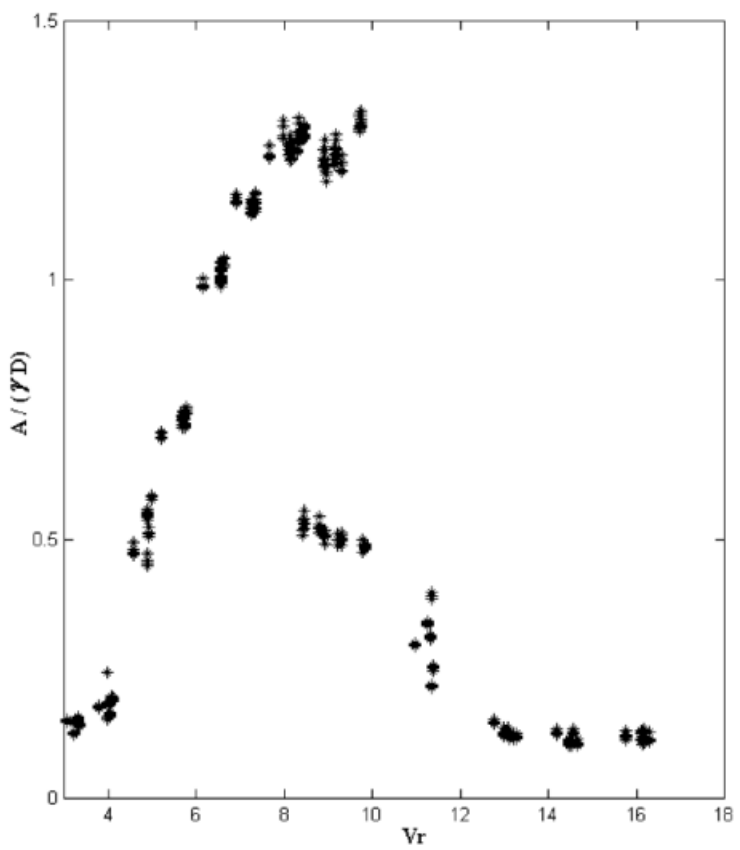

Figura 2.11 - Amplitude modal normalizada versus a velocidade reduzida para o $1^{\circ} \mathcal{M}$ (Pesce \& Fujarra, 2000).

Foram obtidos dois padrões bem distintos de vibração onde pode-se definir claramente o upper branch e o lower branch. O salto entre um e outro ocorre para valores de $V_{r} \cong$ 8.3 e é possível observar a coexistência dos dois ramos para valores da velocidade reduzida na faixa $8.3 \leq V_{r} \leq 10$. Além disso, foi observado que os valores de pico acontecem para valores de velocidade reduzida bem maiores que se comparado com os casos de cilindros rígidos em base elástica de um grau de liberdade.

Um outro trabalho com resultados interessantes é o apresentado em Fujarra et al. (2001) no qual um modelo em cantilever é ensaiado em canal de água circulante. A grande particularidade deste ensaio é a utilização de um modelo flexível com rigidez flexional diferente nas direções da correnteza e transversal a esta. O modelo foi posicionado de forma que a rigidez no plano transversal à correnteza fosse bem menor,

\footnotetext{
${ }^{5}$ Strain gauges são dispositivos que medem a deformação de um material no ponto em que são instalados. A partir da deformação local dos vários dispositivos instalados e do conhecimento dos modos de vibrar do sistema, é possível obter a configuração global do sistema.
} 
de forma a promover o movimento nessa direção.

Como resultado, foi obtido um comportamento bem semelhante ao de cilindros rígidos montados em base elástica, apesar da amplitude de vibração variar ao longo do comprimento. Notou-se também a existência de apenas dois ramos de resposta em comparação com os três observados nos cilindros rígidos. No entanto, os autores recomendam um estudo mais aprofundado do padrão de emissões para delinear se realmente o initial branch não existe, ou a transição não é muito bem definida.

Um resultado mais interessante foi a obtenção de um novo ramo, denominado highspeed mode, a realizar o ensaio com velocidades decrescentes de correnteza. Este comportamento de histerese é apresentado na Figura 2.12.
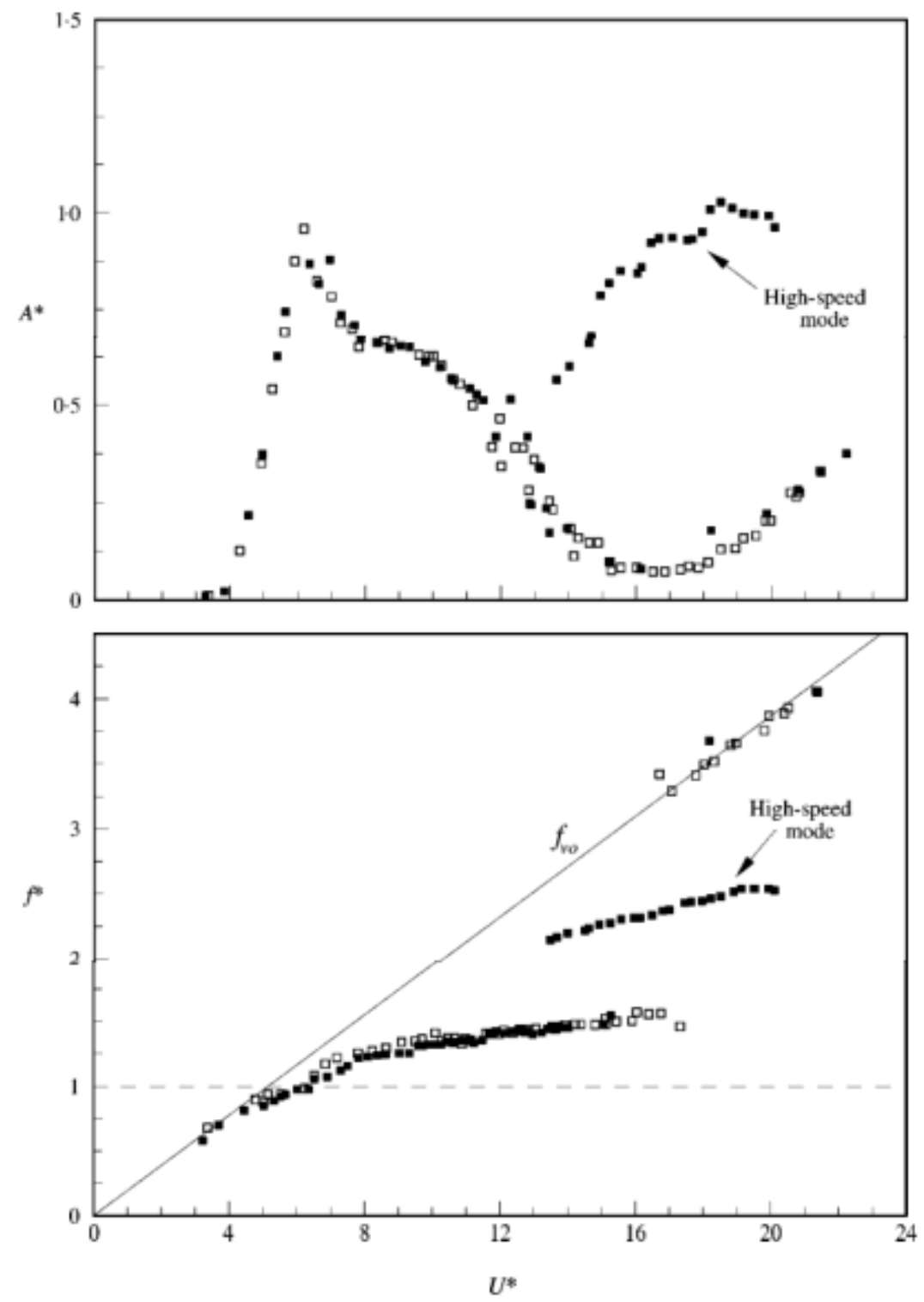

Figura 2.12 - Amplitude e frequência versus a velocidade reduzida: $\square$ - velocidades crescentes, $\mathbf{\square}$ - velocidades decrescentes. Extraído de Fujarra et al. (2001). 
O High-speed mode caracteriza-se pela presença de grandes amplitude de vibração em uma faixa de velocidades reduzidas fora da zona principal de sincronização. No caso, foram obtidas amplitudes maiores que um diâmetro para $V_{r} \geq 12$, que é a velocidade reduzida onde este novo ramo apresenta o início da bifurcação.

Em um estudo mais aprofundado dos resultados do ensaio de Pesce \& Fujarra (2000), Pesce et al. (2006) analisou alguns fenômenos interessantes, tais como os "saltos" obtidos nas regiões de transição entre os ramos de resposta. A transformada de Hilbert-Huang (Huang et al., 1998) foi aplicada para a obtenção, dentre outros pontos, da frequência instantânea do sinal, obtendo um panorama maior para o estudo de sistemas estacionários modulados em frequência e amplitude.

A Figura 2.13 apresenta um exemplo deste estudo na análise de uma série temporal na qual, notadamente, ocorre uma mudança no padrão de vibração do sistema em torno de $15 \mathrm{~s}$. No gráfico da direita é apresentado o Espectro de Hilbert-Huang, no qual são apresentados tanto a frequência instantânea de oscilação (no eixo vertical), como a amplitude de oscilação (na escala de cores).
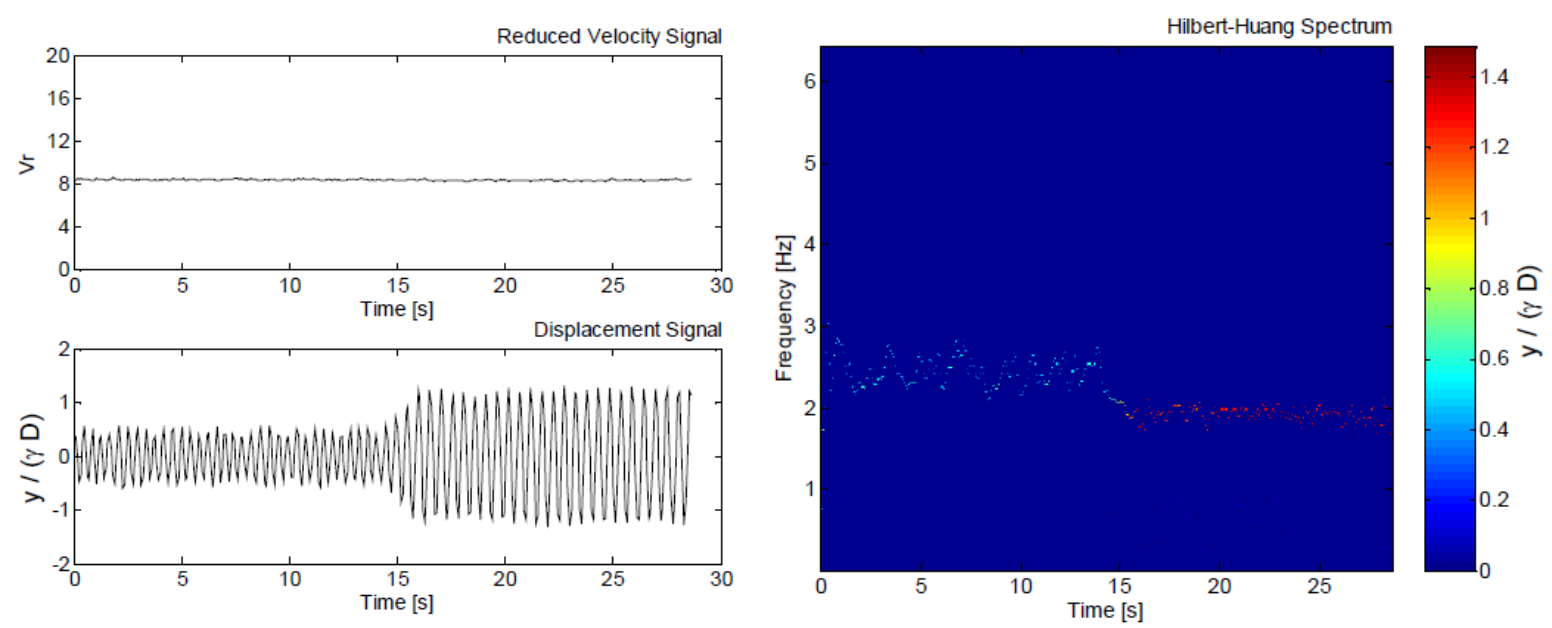

Figura 2.13 - Aplicação da transformada de Hilbert-Huang para o estudo do fenômeno de "salto". (Esq.) Velocidade reduzida e oscilação transversal do cilindro; (Dir.) Espectro de Hibert-Huang. Extraído de Pesce et al. (2006).

Neste exemplo, podemos ver claramente os dois comportamentos do sistema, anterior e posterior ao "salto". Dos 0 aos $15 \mathrm{~s}$ o sistema está oscilando com uma amplitude de aproximadamente $0.6 \mathrm{D}$ e uma frequência de $2.5 \mathrm{~Hz}$, caracterizando uma vibração no lower branch. Dos 15 aos $28 \mathrm{~s}$, a amplitude sofre um aumento e o sistema oscila em aproximadamente $1.2 \mathrm{D}$ e a frequência cai para $2.0 \mathrm{~Hz}$, o que caracteriza, segundo os autores, uma vibração do super-upper branch.

Os autores aplicam o método para diversos desses comportamentos não-lineares, inerentes ao VIV, mostrando assim que a aplicação da transformada de Hilbert-Huang 
é uma poderosa ferramenta para a análise de sistemas dinâmicos.

Saindo momentaneamente do âmbito da EP-USP, um experimento com pontos pertinentes à presente pesquisa é o apresentado em Chaplin et al. (2005) e, de forma mais detalhada, na tese de doutorado de Huera Huarte (2006), que realizou o ensaio com um modelo de riser flexível de aproximadamente 13 metros em um tanque de reboque. Uma particularidade deste ensaio foi a utilização de um tanque de vácuo capaz de deixar o modelo totalmente imerso na água, mesmo no trecho que se encontra acima da superfície do tanque. Um arranjo esquemático deste ensaio pode ser visualizado na Figura 2.14.

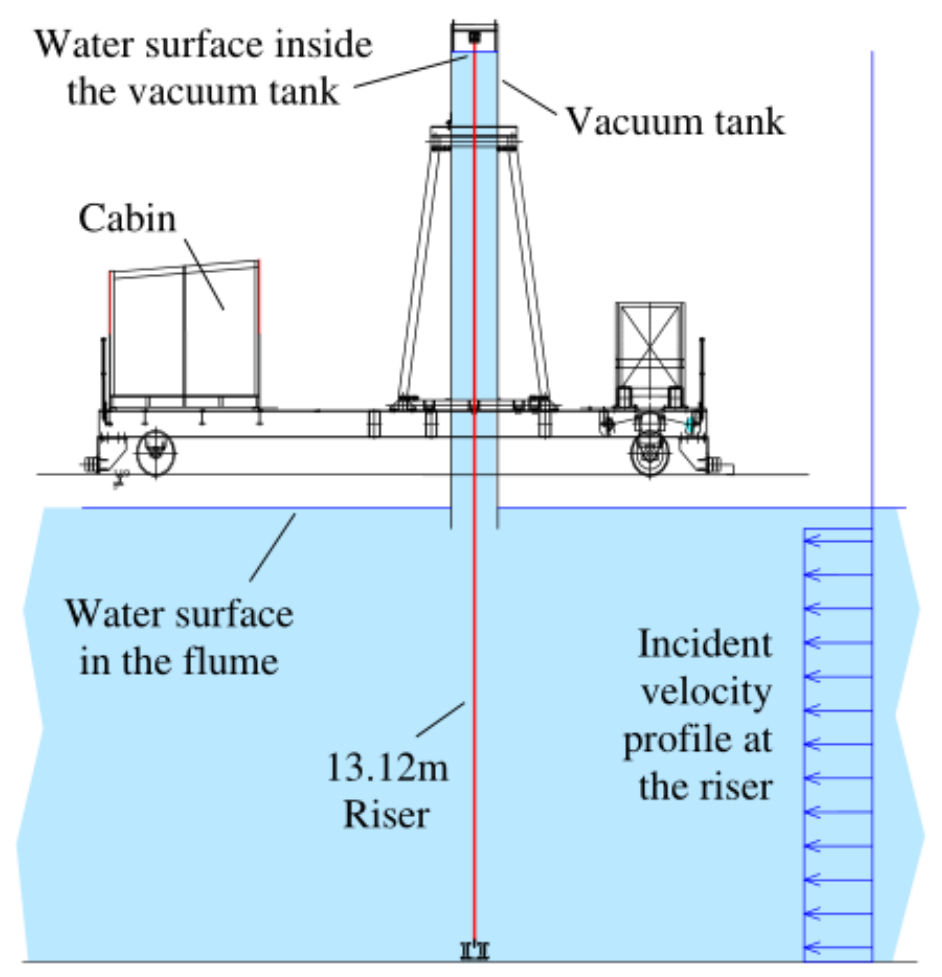

Figura 2.14 - Arranjo esquemático do experimento realizado por Chaplin et al. (2005)

Esta configuração permite que o perfil de correnteza incidente seja estratificado, ou seja, as vibrações são geradas em apenas uma região do modelo (cerca de $45 \%$ do comprimento), mas podem se propagar ao longo de todo comprimento. Esse arranjo também permite a obtenção de vibração em diversos modos concomitantemente. Uma análise com base na amplitude modal de vibração se justifica neste caso, podendo ser visualizada para os sete primeiros modos de vibrar na Figura 2.15.

No gráfico (a) da Figura 2.15 é possível identificar vários patamares de frequências. Cada um desses patamares representa a região de lock-in para um modo de vibrar, o que nos leva à conclusão que sempre existe uma frequência dominante, apesar da coexistência de vibração para diversos modos. 


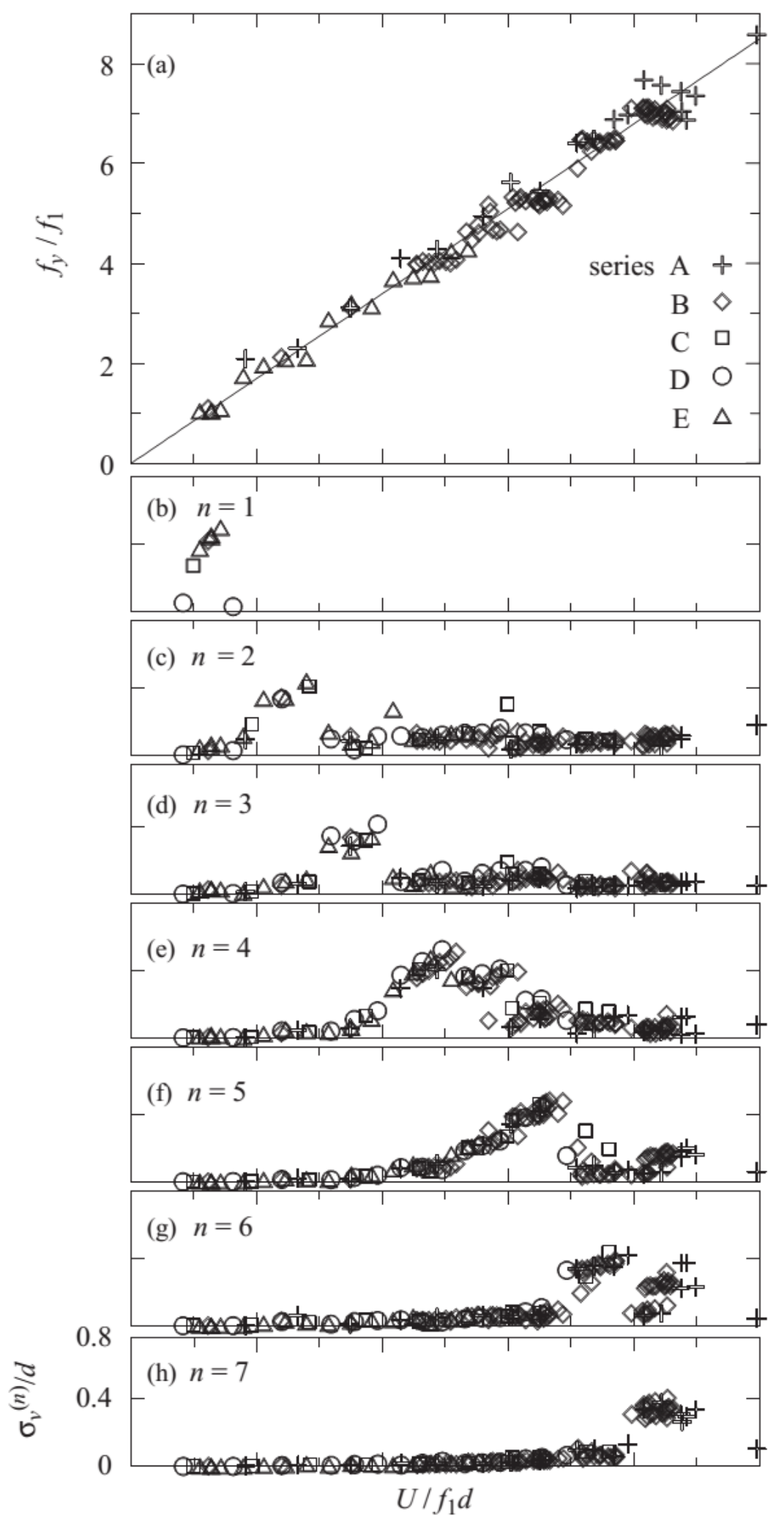

Figura 2.15 - (a) Frequências de resposta do movimento transversal, (b-h) desvio-padrão da amplitude modal do $1^{\circ} \mathcal{M}$ ao $7^{\circ} \mathcal{M}$. Ambos gráficos em função da velocidade reduzida calculada com a frequência do $1^{\circ} \mathcal{M}$. Adaptado de Chaplin et al. (2005). 
Em um contexto mais recente, podemos citar os trabalhos de Rateiro (2014) e Malta (2014) que desenvolveram duas pesquisas correlatas, focadas na dinâmica do VIV em cilindros flexíveis lançados em catenária. No primeiro, o problema é desenvolvido considerando perfis uniformes de correnteza agindo tanto na longitudinal como na transversal do plano de lançamento da linha; os ensaios foram executados em tanque de reboque. Já o segundo, analisou apenas incidências transversais de correnteza. No entanto, esta com perfil linear de velocidade modelado através da utilização de um braço giratório para arrasto em trajetória circular dentro de um tanque oceânico.

Ambos trabalhos valeram-se da aplicação do método de decomposição modal (detaIhado à frente na seção 3.2.1) para analisar o comportamento vibratório em múltiplos modos de vibrar. Um exemplo desta análise pode ser observado na Figura 2.16.
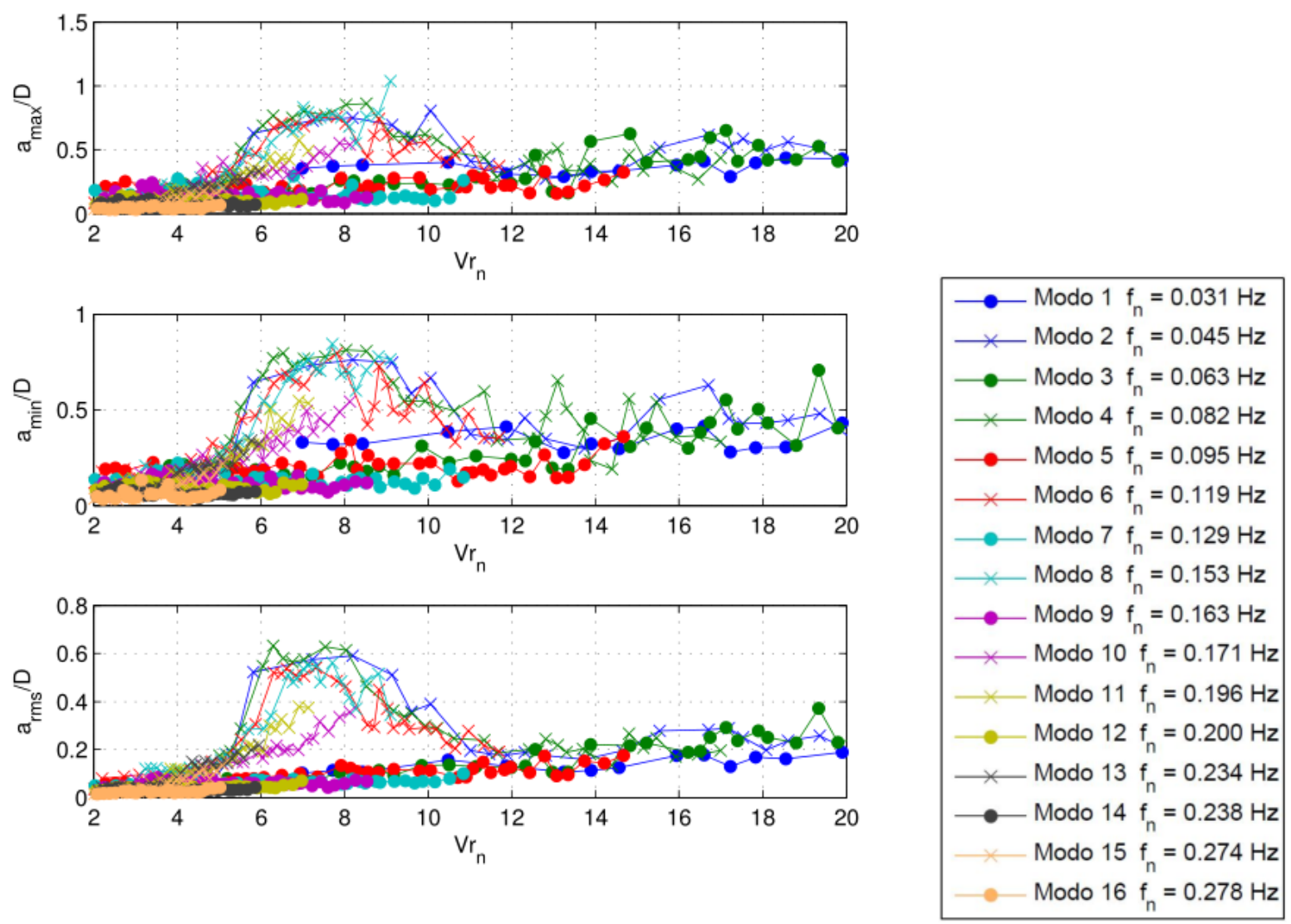

Figura 2.16 - Variação das Amplitudes Modais versus a velocidade reduzida baseada na frequência natural de cada modo de vibrar (Malta, 2014).

Resultados como os exemplificados acima levaram os autores a conclusões de que apesar do fato de a correnteza possuir sua magnitude variável, a dinâmica do VIV se mostra coerente com resultados para linhas flexíveis longas, com vários modos agindo simultaneamente, com sincronizações sucessivas, ao passo que os modos naturais vão sendo alcançados pela frequência de emissão de vórtices. 
Um dos pontos que se mostra central é a determinação coerente das frequências naturais e modos de vibrar, passo este que tem que ser feito previamente à execução dos experimentos, uma vez que os modos de vibrar dificilmente são passíveis de determinação experimental precisa. Neste caso, modelos analíticos e numéricos devem ser utilizados para a caracterização modal.

Uma vez delineados os principais pontos dos estudos e experimentos que estudam o VIV em cilindros flexíveis, faz-se necessário o levantamento bibliográfico da questão da inclinação destes em relação à correnteza incidente; o que é realizado na próxima seção.

\subsection{A questão da inclinação em relação ao perfil de correnteza: Cilindros Flexíveis}

No tocante à questão relacionada à inclinação do cilindro em relação ao perfil de correnteza, o recente trabalho de Franzini (2013) realizou uma investigação profunda acerca deste assunto. Com foco no comportamento dos sistemas rígidos montados em base elástica, o trabalho apresentou uma extensa revisão bibliográfica sobre o tema.

Dado que o presente trabalho é uma continuação do trabalho de Franzini, que se insere em uma linha de pesquisa de VIV no âmbito da EP-USP, seria desnecessário e repetitivo a realização de uma revisão com mesma pauta. Deste modo, a presente pesquisa pretende dedicar esta seção da revisão bibliográfica aos estudos realizados apenas com cilindros flexíveis e aos principais pontos que os diferem dos cilindros rígidos.

Sempre que tratada no campo do VIV, a inclinação em relação ao perfil de correnteza é investigada em termos do chamado Princípio da Independência (PI). Este princípio diz que a parcela de velocidade tangencial não influencia no comportamento oscilatório devido ao VIV e, nestes termos,

\footnotetext{
"as forças e as frequências de emissão de vórtices, nos cilindros inclinados em relação ao perfil da correnteza, são as mesmas obtidas para cilindros paralelos se considerada apenas a componente normal da velocidade incidente" (Marshall, 2003, p. 97, tradução própria).
}

Esta componente normal $\left(U_{n}\right)$ pode ser calculada como:

$$
U_{n}=U \cdot \cos \theta
$$


Este fato foi descrito por King (1977) em termos da frequência da emissão de vórtices, onde foi observado que:

$$
f_{S}(\theta)=f_{S}(\theta=0) \cdot \cos \theta
$$

Em seus experimentos King realizou testes com um cilindro flexível $(L / D=37.3)$ com inclinações variando de $-45^{\circ}<\theta<45^{\circ}$ e para todas as inclinações observou comportamento oscilatório condizente com o Pl. Além disso, foram realizados alguns ensaios de visualização do escoamento que mostraram que o escoamento local (para estas inclinações) é realmente normal ao cilindro e atende (2.9). Assim sendo, com base no $\mathrm{PI}$, a velocidade reduzida pode ser calculada como:

$$
V r=\frac{U_{n}}{f n \cdot D}=\frac{U \cdot \cos \theta}{f n \cdot D}
$$

Foram observadas amplitudes significativas de vibração para $V r>1.2$ na direção da velocidade e para $V r>4.5$ na direção transversal à velocidade. Uma das conclusões do trabalho foi que não houve diferenças significativas em se inclinar o cilindro à montante ou à jusante. No entanto, foram levantadas questões acerca dos comportamentos obtidos não serem os mesmos devido à experimentação de cilindros com outras razões de aspecto $L_{h} / D$.

Como será visto a seguir, a boa relação do experimento de King com o PI advém do fato de que seu experimento foi realizado com cilindro flexível (livre para oscilar).

Ramberg (1983), por sua vez, no estudo de cilindros rígidos levantou questões importantíssimas sobre a validade do PI, sendo que notou a grande sensibilidade que o sistema possui de acordo com as condições de contorno nas extremidades. Este fato deve-se à tridimensionalidade intrínseca aos escoamentos ao redor de cilindros inclinados como, por exemplo, o escoamento apresentado na Figura 2.17.

Nesta figura é notadamente apresentada a convivência de dois modos de emissão de vórtices: um mais abaixo com ângulo praticamente idêntico ao da inclinação do cilindro e outro acima com um ângulo muito maior. Os resultados de Ramberg apontaram para uma forte dependência entre o ângulo da end plate e o ângulo deste segundo modo. Um dos pontos interessantes decorre do fato de os dois modos de emissão de vórtices possuírem frequências distintas. 


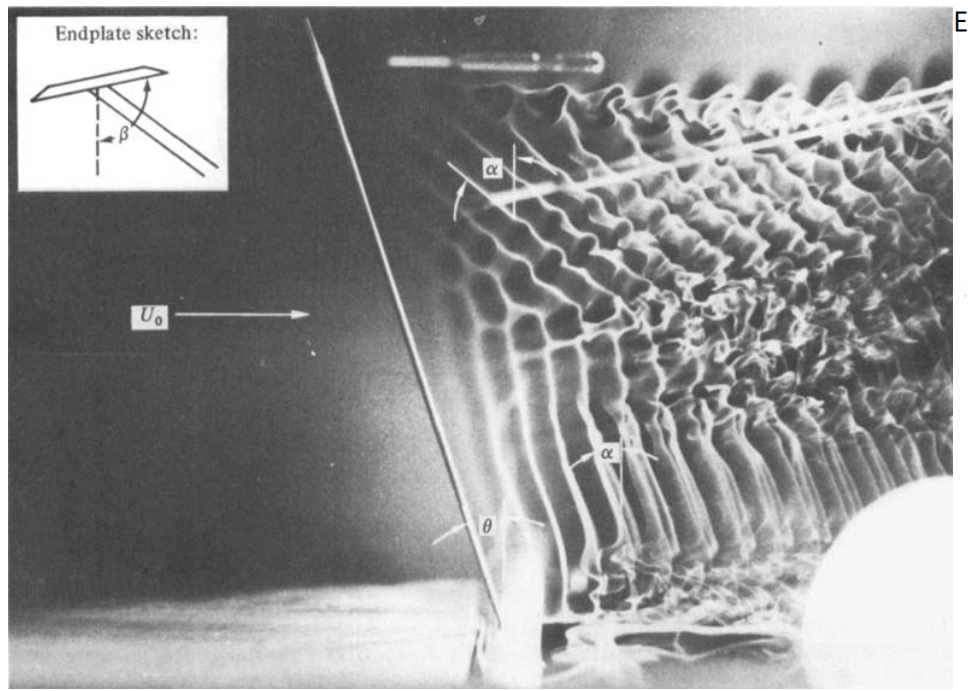

(a)

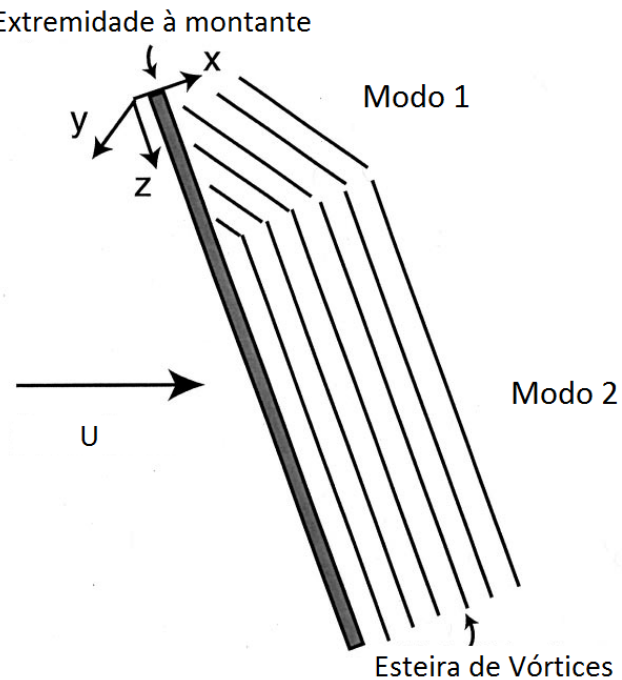

(b)

Figura 2.17 - (a) Visualização do escoamento apresentando dois modos de emissão de vórtice para $R e=160$. Extraído de Ramberg (1983). (b) Esquematização da esteira obtida por Ramberg para cilindros inclinados de comprimento finito. Adaptado de Marshall (2003).

Recentemente, Marshall (2003) estudou este comportamento obtido por Ramberg do ponto de vista teórico e computacional, destacando a importância da emissão de vórtices na direção axial do cilindro e a interação destes com a esteira clássica de von Karmán. Na Figura 2.18 é apresentada uma esquematização da formação destas estruturas.

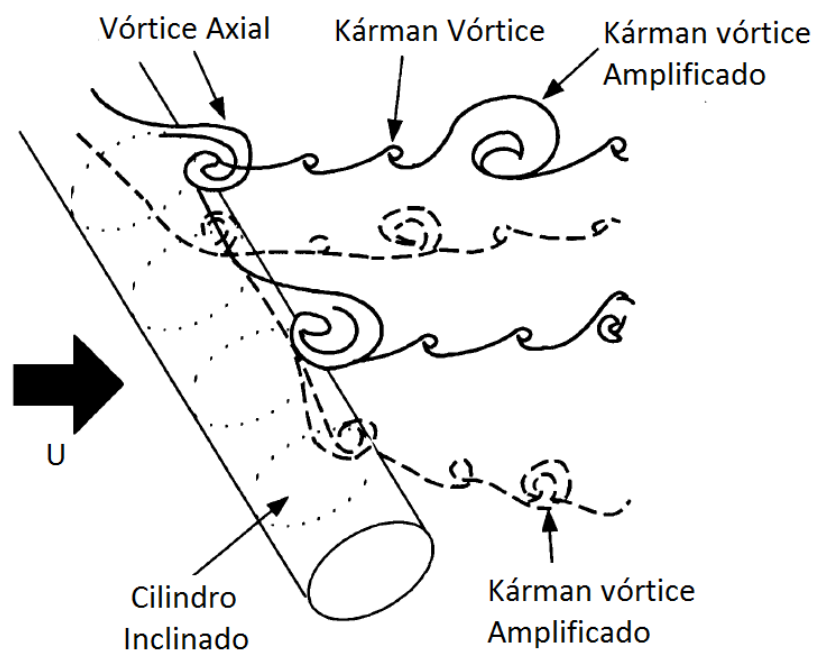

Figura 2.18 - Esquematização da emissão de vórtice axial e da esteira de von Karmán em cilindros inclinados. Adaptado de Matsumoto et al. (2001). 
Outra particularidade destacada por Ramberg é que quando o cilindro está em regime oscilatório, a oscilação força a emissão de vórtices e há um fenômeno de "captura" da esteira, de forma que essa se pronuncia na direção normal ao cilindro. Este fato foi também observado em trabalhos mais recentes como, por exemplo, Lucor \& Karniadakis (2003), através de estudos de Dinâmica de Fluidos Computacional, ou Computational Fluid Dynamics (CFD). A Figura 2.19 apresenta uma comparação entre a emissão de vórtices em cilindros inclinados fixos e livres.

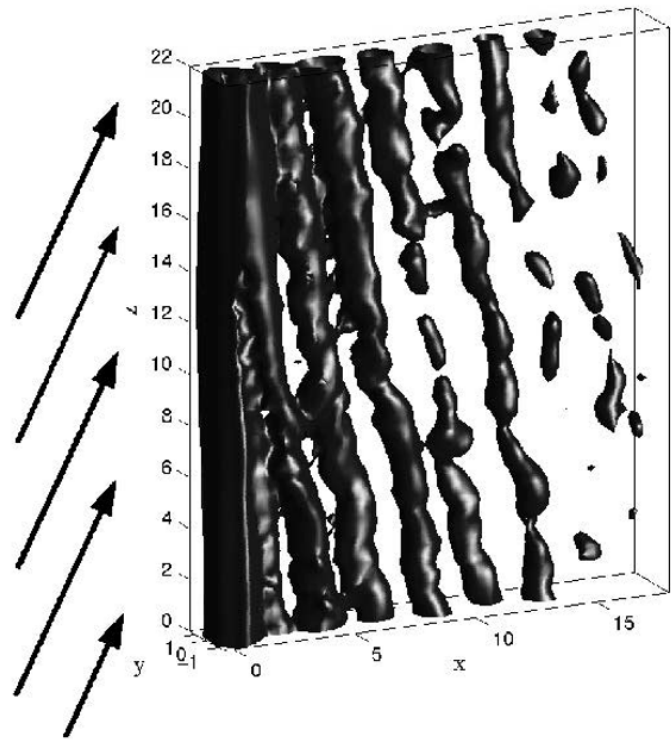

(a)

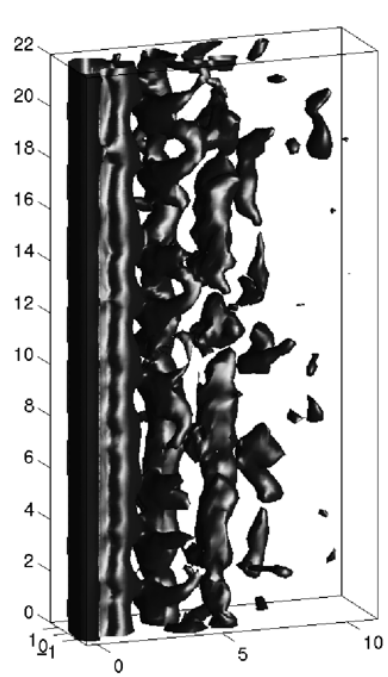

(b)

Figura 2.19 - Visualização tridimensional da esteira formada por escoamento inclinado ao redor de cilindro (a) fixo e (b) livre para oscilar. As setas representam a incidência do escoamento $\left(\theta=70^{\circ}\right)$. Adaptado de Lucor \& Karniadakis (2003).

Como pode ser visto na imagem da esquerda, na qual o cilindro está fixo, o desprendimento de vórtices não ocorre de forma paralela ao cilindro, já na imagem da direita, na qual o cilindro é livre pra oscilar, percebe-se um paralelismo bem acentuado entre os vórtices e a estrutura. Ramberg aponta que nas regiões de lock-in o comportamento do cilindro oscilando pode ser descrito pelo $\mathrm{PI}$, mesmo nos casos onde não é válido para o caso fixo.

Outras simulações numéricas, como a apresentada em Bourguet et al. (2015), apresentam este mesmo comportamento de "captura", agora obtido para cilindros flexíveis. A visualização do padrão de emissão de vórtices é apresentada na Figura 2.20.

Tanto o caso vertical como o caso inclinado mostram padrões de emissão de vórtices bem parecidos e paralelos ao cilindro. Este fato reforça a ideia de que no caso dos cilindros livres para oscilar o PI pode ser válido para valores maiores de $\theta$. 
(a)

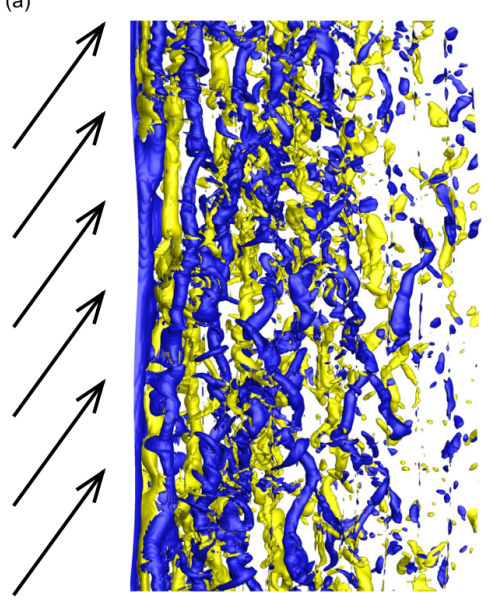

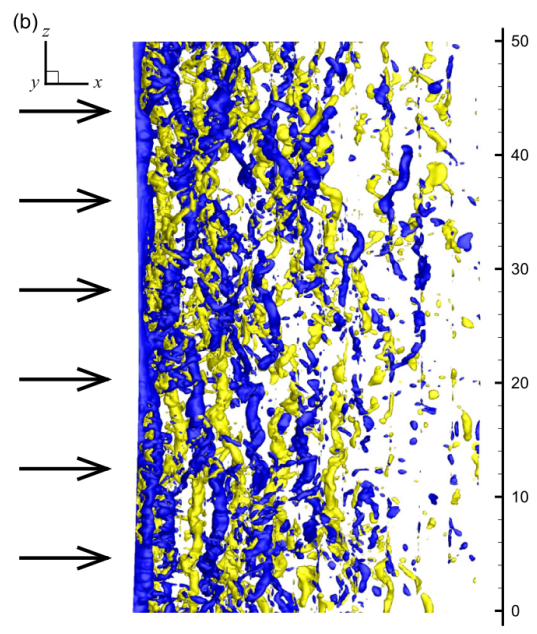

Figura 2.20 - Iso-superfícies instantâneas da vorticidade à jusante do cilindro flexível para as configurações (a) inclinada $\theta=60^{\circ} \mathrm{e}$ (b) vertical. As setas representam o fluxo incidente. Extraído de Bourguet et al. (2015)

Um dos pontos que Bourguet et al. levanta é a consideração do ângulo de inclinação local na linhas flexíveis devido à deflexão causada pelo arrasto. A Figura 2.21 apresenta os ângulos envolvidos quando se considera apenas a componente normal ou a componente normal local da velocidade.

Dada a abordagem numérica, os autores estudaram este efeito local através da geração de um perfil de velocidades de forma que localmente a componente seria sempre proporcional à $U \cdot \cos \theta$. Essa abordagem rendeu resultados interessantes, porém divergentes dependendo do nível de tração aplicada no cilindro. Para avaliar a tração, esta foi adimensionalizada da seguinte forma:

$$
\bar{T}=\frac{T}{\rho_{f} D^{2} U^{2}}
$$

e estudada para dois valores: $\bar{T}=124$ e $\bar{T}=13.5$. A conclusão foi que o PI é válido para grandes valores de tração e apresenta resultados divergentes para valores menores. As simulações com o perfil de velocidade modificado mostraram que neste segundo caso, onde o cilindro apresenta uma deflexão maior, o comportamento do sistema é principalmente dominado pela velocidade localmente normal ao cilindro.

Apesar da enorme importância para indústria naval e oceânica, como apontado na introdução deste texto, os grandes avanços experimentais na área de cilindros flexíveis inclinados foram feitos para o estudo de vibração em pontes estaiadas e suspensas por cabos, ou seja, a maioria dos ensaios disponíveis na literatura apresentam testes realizados em túneis de vento. Pode-se citar, entre outros, os trabalhos de Matsumoto et al. (1998), Matsumoto et al. (2003) e Chen et al. (2015). Uma característica própria destas estruturas é o alto nível de tracionamento dos estais e cabos. 


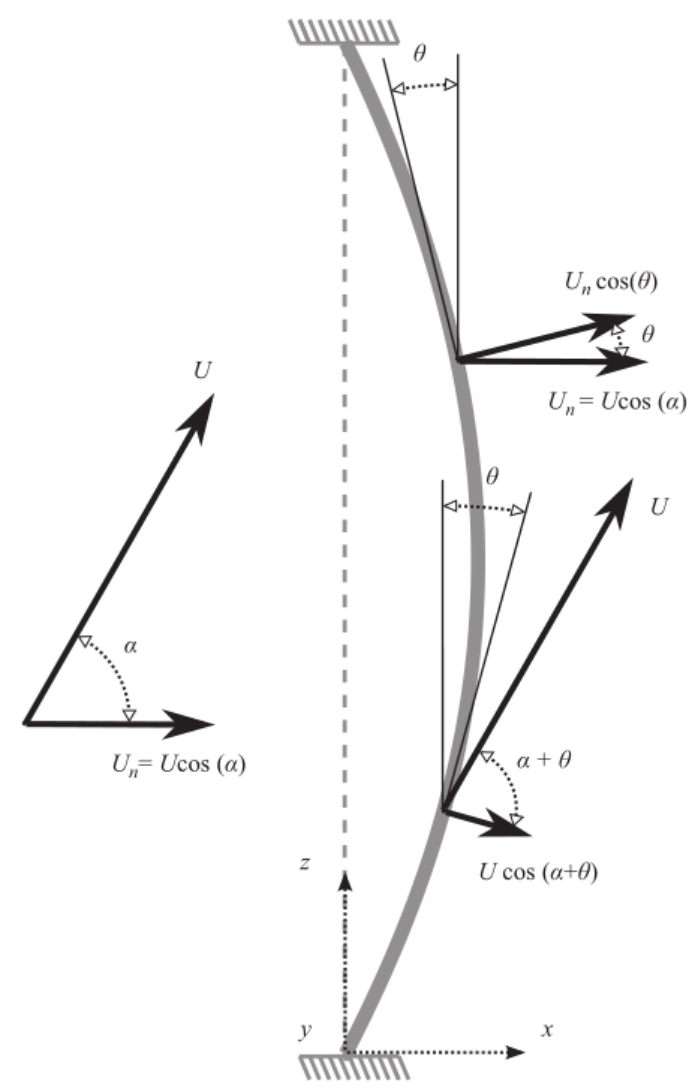

Figura 2.21 - Arranjo esquemático apresentando os principais ângulos envolvidos para a consideração das componentes normais local e global. A posição do cilindro na ausência de velocidade é denotado pela linha cinza tracejada. Extraído de Bourguet et al. (2015)

Um ponto que nenhum dos trabalhos mencionados até o momento tratou é a questão da mudança de azimute concomitante à inclinação do cilindro. Dos poucos textos encontrados, as investigações numéricas realizada em Yeo \& Jones (2008) e Yeo \& Jones (2011) são as mais elucidativas. Os dois trabalhos foram realizados para estruturas fixas e a principal conclusão é a dominância do comportamento tridimensional das esteiras de vórtices que apresentam pontos de geração de esteira axial, que modificam a esteira principal de von Karmán. Segundo os autores "as características do escoamento oblíquo a um cilindro são complicadas e significativamente diferentes das de um escoamento ao redor de um cilindro vertical" (tradução própria).

Um dos únicos trabalhos experimentais com inclinação e azimute é o apresentado em Matsumoto et al. (1990). Quanto à questão do azimute os autores dizem que "o ponto de estagnação do escoamento em cilindros com azimute determina a direção principal de vibração do cabo, que pode vibrar de maneira acoplada dentro e fora do plano de inclinação" (tradução própria). Além desta conclusão, os autores consideraram de suma importância a interação entre a esteira axial e de von Karmán.

Dados os diversos trabalhos apresentados nesta seção, pode-se resumir os principais 
pontos em que as pesquisas convergem e que são de extrema importância para o estudo que se segue nos próximos capítulos.

- Os limites de aplicação do princípio da independência (PI), apesar de amplamente utilizado em programas de análise e modelos de previsão de VIV, não estão devidamente estabelecidos para cilindros flexíveis, necessitando assim, mais estudos experimentais.

- A capacidade de oscilar das estruturas flexíveis influencia na própria formação da esteira. Comportamentos que são observados em cilindros fixos e inclinados, não são observados em cilindros flexíveis dada a "captura" da esteira. Ou seja, mesmo para grandes ângulos de inclinação há uma correlação entre o ângulo do cilindro e o da esteira de vórtices.

- Sabe-se a priori que a tração aplicada nos sistemas flexíveis influencia diretamente nas frequências naturais de oscilação. Isso por si só já influenciaria a dinâmica de VIV. No entanto, um outro ponto notável, é a configuração média que o peso próprio e o arrasto impõe às estruturas cilíndricas flexíveis. Esta configuração, que também é ditada pela tração, implica em velocidades normais variáveis ao longo do comprimento, que podem ou não influenciar nos resultados.

- Estudos de cilindros flexíveis inclinados são muito mais recorrentes na literatura de aeroelasticidade do que na de hidroelasticidade. No entanto, sua ampla aplicação no ambiente oceânico justifica a intensificação de estudos em tanques de reboque e canais de água circulante.

- Mesmo em aerodinâmica, o estudo da mudança de azimute em relação ao perfil de velocidade incidente é escasso de resultados, tanto no campo da experimentação como no campo da dinâmica de fluidos computacional. No entanto, a ocorrência desta configuração oblíqua é comum, necessitando assim de uma descrição mais apurada.

Finalizada a apresentação dos principais tópicos relacionados ao tema central da presente pesquisa, pode-se encaminhar agora a descrição detalhada da metodologia empregada para obtenção da base experimental que compõe os resultados desta tese. 


\section{Capítulo 3}

\section{Metodologia}

Com base nos experimentos pregressos realizados pelo grupo de estudos da EP-USP, tais quais os apresentados na seção 2.2, uma metodologia foi elaborada de forma a obter experimentalmente e em ambiente controlado o fenômeno de VIV agindo sobre diversas configurações de lançamento de um modelo flexível.

Ao que tange às técnicas e processos adotados nesta pesquisa, podemos dividir os assuntos em quatro diferentes tópicos, que abordam as diferentes fases empregadas para se alcançar os objetivos do experimento: Materiais \& Infraestrutura, Métodos de Análise de Dados, Métodos Numéricos e Métodos Experimentais.

O ponto de partida de todo e qualquer ensaio é a definição das premissas do experimento. Estas premissas servirão de base para a concepção do experimento e por si só já impõem uma série de restrições que se somam às limitações impostas pela infraestrutura disponível.

1. Utilização de um modelo flexível;

2. Atender aos limites de velocidade do carro de reboque:

(a) Evitar velocidades muito altas (acima de $1 \mathrm{~m} / \mathrm{s}$ ) para não causar vibração nas câmeras;

(b) Necessidade de uma velocidade suficiente para obter vibração até $08^{\circ} \mathcal{M}$ do modelo;

3. Capacidade de inclinar o modelo em até $45^{\circ} \mathrm{com}$ a vertical (ângulo $\theta$ );

4. O modelo deve ser tracionado de forma que inclinação máxima relativa entre o modelo e a linha que une suas duas extremidades não ultrapasse $10^{\circ}$;

5. Capacidade de alterar o azimute em relação à correnteza até $180^{\circ}$ (ângulo $\beta$ ); 
6. Atender aos limites geométricos do tanque de reboque;

7. Atender às limitações de disponibilidade do tanque de reboque.

A Figura 3.1 foi elaborada com o intuito de apresentar o fluxo de informação e a hierarquia entre as diversas etapas do experimento proposto, desde a definição das premissas adotadas até a geração dos gráficos e imagens que serão apresentados nos capítulos seguintes.

Uma vez definidas as premissas, tem-se dois ramos que podem ser realizados em paralelo, um diz respeito ao projeto, construção e instalação do modelo e o outro à montagem dos equipamentos necessários à realização do experimento. Ambos estão descritos na seção Materiais \& Infraestrutura, assim como os procedimentos para troca de configuração, aquisição de dados e reboque do modelo.

A determinação da configuração estática, das frequências e modos naturais é feita previamente à definição das velocidades de reboque de forma a facilitar o projeto do ensaio. A partir do conhecimento destes parâmetros praticamente toda a matriz de ensaio pode ser verificada e adequada de forma a otimizar o tempo disponível para realização dos experimentos. O modelo computacional adotado para a caracterização prévia da linha ensaiada é apresentado na seção Métodos Numéricos.

Em seguida são realizados os ensaios de decaimento para a determinação e validação das frequências obtidas numericamente e logo em seguida realizado o reboque do modelo nas diversas velocidades propostas de forma a se obter os comportamentos oscilatórios de acordo com o definido nas premissas. Após a execução do reboque o modelo é instalado numa nova configuração e novamente submetido aos ensaios de decaimento e VIV. As etapas iterativas apresentadas na Figura 3.1 tratam justamente da ordem em que estes testes são executados. $O$ detalhamento deste ensaios estão apresentados na seção Métodos Experimentais.

As séries temporais são armazenadas e pós processadas para a obtenção dos principais parâmetros e resultados. As diversas análises são explicadas e devidamente equacionadas na seção Métodos de Análise de Dados.

A ordem de apresentação das seções deste capítulo não condiz diretamente com a ordem de execução das tarefas, pois são necessárias várias avaliações prévias até se chegar a um formato interessante de ensaio. Essas avaliações utilizam etapas diversas apresentadas em cada uma das seções. A sequência apresentada tenta, ao máximo, apresentar estas etapas de forma linear facilitando o entendimento por parte do leitor. 


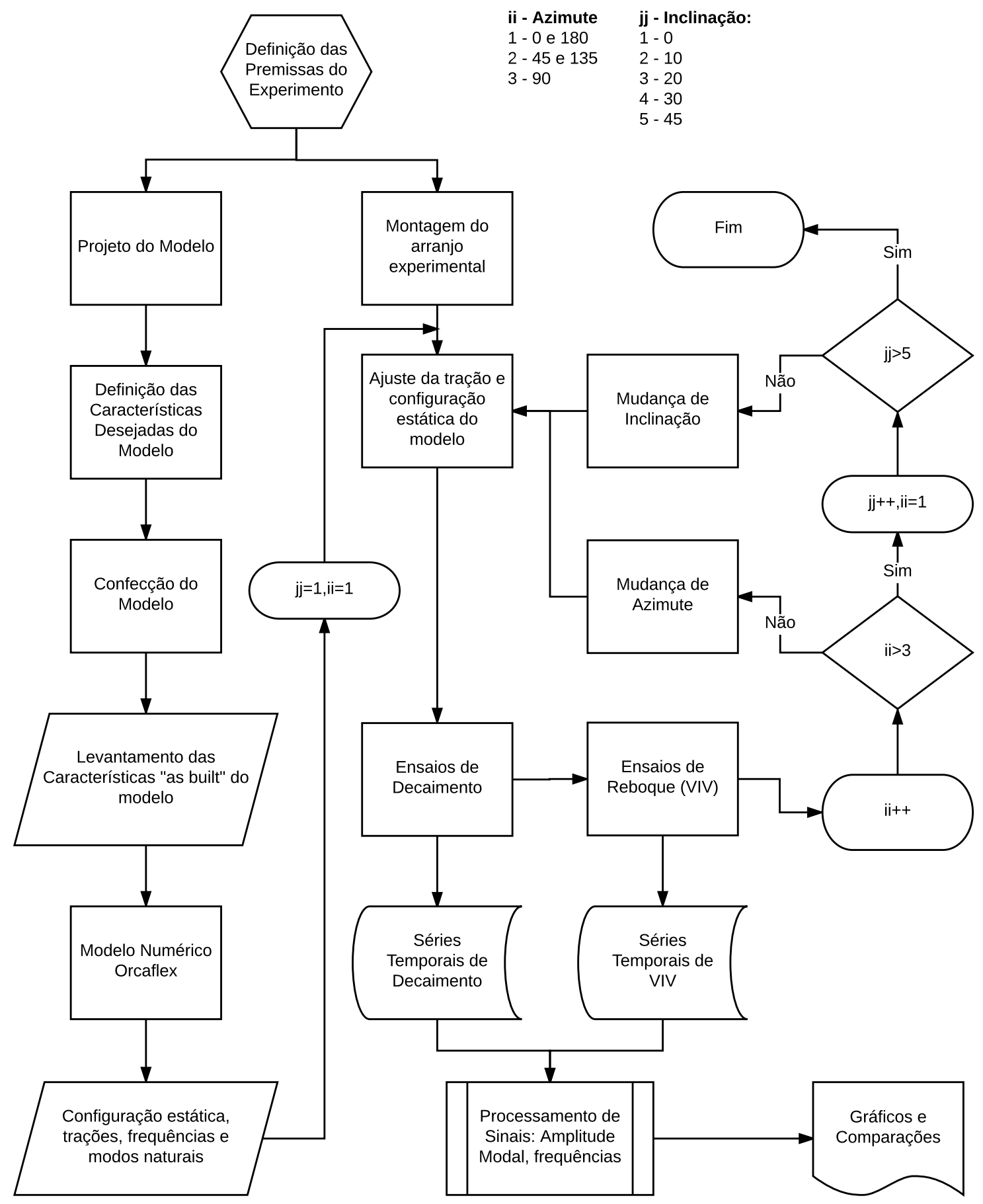

Figura 3.1 - Fluxo de dados da metodologia empregada. 


\subsection{Materiais \& Infraestrutura}

O know-how desenvolvido ao longo dos últimos anos pelo grupo de pesquisas em VIV da EP-USP, juntamente à experiência na execução de ensaios e experimentos do Laboratório de Engenharia Naval e Oceânica do Instituto de Pesquisas Técnológicas do Estado de São Paulo (IPT-SP) proporcionou à presente pesquisa a utilização de uma infraestrutura adequada que se fez de grande valia para a obtenção de uma base de dados confiáveis, que foram tratados de acordo com análises pautadas nos trabalhos e referências apresentados anteriormente.

As principais estruturas e equipamentos utilizados na concepção e execução do experimento de VIV podem ser agrupadas nos cinco itens seguintes:

1. Modelo de cilindro flexível

2. Tanque de reboque

3. Sistema de reboque

- Carro de reboque

- Carro auxiliar

- Fundo falso

- End plate

4. Sistema de ajuste da tração

- Célula de Carga

- Atuador Vertical (280 mm de curso)

- Atuador Horizontal (800 mm de curso)

- Drivers PLC

5. Sistema de monitoração Qualisys $\AA$

- Aéreo

- Submerso

Cada um destes itens é devidamente detalhado a seguir nas seções 3.1.1 até 3.1.5, respectivamente. Antes de entrar nos detalhes de cada item, a Figura 3.2 apresenta uma visão geral da montagem do experimento. 


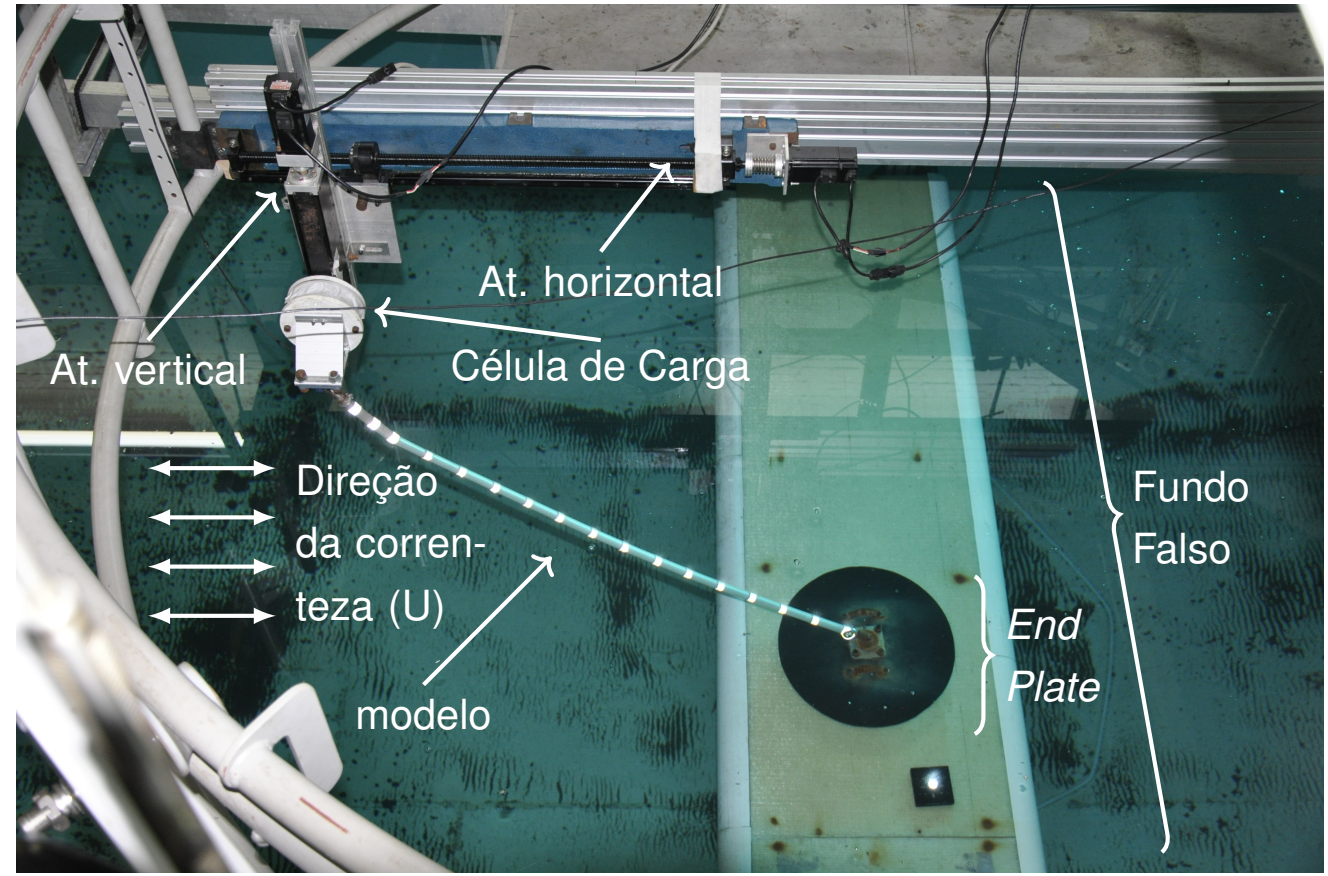

Figura 3.2 - Visão geral da montagem do experimento.

\subsubsection{Modelo de cilindro flexível}

A escolha do modelo em ensaios de VIV é sempre uma questão delicada do ponto de vista da representação dos fenômenos em escala reduzida. Existem diversas incompatibilidades de escala que impedem que um riser ou uma linha de amarração consigam ser representados em escala na sua totalidade. Deste modo, algumas simplificações devem ser realizadas e alguns parâmetros geométricos são deixados de lado possibilitando uma representação dinâmica mais adequada. Essas considerações são exatamente as apresentadas em Rateiro et al. (2012), onde uma metodologia adequada para a modelagem em escala deste tipo de sistema foi realizada.

Uma vez que a presente pesquisa não tem o intuito de representar algum sistema específico e sim levantar questões e discussões acerca da mudança de inclinação e de azimute do sistema estudado em relação à correnteza, optou-se por utilizar o mesmo modelo utilizado em Rateiro et al. (2012), realizando as devidas adaptações necessárias ao presente cenário. As principais mudanças realizadas no modelo dizem respeito ao seu comprimento e suas condições de contorno. A utilização do referido modelo tem vantagens práticas, pois repetidos testes foram realizados de forma que as propriedades mecânicas já estão bem definidas, dispensando a necessidade de realização de novos ensaios de caracterização (ver Figura 3.3).

Neste trabalho, como dito anteriormente, optou-se por uma configuração inclinada bem próxima da reta que liga as duas extremidades do modelo. Este tipo de configu- 

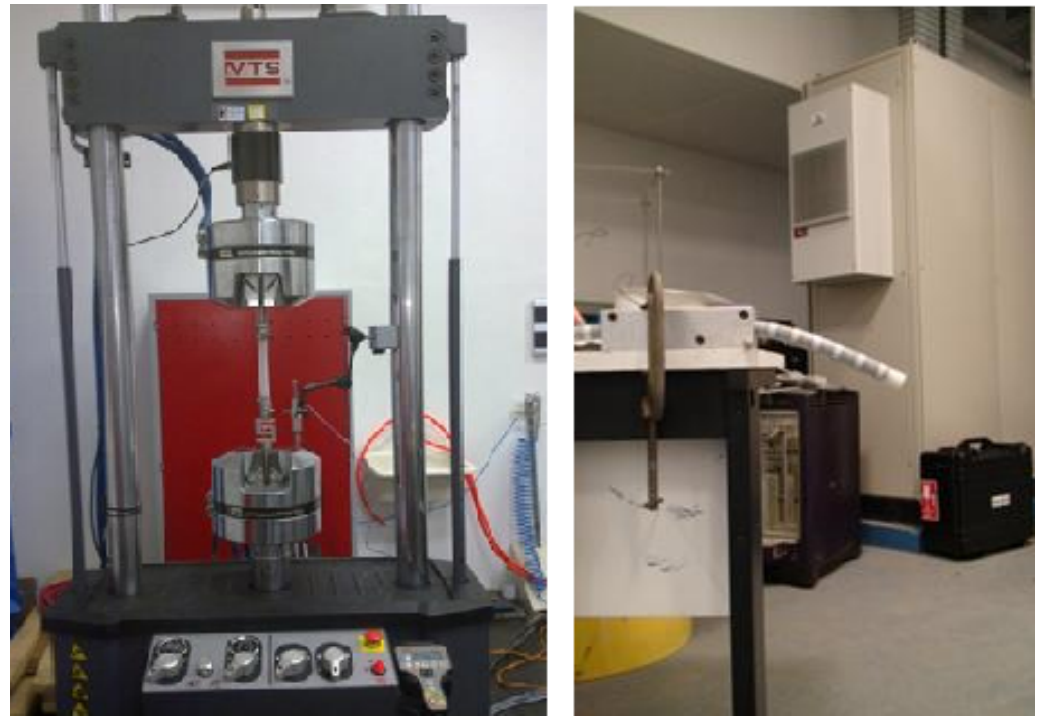

Figura 3.3 - Ensaios de caracterização para determinação de rigidez axial (a) e flexional (b) do modelo desenvolvido anteriormente e utilizado na presente pesquisa. Adaptado de Rateiro (2014).

ração, diferentemente dos tipos de lançamento mais comuns de risers e linhas, não possui Touch Down Point (TDP) (dependendo do enfoque, podemos dizer que o TDP é sempre coincidente com a âncora). Esta escolha foi feita para que se reduzisse o número de variáveis do problema, focando o estudo apenas na questão da inclinação.

O modelo, já apresentado na Figura 3.2, é constituído por um tubo de silicone preenchido internamente por microesferas de aço inoxidável sendo fixado em suas extremidades por um conjunto composto por um eixo universal acoplado a um rolamento montado em mancal de flange, conferindo ao modelo uma condição de contorno biarticulada, ou seja, uma condição que restringe os movimentos translacionais, porém permite movimentos rotacionais dos pontos de conexão. Os elementos utilizados para a montagem dessa conexão são apresentados abaixo, na Figura 3.4.

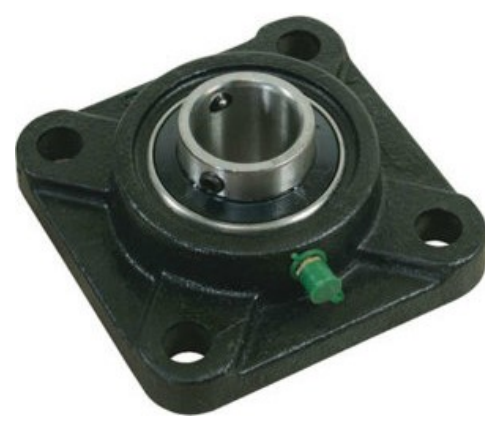

(a)

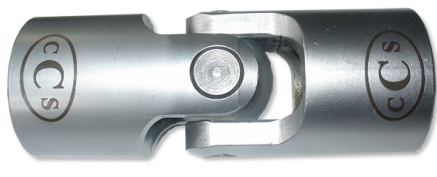

(b)

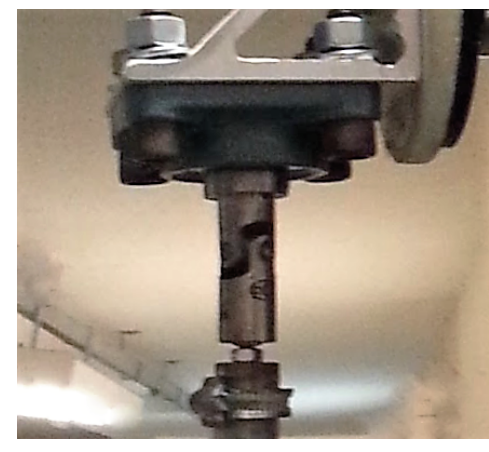

(c)

Figura 3.4 - (a) Rolamento apoiado em mancal de flange. (b) Eixo Universal. (c) Detalhe da montagem da articulação na extremidade do modelo. 
Modelos com esta constituição já foram estudados por outras pesquisas relacionadas, entre elas: Rateiro (2014), Malta (2014) e Amarante (2015). A sua utilização tem se mostrado bem robusta do ponto de vista da obtenção de características necessárias para ensaios de fenômenos de interação fluido-estrutura no campo da dinâmica de linhas.

Na Tabela 3.1 são apresentados os principais parâmetros e características do modelo tal qual foi utilizado no presente trabalho.

Tabela 3.1 - Principais parâmetros e características do modelo utilizado nos ensaios.

\begin{tabular}{clcc}
\hline Parâmetro & Descrição & Valor & Unidade \\
\hline$L_{0}$ & Comprimento Indeformado & 1.67 & $\mathrm{~m}$ \\
$L_{h}$ & Comprimento Submerso & 1.50 & $\mathrm{~m}$ \\
$D_{\text {int }}$ & Diâmetro Interno & 15.8 & $\mathrm{~mm}$ \\
$D$ & Diâmetro Externo & 22.2 & $\mathrm{~mm}$ \\
$E A$ & Rigidez axial & $1.0-1.6$ & $\mathrm{kN}$ \\
$E I$ & Rigidez Flexional & 0.056 & $\mathrm{Nm}^{2}$ \\
$\gamma^{a r}$ & Peso linear, no ar & 11.4 & $\mathrm{~N} / \mathrm{m}$ \\
$\gamma$ & Peso linear, na água & 7.5 & $\mathrm{~N} / \mathrm{m}$ \\
$m_{a}^{P O T}$ & Massa adicional & 0.387 & $\mathrm{~kg} / \mathrm{m}$ \\
$m^{*}$ & Razão de massa & 2.95 & $\mathrm{adm}$ \\
$a$ & Razão de massa adicional & 0.51 & $\mathrm{adm}$. \\
\hline
\end{tabular}

\subsubsection{Tanque de reboque}

Uma das possibilidades para a execução de experimentos de VIV é a utilização de tanques de reboque, no qual é possível arrastar o modelo por uma determinada distância emulando assim um perfil de correnteza contínuo ao longo do modelo. Para cada configuração de modelo são executadas diversas corridas em velocidades constantes percorrendo a faixa de velocidades interessantes ao estudo do fenômeno.

Este tipo de tanque permite uma grande precisão quanto ao perfil de velocidade da correnteza, pois a água está em repouso tornando a turbulência à montante do sistema praticamente nula. Outra característica dos tanques de reboque são sua largura e profundidade que, no caso de ensaios de VIV como o aqui proposto, possui a vantagem de se poder utilizar modelos flexíveis de maior comprimento, se comparado com canais de água circulante. 
Os experimentos apresentados nesta tese foram executados no tanque de reboque do IPT-SP (Figura 3.5).

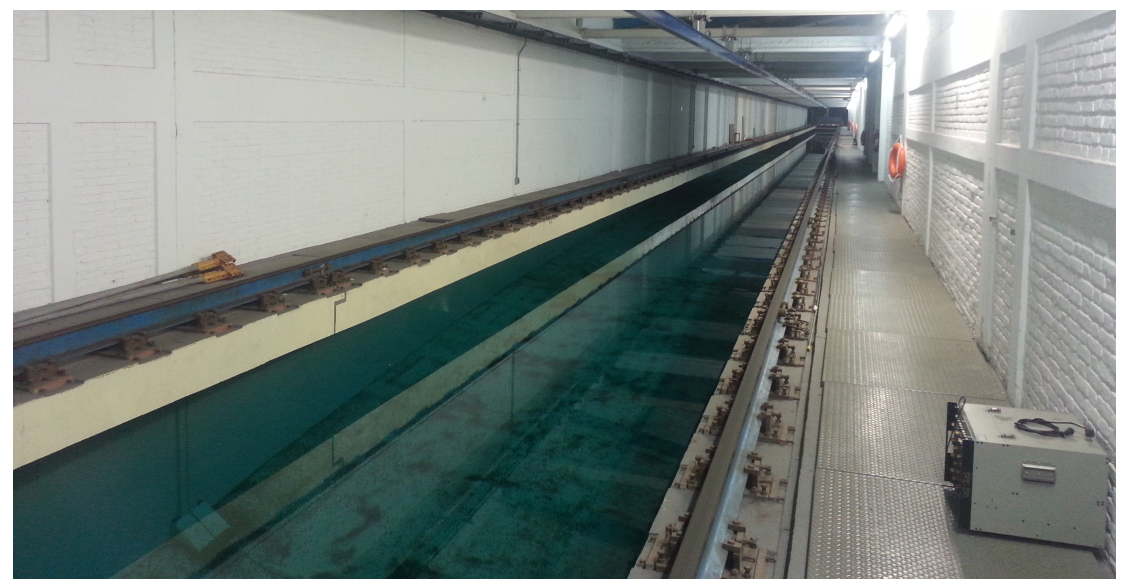

Figura 3.5 - Tanque de reboque do IPT-SP.

O tanque do IPT-SP possui 280 metros de comprimento, 6.6 metros de largura e 3.7 metros de profundidade (Figura 3.6) e foi pensado inicialmente para a realização de ensaios de reboque de modelos em escala reduzida de navios, a fim de se determinar, entre outros parâmetros, sua curva de resistência ao avanço. No entanto, devido a sua estrutura composta por diferentes tipos de carros de reboque, geradores e amortecedores de onda, fundos falsos, etc., é possível realizar uma grande gama de tipos de ensaios, entre eles, o que se pretende apresentar nesta pesquisa.

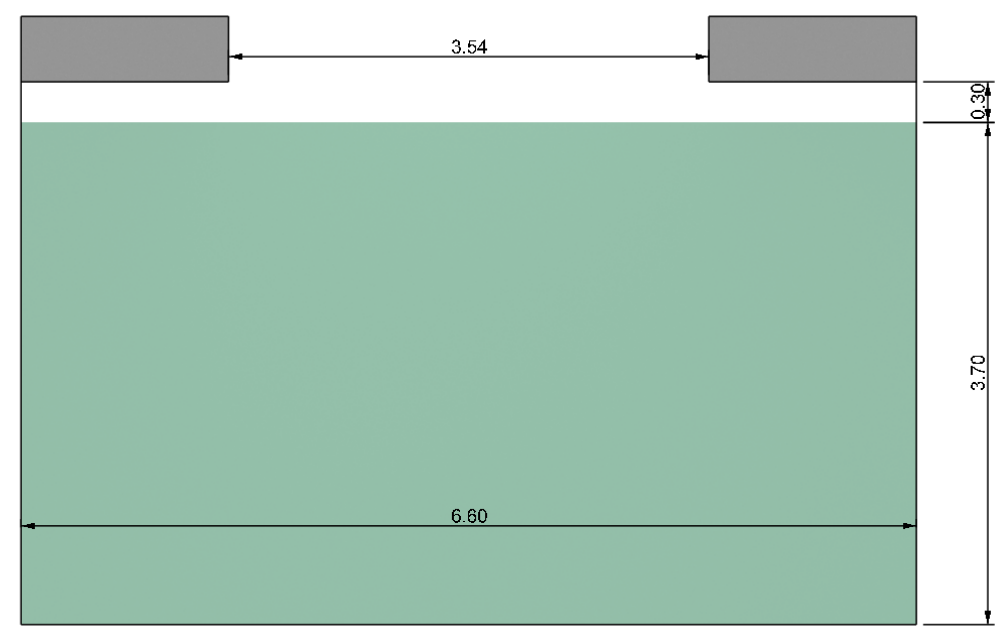

Figura 3.6 - Dimensões principais da seção transversal do tanque de reboque do IPT-SP (Unidades: $m$ ). 


\subsubsection{Sistema de Reboque}

O tanque possui um carro de reboque (Figura 3.7) que se movimenta ao longo do comprimento do tanque apoiado em trilhos localizados na duas laterais. Este carro possui um sistema de controle de velocidade para assegurar que esta permaneça constante ao longo de cada ensaio.

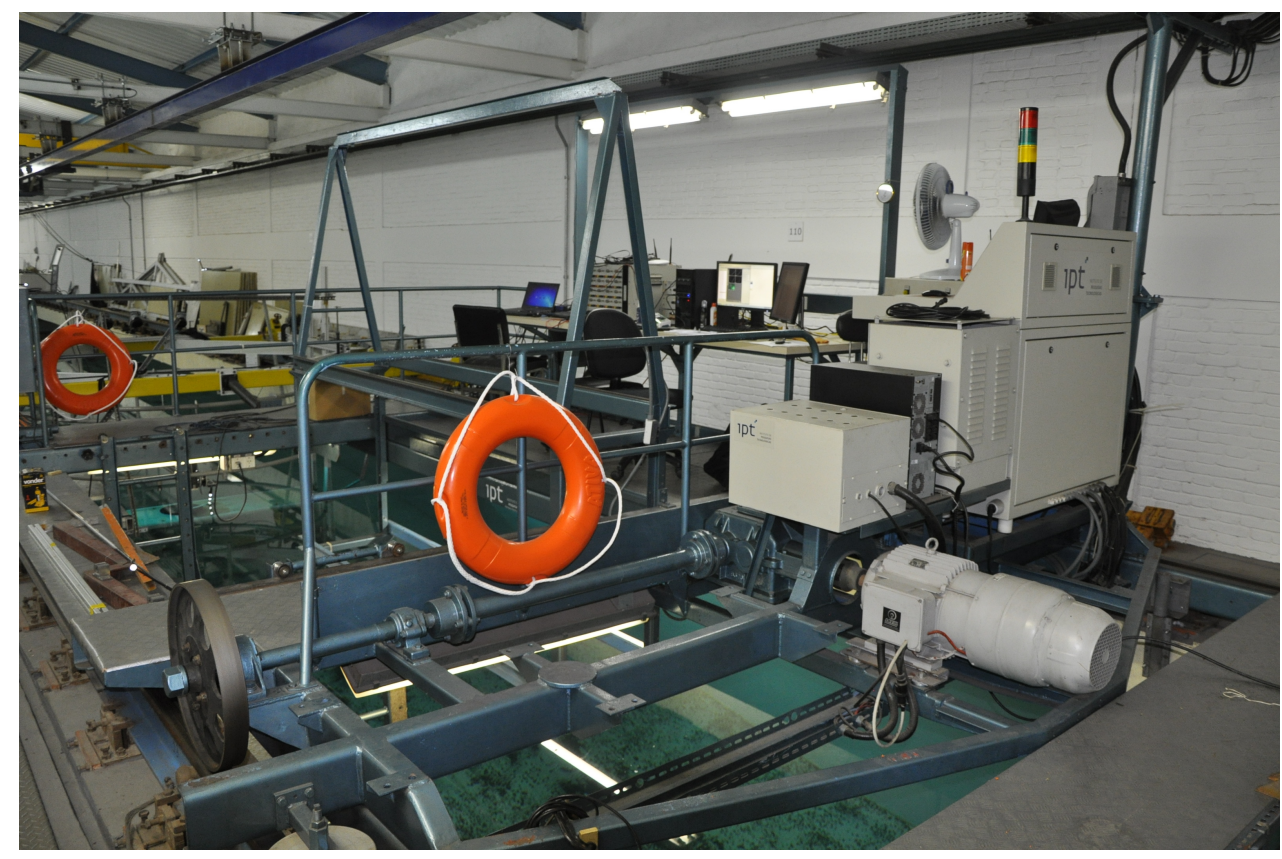

Figura 3.7 - Carro de reboque utilizado no tanque do IPT-SP.

Para alcançar esta velocidade é utilizada uma rampa de aceleração compatível com a velocidade, de forma a alcançá-la suavemente. A velocidade é obtida pelo sistema AqDados ${ }^{\circledR}$, o que torna possível uma leitura instantânea e com isso possibilita o cálculo dos desvios ao redor da velocidade nominal. Na Figura 3.8 é apresentado um exemplo da aquisição da velocidade da corrida 22, cujo valor nominal seria $492 \mathrm{~mm} / \mathrm{s}$. Nesta curva foram traçadas as linhas de tendência para a região da rampa e para a região de velocidade constante. A rampa apresenta uma aceleração de $75.18 \mathrm{~mm} / \mathrm{s}^{2}$, ao passo que o trecho de velocidade constante possui média $=492.24 \mathrm{~mm} / \mathrm{s}$, máximo $=493.29 \mathrm{~mm} / \mathrm{s}$, mínimo $489.99 \mathrm{~mm} / \mathrm{s}$ e desvio padrão de $0.59 \mathrm{~mm} / \mathrm{s}$. 


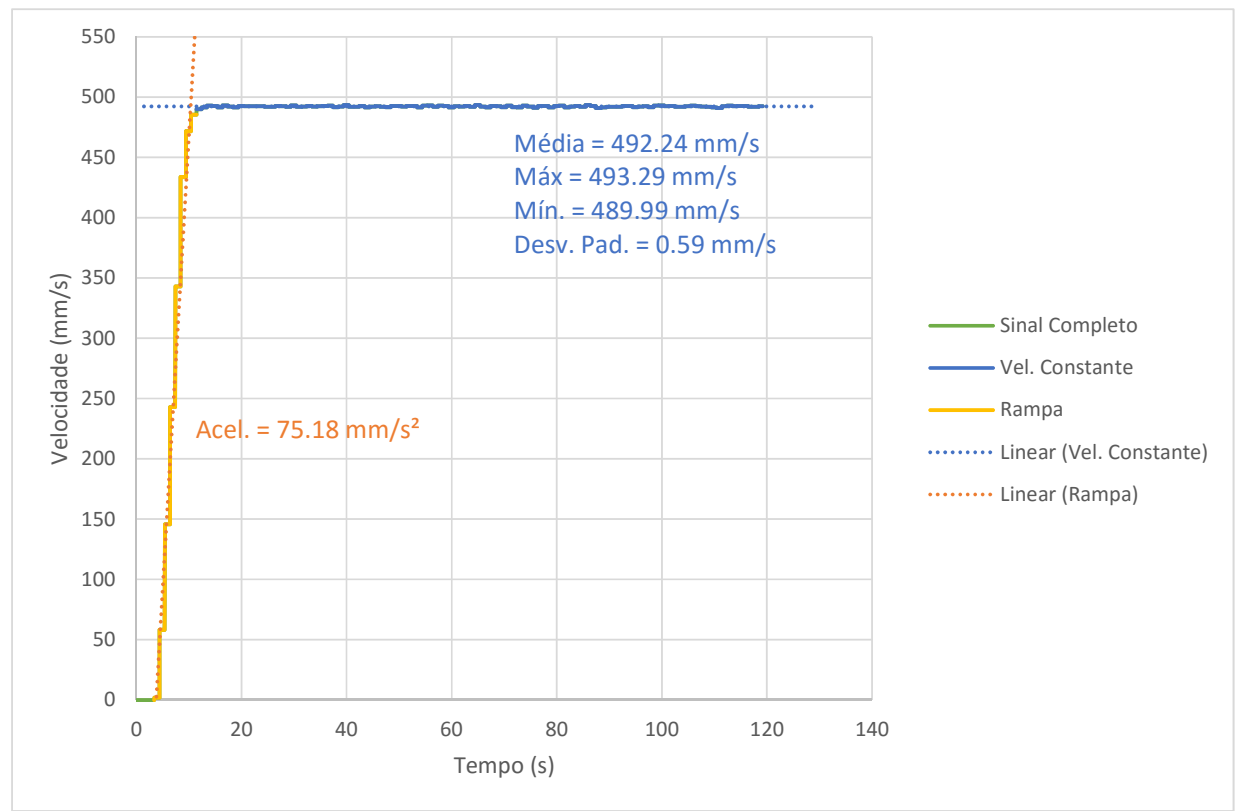

Figura 3.8 - Exemplo de aquisição velocidade de reboque - Corrida 22 - Velocidade Nominal $=492.00 \mathrm{~mm} / \mathrm{s}$

A velocidade reduzida é sempre calculada com base na velocidade média medida no trecho constante. $O$ corte do sinal para avaliação das amplitudes também é realizado com base neste trecho. Para se ter uma ideia, com base neste gráfico apresentado teríamos o seguinte impacto na velocidade reduzida, para o cilindro em questão, ensaiado perpendicularmente ao escoamento:

Tabela 3.2 - Impacto na velocidade reduzida com base na flutuação da velocidade do carro de reboque - Corrida 22

\begin{tabular}{cccccc}
\hline & Nominal & Média & Máxima & Mínima & Desvio Padrão \\
\hline$U(\mathrm{~mm} / \mathrm{s})$ & 492.00 & 492.24 & 493.29 & 489.99 & 0.59 \\
$\mathrm{Vr}(\mathrm{adm})$. & 22.22 & 22.22 & 22.27 & 22.12 & 0.02 \\
\hline
\end{tabular}

Além do carro principal que é responsável pela propulsão, o ensaio contou com um segundo carro ao qual foi fixado o experimento propriamente dito. O carro auxiliar possui duas características que justificam a sua utilização junto ao carro de reboque: possuir um sistema rotatório que facilita a mudança do ângulo de azimute $(\beta)$ do modelo e possuir espaço suficiente para alocação de um fundo falso com altura regulável que facilita o ajuste do ângulo vertical $(\theta)$ do modelo.

Neste carro foram instalados ambos sistemas, de ajuste de tração do modelo e de monitoração da posição do modelo. Para facilitar o posicionamento dos equipamentos e a visualização espacial do experimento, uma maquete eletrônica foi desenvolvida 
com base na geometria do carro auxiliar e de seus apêndices, conforme o apresentado na Figura 3.9.

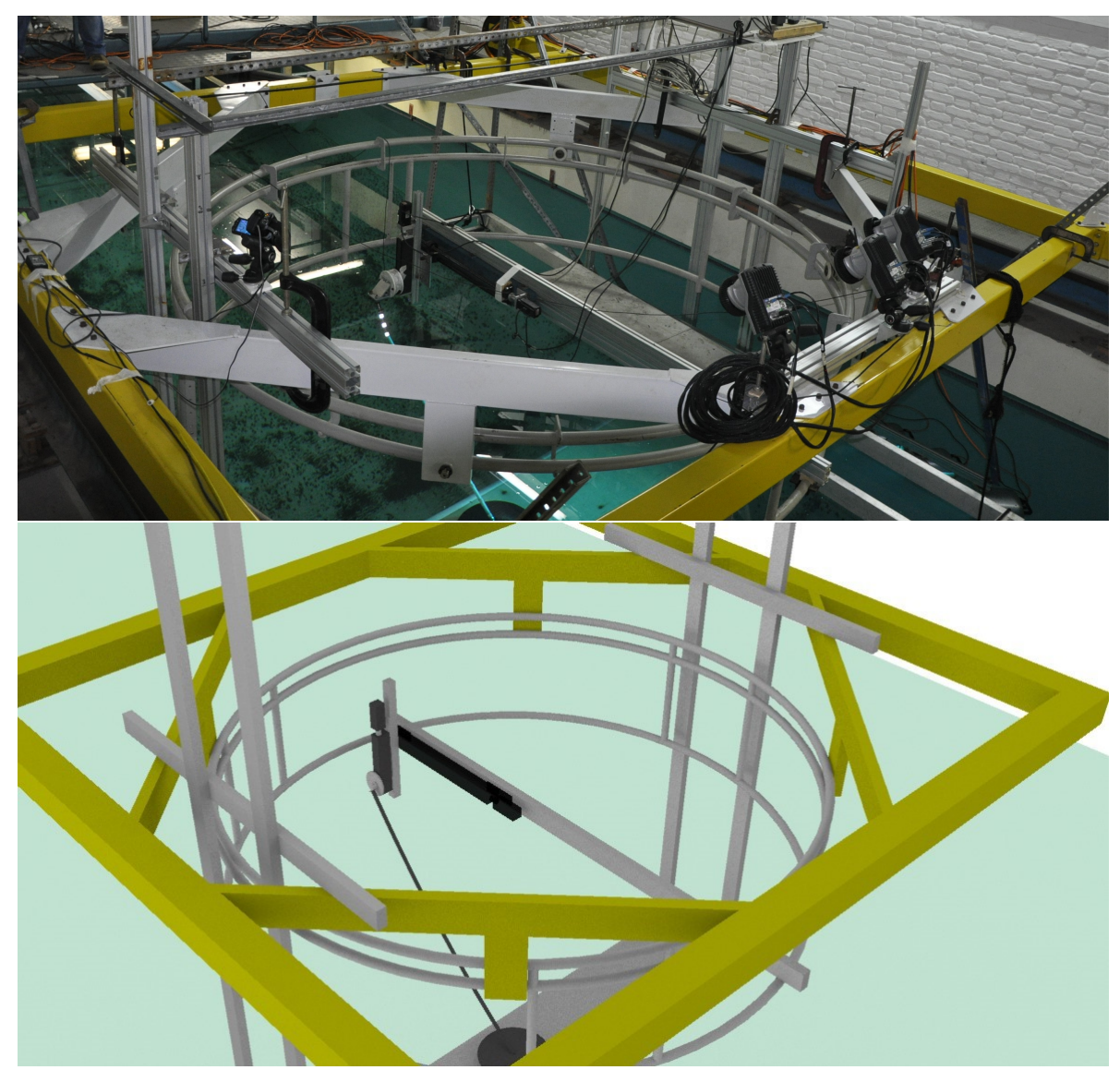

Figura 3.9 - Comparação entre a instalação do experimento e maquete digital.

Um dos apêndices utilizados foi o fundo falso. Este equipamento tem o intuito de prover um apoio inferior para o modelo de forma que seja solidário ao carro auxiliar, movendo-se em conjunto com o modelo. Este fundo é formado por uma placa instalada paralelamente ao fundo do tanque com $0.70 \mathrm{~m}$ de comprimento, $3 \mathrm{~m}$ de largura e $0.12 \mathrm{~m}$ de altura e possui os bordos de ataque arredondados, de forma a diminuir a turbulência do escoamento. A instalação do fundo falso, assim como suas principais medidas, podem ser visualizados na Figura 3.10

A extremidade inferior do modelo foi apoiada no fundo falso através de uma âncora (Figura 3.11) dotada de uma placa circular (End Plate) com diâmetro de $408 \mathrm{~mm}$, aproximadamente 18 vezes o diâmetro do modelo $(22.2 \mathrm{~mm})$. Esta placa circular foi utilizada com o intuito de minimizar o efeito da turbulência causada pelo escoamento ao redor do fundo falso e ao redor da âncora. 

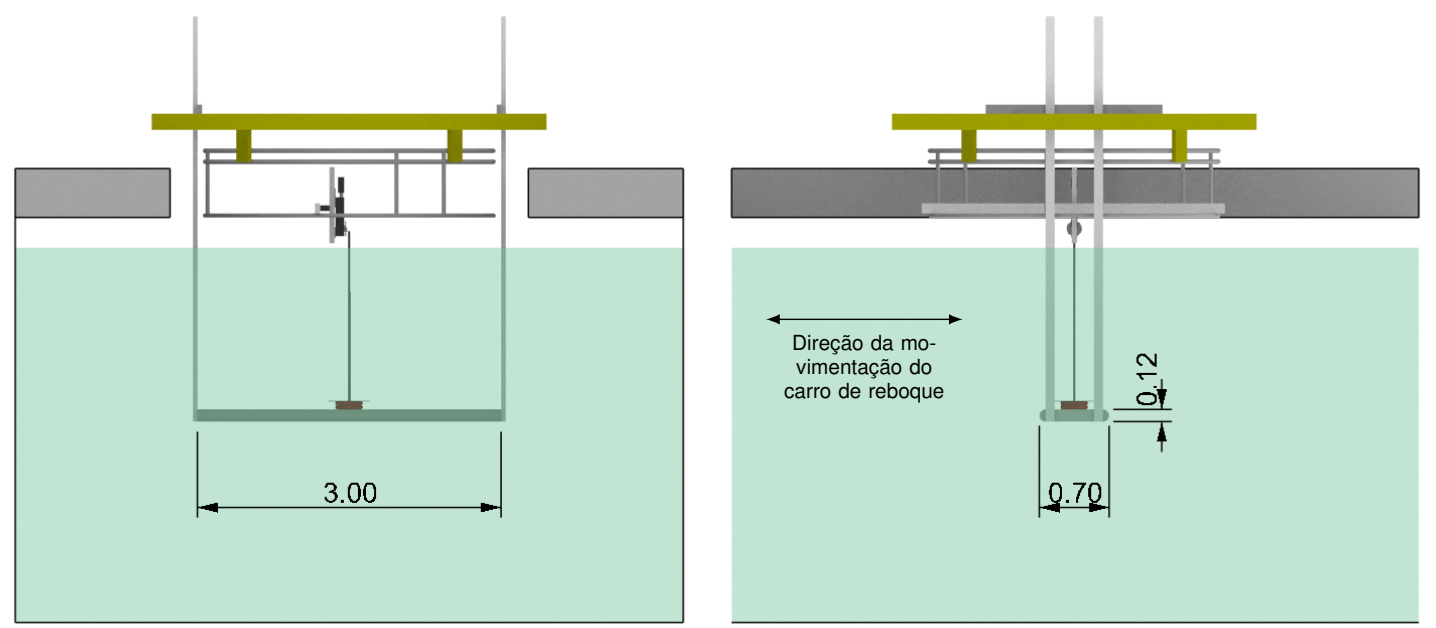

Figura 3.10 - Vistas frontal (esq.) e lateral (dir.) da instalação do fundo falso (Unidades: m).

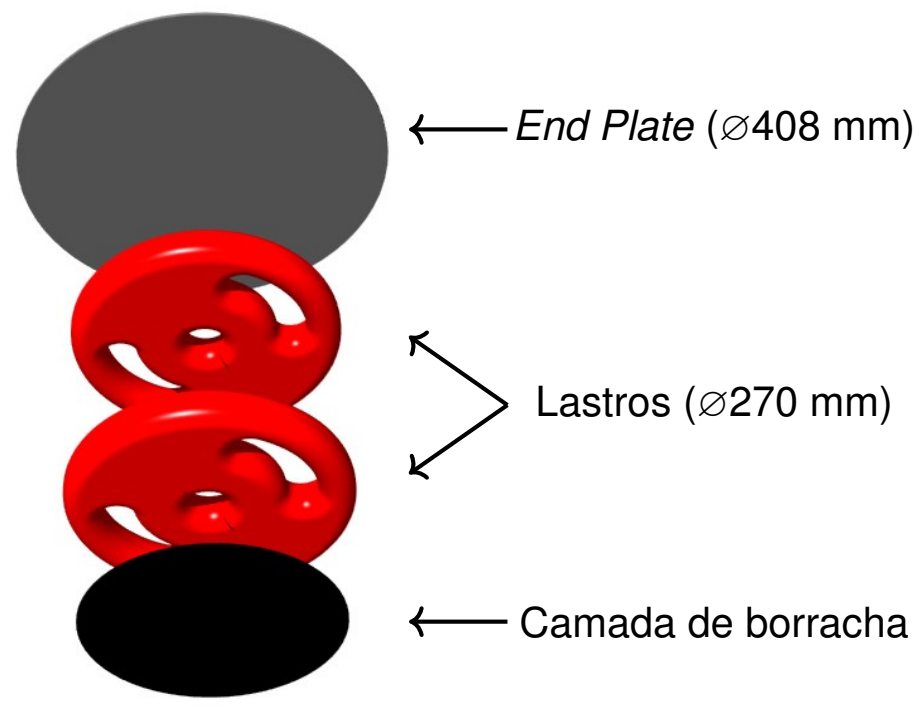

Figura 3.11 - Vista explodida do arranjo utilizado como âncora para a extremidade inferior.

A âncora possui peso submerso ao redor de $16.4 \mathrm{kgf}$ (peso no ar: $20 \mathrm{kgf}$ ), o que proporciona lastro suficiente para manter a posição vertical desta extremidade sempre fixa. Para garantir que a posição horizontal também permaneça fixa em relação ao fundo falso, uma camada de borracha foi colada no fundo da âncora de forma a aumentar o coeficiente de atrito. As dimensões principais da âncora estão apresentadas na Figura 3.12. É importante ressaltar que um alvo foi colocado solidário ao fundo falso para monitorar qualquer possível deslocamento da âncora, porém em nenhum dos testes foi observado qualquer tipo de movimento relativo entre a âncora e o fundo falso. 


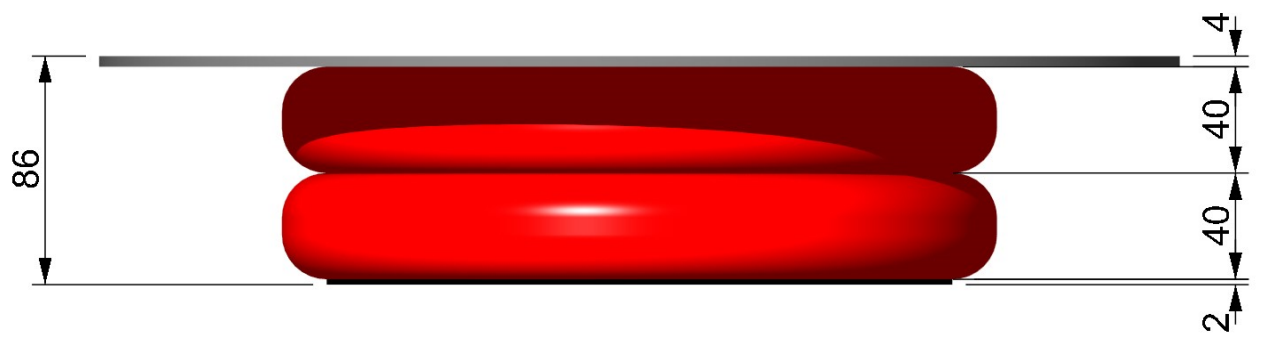

Figura 3.12 - Dimensões principais da âncora (Unidades: mm)

A extremidade superior do modelo foi fixada no sistema de ajuste de tração, que será detalhado na seção seguinte. Esse sistema por sua vez foi fixado na estrutura circular localizada na parte central do carro auxiliar. Na Figura 3.13 temos o arranjo esquemático para cada uma das inclinações mostrando o posicionamento do modelo, do fundo falso, da âncora e dos atuadores.

Com as distâncias apresentadas na Figura 3.13 predefinidas, marcações foram realizadas nas barras laterais que sustentam o fundo falso de forma a facilitar a mudança de altura para cada uma das inclinações. Os experimentos foram realizados primeiramente com o modelo na vertical e em seguida os ângulos $\theta$ foram sendo aumentados em ordem crescente. O procedimento para mudança de inclinação primeiramente compreende a suspensão do fundo falso (e consequente suspensão da extremidade inferior do modelo) e em seguida a movimentação do atuador horizontal (afastando do centro). Como o curso do atuador horizontal é insuficiente para atingir a posição indicada para $\theta=30^{\circ}$ e $\theta=45^{\circ}$, após os ensaios com as três primeiras inclinações, este atuador teve que ser reposicionado.

A Figura 3.14 mostra uma vista superior de um arranjo esquemático do carro auxiliar, dando destaque para os principais elementos.

Como dito anteriormente, essa estrutura circular facilita o ajuste do azimute. Uma vez que a extremidade inferior está fixa, basta girar a estrutura circular de um ângulo $(\beta)$. Os azimutes ensaiados foram $0^{\circ}, 45^{\circ}, 90^{\circ}, 135^{\circ}$ e $180^{\circ}$. Como o experimento pode ser executado nas duas direções de movimento do carro de reboque (ida ou volta), uma vez que o modelo esteja ajustado para $0^{\circ}$ ou $45^{\circ}$, basta executar o experimento na direção da volta e obtemos os azimutes 135 e 180 graus, respectivamente. Desta forma para o ensaio de todos azimutes é necessário rotacionar o conjunto em apenas um quarto de volta, o que facilita o posicionamento das câmeras submersas conforme será tratado nas seções seguintes. As Figuras 3.15, 3.16 e 3.17 apresentam um exemplo da configuração do experimento para cada um dos azimutes citados acima. 

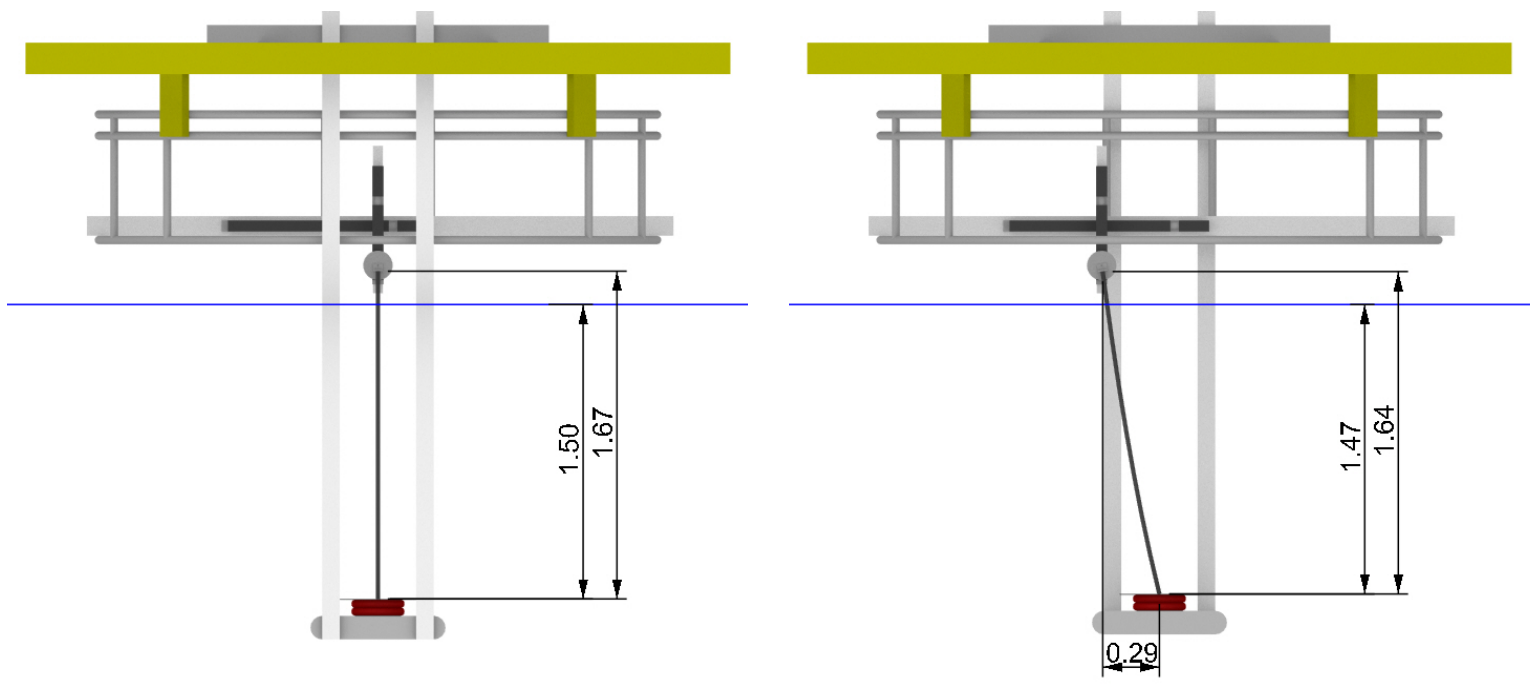
$\theta=0^{\circ}$
$\theta=10^{\circ}$

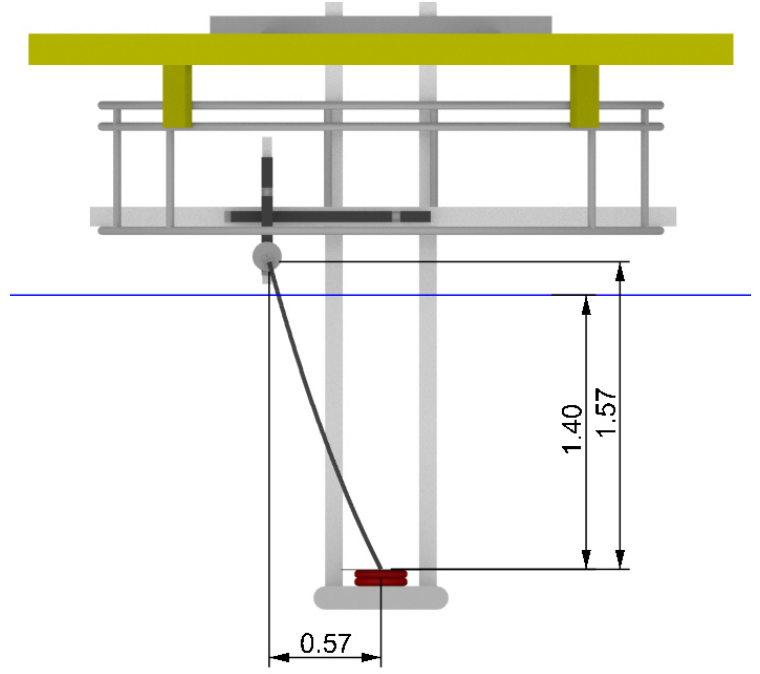

$$
\theta=20^{\circ}
$$

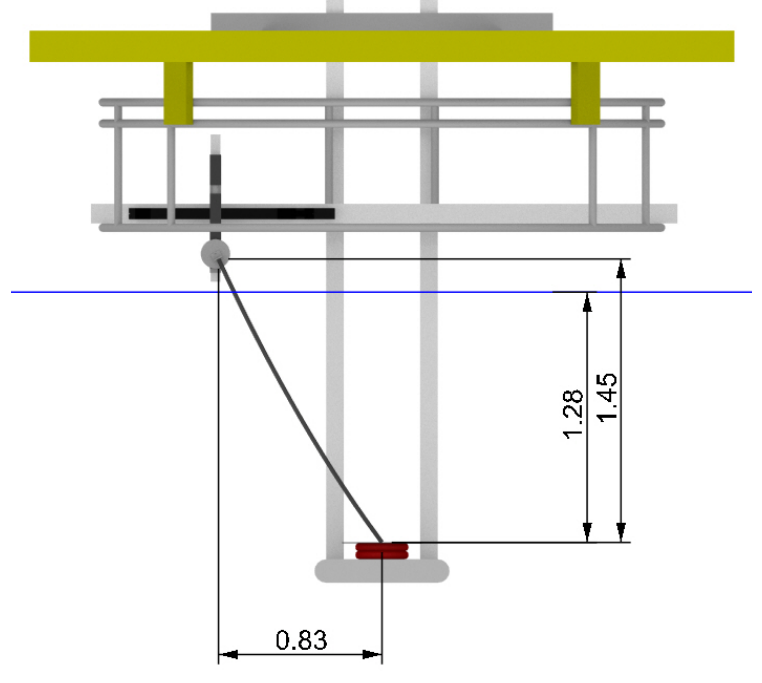

$$
\theta=30^{\circ}
$$

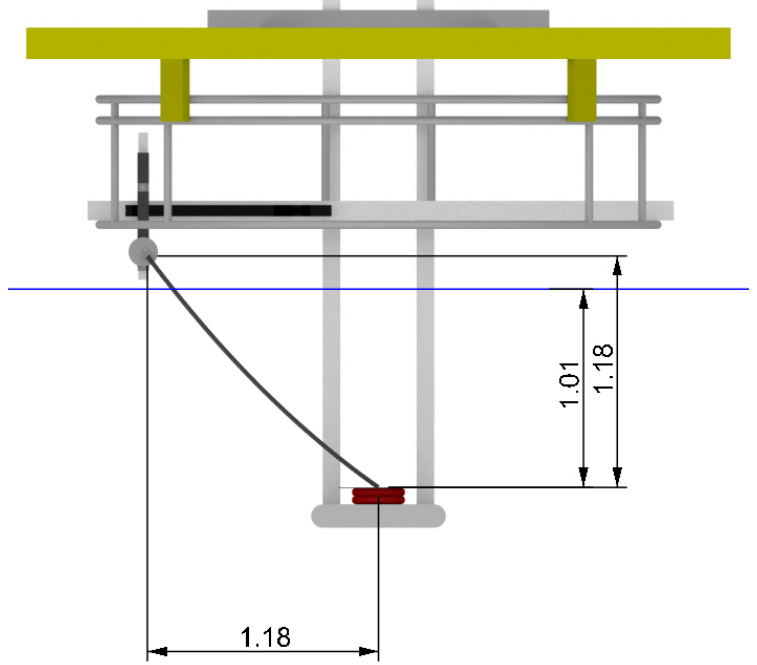

$\theta=45^{\circ}$

Figura 3.13 - Vista lateral do arranjo esquemático do posicionamento do modelo e do fundo falso no carro auxiliar para cada uma das inclinações estudadas (Unidades: $\mathrm{m}$ ). 


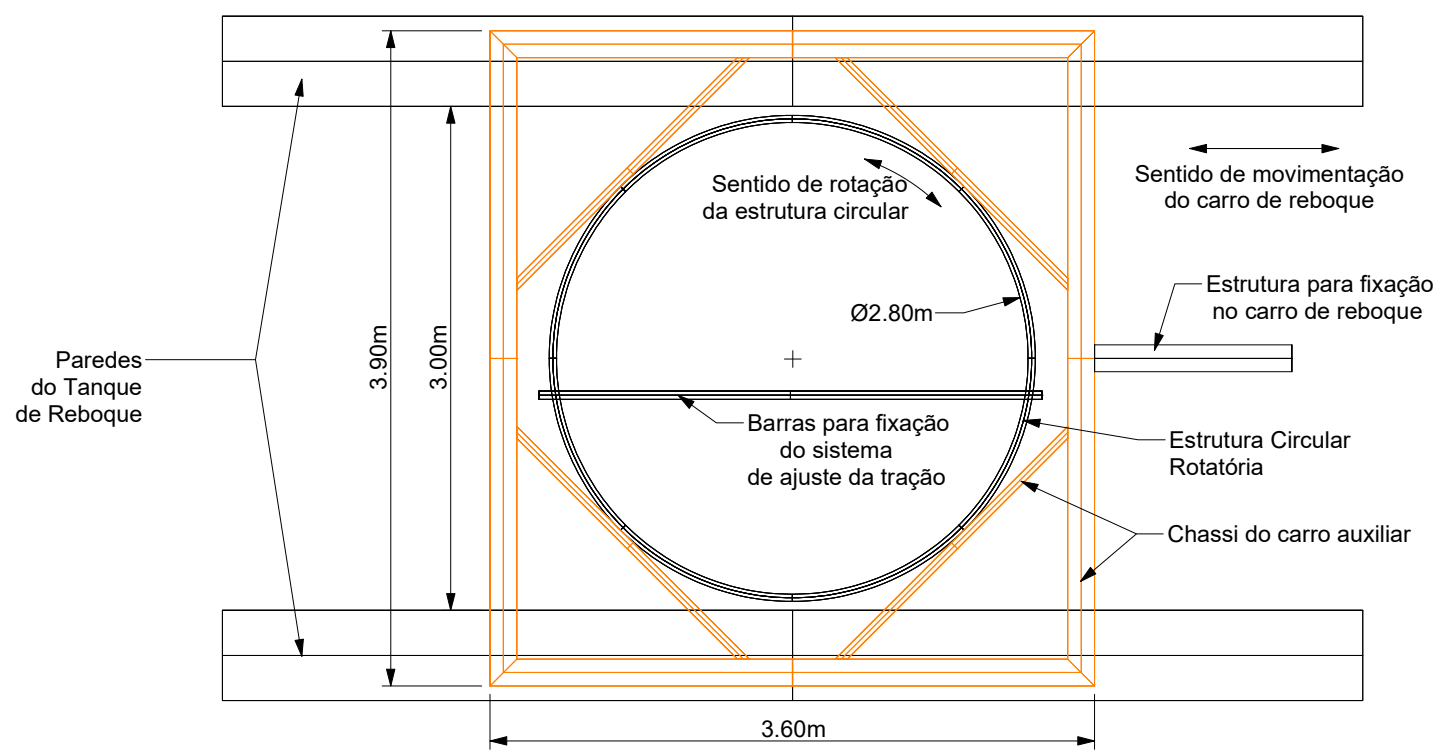

Figura 3.14 - Vista superior do arranjo esquemático da estrutura circular localizada no carro auxiliar (Unidades: $\mathrm{m}$ ).

Uma vez que a mudança de azimute é mais simples de se realizar do que a mudança de inclinação, para cada inclinação ajustada são realizadas as três mudanças de azimute, facilitando a logística do experimento. Após a realização dos ensaios para essas três configurações, o modelo é reposicionado e uma nova mudança de inclinação é realizada.

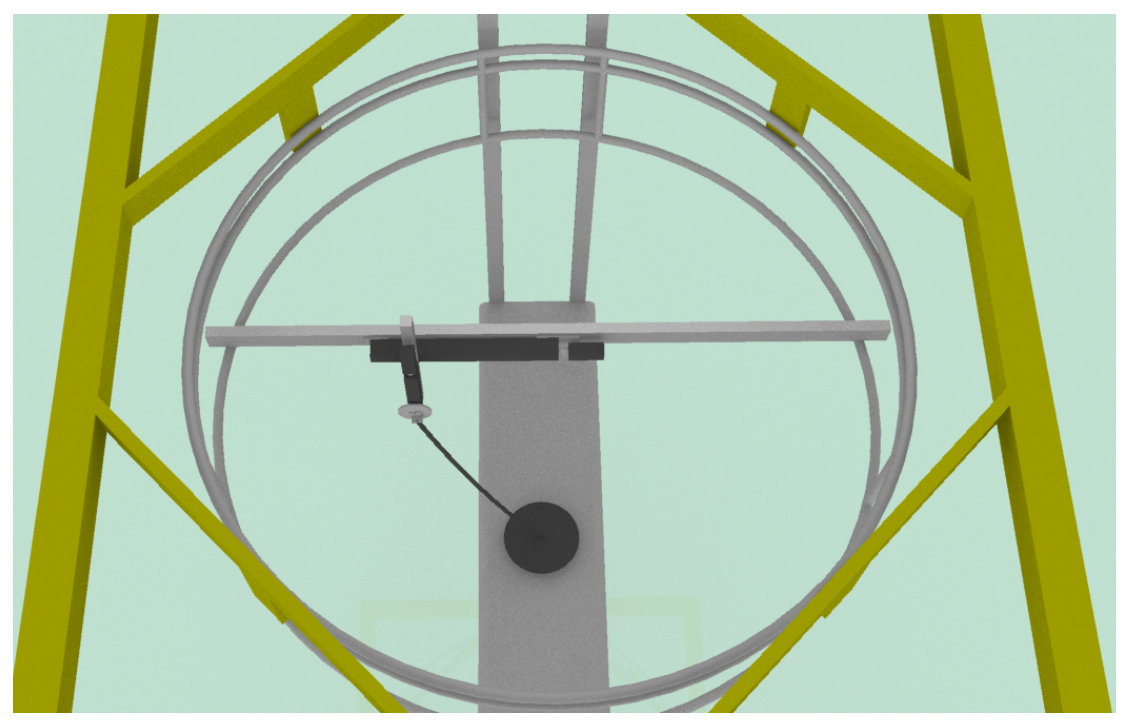

Figura 3.15 - Arranjo esquemático da mudança de azimute do modelo $-\beta=0^{\circ} \mathrm{e} \beta=180^{\circ}$ 


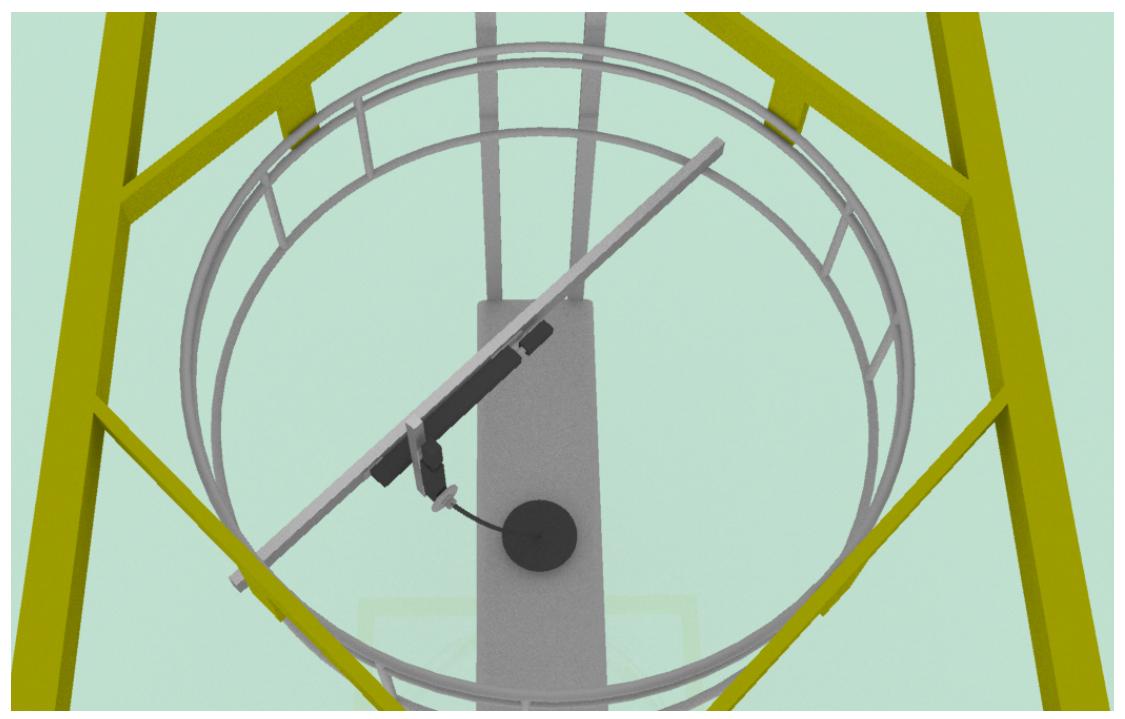

Figura 3.16 - Arranjo esquemático da mudança de azimute do modelo $-\beta=45^{\circ} \mathrm{e} \beta=135^{\circ}$

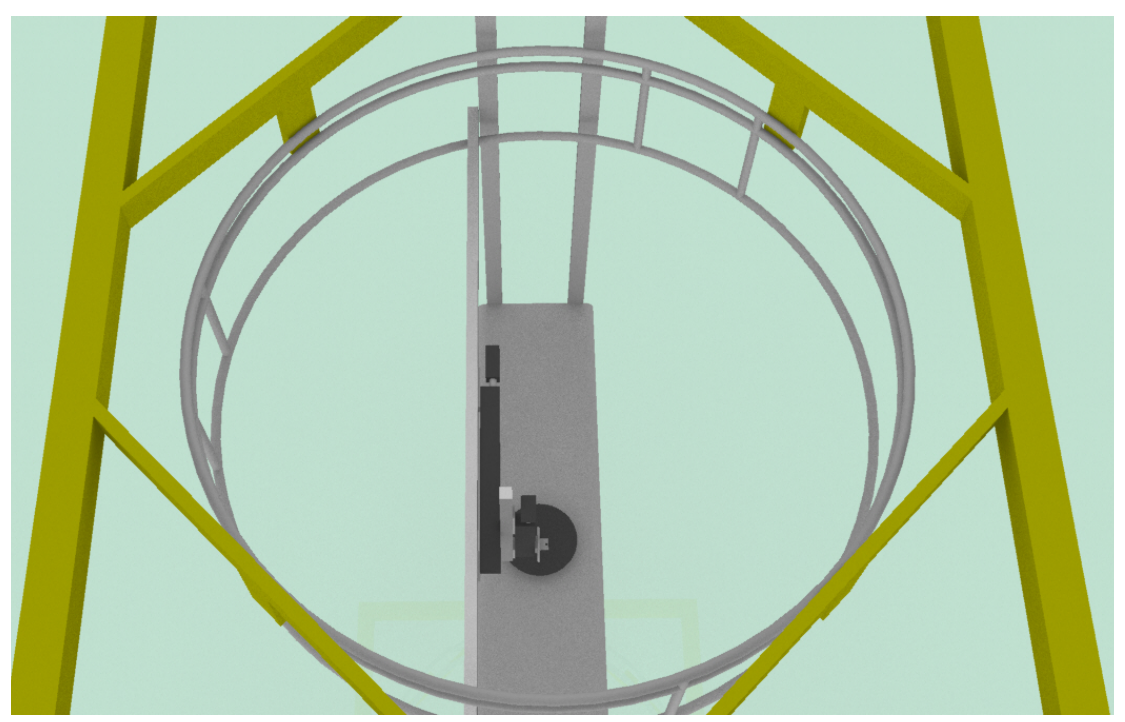

Figura 3.17 - Arranjo esquemático da mudança de azimute do modelo $-\beta=90^{\circ}$

\subsubsection{Sistema de ajuste da tração}

Para o ajuste da tração do modelo, a sua extremidade superior foi fixada em um sistema constituído de uma célula de carga instalada em conjunto com dois servoatuadores montados em um arranjo para fornecer um sistema com dois graus de liberdade (capacidade de translação na horizontal e na vertical). Para o eixo horizontal foi utilizado um atuador com curso máximo de $800 \mathrm{~mm}$ e para o eixo vertical um atuador com curso máximo de $280 \mathrm{~mm}$. A montagem destes atuadores pode ser vista na Figura 3.18a. Ambos atuadores possuem servos de $400 \mathrm{~W}$ controlados por dois Drivers $P L C^{1}$ do tipo R8C/1B da Renesas. Além disso uma conexão do tipo RS-232 foi

\footnotetext{
${ }^{1}$ do inglês Programmable Logic Controller, ou Controlador Lógico Programável.
} 
utilizada para comunicação com um computador, a instalação do sistema de controle pode ser vista na Figura 3.18b.

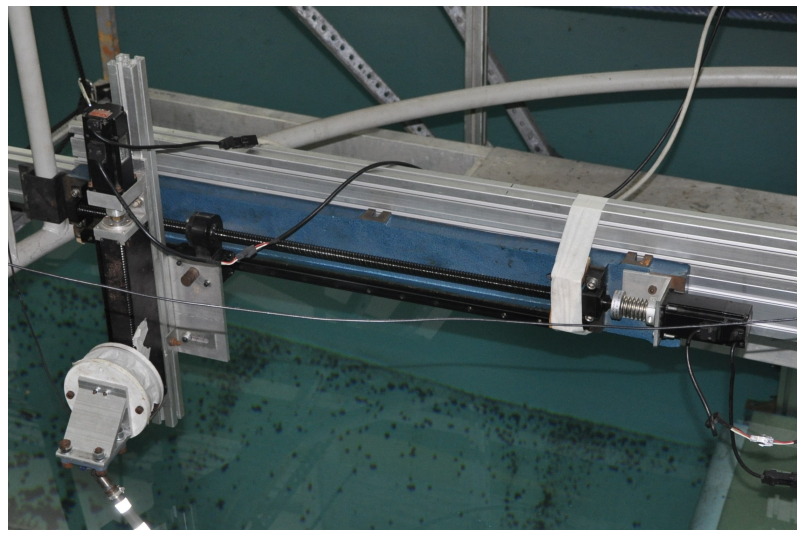

(a)

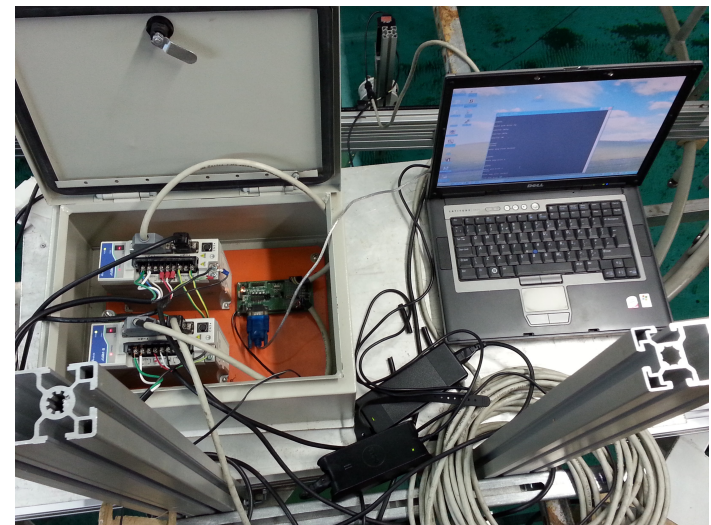

(b)

Figura 3.18 - (a) Atuadores montados para fornecer um sistema com dois graus de liberdade: $800 \mathrm{~mm}$ na horizontal e $280 \mathrm{~mm}$ na vertical. (b) Drivers PLC utilizados para o controle dos atuadores.

O desenvolvimento deste conjunto foi apresentado em de Mello et al. (2011) e utilizado nesta pesquisa com o intuito de mover a extremidade superior ao longo da linha inclinada com a vertical, de forma a diminuir ou aumentar a tração no modelo e por consequência ajustar suas frequências naturais sem, contudo, alterar a inclinação do modelo. Ou seja, dada uma inclinação $\theta$, para mudar a elongação do modelo de uma distância $\delta$, deve-se mover o atuador horizontal de uma distância $\delta_{x}$ e o atuador vertical de uma distância $\delta_{z}$, tal que:

$$
\begin{aligned}
& \delta_{x}=\operatorname{sen} \theta \\
& \delta_{z}=\cos \theta
\end{aligned}
$$

A célula de carga de seis graus de liberdade modelo Mini 85 (Figura 3.19a) da ATI Industrial Automation foi instalada entre a extremidade superior do modelo e o atuador vertical. Esta célula tem dois objetivos: auxiliar no ajuste da tração do modelo e medir as flutuações de tração e forças de arrasto durante os ensaios de VIV.

Nas Tabelas 3.3 e 3.4 estão apresentadas as principais características físicas e operacionais da célula de carga, respectivamente. Os eixos para consideração das forças e momentos são apresentados na Figura 3.19b. 


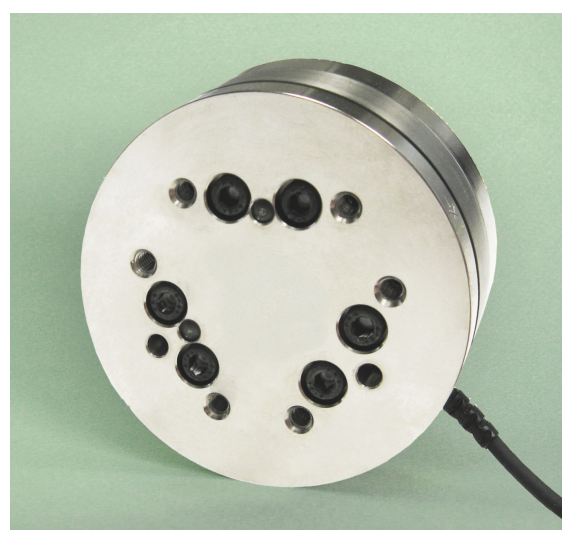

(a)

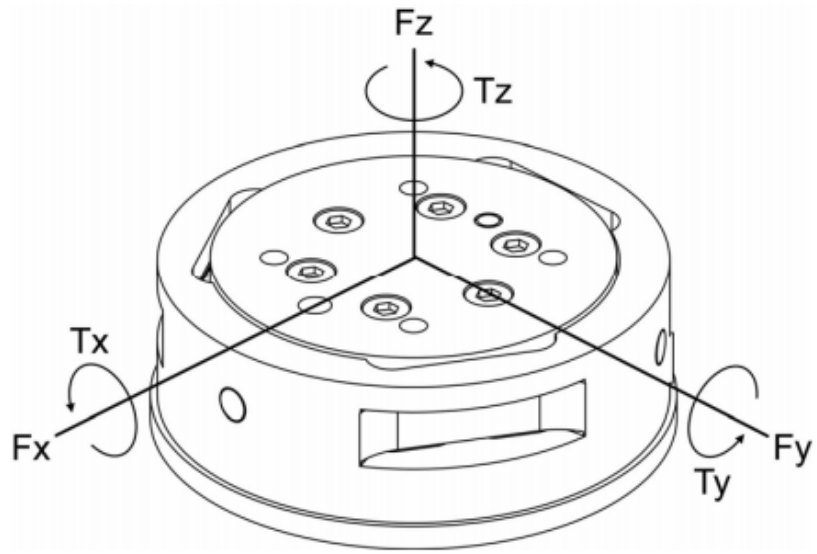

(b)

Figura 3.19 - (a) Célula de carga modelo Mini 85 da ATI Industrial Automation. (b) Definição dos eixos da célula de carga para medição das forças e momentos nos 6 graus de liberdade. Extraído de ATI Industrial Automation (2010).

Tabela 3.3 - Características físicas da célula de carga modelo Mini 85 da ATI Industrial Automation.

\begin{tabular}{cc}
\hline Característica* $^{*}$ & Valor \\
\hline Peso & $0.635 \mathrm{~kg}$ \\
Diâmetro & $85.1 \mathrm{~mm}$ \\
Altura & $29.8 \mathrm{~mm}$ \\
\hline *Incluindo as placas de fixação padrão.
\end{tabular}

Tabela 3.4 - Características operacionais da célula de carga modelo Mini 85 da ATI Industrial Automation.

\begin{tabular}{ccccc}
\hline Eixo & Alcance & Resolução & Rigidez & Ressonância \\
\hline Fx,Fy & $\pm 1900 \mathrm{~N}$ & $<2 \mathrm{mN}$ & $7.7 \times 10^{7} \mathrm{~N} / \mathrm{m}$ & $2400 \mathrm{~Hz}$ \\
$\mathrm{Fz}$ & $\pm 3800 \mathrm{~N}$ & $<2 \mathrm{mN}$ & $1.2 \times 10^{8} \mathrm{~N} / \mathrm{m}$ & $3100 \mathrm{~Hz}$ \\
$\mathrm{Tx}, \mathrm{Ty}$ & $\pm 80 \mathrm{Nm}$ & $<0.1 \mathrm{mNm}$ & $8.1 \times 10^{4} \mathrm{Nm} / \mathrm{rad}$ & $3100 \mathrm{~Hz}$ \\
$\mathrm{Tz}$ & $\pm 80 \mathrm{Nm}$ & $<0.1 \mathrm{mNm}$ & $1.3 \times 10^{5} \mathrm{Nm} / \mathrm{rad}$ & $2400 \mathrm{~Hz}$ \\
\hline
\end{tabular}

Outros pontos importantes, tais como os detalhes de calibração e instalação, podem ser obtidos em ATI Industrial Automation (2010). 


\subsubsection{Sistema de monitoração da Qualisys ${ }^{\circledR}$}

A posição ao longo do tempo do modelo foi medida através de um sistema de câmeras submersas capazes de capturar o movimento de alvos refletivos colocados em posições pré-determinadas no modelo. Deste modo são capturados os movimentos de pontos discretos localizados ao longo do modelo. Para determinar os deslocamentos ao longo do modelo, a linha elástica é recuperada através da interpolação destes pontos capturados. Este método de aquisição de dados é bastante utilizado nas pesquisas e projetos desenvolvidos na EP-USP e está devidamente apresentado em Fujarra et al. (2009).

Para garantir que o movimento do modelo como um todo fosse obtido corretamente, tomou-se o cuidado para que a distância entre os alvos fosse menor do que o comprimento de onda da vibração dos graus de liberdade que se deseja estudar. Para o caso do modelo aqui estudado, o menor comprimento de onda teria por volta de 33 $\mathrm{mm}$ e a distância entre alvos adotada foi de $10 \mathrm{~mm}$.

Deste modo, será utilizado o sistema de câmeras submersas "Oqus Underwater" da Qualisys ${ }^{\circledR}$ apresentada na Figura 3.20, cujas principais características são apresentadas na Tabela 3.5.

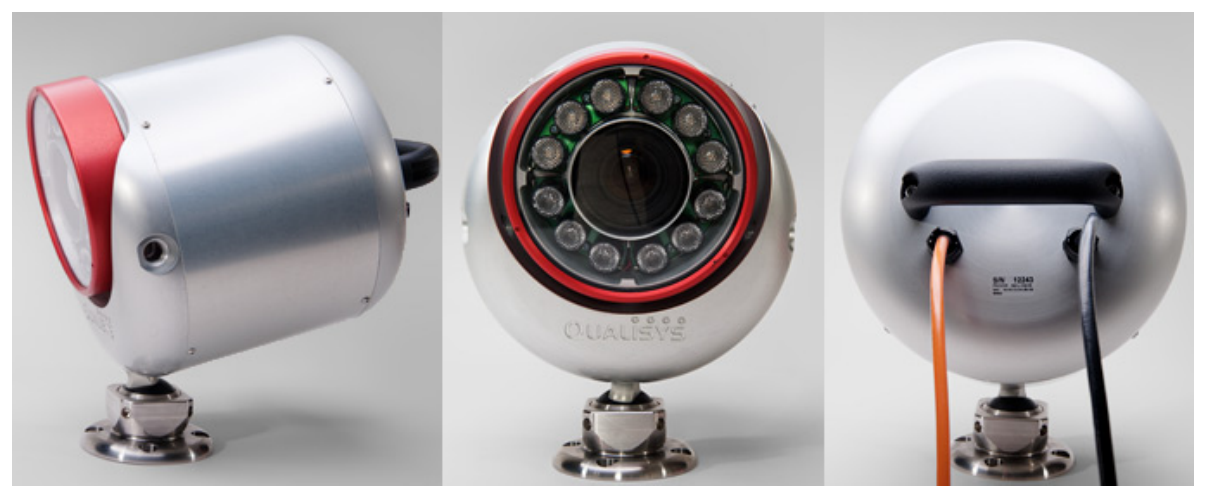

Figura 3.20 - Detalhes da câmera submersa "Oqus Underwater" da Qualisys ${ }^{\circledR}$. Fonte: qualisys.com

Tabela 3.5 - Propriedades da câmera submersa “Oqus Underwater" da Qualisys ${ }^{\circledR}$. Fonte: qualisys.com

\begin{tabular}{lr}
\hline Propriedade & Descrição \\
\hline Dimensões & $300 \times 300 \times 240 \mathrm{~mm}$ \\
Peso & $12 \mathrm{~kg}$ \\
Alcance & $20 \mathrm{~m}$ \\
Resolução & até 4 Megapixel \\
\hline
\end{tabular}


Estas câmeras capturam o movimento de alvos refletivos aderidos ao objeto que pretende-se estudar. No modelo descrito na seção anterior foram coladas algumas tiras do material reflexivo ao longo do seu comprimento, distanciados de aproximadamente $100 \mathrm{~mm}$, conforme apresentado na Figura 3.21. A utilização destes alvos não influencia o escoamento ao redor do modelo, sendo adotada como prática nãoinvasiva de medição.

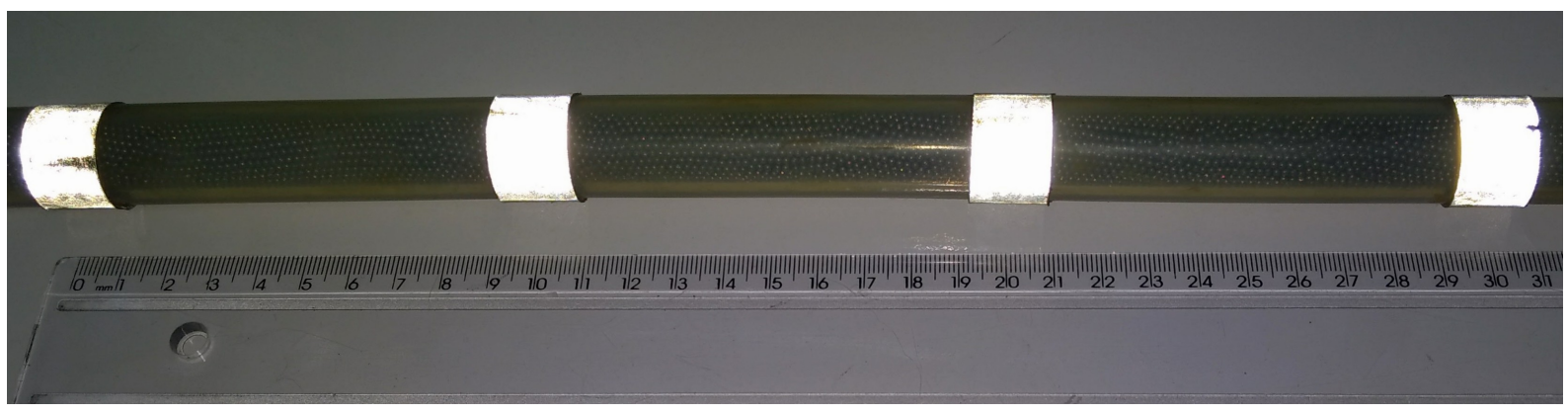

Figura 3.21 - Alvos refletivos aderidos ao modelo de cilindro flexível.

A seguir, na Figura 3.22, é possível visualizar a instalação das câmeras submersas no carro auxiliar do Tanque de Reboque do IPT-SP. Como pode ser observado, as câmeras foram montadas solidárias ao carro. Isso significa que ao movimentá-lo as câmeras se movimentam com a mesma velocidade. Assim, é possível captar os movimentos relativos do modelo em relação ao carro, o que já poupa o trabalho de se realizar mudanças de coordenadas e referenciais.

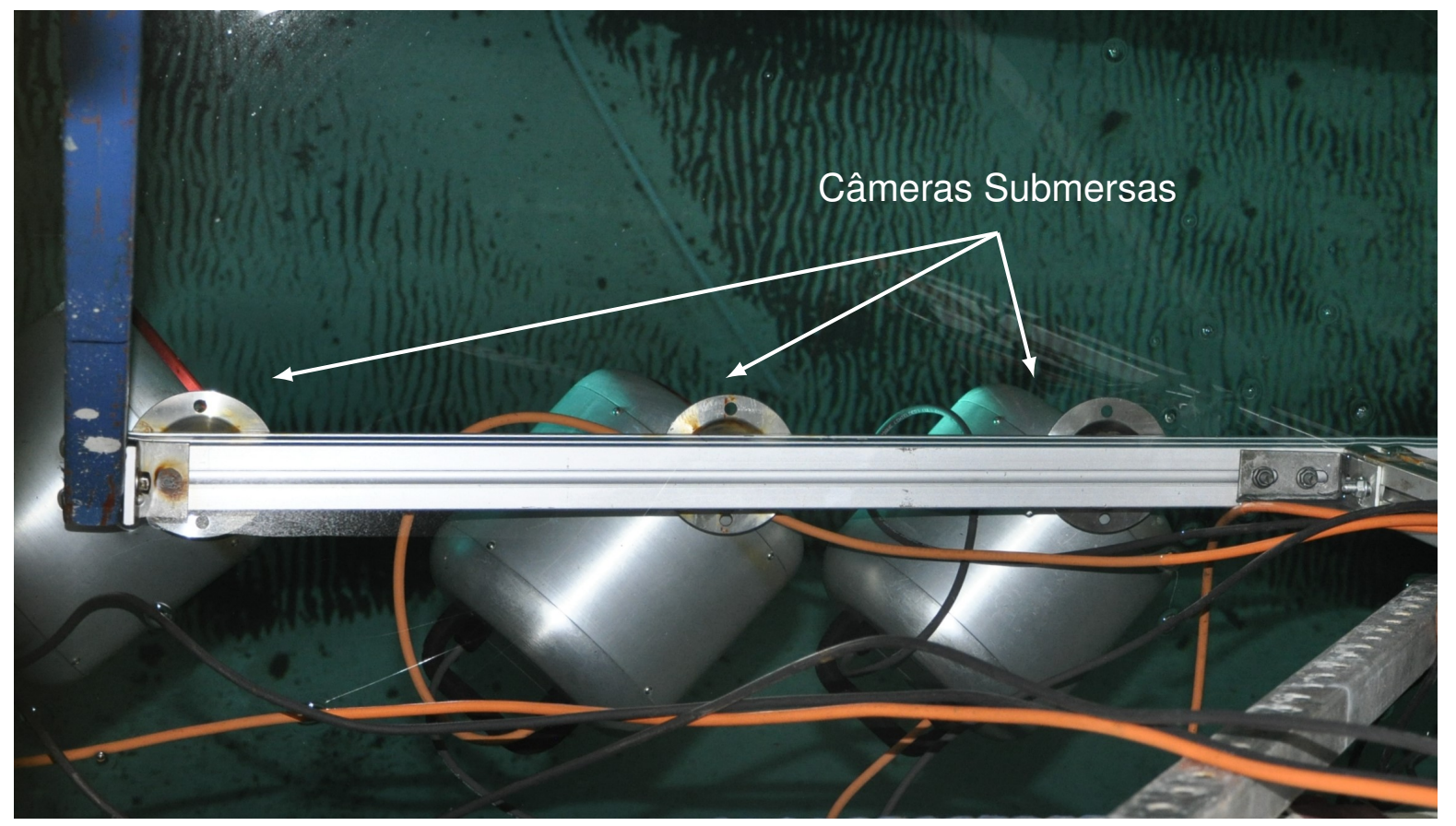

Figura 3.22 - Vista superior da instalação das câmeras submersas da Qualisys ${ }^{\circledR}$ no Carro Auxiliar do Tanque de Reboque do IPT-SP 
A estrutura na qual as câmeras foram suspensas foi enrijecida com barras de forma a minimizar possíveis vibrações, o que prejudicaria a qualidade da medição. Testes prévios mostraram que o carro pode atingir velocidades de até $1 \mathrm{~m} / \mathrm{s}$ sem que apresente vibrações significativas nas câmeras. Desta forma, todos os reboques foram realizados em uma velocidade abaixo deste limite.

As imagens capturadas pelo sistema de câmeras são então processadas pelo programa Qualysis Tracker Manager (QTM). Na Figura 3.23 é possível observar a imagem capturada por cada câmera após o processamento. Nessas imagens é possível visualizar a imagem dos alvos que cada uma das câmeras está capturando no momento.

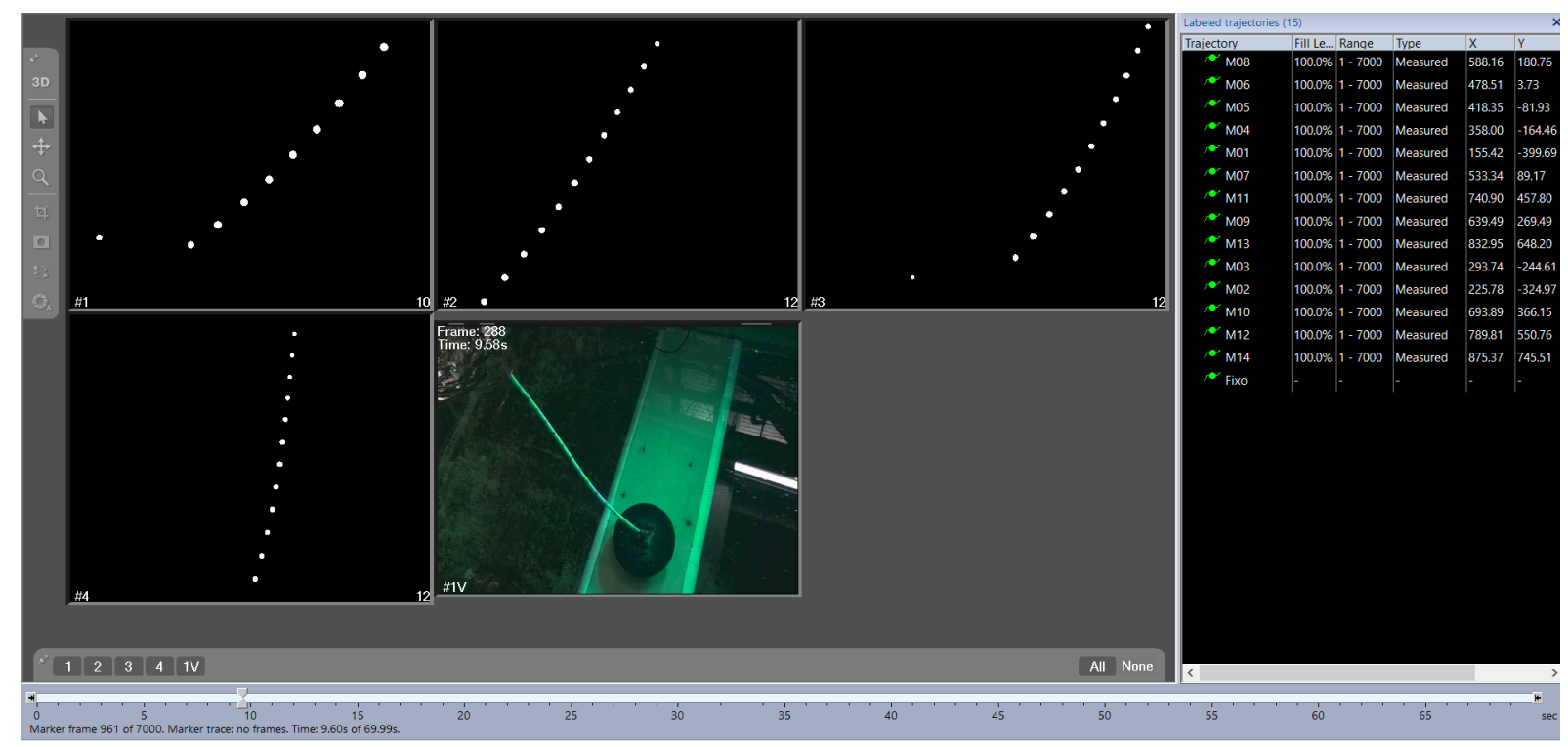

Figura 3.23 - Imagens processadas em cada uma das câmeras submersas.

Nesta figura é possível observar, além das quatro imagens capturadas para medição, uma quinta imagem que foi capturada através de uma câmera de vídeo digital com o intuito de filmar o comportamento do modelo em cada um dos ensaios. Esses vídeos são importantes para a visualização de qualquer comportamento diferente que se venha obter no pós-processamento dos sinais. Um atributo importante é que esses videos são gravados de forma sincronizada com o movimento dos alvos. A Figura 3.24 apresenta o posicionamento desta câmera de vídeo. 


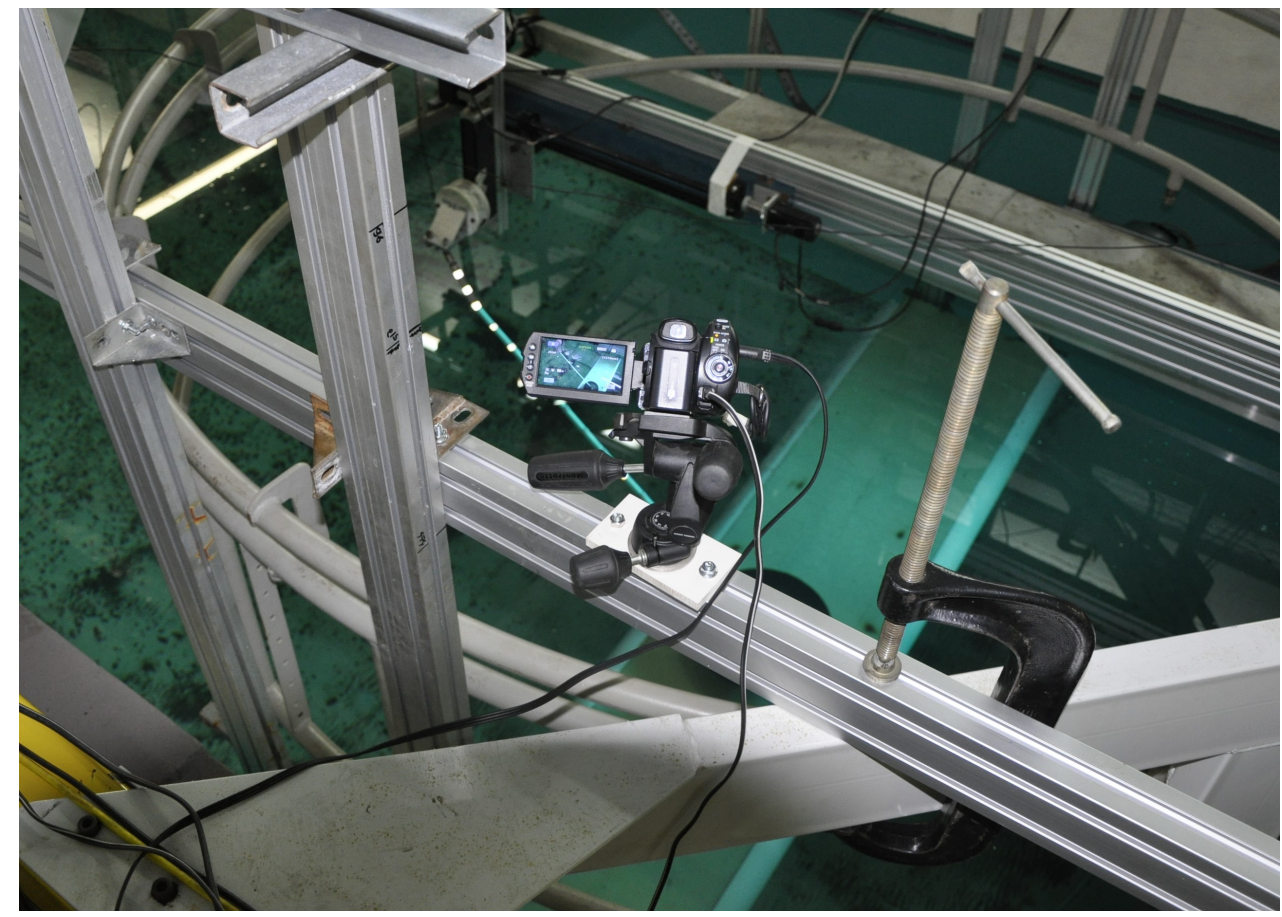

Figura 3.24 - Posicionamento da câmera de vídeo no carro auxiliar.

Para a captura da série temporal do movimento nas três dimensões espaciais é necessário realizar um processo de calibração. Neste processo coloca-se um sistema de quatro alvos fixos dispostos em um esquadro em forma de "L" à vista de todas as câmeras. Em seguida é necessário capturar os alvos de uma haste em forma de "T" com dimensão preestabelecida em todo o volume onde se pretende capturar o movimento do modelo. Para isso deve-se percorrer com a haste todo o volume que se deseja calibrar por um determinado tempo.

Após o processo de calibração, o programa QTM identifica cada um dos alvos e, por consequência, mede a sua posição espacial em relação ao eixo do esquadro (ou outro sistema de coordenadas definido pelo usuário em relação ao do esquadro), gravando as séries temporais do movimento em um arquivo para um pós-processamento. $\mathrm{O}$ movimento tridimensional pode ser observado simultaneamente no programa, como apresentado na Figura 3.25. 


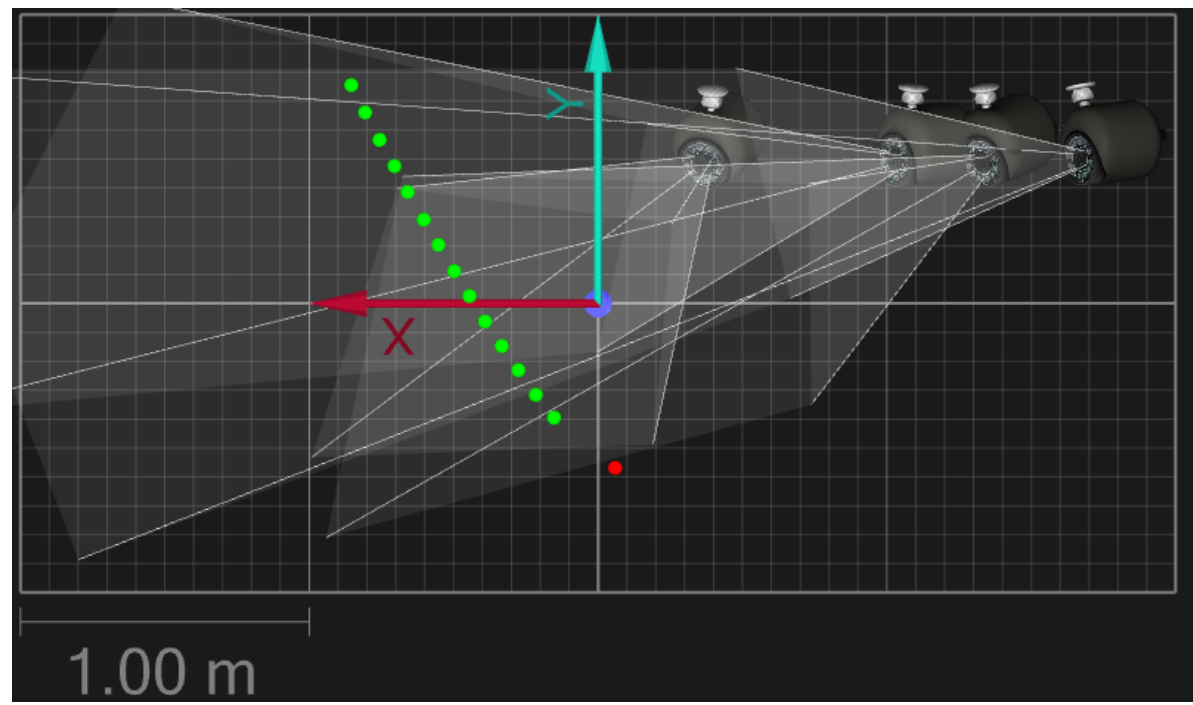

Figura 3.25 - Visualização do movimento tridimensional dos alvos e da posição relativa das câmeras submersas.

Outro cuidado tomado foi o de se instalar as câmeras há uma distância de aproximadamente 1.5 metros do modelo (Figura 3.26), de forma que a turbulência gerada não influenciasse no escoamento incidente no modelo.

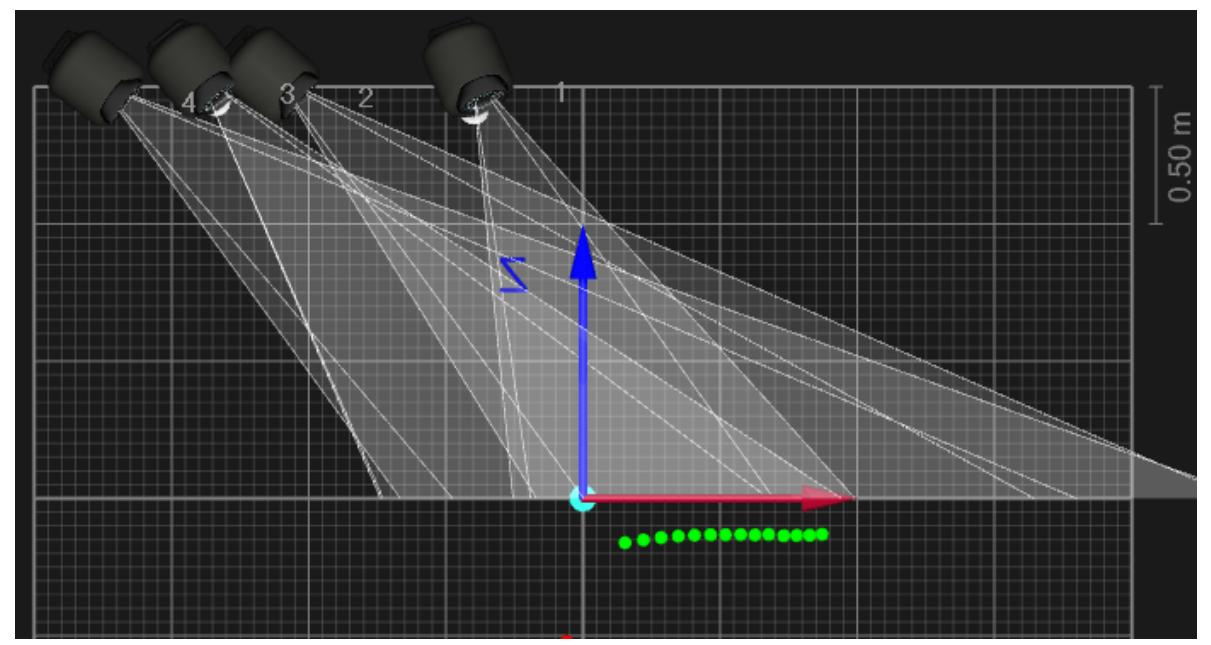

Figura 3.26 - Vista superior do sistema QTM mostrando a distância de aproximadamente 1.5 metros entre o modelo e as câmeras submersas.

Além do sistema de câmeras submersas, foram utilizadas câmeras aéreas do modelo Oqus 500 para a medição dos ensaios de decaimento realizados no ar. Suas principais características são apresentadas na Tabela 3.6. As câmeras aéreas utilizam o mesmo sistema de calibração e aquisição de dados apresentado para as câmeras submersas. 
Tabela 3.6 - Propriedades da câmera aérea "Oqus 500" da Qualisys ${ }^{\circledR}$. Fonte: qualisys.com

\begin{tabular}{lr}
\hline Propriedade & Descrição \\
\hline Dimensões & $185 \times 110 \times 124 \mathrm{~mm}$ \\
Peso & $1.9 \mathrm{~kg}$ \\
Alcance & $25 \mathrm{~m}$ \\
Resolução & 4 Megapixel \\
\hline
\end{tabular}

\subsection{Métodos de Análise de Dados}

Nesta seção serão abordados os aspectos gerais relacionadas à análise do dados obtidos no experimento descrito anteriormente. Devido à grande quantidade de casos ensaiados, o principal objetivo da análise é sintetizar os resultados em uma base passível de comparação.

Os sinais obtidos pelo sistema QTM foram analisados utilizando-se de rotinas computacionais desenvolvidas em ambiente MatLab® que dispõe de uma gama diversa de funções adequadas para o tratamento numérico dos resultados do experimento. As funções nativas do MatLab® estão devidamente identificadas no texto através da utilização de fontes do tipo mono espaçadas.

\subsubsection{Método da Decomposição Modal}

Neste texto optou-se por uma análise modal dos resultados obtidos, ou seja, os resultados finais serão comparados em termos dos modos naturais de vibrar do sistema. Para tal, foi necessária realizar algumas mudanças de base nos dados brutos até 0 ponto da obtenção das Amplitudes Modais, $A_{m_{i}}$. De forma a facilitar o entendimento das equações que seguem, a Figura 1.4 apresenta todos os sistemas de coordenadas utilizados.

As componentes locais $\boldsymbol{n}(s), \boldsymbol{b}(s)$ e $\boldsymbol{t}(s)$ são nomeadas como normal, bi-normal e tangencial, respectivamente, e são funções da coordenada curvilínea $s$. A componente $t$ é tangente ao ângulo local $\bar{\theta}(s)$ da linha com a vertical. A componente $n$ está contida no plano $O x z$ (plano da catenária) e forma um ângulo reto com a componente $t$. A componente $\boldsymbol{b}$ é obtida pelo produto vetorial $\boldsymbol{n} \times \boldsymbol{t}$. 


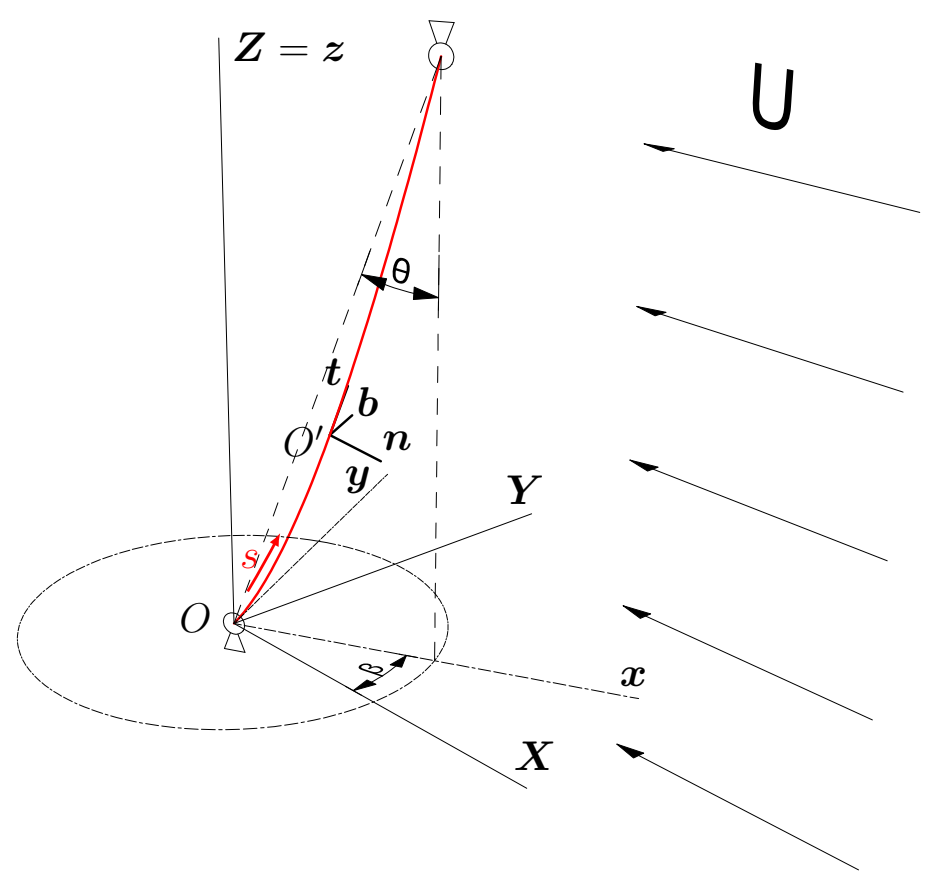

Figura 3.27 - Arranjo esquemático com os sistemas de coordenadas adotados no problema estudado na presente tese.

Os dados brutos das posições dos alvos, obtidos pelo sistema QTM, estão referenciados no sistema global de coordenadas $O X Y Z$. Assim, o primeiro passo é fazer a mudança de base para o sistema $O x y z$. Essa mudança é realizada de acordo com as equação (3.3). Note que esta operação é a rotação das coordenas em relação ao eixo $\overline{O Z}$ de acordo com o ângulo de azimute $\beta$.

$$
\left[\begin{array}{l}
\boldsymbol{x}(s, t) \\
\boldsymbol{y}(s, t) \\
\boldsymbol{z}(s, t)
\end{array}\right]=\left[\begin{array}{ccc}
\cos \beta & \operatorname{sen} \beta & 0 \\
-\operatorname{sen} \beta & \cos \beta & 0 \\
0 & 0 & 1
\end{array}\right]\left[\begin{array}{l}
\boldsymbol{X}(s, t) \\
\boldsymbol{Y}(s, t) \\
\boldsymbol{Z}(s, t)
\end{array}\right]
$$

Em seguida, realiza-se uma segunda operação de rotação, de forma a descrever as posições de acordo com o sistema de Frenet-Serret referenciados como $O^{\prime} n b t$ (eq. 3.4). A componente bi-normal $b$ permanece exatamente igual à componente $y$ que está localizada fora do plano da catenária. Já as componentes $n$ e $t$ são obtidas pela rotação das coordenadas $\boldsymbol{x}$ e $\boldsymbol{y}$ de acordo com o ângulo local da linha ao longo do comprimento em relação à vertical $\bar{\theta}(s)$. 


$$
\left[\begin{array}{l}
\boldsymbol{n}(s, t) \\
\boldsymbol{b}(s, t) \\
\boldsymbol{t}(s, t)
\end{array}\right]=\left[\begin{array}{ccc}
\cos \bar{\theta}(s) & 0 & -\operatorname{sen} \bar{\theta}(s) \\
0 & 1 & 0 \\
\operatorname{sen} \bar{\theta}(s) & 0 & \cos \bar{\theta}(s)
\end{array}\right]\left[\begin{array}{c}
\boldsymbol{x}(s, t) \\
\boldsymbol{y}(s, t) \\
\boldsymbol{z}(s, t)
\end{array}\right]
$$

Definindo $\boldsymbol{q}(s, t)$ como a posição da linha no sistema $O^{\prime} n b t$ na coordenada $s$ e no instante $t$, então:

$$
\boldsymbol{q}(s, t)=[\boldsymbol{n}(s, t), \boldsymbol{b}(s, t), \boldsymbol{t}(s, t)]
$$

e, sendo $\phi_{i}(s)$ a função que descreve o $i$-ésimo modo de vibrar no sistema $O^{\prime} n b t$ :

$$
\phi_{i}(s)=\left[\phi_{n_{i}}(s), \phi_{b_{i}}(s), \phi_{t_{i}}(s)\right]
$$

considerando também a ortogonalidade ${ }^{2}$ entre os modos $i$ e $j$, tal que, $i \neq j$ :

$$
<\phi_{i}(s), \phi_{j}(s)>=0
$$

no qual produto interno de duas funções $u(s)$ e $v(s)$ contínuas em $s \subset[0,1]$ é definido por:

$$
<u(s), v(s)>=\int_{0}^{1} u(s) \cdot v(s) d s
$$

Podemos, então, descrever $\boldsymbol{q}(s, t)$ como:

$$
\boldsymbol{q}(s, t)=\sum_{i=1}^{\infty} A_{m_{i}}(t) \cdot \boldsymbol{\phi}_{i}(s)
$$

onde $A_{m_{i}}$ é calculado para cada instante de tempo, conforme o apresentado em Franzini et al. (2015), como:

$$
A_{m_{i}}(t)=\frac{<\boldsymbol{\phi}_{i}(s), \boldsymbol{q}(s, t)>}{<\boldsymbol{\phi}_{i}(s), \boldsymbol{\phi}_{i}(s)>}
$$

A equação (3.10) pode também ser escrita na sua forma integral:

\footnotetext{
${ }^{2} \mathrm{~A}$ princípio, devido à não-linearidade inerente do problema de linhas flexíveis inclinadas (ver p. ex. Triantafyllou (1984)), os modos naturais podem não ser perfeitamente ortogonais, porém no contexto da presente tese verificou-se que os produtos internos são muito próximos de zero, podendo assim utilizar a relação (3.7) sem nenhum prejuízo.
} 


$$
A_{m_{i}}(t)=\frac{\int_{0}^{1} \boldsymbol{q}(s, t) \cdot \boldsymbol{\phi}_{i}(s) d s}{\int_{0}^{1} \boldsymbol{\phi}_{i}^{2}(s) d s}
$$

Para a obtenção das funções $\boldsymbol{q}(s, t)$, os alvos originais medidos pelo sistema QTM foram interpolados, a cada instante de tempo, utilizando funções cúbicas de forma a facilitar a integração numérica futura. A Figura 3.28 apresenta um exemplo no qual os pontos verdes são as posições dos alvos medidos e a linha vermelha é a linha elástica obtida através da interpolação. Os dados desta figura estão apresentados no sistema Onbt.
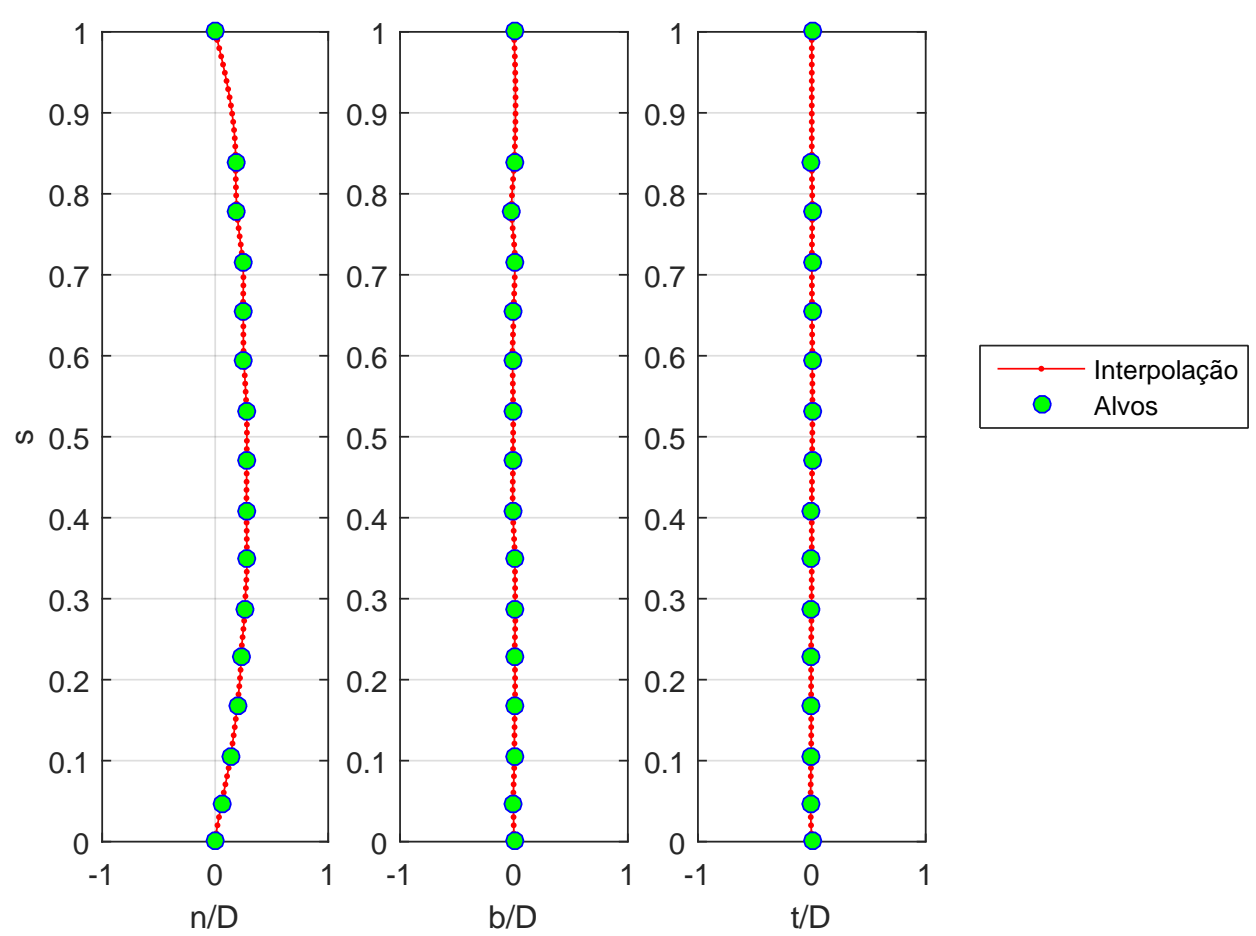

Figura 3.28 - Exemplo de interpolação dos alvos medidos pelo sistema QTM para obtenção da linha elástica do modelo ensaiado.

Após a obtenção da curva acima, a operação (3.4) é realizada de forma a se obter a curva $\boldsymbol{q}(s, t)$. A curva vermelha é interpolada, utilizando-se a função interp1, na mesma discretização da coordenada $s$ das curvas $\phi_{i}$ fornecidas pelo Orcaflex®. A operação (3.10) é realizada numericamente pelo método dos trapézios através da função trapz.

Na Figura 3.29 temos um exemplo de decomposição modal realizada para uma série temporal obtida e tratada conforme o processo descrito acima. No gráfico do lado esquerdo temos a amplitude modal adimensionalizada pelo diâmetro externo do modelo $A_{m_{i}} / D$ para os 10 primeiros modos de vibrar e no gráfico do lado direito temos 0 
Densidade Espectral de Potência, ou Power Spectral Density (PSD) de cada uma das séries temporais de amplitudes. Este último gráfico está adimensionalizado pelo valor do maior espectro que no exemplo abaixo é o do primeiro modo. Os espectros foram avaliados utilizando-se a função pwelch.
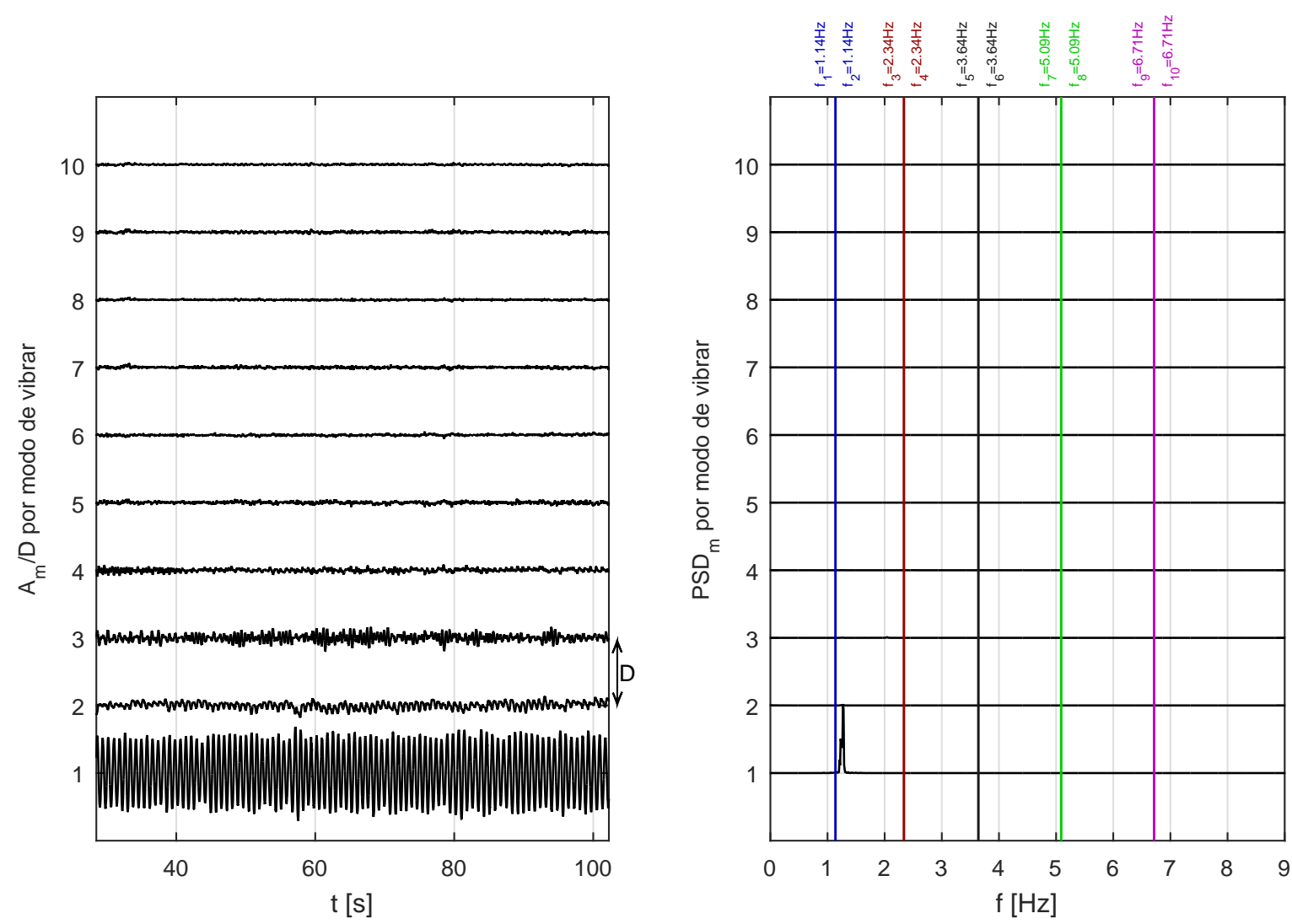

Figura 3.29 - Exemplo de análise de decomposição modal

As linhas coloridas verticais apresentam as frequências naturais calculadas utilizando - Orcaflex®. As cores adotadas para cada frequência são iguais as apresentadas na Figura 3.32 e serão mantidas em todos os gráficos para identificação visual da sequência dos modos naturais.

O procedimento acima foi realizado tanto para as séries temporais de decaimento como para as séries temporais de VIV.

\subsubsection{Avaliação das amplitudes e frequências}

Existem diversas medidas estatísticas que podem ser utilizadas para caracterizar o comportamento oscilatório de sistemas dinâmicos. Classicamente, nos estudos de VIV, as amplitudes são caracterizadas pela:

1. média dos eventos extremos 
2. média dos $10 \%$ maiores eventos extremos

3. pelo cálculo do desvio padrão $(\sigma)$ multiplicado por $\sqrt{2}$

No caso da presente análise estes valores são calculados para cada uma das curvas $A_{m_{i}}(t) / D$ conforme apresentado acima na Figura 3.29. Lembrando que $A_{m_{i}}(t) / D$ possui média nula e $t$ é discreto, os itens 1 e 2 são avaliados de acordo com o seguinte procedimento:

a) Identificação dos zeros ascendentes (posições $t_{k}$ que satisfazem $t_{k} \cdot t_{k+1}<0 \mathrm{e}$ $\left.t_{k}<0\right)$

b) Identificação dos máximos e mínimos no intervalo entre dois zeros ascendentes consecutivos

c) Identificação dos $10 \%$ maiores extremos considerando o valor absoluto de máximos e mínimos

Já o item 3 é calculado pela expressão (3.12) e em seguida multiplicado por $\sqrt{2}$.

$$
\sigma=\sqrt{\frac{\sum_{t=t_{0}}^{t_{f}}\left(A_{m_{i}}(t) / D\right)^{2}}{N_{t}-1}}
$$

onte $t_{0}$ é o instante de tempo inicial, $t_{f}$ é o instante final e $N_{t}$ é o número de amostras de tempo entre $t_{0}$ e $t_{f}$.

Abaixo na Figura 3.30 temos um exemplo da avaliação das amplitudes para um sinal do $1^{\circ} \mathcal{M}$ obtido em um dos ensaios de VIV. Neste gráfico são apresentados o sinal, a identificação dos zeros ascendentes, dos extremos e dos $10 \%$ maiores extremos. As retas azul e magenta representam as médias destes pontos, respectivamente. A reta verde representa o valor calculado a partir do desvio padrão. $O$ sinal na parte inferior é apenas um recorte dos 8 primeiros segundos do sinal apresentado com o intuito de facilitar a visualização dos pontos identificados. 

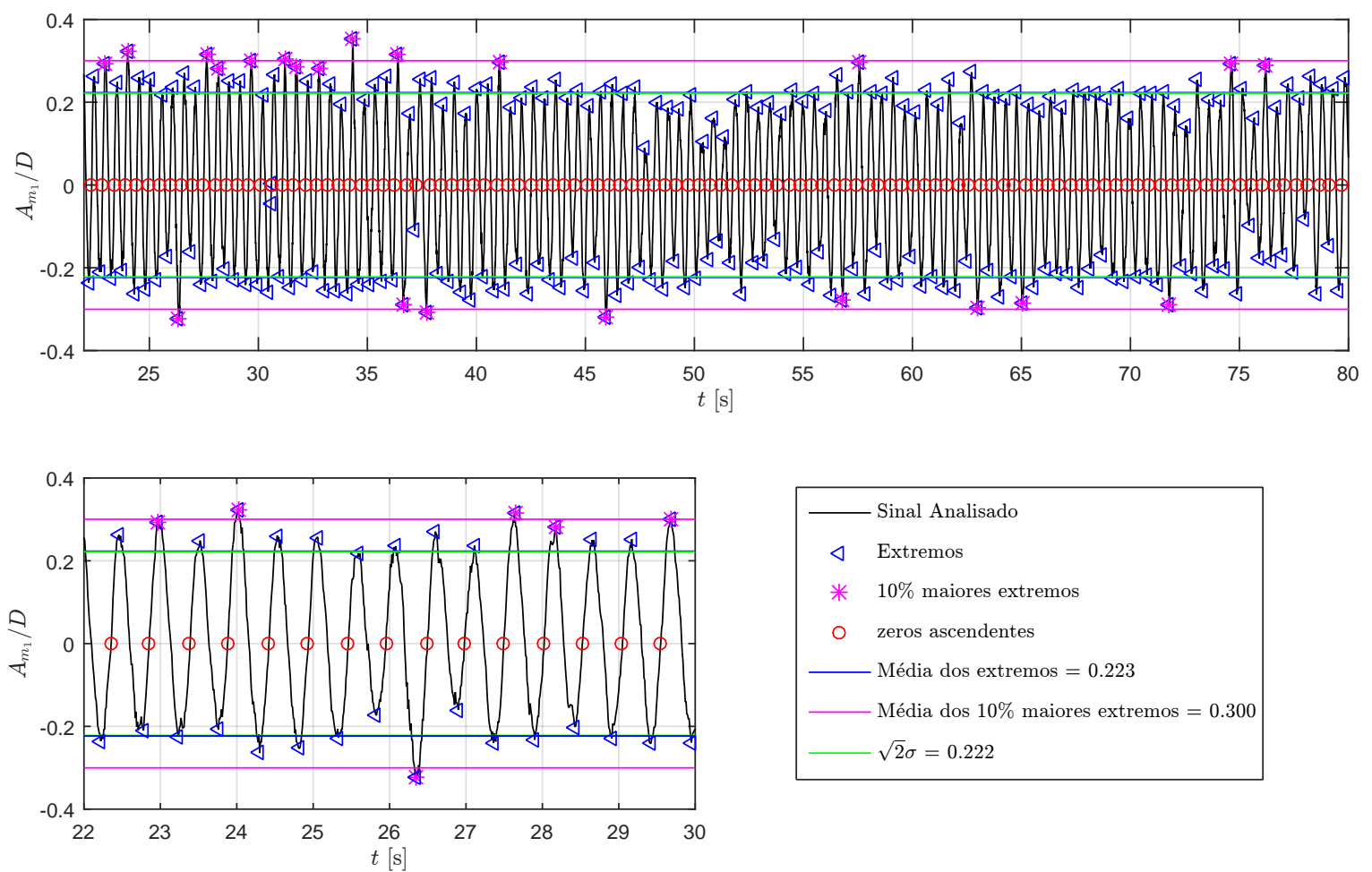

Figura 3.30 - Exemplo da avaliação das amplitudes para um sinal do $1^{\circ} \mathcal{M}$ obtido em um ensaio de VIV.

Os valores de amplitude apontados acima mostram como a utilização de cada um dos métodos de avaliação podem resultar em valores bem diferenciados. Ao passo que a média dos extremos e $\sqrt{2} \sigma$ se aproximam muito bem, apenas com a média dos $10 \%$ se tem uma ideia real da amplitude máxima que o fenômeno de VIV pode excitar o modelo.

Deste modo, os resultados no próximo capítulo serão apresentados em termos destes três métodos de análise de sinal.

\subsubsection{Cálculo da Velocidade Reduzida}

Do PI apresentado anteriormente, na seção 2.3, temos que o comportamento vibratório dos cilindros sujeitos à correnteza depende apenas da componente de velocidade normal, ou seja, a parcela da velocidade que está tangente ao cilindro não tem impacto na amplitude de vibração. Logo não deve ser levado em conta na avaliação da velocidade reduzida.

Neste experimento, um dos pontos centrais do estudo é a mudança do ângulo de azimute do cilindro flexível. Conforme se altera o azimute da linha para ângulos $\beta=45^{\circ}$ e $\beta=135^{\circ}$, além da componente normal, há também uma componente da velocidade na direção binormal. No caso especial $\beta=90^{\circ}$ temos que a velocidade normal é nula, 
só restando a componente bi-normal. Este fato implica em uma escolha adequada da base de comparação para o cálculo da velocidade reduzida.

Adotando-se novamente as coordenadas da Figura 3.27, a velocidade reduzida será sempre calculada de acordo com o ângulo da reta que liga as duas extremidades, ou seja, de acordo $\operatorname{com} \theta$. Assim as operações (3.3) e (3.4) podem ser usadas novamente para o cálculo da velocidade na base $O^{\prime} n b t$.

Dado que a velocidade no sistema $O X Y Z$ é $U_{X Y Z}=[-U, 0,0]$, podemos então escrever:

$$
U_{n b t}=[-U \cdot \cos \beta \cos \theta, U \cdot \operatorname{sen} \beta,-U \cdot \cos \beta \sin \theta]
$$

Como esperado, das aplicações das operações mencionadas surgiram componentes de velocidade em todas coordenadas do sistema $O^{\prime} n b t$. Definindo neste ponto $V r_{i}$ que é a velocidade reduzida do modo $i$, temos que $V r_{i}=V r_{i}(\beta, \theta)$.

Desta forma, para $\beta=0^{\circ} \mathrm{e} \beta=180^{\circ}$, temos:

$$
V r_{i}=\frac{U \cdot \cos \theta}{f_{n_{i}} \cdot D}
$$

para $\beta=45^{\circ}$ e $\beta=135^{\circ}$, temos:

$$
\begin{gathered}
V r_{i}=\frac{U \cdot \cos \beta \cos \theta}{f_{n_{i}} \cdot D} \text { para modos ímpares } \\
V r_{i}=\frac{U \cdot \sin \beta}{f_{n_{i}} \cdot D} \text { para modos pares }
\end{gathered}
$$

e, finalmente, para $\beta=90^{\circ}$, temos:

$$
V r_{i}=\frac{U}{f_{n_{i}} \cdot D}
$$

Essas fórmulas fecham, então, uma base de cálculo para a velocidade reduzida assumindo que o Princípio da Independência, além de válido para inclinações no plano da correnteza, seja válido também para os casos onde há inclinação fora do plano, ou seja, quando há mudança de azimute.

Importante notar que a definição das equações (3.15) e (3.16) só é possível porque, no caso do presente experimento, os modos de vibrar fora do plano de inclinação e os modos contidos no plano de inclinação estão ordenados sempre de forma intercalada, sendo possível a separação em modos ímpares e modos pares, respectivamente; 
como será visto na próxima seção.

A ideia de se obter essa base de cálculo é verificar a compatibilidade dos resultados experimentais entre os diversos ângulos e assim verificar a veracidade da hipótese feita acima para as configurações ensaiadas no presente trabalho.

\subsection{Métodos Numéricos}

Para a determinação dos modos de vibrar do modelo nas suas diversas configurações foi utilizado o programa OrcaFlex® da empresa Orcina. Este programa permite, entre diversas outras aplicações, a modelagem estática e dinâmica de risers e linhas de ancoragem, considerando os diversos esforços presentes devido a correnteza, ondas, movimento da embarcação, interação com o solo, etc.

A modelagem da linha é realizada através do Método dos Elementos Finitos (MEF), no qual a linha é discretizada em elementos de viga. O presente texto não tem o intuito de se aprofundar no equacionamento e considerações do método, visto que o programa é amplamente utilizado por grandes empresas da indústria naval e offshore e já foi testado e validado em diversos sentidos como os exemplos apresentados em Quiggin (2015). Desta forma para o leitor que deseja se aprofundar no MEF é fortemente sugerida a leitura de Bathe (1996).

Para a configuração do modelo numérico de cilindro flexível com as mesmas características do modelo em escala descrito na seção 3.1.1 é preciso fornecer ao programa as seguintes informações:

- $\gamma$ - peso linear no ar.

- EA - Rigidez Axial

- EI - Rigidez Flexional

- $\left(x_{0}, y_{0}, z_{0}\right)$ - Coordenadas da âncora

- $\left(x_{\text {topo }}, y_{\text {topo }}, z_{\text {topo }}\right)$ - Coordenadas do topo

- $L_{0}$ - Comprimento indeformado da linha

- $h$ - Profundidade da Lâmina D’água (LDA)

- $N$ - Número de elementos utilizados para a discretização da linha

A partir das informações acima listadas o programa executa a análise estática da linha que tem como principais resultados: 
- $T_{0}$ - Tração axial na âncora

- $T_{\text {topo }}$ - Tração axial no topo

- $(\boldsymbol{x}(s), \boldsymbol{y}(s), \boldsymbol{z}(s))$ - Configuração estática

A Figura 3.31 apresenta a definição dos parâmetros geométricos utilizados no modelo do Orcaflex para a obtenção da configuração estática da linha. Para a obtenção destas configurações foram utilizados $N=100$ elementos.

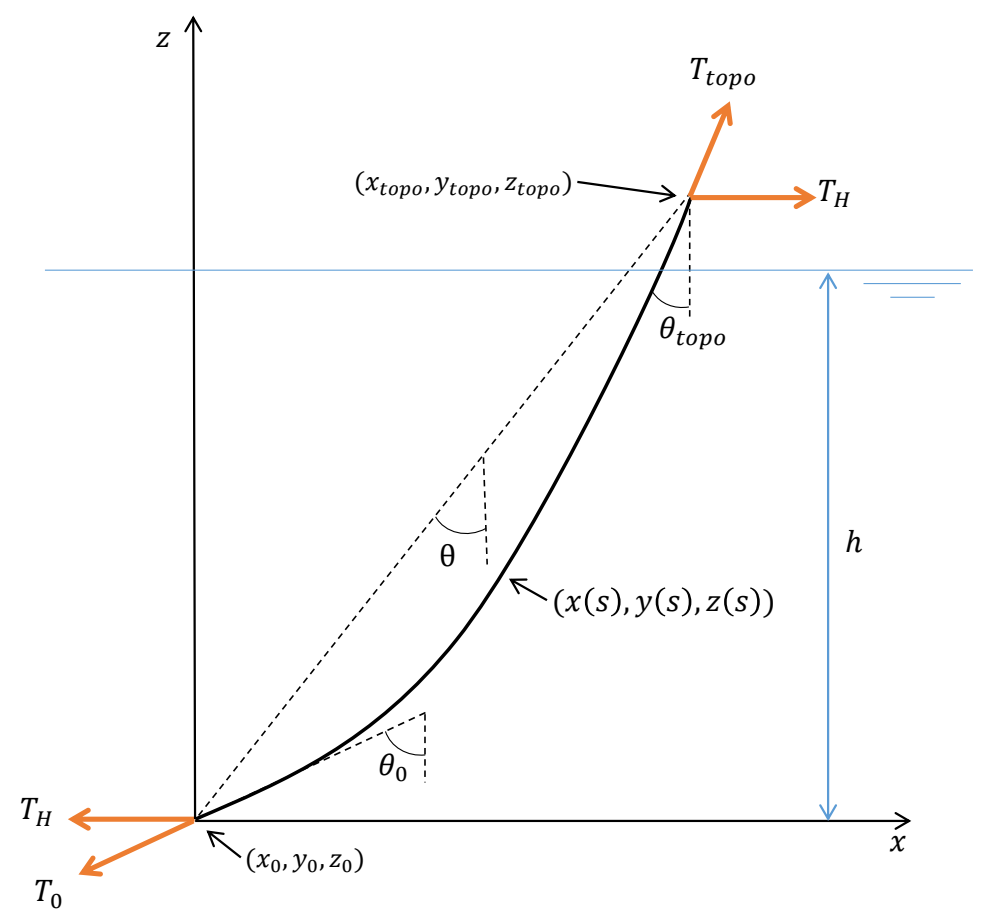

Figura 3.31 - Definição dos parâmetros utilizados no modelo numérico do Orcaflex.

Estes valores são então utilizados no módulo de análise modal para a obtenção das frequências naturais e dos modos de vibrar. Na Figura 3.32 é apresentado um exemplo de análise modal de uma linha inclinada, onde é possível visualizar sua configuração estática e o respectivo modo de vibrar selecionado. 


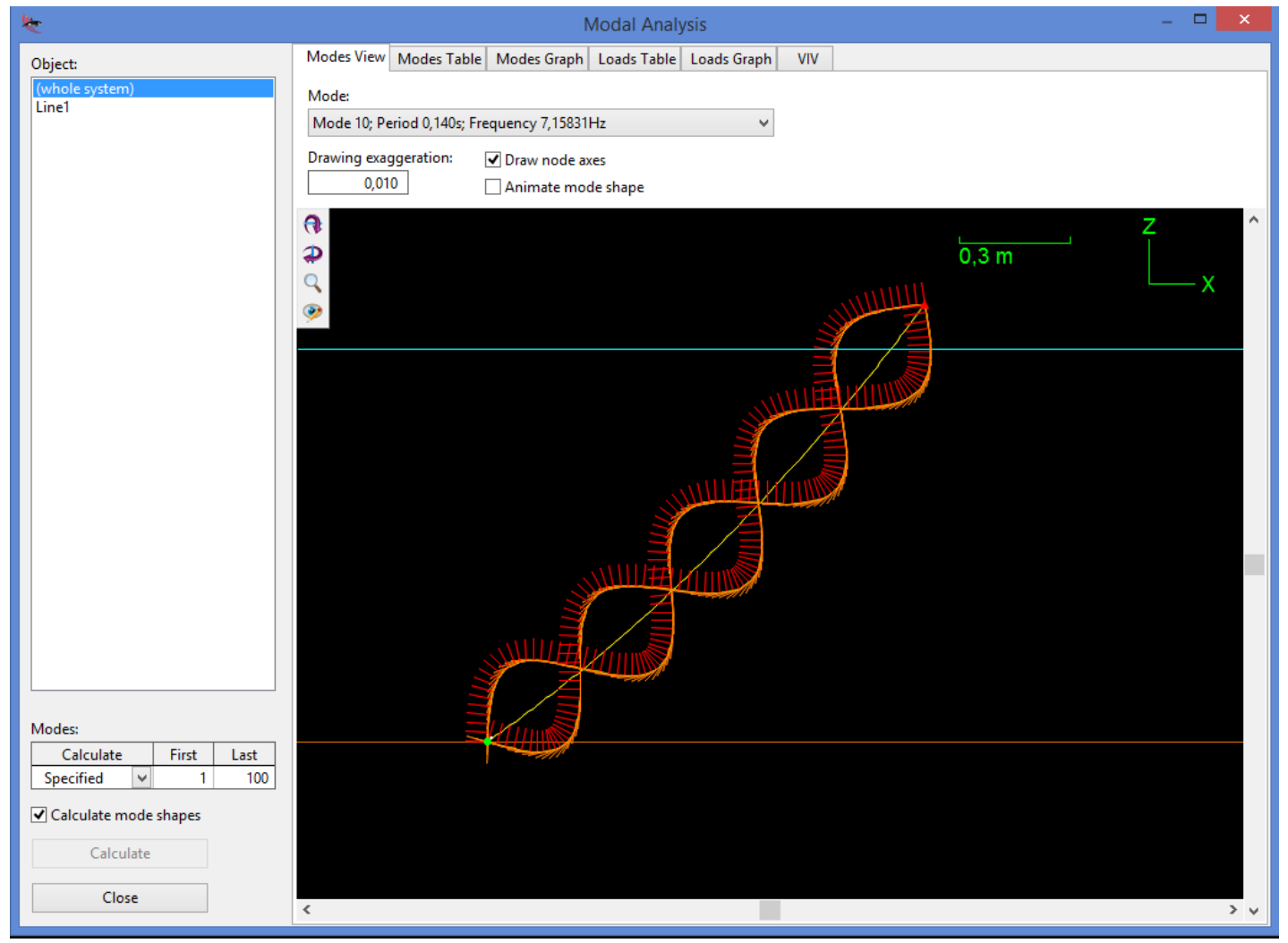

Figura 3.32 - Exemplo de análise modal de linha inclinada realizada no OrcaFlex®.

Os modelos desenvolvidos nesta seção foram utilizados tanto para caracterizar a configuração estática, as frequências naturais e os modos naturais do modelo para as configurações em ar como para as configurações submersas em água. Os parâmetros principais para definição dos modelos, assim como as curvas características de cada modo natural são apresentadas a seguir.

Os valores apresentados nestas seções foram obtidos iterativamente. Primeiro realizouse uma avaliação prévia das frequências naturais dos modos desejados e com isso foi possível a realização da montagem e calibração do modelo experimental. Após a montagem e a realização dos ensaios de decaimento (que serão detalhados na seção 3.4.1), os dados colhidos (trações e frequências) foram utilizados novamente no Orcaflex® para a obtenção do modelo numérico "as-built".

\subsubsection{Configurações em ar}

A Tabela 3.7 apresenta os principais parâmetros obtidos para o modelo lançado em ar. A visualização das curvas $(\boldsymbol{x}(s), \boldsymbol{y}(s), \boldsymbol{z}(s))$ pode ser realizada no gráfico (a) da Figura 3.33. As linhas pretas representam a configuração estática obtida através do Orcaflex® e os pontos vermelhos representam os alvos medidos pelo sistema QTM conforme o explicado na seção 3.1.5. Como pode ser observado, as curvas modela- 
das estão bem coerentes com as posições do modelo instalado.

No gráfico (b) são apresentados os ângulos locais $\bar{\theta}(s)$ de acordo com a coordenada local. Estes ângulos são apresentados de forma a se ter uma ideia de quanto o modelo real se distancia da linha reta. Como apresentado no início deste capítulo, é premissa do ensaio que as linhas não se distanciem mais do que $10^{\circ}$ da linha média, o que não ocorreu para nenhum caso.

Tabela 3.7- Resumo dos parâmetros das configurações estáticas do modelo lançado em ar.

\begin{tabular}{cccccc}
\hline$\theta\left[^{\circ}\right]$ & $T_{\text {topo }}[\mathrm{N}]$ & $\theta_{\text {topo }}\left[{ }^{\circ}\right]$ & $T_{0}[\mathrm{~N}]$ & $\theta_{0}\left[^{\circ}\right]$ & $T_{H}[\mathrm{~N}]$ \\
\hline 0 & 41.22 & 0.0 & 22.98 & 0.0 & 0.00 \\
10 & 40.98 & 7.6 & 23.02 & 13.4 & 5.41 \\
20 & 41.99 & 15.6 & 24.87 & 24.2 & 11.13 \\
30 & 41.95 & 23.6 & 26.18 & 36.1 & 16.57 \\
45 & 40.19 & 35.6 & 27.31 & 54.4 & 23.12 \\
\hline
\end{tabular}

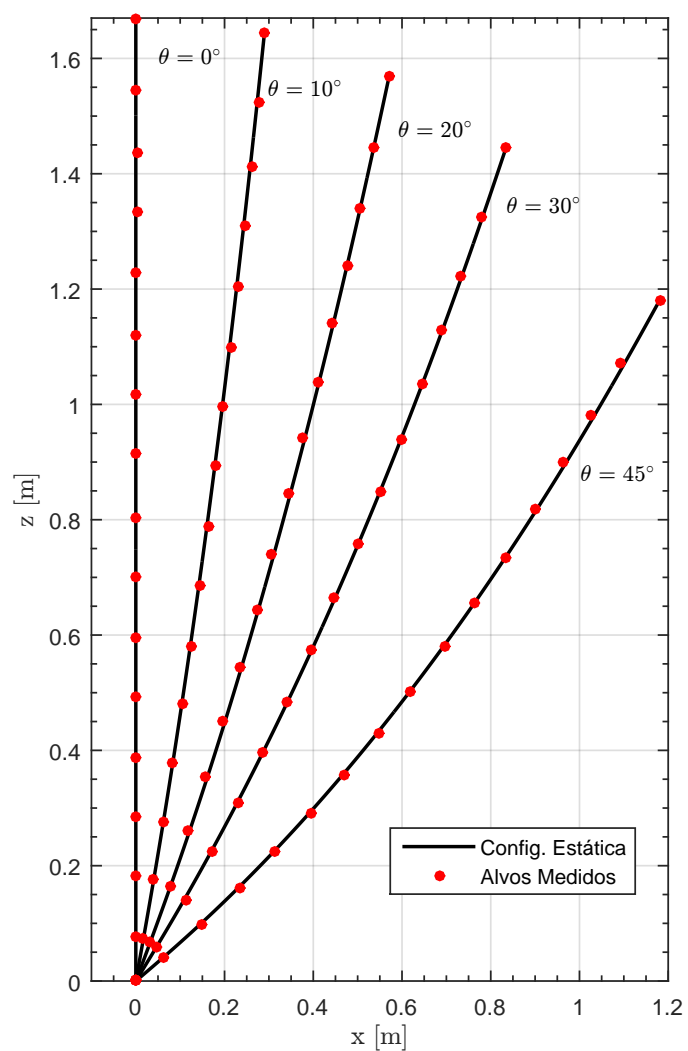

(a)

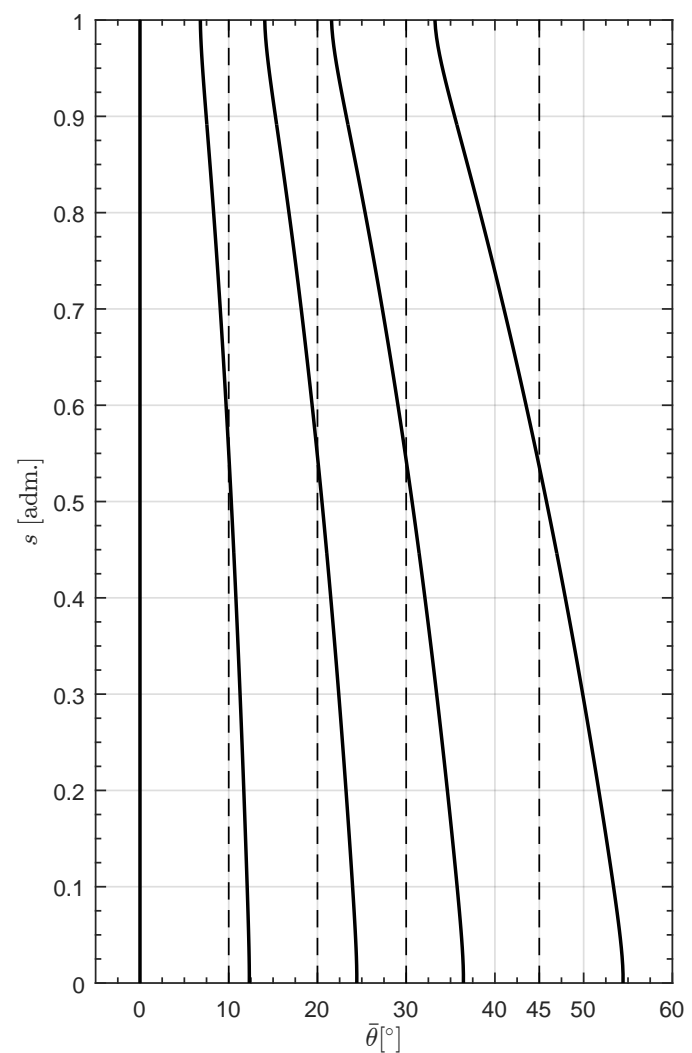

(b)

Figura 3.33 - Configurações estáticas do modelo lançado em ar. 
Na Figura 3.34 são apresentadas as avaliações dos dez primeiros modos de vibrar do modelo estudado na inclinação de referência $\theta=0^{\circ}$. Nesta figura são apresentadas as frequências naturais obtidas $\left(f_{n_{i}}^{a r}\right)$ bem como a descrição das funções $\phi_{i}$ através do gráfico das componentes normal $(n)$, bi-normal $(b)$ e tangencial $(t)$ também em função da coordenada $s$.

Para as inclinações $\theta>0$ a direção dos vetores normais está sempre contida no plano da catenária, independente do ângulo de azimute. Nestes casos os modos transversais (modos ímpares) estão identificados com o marcador $(x)$ e os modos no plano da catenárias (modos pares) estão identificados com o marcador (o). Os gráficos para estes modos estão apresentados no Apêndice B.1
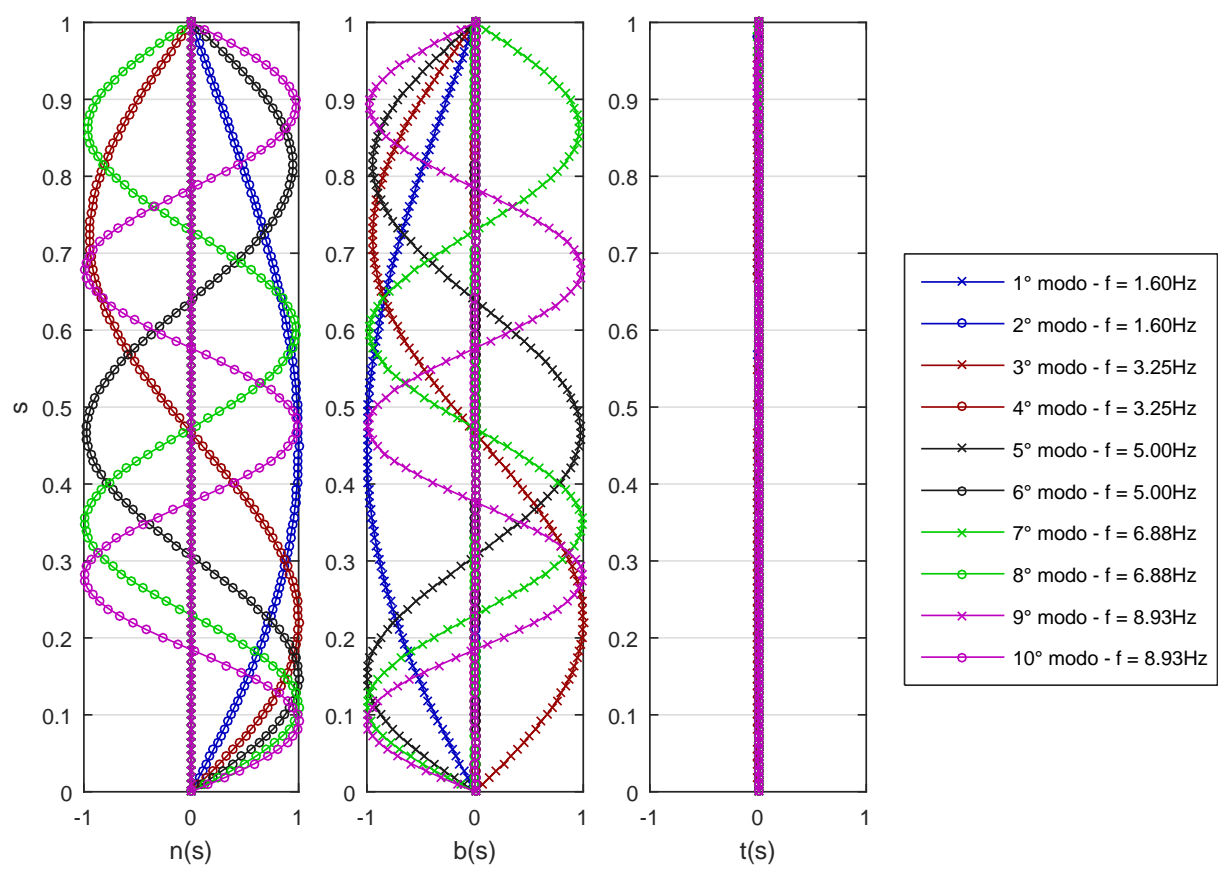

Figura 3.34 - Componentes locais dos modos de vibrar do modelo em ar - Inclin. $\theta=0$ graus.

\subsubsection{Configurações submersas em água}

Na Tabela 3.8 estão apresentados os resultados obtidos para a configuração estática da linha ensaiada quando submersa em água. A definição do parâmetro $h$ (profundidade da LDA para cada configuração) se faz necessária pois, devido às limitações dos equipamentos, não é possível manter a linha completamente submersa. A consideração da massa adicional e o cálculo dos coeficientes de força são realizados apenas no comprimento submerso da linha, conforme as formulações apresentadas anteriormente na Tabela 2.2. 
Tabela 3.8-Resumo dos parâmetros de configurações estáticas do modelo submerso em água.

\begin{tabular}{ccccccc}
\hline$\theta\left[{ }^{\circ}\right]$ & $h[\mathrm{~m}]$ & $T_{\text {topo }}[\mathrm{N}]$ & $\theta_{\text {topo }}\left[^{\circ}\right]$ & $T_{0}[\mathrm{~N}]$ & $\theta_{0}\left[^{\circ}\right]$ & $T_{H}[\mathrm{~N}]$ \\
\hline 0 & 1.50 & 28.5 & 0.0 & 16.2 & 0.0 & 0.0 \\
10 & 1.48 & 25.9 & 7.4 & 13.7 & 13.4 & 3.3 \\
20 & 1.41 & 35.3 & 16.4 & 23.7 & 24.2 & 9.8 \\
30 & 1.30 & 34.7 & 24.7 & 24.1 & 36.1 & 14.3 \\
45 & 1.06 & 31.3 & 36.8 & 22.6 & 54.4 & 18.4 \\
\hline
\end{tabular}

A Figura 3.35 apresenta, assim como para as configurações em ar, a configuração estática obtida para cada um dos ângulos de inclinação $\theta$ quando o modelo está submerso em água. No gráfico (a), além das coordenadas $(\boldsymbol{x}(s), \boldsymbol{y}(s), \boldsymbol{z}(s))$, é apresentada uma linha azul que representa o profundidade $h$ adotada em cada configuração. No gráfico (b) são apresentadas as curvas do ângulo local da linha em relação a vertical $(\bar{\theta})$ em função da coordenada curvilínea $s$.

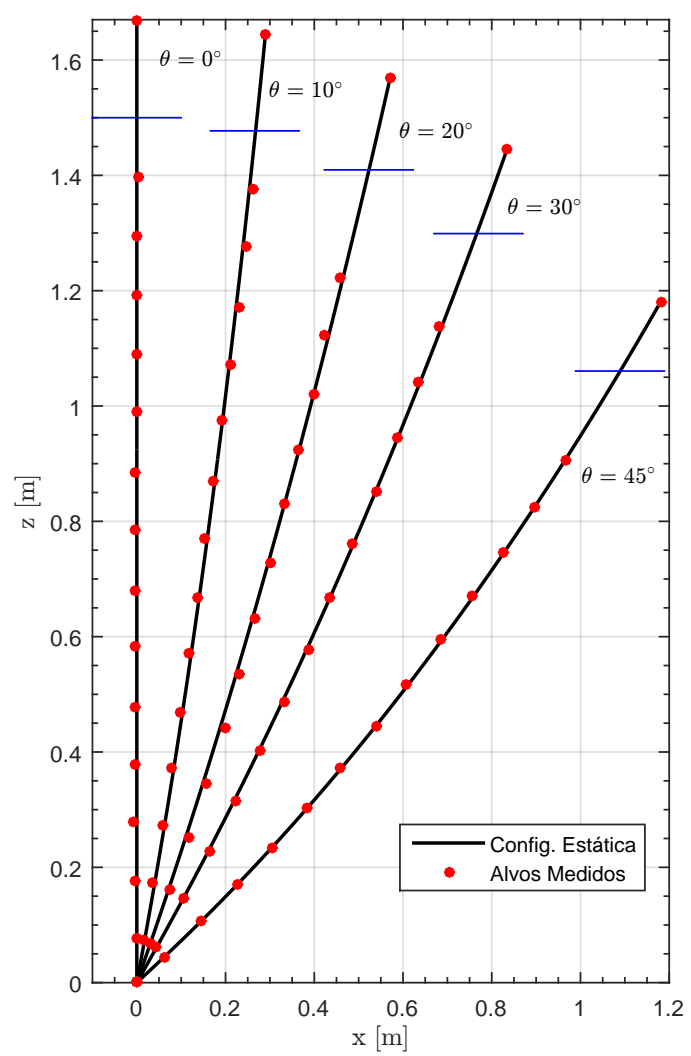

(a)

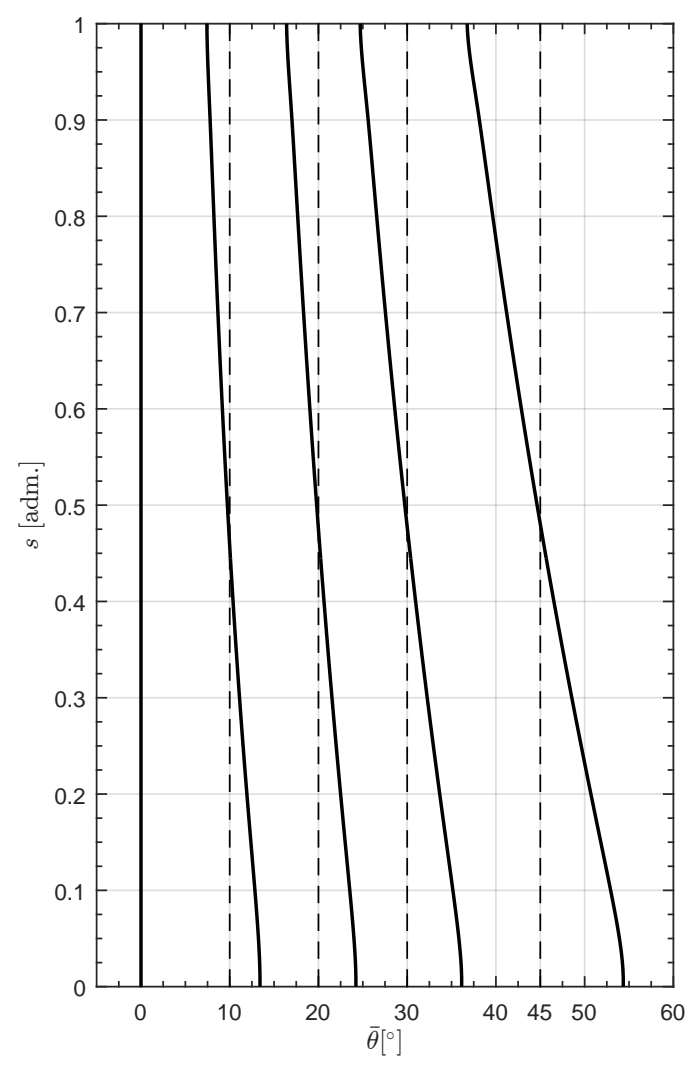

(b)

Figura 3.35 - Configurações estáticas do modelo submerso em água. 
Os modos de vibrar foram igualmente avaliados e suas curvas são mostradas em detalhe no Apêndice B.2.

\subsection{Métodos Experimentais}

\subsubsection{Ensaio de Decaimento}

O ensaio de decaimento compõe parte dos ensaios de caracterização do modelo e tem como principais objetivos a obtenção das frequências naturais $\left(f_{n_{i}}\right)$ e os coeficientes de amortecimento $(\zeta)$. O procedimento consiste basicamente em mover os sistema do equilíbrio e medir o seu comportamento ao ser liberado para retornar à posição de equilíbrio.

Em sistemas como os estudados neste trabalho, geralmente o amortecimento é do tipo sub-crítico, isto é, o sistema oscila várias vezes no entorno da posição de equilíbrio até alcançá-la novamente.

Na Figura 3.36 é apresentada uma curva típica obtida a partir de um ensaio de decaimento.
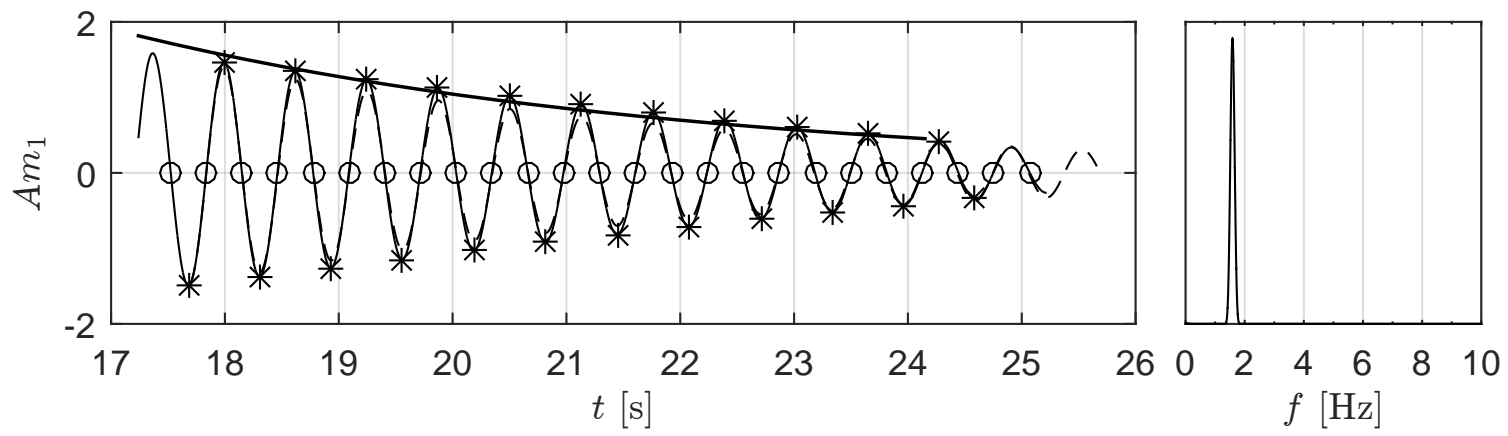

$$
\begin{aligned}
& - \text { Sinal } \\
& - \text { Simulado com } \zeta_{\mathrm{s}}=2.0 \% \mathrm{f}_{\mathrm{n}}=1.59 \mathrm{~Hz} \\
& \hline \text { Envoltória } \mathrm{e}^{\left(-\zeta_{\mathrm{s}} \omega_{\mathrm{n}} \mathrm{t}\right)} \operatorname{com} \zeta_{\mathrm{s}}=2.0 \% \\
& \text { * } \quad \text { Zeros } \\
&
\end{aligned}
$$

Figura 3.36 - Série temporal típica de uma análise de decaimento.

Para a idealização de um sistema linear com um único grau de liberdade (modelo vibrando em um único modo), pode-se obter o amortecimento a partir do cálculo dos decrementos logarítmicos $(\delta)$ dos pontos provenientes de máximos e mínimos de cada ciclo do sinal. O decremento logarítmico entre $n$ extremos consecutivos é dado por: 


$$
\delta=\frac{1}{n} \ln \left|\frac{A_{k}}{A_{k+n}}\right|
$$

sendo $A_{k}$ e $A_{k+n}$ os valores da amplitude de $n$ eventos extremos consecutivos.

Calculado o decremento, o amortecimento linear do sistema $\left(\zeta_{s}\right)^{3}$ é dado, segundo França \& Sotelo Jr. (2006), por:

$$
\zeta_{s}=\frac{\delta}{\sqrt{\pi^{2}+\delta^{2}}}
$$

Realizando o ajuste de uma curva exponencial do tipo $e^{-\zeta \omega_{n} t}$ nos pontos de máximos, através do Método dos Mínimos Quadrados (MMQ), obtém-se uma aproximação para o parâmetro $\zeta_{s} \omega_{n}$ que por consequência nos leva ao valor da frequência natural $\left(f_{n}\right)$ do sistema. Sendo que:

$$
f_{n}=\frac{\omega_{n}}{2 \pi}
$$

Este valor pode ser confirmado realizando uma análise de Fourier (Figura 3.36 (esq.)) no sinal do decaimento e obter o valor $\omega_{d}$ que é a frequência natural amortecida. Este valor se relaciona a frequência natural não-amortecida pela seguinte fórmula:

$$
\omega_{d}=\omega_{n} \sqrt{1-\zeta_{s}^{2}}
$$

Numa abordagem mais voltada ao estudo de VIV, como a utilizada em Khalak \& Williamson (1999), o valor de amortecimento $(\zeta)$ é avaliado conforme o apresentado anteriormente na Tabela 2.2, ou seja:

$$
\zeta=\frac{c}{2 \sqrt{k\left(m+m_{a}^{P O T}\right)}}
$$

Considerando que o coeficiente de amortecimento $\left(\zeta_{s}\right)$, calculado pelo método acima, não considera a adimensionalização pela massa adicional, ou seja:

$$
\zeta_{s}=\frac{c}{2 \sqrt{k m}}
$$

e que o parâmetro de massa reduzida é:

\footnotetext{
${ }^{3}$ Há uma diferença entre autores neste quesito, sendo que alguns definem o decremento logarítmico como a diferença do módulo das amplitudes entre $n$ máximos ou mínimos consecutivos e deste modo a equação (3.19) ficaria $\zeta_{s}=\delta / \sqrt{(2 \pi)^{2}+\delta^{2}}$
} 


$$
m^{*}=\frac{m}{\pi \rho_{f} D^{2} / 4}
$$

e o coeficiente de massa adicional potencial $\left(C_{a}^{P O T}\right)$, tal que:

$$
m_{a}^{P O T}=C_{a}^{P O T} \cdot \pi \rho_{f} D^{2} / 4
$$

a razão $\zeta / \zeta_{s}$ fica:

$$
\frac{\zeta}{\zeta_{s}}=\frac{\frac{c}{2 \sqrt{k\left(m+m_{a}^{P O T}\right)}}}{\frac{c}{2 \sqrt{k m}}}
$$

logo:

$$
\zeta=\zeta_{s} \cdot \sqrt{\frac{m^{*}}{m^{*}+C_{a}^{P O T}}}
$$

Desta forma é obtido o coeficiente de amortecimento ( $\zeta$ ), conforme o descrito em Khalak \& Williamson (1999). Para os casos estudados neste trabalho, utilizaremos sempre o valor clássico para o coeficiente de massa adicional potencial de um cilindro oscilando em pequenas amplitudes na ausência de escoamento, $C_{a}^{P O T}=1$.

Desta forma possível é possível avaliar o parâmetro $\alpha$ tal que:

$$
\alpha=\left(m^{*}+C_{a}^{P O T}\right) \zeta
$$

Como comentado anteriormente na seção 2.2, esse parâmetro está diretamente relacionado à previsão da amplitude máxima de resposta de VIV dos sistemas.

Cumpre dizer que os valores de $\zeta_{s}$ e $\zeta$ acima são obtidos com ensaios de decaimento realizados no ar. Quando o ensaio é realizado no ar o amortecimento obtido do ensaio é praticamente todo devido ao amortecimento interno da estrutura, uma vez que a resistência do ar fornece uma parcela praticamente desprezível para as velocidades de vibração do modelo. A Figura 3.37 apresenta uma foto do modelo posicionado no local onde foram realizados os ensaios de decaimento no ar. 

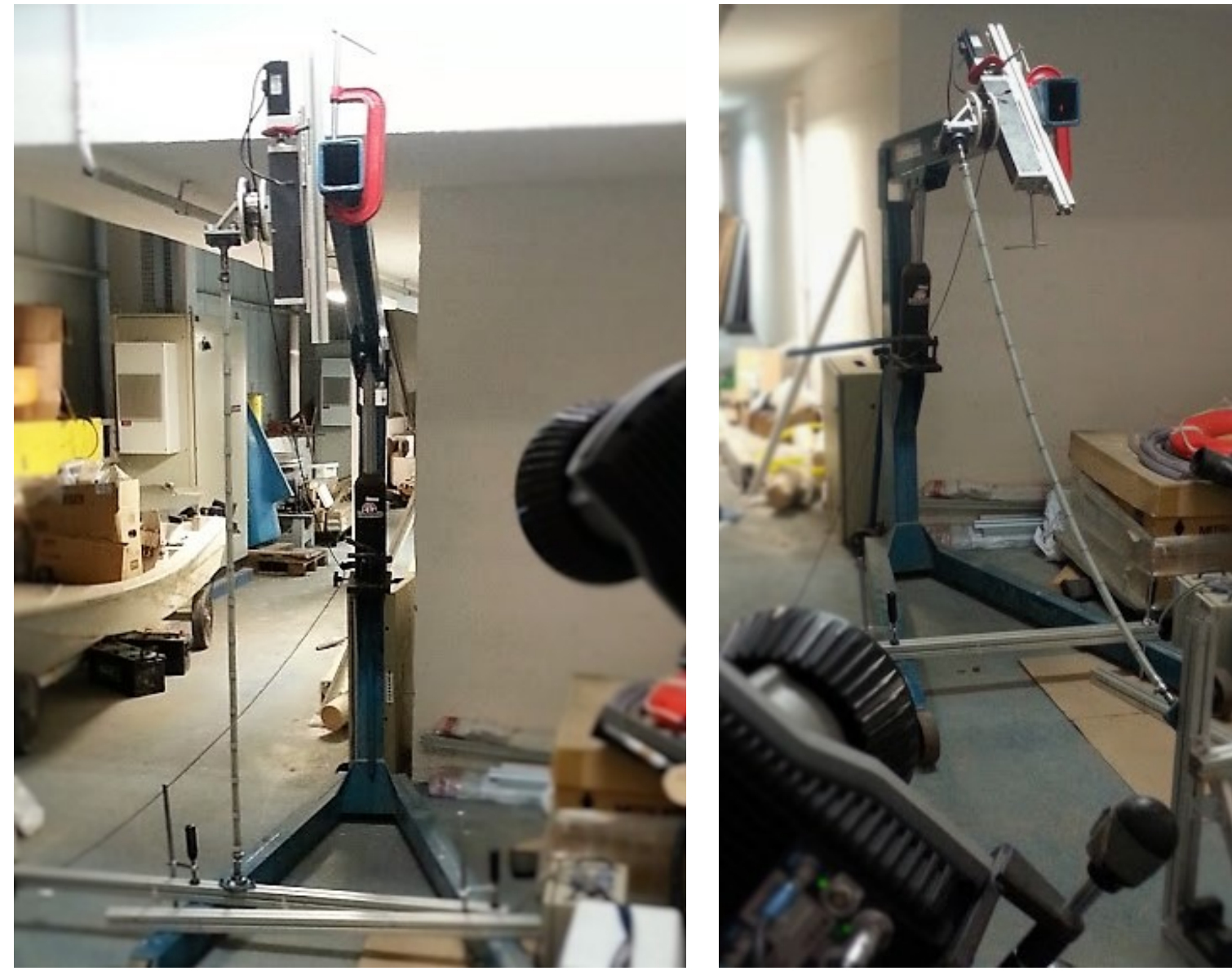

Figura 3.37 - Instalação em ar do modelo flexível para realização dos ensaios de decaimento - (Esq.) $\theta=0^{\circ}$, (Dir.) $\theta=45^{\circ}$.

Ensaios de decaimento com o modelo em água (Figura 3.38) devem ser realizados principalmente com o intuito de se obter as frequências naturais do maior número possível de modos de vibrar.

Nos ensaios de decaimento será empregado o método da decomposição modal como detalhado na seção 3.2.1, porém um detalhe com relação à determinação das frequências naturais de cada um dos modos de vibrar. Na Figura 3.39 são apresentados dois gráficos contendo a análise de Fourier dos mesmos sinais de amplitudes modais obtidos a partir de um ensaio de decaimento. O gráfico (a) foi obtido a partir da análise direta dos sinais, sem nenhum tipo de manipulação. Como é possível observar, em todos os modos aparecem um pico evidente no entanto somente até o quarto modo os picos estão próximos das frequências estimadas através do modelo numérico. No entanto para outros modos como, por exemplo para o sexto modo, é possível notar picos menores. 


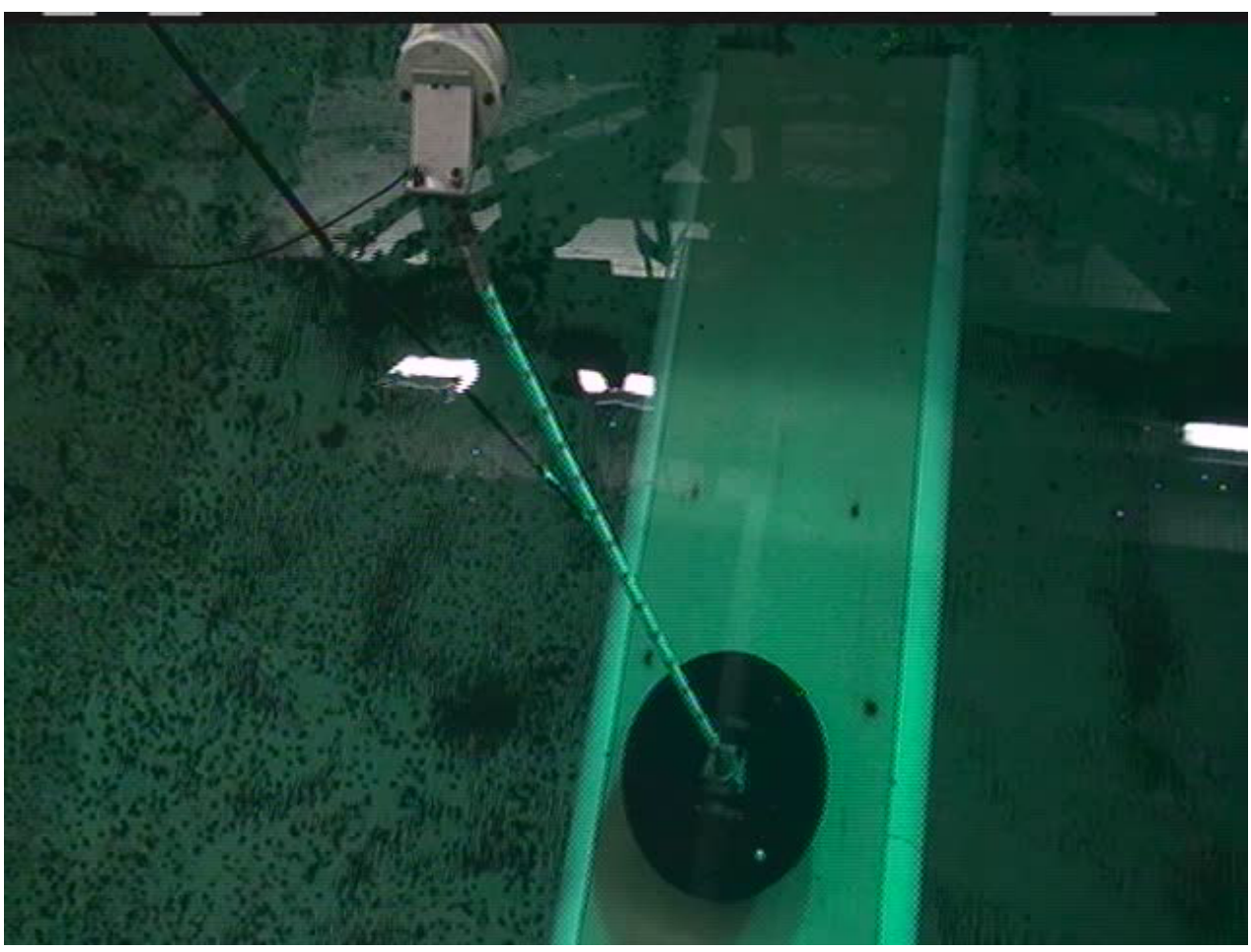

Figura 3.38 - Realização do ensaio de decaimento em água - $\theta=0^{\circ}$ - Repetição 01

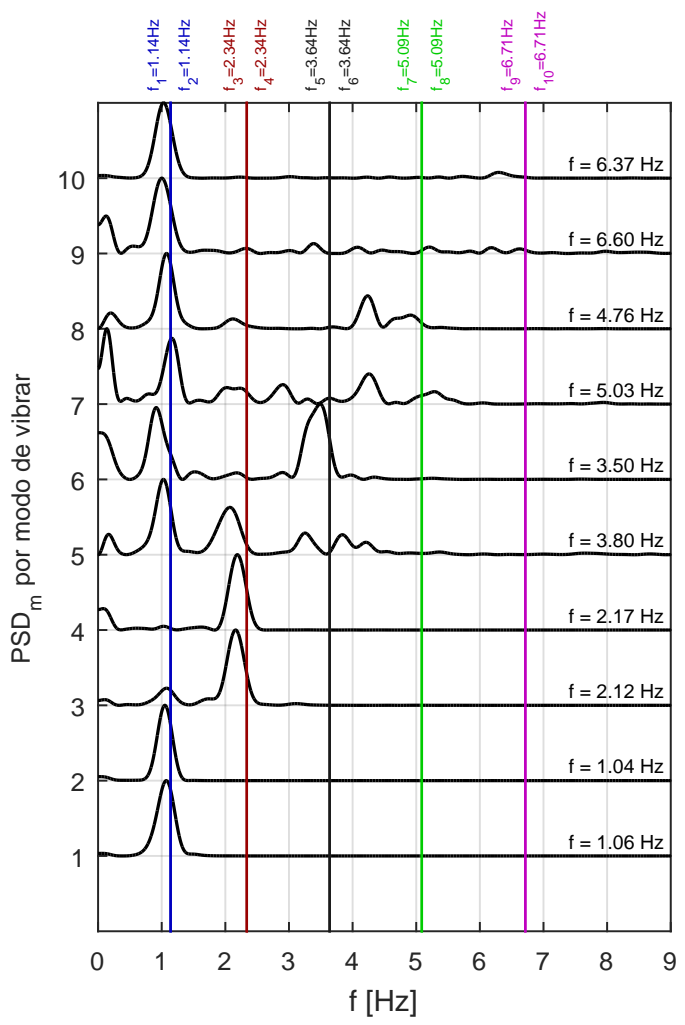

(a)

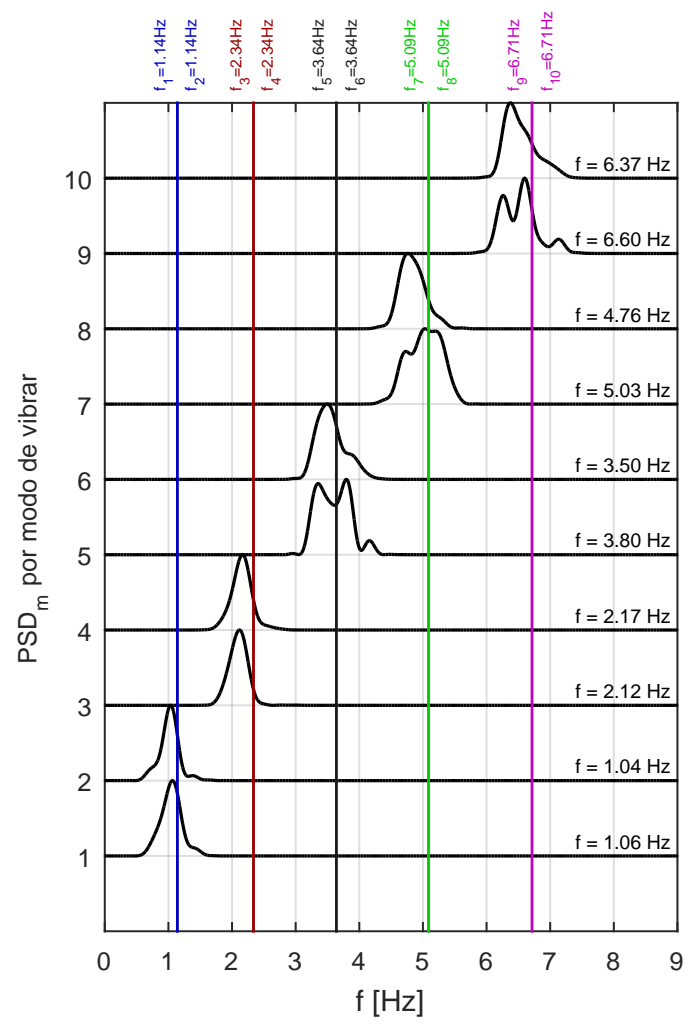

(b)

Figura 3.39 - Análise de Fourier para os sinais calculado a partir das amplitudes modais obtidas em ensaio de decaimento: (a) Sinal Original; (b) Sinal Filtrado. 
Devido a este comportamento, foi obtido o gráfico (b) filtrando, para os modos a partir do terceiro, as frequências distantes daquelas estimadas pelo modelo numérico. Com isso os picos menores ficaram bem evidenciados e foi possível obter a estimativa das frequências naturais dos modos mais altos.

Os picos próximos de $f_{1}$ e $f_{2}$ no gráfico (a) são obtidos pois, a maior amplitude de vibração ocorre nestes modos. Nos modos mais altos as amplitudes são de uma ordem de grandeza menor. Como a avaliação é feita numericamente e há uma imprecisão nas funções que definem os modos de vibrar, a análise de Fourier acaba por evidenciar no modos a partir do quinto frequências próximas ao modo 1 e 2. No entanto, o procedimento de filtragem do sinal, como mostrado acima, forneceu boas aproximações das frequências até o décimos modo.

\subsubsection{Ensaios de VIV}

Os ensaios de VIV propriamente ditos consistem do reboque do modelo em diferentes velocidades nas diversas configurações apresentadas anteriormente. A matriz de ensaio completa contou com a execução de 21 configurações distribuídas em 13 diferentes ensaios conforme apresentado na Tabela 3.9. Toda a matriz de ensaio foi realizada com velocidades crescentes, ou seja, o modelo sempre parte do repouso e é acelerado de forma suave até a velocidade de reboque correspondente daquele teste. Este ponto é muito importante, pois diversos trabalhos mostraram anteriormente o comportamento histerético do fenômeno de VIV ao estar sujeito a velocidades crescentes ou decrescentes como, por exemplo, Pesce \& Fujarra (2000). Entre ensaios de duas velocidades foi aguardado um tempo de aproximadamente $3 \mathrm{~min}$.

A configuração de referência foi tomada como o caso vertical $\left(\theta=0^{\circ}\right)$ e a Tabela 3.10 apresenta a variação do número de Reynolds e das velocidades reduzidas para os 10 primeiros modos de vibrar, com destaque para aquelas que estão no intervalo $4<V r_{i}<12$ que possuem a tendência de apresentar maiores amplitudes de resposta. Os ensaios cobriram uma faixa de número de Reynolds, tal que, $1.8 \times 10^{3}<R e<$ $1.8 \times 10^{4}$. Em toda a matriz de ensaio são obtidas regiões onde dois ou mais modos possam apresentar elevadas amplitudes de vibração. Nestas regiões é esperada a obtenção de comportamentos tais quais, convivência da vibração entre dois ou mais modos, saltos entre modos numa mesma velocidade dentre outros tipos de interações modais. 
Tabela 3.9 - Matriz completa dos Ensaios de VIV

\begin{tabular}{ccccc}
\hline Configuração & Ensaio & $\theta\left[{ }^{\circ}\right]$ & $\beta\left[{ }^{\circ}\right]$ & $\begin{array}{c}\text { Velocidades } \\
\text { ensaiadas }\end{array}$ \\
\hline 1 & 1 & 0 & 0 & 30 \\
2 & 2 & 10 & 0 & 28 \\
3 & 2 & 10 & 180 & 28 \\
4 & 3 & 10 & 45 & 28 \\
5 & 3 & 10 & 135 & 28 \\
6 & 4 & 10 & 90 & 28 \\
7 & 5 & 20 & 0 & 28 \\
8 & 5 & 20 & 180 & 28 \\
9 & 6 & 20 & 45 & 28 \\
10 & 6 & 20 & 135 & 28 \\
11 & 7 & 20 & 90 & 28 \\
12 & 8 & 30 & 0 & 28 \\
13 & 8 & 30 & 180 & 28 \\
14 & 9 & 30 & 45 & 28 \\
15 & 9 & 30 & 135 & 28 \\
16 & 10 & 30 & 90 & 28 \\
17 & 11 & 45 & 0 & 28 \\
18 & 11 & 45 & 180 & 28 \\
19 & 12 & 45 & 45 & 28 \\
20 & 12 & 45 & 135 & 28 \\
21 & 13 & 45 & 90 & 28 \\
\hline & & & Total & \\
& 5 & & & 590 \\
\hline
\end{tabular}


Tabela 3.10 - Número de Reynolds e Velocidades Reduzidas para o ensaio da configuração de referência $-\theta=0^{\circ}$

\begin{tabular}{|c|c|c|c|c|c|c|c|c|c|c|c|c|}
\hline & & & & & & & & & & & & \\
\hline & & & \multicolumn{10}{|c|}{ Modo } \\
\hline & & & 1 & 2 & 3 & 4 & 5 & 6 & 7 & 8 & 9 & 10 \\
\hline & & & \multicolumn{10}{|c|}{$\mathrm{Fn}(\mathrm{Hz})$} \\
\hline & & & 1.14 & 1.14 & 2.34 & 2.34 & 3.64 & 3.64 & 5.09 & 5.09 & 6.71 & 6.71 \\
\hline Corrida & $U(m / s)$ & $\mathbf{R e}$ & $V r_{1}$ & $V r_{2}$ & $V r_{3}$ & $V r_{4}$ & $V r_{5}$ & $V r_{6}$ & $V r_{7}$ & $V r_{8}$ & $V r_{9}$ & $V r_{10}$ \\
\hline 1 & 0.090 & 1998 & 3.56 & 3.56 & 1.73 & 1.73 & 1.11 & 1.11 & 0.80 & 0.80 & 0.60 & 0.60 \\
\hline 2 & 0.105 & 2331 & 4.15 & 4.15 & 2.02 & 2.02 & 1.30 & 1.30 & 0.93 & 0.93 & 0.70 & 0.70 \\
\hline 3 & 0.120 & 2664 & 4.74 & 4.74 & 2.31 & 2.31 & 1.49 & 1.49 & 1.06 & 1.06 & 0.81 & 0.81 \\
\hline 4 & 0.135 & 2997 & 5.33 & 5.33 & 2.60 & 2.60 & 1.67 & 1.67 & 1.19 & 1.19 & 0.91 & 0.91 \\
\hline 5 & 0.150 & 3330 & 5.93 & 5.93 & 2.89 & 2.89 & 1.86 & 1.86 & 1.33 & 1.33 & 1.01 & 1.01 \\
\hline 6 & 0.165 & 3663 & 6.52 & 6.52 & 3.18 & 3.18 & 2.04 & 2.04 & 1.46 & 1.46 & 1.11 & 1.11 \\
\hline 7 & 0.180 & 3996 & 7.11 & 7.11 & 3.47 & 3.47 & 2.23 & 2.23 & 1.59 & 1.59 & 1.21 & 1.21 \\
\hline 8 & 0.195 & 4329 & 7.71 & 7.71 & 3.75 & 3.75 & 2.41 & 2.41 & 1.73 & 1.73 & 1.31 & 1.31 \\
\hline 9 & 0.210 & 4662 & 8.30 & 8.30 & 4.04 & 4.04 & 2.60 & 2.60 & 1.86 & 1.86 & 1.41 & 1.41 \\
\hline 10 & 0.225 & 4995 & 8.89 & 8.89 & 4.33 & 4.33 & 2.78 & 2.78 & 1.99 & 1.99 & 1.51 & 1.51 \\
\hline 11 & 0.240 & 5328 & 9.48 & 9.48 & 4.62 & 4.62 & 2.97 & 2.97 & 2.12 & 2.12 & 1.61 & 1.61 \\
\hline 12 & 0.255 & 5661 & 10.08 & 10.08 & 4.91 & 4.91 & 3.16 & 3.16 & 2.26 & 2.26 & 1.71 & 1.71 \\
\hline 13 & 0.270 & 5994 & 10.67 & 10.67 & 5.20 & 5.20 & 3.34 & 3.34 & 2.39 & 2.39 & 1.81 & 1.81 \\
\hline 14 & 0.285 & 6327 & 11.26 & 11.26 & 5.49 & 5.49 & 3.53 & 3.53 & 2.52 & 2.52 & 1.91 & 1.91 \\
\hline 15 & 0.300 & 6660 & 11.85 & 11.85 & 5.78 & 5.78 & 3.71 & 3.71 & 2.65 & 2.65 & 2.01 & 2.01 \\
\hline 16 & 0.327 & 7259 & 12.92 & 12.92 & 6.29 & 6.29 & 4.05 & 4.05 & 2.89 & 2.89 & 2.20 & 2.20 \\
\hline 17 & 0.355 & 7881 & 14.03 & 14.03 & 6.83 & 6.83 & 4.39 & 4.39 & 3.14 & 3.14 & 2.38 & 2.38 \\
\hline 18 & 0.382 & 8480 & 15.09 & 15.09 & 7.35 & 7.35 & 4.73 & 4.73 & 3.38 & 3.38 & 2.56 & 2.56 \\
\hline 19 & 0.409 & 9080 & 16.16 & 16.16 & 7.87 & 7.87 & 5.06 & 5.06 & 3.62 & 3.62 & 2.75 & 2.75 \\
\hline 20 & 0.436 & 9679 & 17.23 & 17.23 & 8.39 & 8.39 & 5.40 & 5.40 & 3.86 & 3.86 & 2.93 & 2.93 \\
\hline 21 & 0.464 & 10301 & 18.33 & 18.33 & 8.93 & 8.93 & 5.74 & 5.74 & 4.11 & 4.11 & 3.11 & 3.11 \\
\hline 22 & 0.491 & 10900 & 19.40 & 19.40 & 9.45 & 9.45 & 6.08 & 6.08 & 4.35 & 4.35 & 3.30 & 3.30 \\
\hline 23 & 0.518 & 11500 & 20.47 & 20.47 & 9.97 & 9.97 & 6.41 & 6.41 & 4.58 & 4.58 & 3.48 & 3.48 \\
\hline 24 & 0.546 & 12121 & 21.57 & 21.57 & 10.51 & 10.51 & 6.76 & 6.76 & 4.83 & 4.83 & 3.67 & 3.67 \\
\hline 25 & 0.573 & 12721 & 22.64 & 22.64 & 11.03 & 11.03 & 7.09 & 7.09 & 5.07 & 5.07 & 3.85 & 3.85 \\
\hline 26 & 0.600 & 13320 & 23.71 & 23.71 & 11.55 & 11.55 & 7.43 & 7.43 & 5.31 & 5.31 & 4.03 & 4.03 \\
\hline 27 & 0.650 & 14430 & 25.68 & 25.68 & 12.51 & 12.51 & 8.04 & 8.04 & 5.75 & 5.75 & 4.36 & 4.36 \\
\hline 28 & 0.700 & 15540 & 27.66 & 27.66 & 13.48 & 13.48 & 8.66 & 8.66 & 6.19 & 6.19 & 4.70 & 4.70 \\
\hline 29 & 0.750 & 16650 & 29.63 & 29.63 & 14.44 & 14.44 & 9.28 & 9.28 & 6.64 & 6.64 & 5.03 & 5.03 \\
\hline 30 & 0.800 & 17760 & 31.61 & 31.61 & 15.40 & 15.40 & 9.90 & 9.90 & 7.08 & 7.08 & 5.37 & 5.37 \\
\hline
\end{tabular}


O ensaio como um todo foi pensado de forma que para todas as configurações ocorressem esse tipo de comportamento que enriquece as análises a serem desenvolvidas nos próximos capítulos. Desta forma, a Figura 3.40 apresenta a variação da velocidade reduzida $V r_{i}$, conforme calculada na seção 3.2.3, para as 21 configurações ensaiadas mais as 4 configurações derivadas do caso de referência. A região destacada em verde apresenta justamente $4<V r_{i}<12$.

Esta figura nos mostra um panorama geral de quais modos serão excitados para cada ângulo de inclinação $\theta$ e cada ângulo de azimute $\beta$. Em todas as configurações são esperadas vibrações em toda região de ressonância para os quatro primeiros modos. Já para o quinto e o sexto são esperadas amplificações significativas com obtenções de $V r_{i}$ até 6 , sendo que no caso vertical até $V r_{i}=10$. São esperadas respostas significativas dos $7^{\circ} \mathrm{M}$ ao $10^{\circ} \mathrm{M}$ apenas para as configurações vertical e para $\theta=10^{\circ}$. 


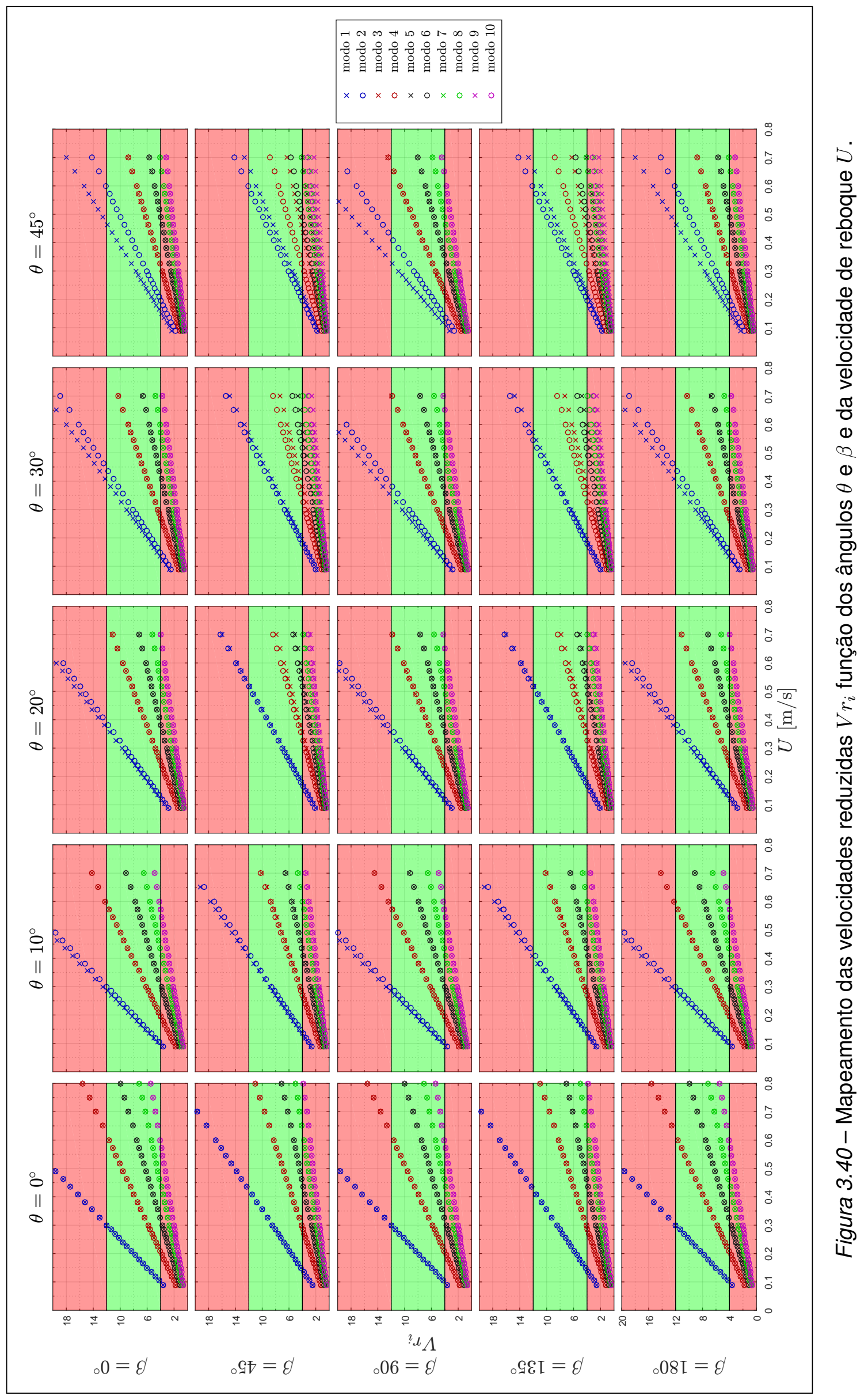




\section{Capítulo 4}

\section{Apresentação e Discussão dos Resultados Obtidos}

O presente capítulo tem o intuito de apresentar e discutir os principais resultados obtidos a partir da execução das etapas descritas no Capítulo 3.

Primeiramente, na seção 4.1, são apresentados os resultados das frequências naturais e dos coeficientes de amortecimento obtidos com os ensaios de decaimento. Além dos valores destes parâmetros, uma avaliação dos fatores $\alpha$ e $m^{*} \zeta$ é realizada caracterizando assim o presente experimento dentre alguns semelhantes na literatura, conforme discutido na seção 2.2.

Os principais resultados dos ensaios são geralmente indicados em termos de amplitude e frequência de vibração e estão detalhados na seção 4.2. Pela grande quantidade de informação gerada através da execução da extensa matriz de ensaios apresentada na seção 3.4.2, optou-se pela apresentação conjunta dos resultados das diversas configurações, abrangendo todos os ângulos $\theta$ e $\beta$ ensaiados.

Após essa apresentação, serão então discutidos os pontos interessantes e as particularidades pertinentes a cada uma das configurações de maneira individualizada ou através de comparações em regiões de interesse.

\subsection{Frequências naturais e coeficientes de amorteci- mento}

Nesta seção são apresentados os resultados para as frequências naturais e coeficientes de amortecimento obtidos com os ensaios de decaimento realizados tanto com o modelo em ar, como com o modelo submerso em água. 
Os valores obtidos experimentalmente foram comparados com aqueles obtidos de forma numérica, conforme metodologia explicada anteriormente na seção 3.3, e apresentados resumidamente na Tabela 4.1 e de forma detalhada no Apêndice B.1.

Tabela 4.1 - Comparação entre as frequências naturais em ar $\left(f_{n_{i}}^{a r}\right)$ obtidas pelos ensaios de decaimento (Exp.) e pelo modelo Orcaflex® (Num.)

\begin{tabular}{|c|c|c|c|c|c|c|c|c|c|c|c|}
\hline \multirow{2}{*}{$\theta\left[{ }^{\circ}\right]$} & \multirow{2}{*}{ Método } & \multicolumn{10}{|c|}{ Modo $i$} \\
\hline & & 1 & 2 & 3 & 4 & 5 & 6 & 7 & 8 & 9 & 10 \\
\hline \multirow{3}{*}{0} & $f_{n_{i}}^{a r}[\mathrm{~Hz}]-\operatorname{Exp}$. & 1.60 & 1.59 & 3.23 & 3.18 & 4.84 & 4.85 & 6.52 & 6.60 & 9.01 & 8.86 \\
\hline & $f_{n_{i}}^{a r}[\mathrm{~Hz}]-$ Num. & 1.60 & 1.60 & 3.25 & 3.25 & 5.00 & 5.00 & 6.88 & 6.88 & 8.93 & 8.93 \\
\hline & Diferença [\%] & $0.4 \%$ & $0.8 \%$ & $0.7 \%$ & $2.1 \%$ & $3.2 \%$ & $3.0 \%$ & $5.2 \%$ & $4.0 \%$ & $0.8 \%$ & $0.8 \%$ \\
\hline \multirow{3}{*}{10} & $f_{n_{i}}^{a r}[\mathrm{~Hz}]-$ Exp. & 1.61 & 1.63 & 3.26 & 3.25 & 4.90 & 4.89 & 6.55 & 6.53 & 8.53 & 8.76 \\
\hline & $f_{n_{i}}^{a r}[\mathrm{~Hz}]-$ Num. & 1.60 & 1.64 & 3.24 & 3.24 & 4.99 & 4.99 & 6.86 & 6.87 & 8.92 & 8.92 \\
\hline & Diferença [\%] & $0.7 \%$ & $0.2 \%$ & $0.5 \%$ & $0.3 \%$ & $1.6 \%$ & $2.0 \%$ & $4.6 \%$ & $4.9 \%$ & $4.4 \%$ & $1.7 \%$ \\
\hline \multirow{3}{*}{20} & $f_{n_{i}}^{a r}[\mathrm{~Hz}]-$ Exp. & 1.64 & 1.71 & 3.27 & 3.31 & 4.95 & 5.01 & 6.65 & 6.65 & 8.84 & 8.90 \\
\hline & $f_{n_{i}}^{a r}[\mathrm{~Hz}]-$ Num. & 1.63 & 1.77 & 3.31 & 3.31 & 5.08 & 5.09 & 6.99 & 6.99 & 9.06 & 9.07 \\
\hline & Diferença [\%] & $0.5 \%$ & $3.4 \%$ & $1.1 \%$ & $0.0 \%$ & $2.6 \%$ & $1.5 \%$ & $4.9 \%$ & $4.8 \%$ & $2.4 \%$ & $1.8 \%$ \\
\hline \multirow{3}{*}{30} & $f_{n_{i}}^{a r}[\mathrm{~Hz}]-$ Exp. & 1.67 & 1.88 & 3.34 & 3.45 & 5.10 & 5.18 & 6.87 & 7.08 & 8.85 & 8.92 \\
\hline & $f_{n_{i}}^{a r}[\mathrm{~Hz}]-$ Num. & 1.64 & 1.91 & 3.32 & 3.33 & 5.12 & 5.12 & 7.02 & 7.03 & 9.11 & 9.11 \\
\hline & Diferença [\%] & $1.7 \%$ & $1.6 \%$ & $0.4 \%$ & $3.5 \%$ & $0.4 \%$ & $1.1 \%$ & $2.2 \%$ & $0.7 \%$ & $2.8 \%$ & $2.0 \%$ \\
\hline \multirow{3}{*}{45} & $f_{n_{i}}^{a r}[\mathrm{~Hz}]-$ Exp. & 1.57 & 2.21 & 3.13 & 3.19 & 4.70 & 4.80 & 6.51 & 6.67 & 8.87 & 8.89 \\
\hline & $f_{n_{i}}^{a r}[\mathrm{~Hz}]-\mathrm{Num}$. & 1.63 & 2.13 & 3.28 & 3.30 & 5.07 & 5.07 & 6.95 & 6.96 & 9.02 & 9.02 \\
\hline & Diferença [\%] & $3.9 \%$ & $3.4 \%$ & $4.5 \%$ & $3.4 \%$ & $7.3 \%$ & $5.5 \%$ & $6.3 \%$ & $4.3 \%$ & $1.6 \%$ & $1.4 \%$ \\
\hline
\end{tabular}

Os coeficientes de amortecimento foram obtidos através da média entre cinco repetições dos ensaios de decaimento. O valor final considerado, bem como outros parâmetros importantes derivados deste $\left(\zeta, \alpha\right.$ e $\left.S_{G}\right)$ estão apresentados na Tabela 4.2 e os valores obtidos para cada repetição estão apresentados no Apêndice B.1. Enfatiza-se que o parâmetro $S_{G}$ foi calculado conforme equação (2.7). 
Tabela 4.2 - Coeficientes de amortecimento linear obtidos através de ensaio de decaimento com o modelo em ar e parâmetros $\alpha$ e $S_{G}$ calculados para cada ângulo de inclinação

\begin{tabular}{ccccc}
\hline$\theta\left[{ }^{\circ}\right]$ & $\zeta_{s}$ & $\zeta$ & $\alpha$ & $S_{G}$ \\
\hline 0 & $2.5 \%$ & $2.2 \%$ & 0.085 & 0.212 \\
10 & $3.0 \%$ & $2.6 \%$ & 0.103 & 0.254 \\
20 & $3.4 \%$ & $2.9 \%$ & 0.116 & 0.288 \\
30 & $3.5 \%$ & $3.0 \%$ & 0.120 & 0.297 \\
45 & $3.6 \%$ & $3.1 \%$ & 0.123 & 0.305 \\
\hline
\end{tabular}

Da mesma forma, o resultados de decaimento para o modelo ensaiados em água são apresentados de forma resumida na Tabela 4.3 (frequências naturais) e na Tabela 4.4 (coeficientes de amortecimento) e de forma detalhada para cada uma das repetições no Apêndice B.2.

Tabela 4.3-Comparação entre as frequências naturais em água $\left(f_{n_{i}}\right)$ obtidas pelos ensaios de decaimento (Exp.) e pelo modelo Orcaflex® (Num.)

\begin{tabular}{|c|c|c|c|c|c|c|c|c|c|c|c|}
\hline \multirow{2}{*}{$\theta\left[{ }^{\circ}\right]$} & \multirow{2}{*}{ Método } & \multicolumn{10}{|c|}{ Modo $i$} \\
\hline & & 1 & 2 & 3 & 4 & 5 & 6 & 7 & 8 & 9 & 10 \\
\hline \multirow{3}{*}{0} & $f_{n_{i}}[\mathrm{~Hz}]-$ Exp. & 1.14 & 1.07 & 2.26 & 2.20 & 3.52 & 3.39 & 4.87 & 4.79 & 6.58 & 6.43 \\
\hline & $f_{n_{i}}[\mathrm{~Hz}]-$ Num. & 1.14 & 1.14 & 2.34 & 2.34 & 3.64 & 3.64 & 5.09 & 5.09 & 6.71 & 6.71 \\
\hline & Diferença [\%] & $0.0 \%$ & $5.9 \%$ & $3.4 \%$ & $6.0 \%$ & $3.4 \%$ & $7.0 \%$ & $4.3 \%$ & $6.0 \%$ & $2.0 \%$ & $4.2 \%$ \\
\hline \multirow{3}{*}{10} & $f_{n_{i}}[\mathrm{~Hz}]-$ Exp. & 1.07 & 1.16 & 2.22 & 2.24 & 3.42 & 3.50 & 4.73 & 4.88 & 6.41 & 6.44 \\
\hline & $f_{n_{i}}[\mathrm{~Hz}]-$ Num. & 1.07 & 1.12 & 2.20 & 2.20 & 3.44 & 3.44 & 4.83 & 4.83 & 6.41 & 6.41 \\
\hline & Diferença [\%] & $0.0 \%$ & $3.6 \%$ & $0.8 \%$ & $1.8 \%$ & $0.5 \%$ & $1.7 \%$ & $2.0 \%$ & $1.0 \%$ & $0.1 \%$ & $0.5 \%$ \\
\hline \multirow{3}{*}{20} & $f_{n_{i}}[\mathrm{~Hz}]-\operatorname{Exp}$. & 1.31 & 1.36 & 2.62 & 2.83 & 3.99 & 4.12 & 5.50 & 5.46 & 7.48 & 7.67 \\
\hline & $f_{n_{i}}[\mathrm{~Hz}]-$ Num. & 1.32 & 1.39 & 2.68 & 2.68 & 4.14 & 4.14 & 5.73 & 5.73 & 7.48 & 7.48 \\
\hline & Diferença [\%] & $0.5 \%$ & $1.8 \%$ & $2.1 \%$ & $5.5 \%$ & $3.6 \%$ & $0.6 \%$ & $4.1 \%$ & $4.7 \%$ & $0.1 \%$ & $2.5 \%$ \\
\hline \multirow{3}{*}{30} & $f_{n_{i}}[\mathrm{~Hz}]-$ Exp. & 1.35 & 1.52 & 2.73 & 2.80 & 4.23 & 4.11 & 5.76 & 5.79 & 7.35 & 7.39 \\
\hline & $f_{n_{i}}[\mathrm{~Hz}]-$ Num. & 1.31 & 1.46 & 2.67 & 2.68 & 4.13 & 4.13 & 5.71 & 5.71 & 7.46 & 7.46 \\
\hline & Diferença [\%] & $2.4 \%$ & $3.8 \%$ & $2.0 \%$ & $4.8 \%$ & $2.3 \%$ & $0.5 \%$ & $0.9 \%$ & $1.4 \%$ & $1.5 \%$ & $0.9 \%$ \\
\hline \multirow{3}{*}{45} & $f_{n_{i}}[\mathrm{~Hz}]-$ Exp. & 1.26 & 1.57 & 2.53 & 2.67 & 4.02 & 3.99 & 5.35 & 5.37 & 6.96 & 7.02 \\
\hline & $f_{n_{i}}[\mathrm{~Hz}]-$ Num. & 1.25 & 1.59 & 2.54 & 2.55 & 3.95 & 3.95 & 5.46 & 5.47 & 7.16 & 7.16 \\
\hline & Diferença [\%] & $0.8 \%$ & $1.0 \%$ & $0.6 \%$ & $4.7 \%$ & $2.0 \%$ & $0.8 \%$ & $2.1 \%$ & $1.8 \%$ & $2.8 \%$ & $2.0 \%$ \\
\hline
\end{tabular}


Tabela 4.4-Coeficientes de amortecimento linear obtidos através de ensaio de decaimento com o modelo submerso em água

\begin{tabular}{cc}
\hline$\theta\left[{ }^{\circ}\right]$ & $\bar{\zeta}$ \\
\hline 0 & $8.0 \%$ \\
10 & $7.4 \%$ \\
20 & $5.8 \%$ \\
30 & $5.1 \%$ \\
45 & $6.2 \%$ \\
\hline
\end{tabular}

De forma geral podemos dizer que, tanto em água como em ar, as frequências naturais apresentaram boa correlação entre os métodos numérico e experimental. Sendo assim, é possível inferir que as funções $\phi_{i}$, calculadas numericamente, que representam o modos naturais de vibrar, apresentam correlação suficientemente boa para a utilização como base para a decomposição modal.

Um comentário pertinente diz respeito às frequências naturais do caso $\operatorname{com} \theta=10^{\circ}$. Os valores das frequências naturais "as-built" apresentados na Tabela 4.3 está mais baixo do que o inicialmente pretendido, que teriam a ordem de grandeza dos outros casos inclinados. Esse fato decorreu da aplicação de uma tração um pouco menor, como apresentado anteriormente na Tabela 3.8. Apesar de não impactar tanto na questão da configuração estática e da inclinação em relação ao perfil de correnteza, alguns pontos referentes ao impacto na resposta ao VIV foram observados e serão comentados ao longo do texto, quando pertinente.

\subsection{Amplitudes modais e frequências de resposta}

O resultado geral do ensaio de VIV é apresentado na Figura 4.1 que configura o mapeamento das amplitudes modais em função dos ângulos $\theta, \beta$ e de $V r_{i}$. Esta figura apresenta, além dos mapas para as 21 configurações ensaiadas, os mapas de 4 configurações extras obtidos a partir da configuração de referência vertical. Este resultado diz respeito às amplitudes obtidas através do cálculo de $\sqrt{2}$ vezes o desvio padrão $(\sigma)$ do sinal. Os mapas considerando a média dos extremos e a média dos $10 \%$ maiores extremos estão apresentados no Apêndice C, Figuras C.1 e C.2, respectivamente.

Observação: É importante ressaltar que nos mapas da Figura 4.1 os espectros foram interpolados entre os modos apenas com o intuito de visualizar o comportamento do 
sistema. Não existe significado físico para as amplitudes entre dois modos, já que estes são discretos para estruturas finitas.

Devido à simetria axial do dispositivo da montagem, não é necessária a realização de baterias adicionais de ensaios para considerar a mudança de azimute para o modelo posicionado na vertical. As amplitudes para $\theta=0^{\circ} \mathrm{e} \beta=45^{\circ}, 90^{\circ}, 135^{\circ} \mathrm{e} 180^{\circ}$ foram obtidas através da projeção modal nas funções $\phi_{i}$ rotacionadas, conforme apresentado na Figura 4.2.

Voltando à Figura 4.1, cada um dos 25 mapas apresentam, na escala colorida, a amplitude modal adimensionalizada (sendo azul amplitudes baixas e vermelho amplitudes altas), o modo de vibrar $i$ no eixo das ordenadas e a velocidade reduzida para cada modo de vibrar $V r_{i}$ no eixo das abcissas. Para facilitar a visualização, os modos de vibrar foram agrupados de acordo com seu plano de vibração. Os modos ímpares (vibração fora do plano da catenária) foram posicionados na posição superior do mapa. Os modos pares (vibração no plano da catenária) foram posicionados na metade inferior do mapa. Tanto os modos pares como os ímpares foram dispostos de maneira crescente, do centro (linha pontilhada preta) para as extremidades.

A conclusão que se obtém à primeira vista é a de que os movimentos significativos ficam evidentemente restritos aos modos transversais à correnteza, observando-se principalmente os mapas para $\beta=0^{\circ}$ e $180^{\circ}$ (vibração dos modos ímpares) e $90^{\circ}$ (vibração dos modos pares). A ocorrência concomitante de vibração nos modos pares e ímpares ocorre principalmente para as incidências em azimute oblíquo $\left(\beta=45^{\circ} \mathrm{e}\right.$ $135^{\circ}$ ), como era de se esperar.

As maiores amplitudes, independente do ângulo $\theta$ ou $\beta$, foram observadas no $3^{\circ} \mathcal{M}$ ou $4^{\circ} \mathcal{M}$, obedecendo as observações do parágrafo anterior. Além disso, os picos, independente dos modos, ocorrem sempre em uma região bem definida de $V r_{i}$, entre 3 e 8 , mostrando que o de cálculo das velocidades reduzidas adotado com base no PI e apresentada na seção 3.2.3 é coerente para a análise de sistemas inclinados para a correção da faixa de lock-in.

Estas informações corroboram parcialmente para uma validade do PI (do ponto de vista das amplitudes de oscilação) para os casos testados, se comparados com a configuração de referência. No entanto, a avaliação do azimute suscita relações que vão além do que pode ser estimado com o PI. Uma dessas relações advém do fato que o cilindro flexível estudado é dominado pela rigidez geométrica imposta pela tração. A mudança do azimute impacta diretamente na tração do modelo e, consequentemente, nas amplitudes obtidas.

Como exemplo, pode-se comparar os casos $\operatorname{com} \beta=0^{\circ}$ e $\beta=180^{\circ}$, para qualquer ângulo $\theta$. No primeiro caso, a força média normal ao cilindro inclinado imposta pela 


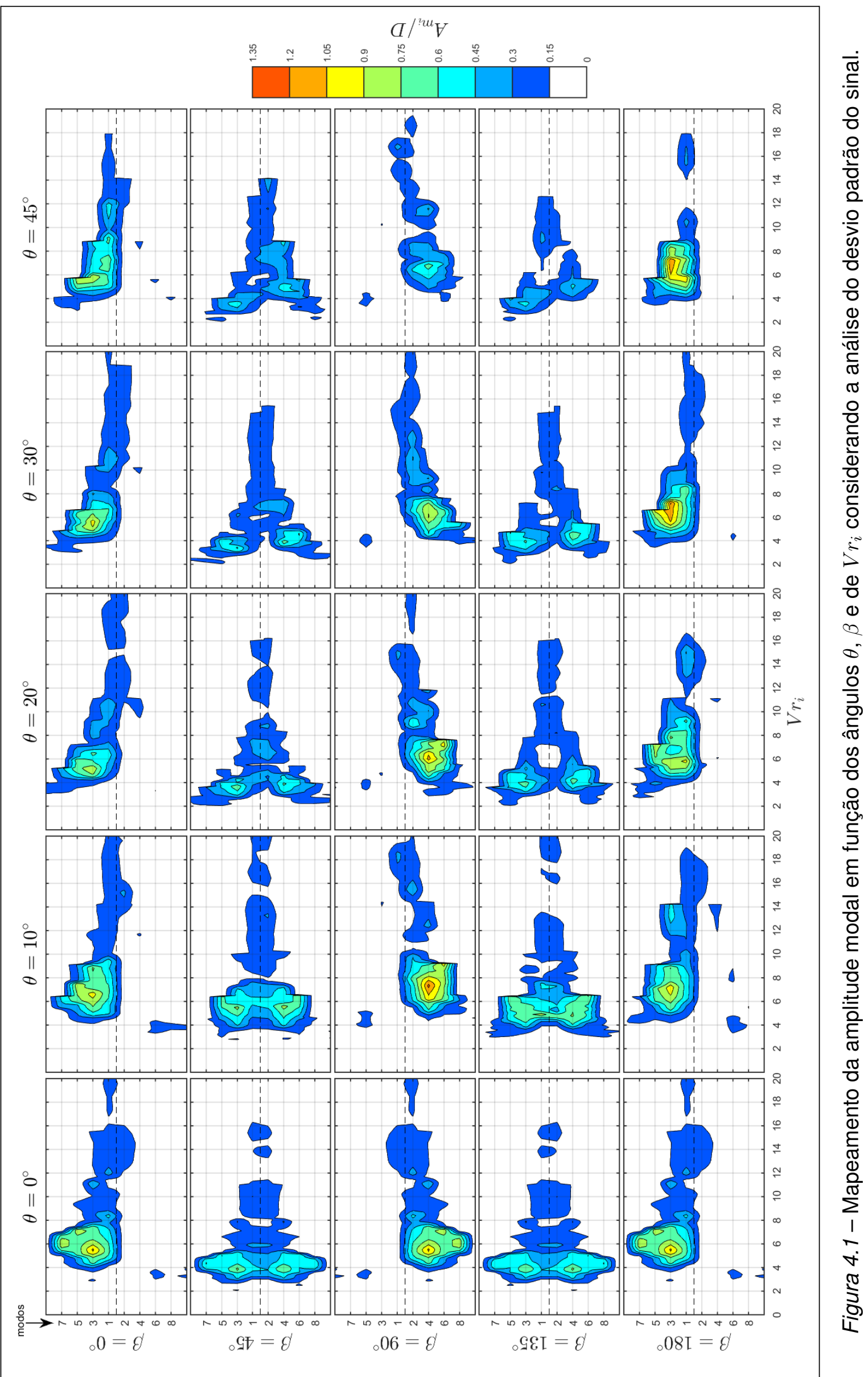




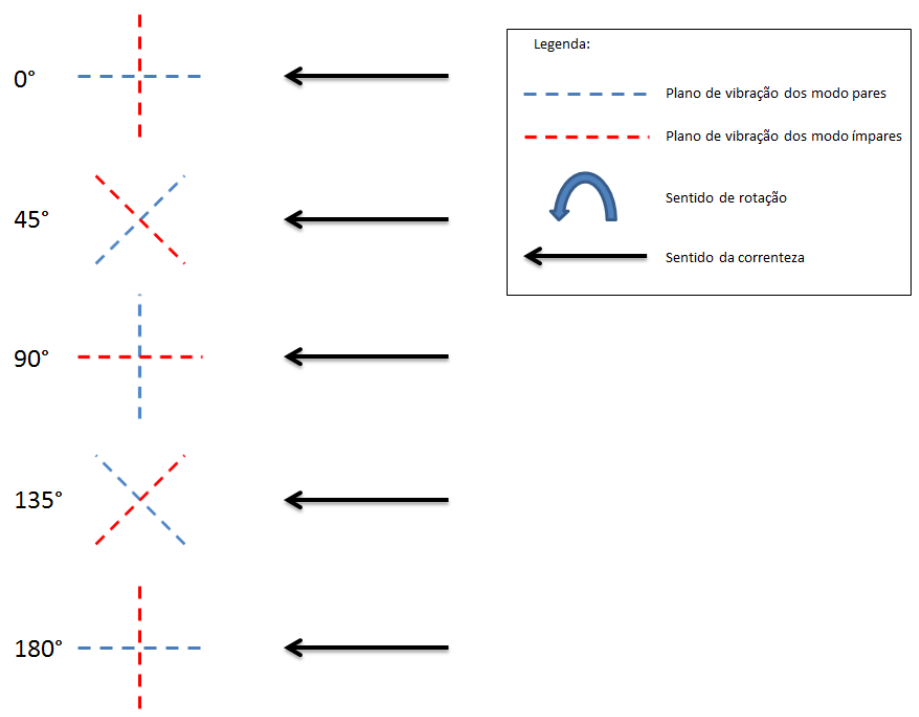

Figura 4.2 - Rotação das direções dos modos de vibrar da configuração vertical para obtenção dos mapas de referência.

correnteza (força de arrasto) age de forma contrária à força imposta pela gravidade, tendendo a suavizar a curvatura inicial obtida para a posição de equilíbrio sem correnteza. Já no segundo caso, a força média normal de arrasto e a força da gravidade agem de forma conjunta, tendendo a aumentar a curvatura do cilindro. Em resumo, temos uma tração média maior para $\beta=180^{\circ}$ do que para $\beta=0^{\circ}$.

O impacto disso pode ser observado diretamente nas amplitudes de resposta, para as quais em um mesmo ângulo de inclinação foram sistematicamente obtidas amplitudes ligeiramente maiores nos casos com $\beta=180^{\circ}$. Para facilitar a visualização dessa importante conclusão, as amplitudes modais são apresentadas novamente na Figura 4.3, agora agrupadas pelo azimute e pelo modo de vibrar.

A mesma conclusão pode ser verificada para os ângulos $\beta=45^{\circ}$ e $\beta=135^{\circ}$, segundo os quais amplitudes maiores foram obtidas no segundo caso, quando o modelo está numa condição mais tracionada. Obviamente, neste casos, a natureza oblíqua da incidência da correnteza diminui as diferenças de amplitude.

Conforme apresentado nas referências bibliográficas, existe uma linha de trabalhos que relaciona os parâmetros $S_{G}$ e $\alpha$ com a amplitude máxima de resposta obtida. Para situar as respostas obtidas neste trabalho perante os demais trabalhos da literatura, as amplitudes modais máximas obtidas pelo método dos $10 \%$ maiores extremos foram posicionados nas Figuras 4.4 e 4.5 .

Ambas figuras possuem a mesma base de dados inicial (apresentada no apêndice de Skop \& Balasubramanian (1997)) e tratam basicamente de experimentos com cilindros flexíveis, tanto em ar como em água. Estas figuras representam a forma mais atual de 


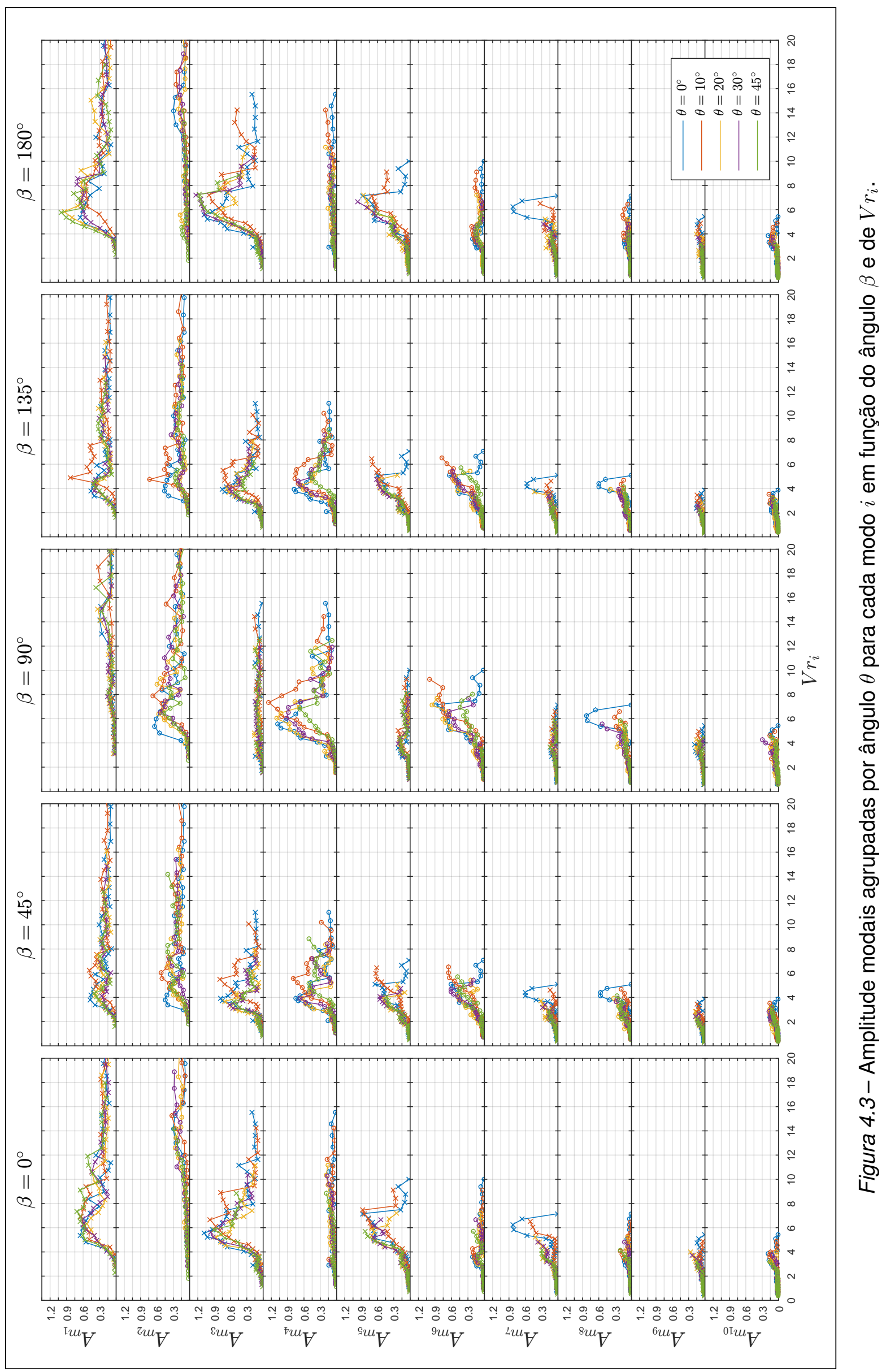




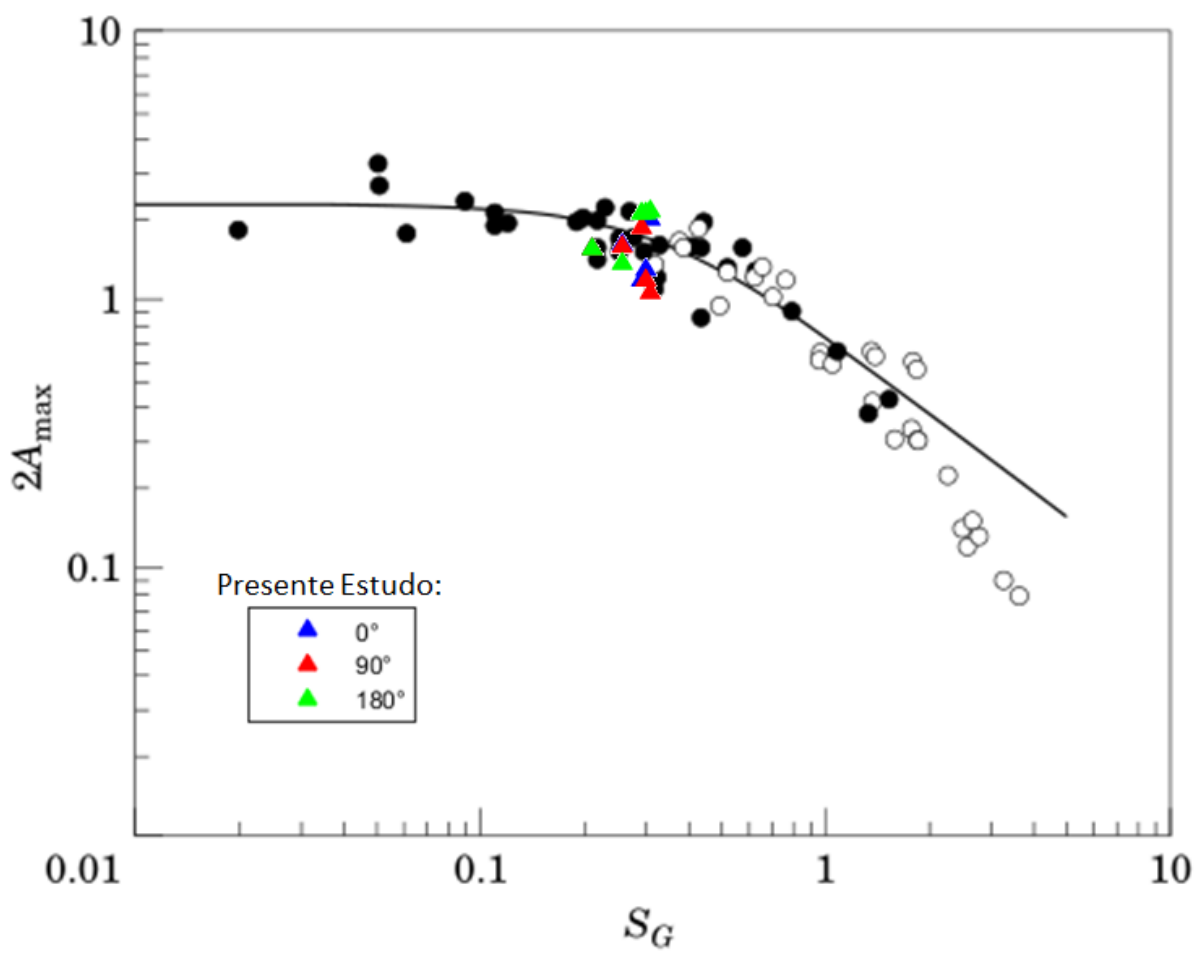

Figura 4.4 - "Griffin Plot" relacionando a amplitude adimensional máxima observada em função do parâmetro $S_{G}$ (eixo vertical escala logarítmica) para diferentes azimutes ( $\beta)$. Adpatado de Skop \& Balasubramanian (1997).

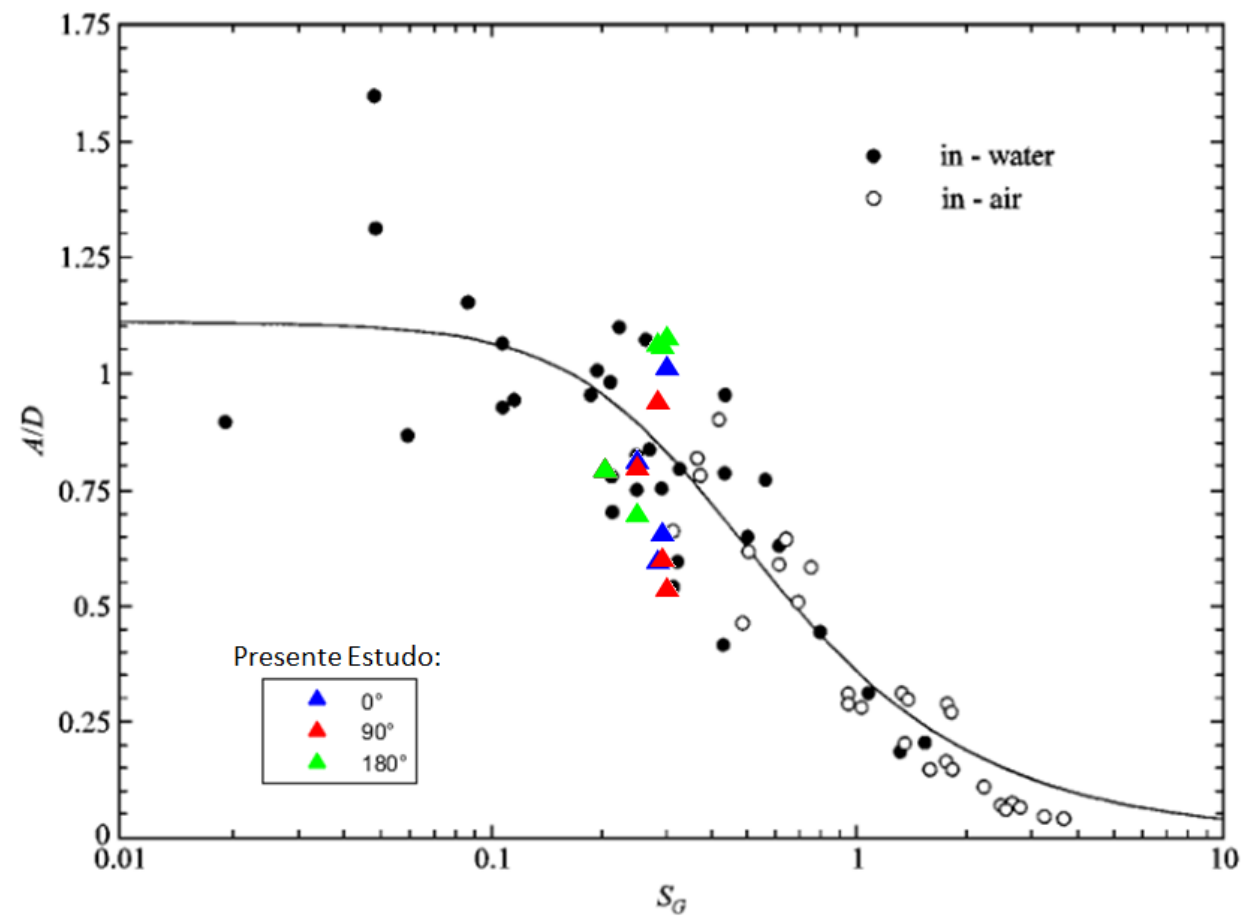

Figura 4.5 - "Griffin Plot" relacionando a amplitude adimensional máxima observada em função do parâmetro $S_{G}$ (eixo vertical escala linear) para diferentes azimutes $(\beta)$. Adaptado de Khalak \& Williamson (1999). 
apresentação dos resultados da Figura 2.7. A linha contínua, definida pelos autores, representa a equação semi-empírica (4.1) que melhor ajustou os dados.

$$
A_{\max }=\frac{0.385}{\sqrt{0.12+S_{G}^{2}}}
$$

A diferença básica entre as duas figuras é a forma de apresentar o eixo vertical, que na Figura 4.4 é apresentado em uma escala logarítmica e na Figura 4.5 em uma escala linear. Khalak \& Williamson (1999) defendem que a utilização da escala logarítmica pode mascarar a dispersão da nuvem de pontos. Independente da aderência à equação semi-empírica, é possível notar que os valores obtidos a partir dos experimentos do presente estudo estão, de forma geral, bem condizentes com outros experimentos realizados com cilindros flexíveis. Os resultados da presente tese representam amplitudes máximas que variaram de 0.54 até 1.01 , correspondendo à um intervalo do parâmetro de Skop-Griffin $0.2<S_{G}<0.3$.

Complementarmente ao mapa das amplitudes, a Figura 4.6 apresenta o mapeamento das frequências de vibração para cada uma das velocidades ensaiadas. Novamente, os gráficos são apresentados para cada combinação de $\theta$ e $\beta$. No eixo das ordenadas é apresentada a frequência dominante de vibração ${ }^{1} f$, ao passo que no eixo das abcissas novamente está apresentada a velocidade reduzida $V r_{i}$. As linhas contínuas horizontais representam as frequências naturais $f_{n_{i}}$. Já as linhas inclinadas tracejadas apresentam idealmente a frequência de emissão de vórtices $f_{S_{i}}$ para cada modo de vibrar $i$ calculada a partir de:

$$
f_{S_{i}}=S t V r_{i} f_{n_{i}}
$$

adotando-se $S t=0.2$.

Tanto para $f_{n_{i}}$ quanto para $f_{S_{i}}$ foram adotadas as mesmas cores introduzidas na seção 3.3 para a diferenciação dos modos.

Com relação às frequências, de modo geral, foi obtido o comportamento clássico de VIV esperado para sistemas oscilantes. A região de lock-in é observada para as diversas configurações quando $3<V r_{i}<8$, principalmente para os quatro primeiros modos. Estas região são bem evidenciadas quando $\beta=0^{\circ} \mathrm{e} \beta=180^{\circ}$. Para os outros azimutes, o comportamento de lock-in também ocorre, porém percebe-se uma relação maior com a reta que representa a frequência de emissão $f_{S_{i}}$. Nestes gráficos de frequência é possível observar, em diversos casos, a ocorrência de modos inferiores sendo excitados em frequências de modos maiores (e vice-versa).

\footnotetext{
${ }^{1}$ Importante ressaltar que para uma melhor visualização não foi adotada a já clássica utilização da frequência adimensional $f^{*}$.
} 


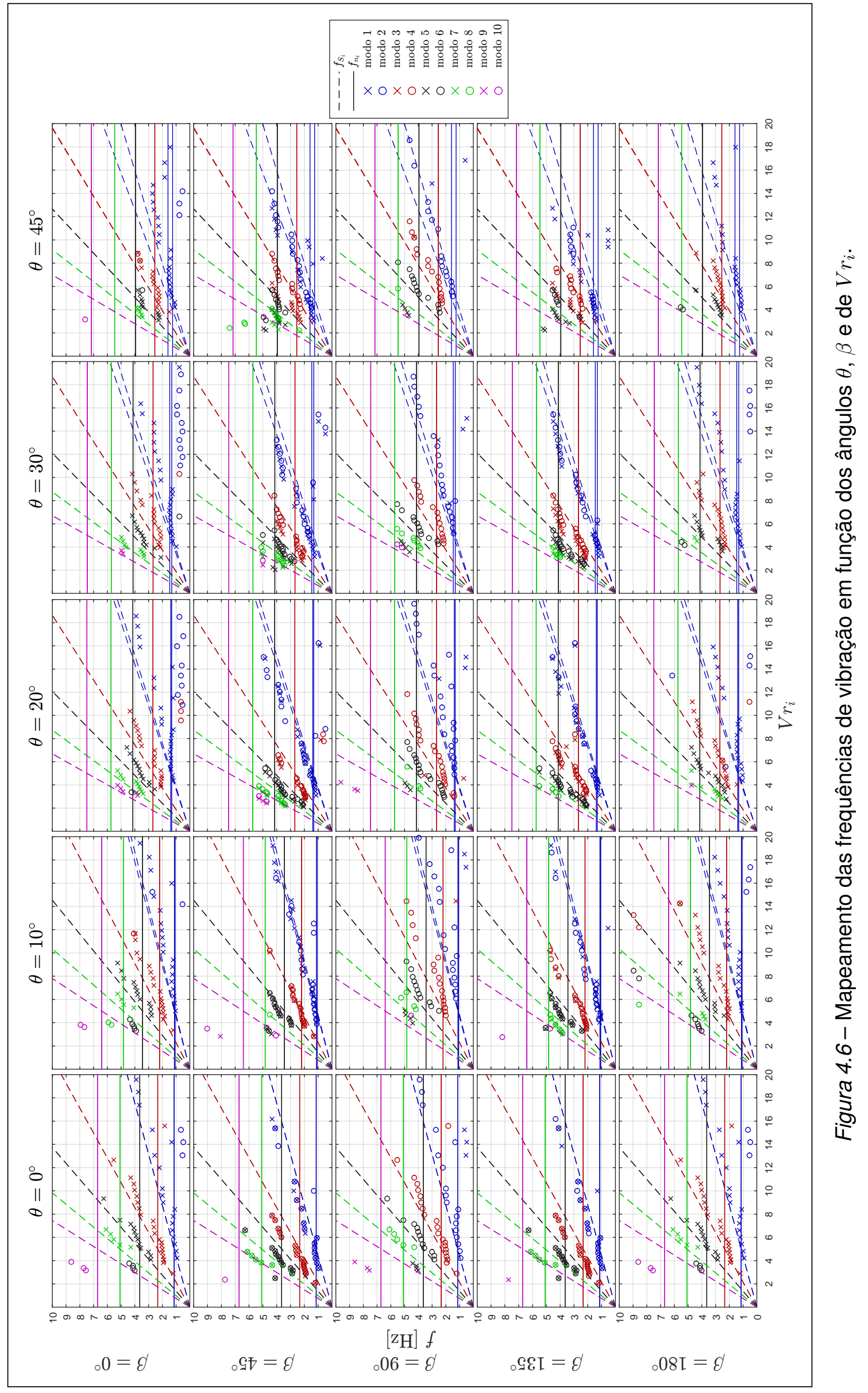


Para ilustrar esse fato, basta observar o gráfico $\operatorname{com} \theta=10^{\circ} \mathrm{e} \beta=0^{\circ}$. Neste caso, observa-se os pontos $(\times)$ do primeiro modo (em azul) formando patamares. O primeiro patamar se estende de $V r_{1}=5$ até $V r_{1}=9.5$ e corresponde à região de lock-in do primeiro modo onde $f_{1} \approx f_{n_{1}}$. Em seguida é observado outro patamar que se estende de $V r_{1}=10$ até $V r_{1}=14$, no qual se tem $f_{1} \approx f_{n_{2}}$, ou seja, o $1^{\circ} \mathcal{M}$ oscilando com a frequência do $2^{\circ} \mathcal{M}$, ou concisamente, $1^{\circ} \mathcal{M}\left\langle f_{2}\right\rangle^{2}$.

A Figura 4.7 apresenta a série temporal que originou um dos pontos em $V r_{1}=12.11$ desse segundo patamar. Amplitudes significativas de movimento são obtidas para o $1^{\circ} \mathcal{M}, 3^{\circ} \mathcal{M}, 5^{\circ} \mathcal{M}$ e $6^{\circ} \mathcal{M}$. Nestes casos temos $1^{\circ} \mathcal{M}\left\langle f_{3}\right\rangle, 3^{\circ} \mathcal{M}\left\langle f_{3}\right\rangle$ e $5^{\circ} \mathcal{M}\left\langle f_{3}\right\rangle$, ou seja, temos $01^{\circ} \mathcal{M}$ e $5^{\circ} \mathcal{M}$ também oscilando próximo à frequência $f_{3}$.
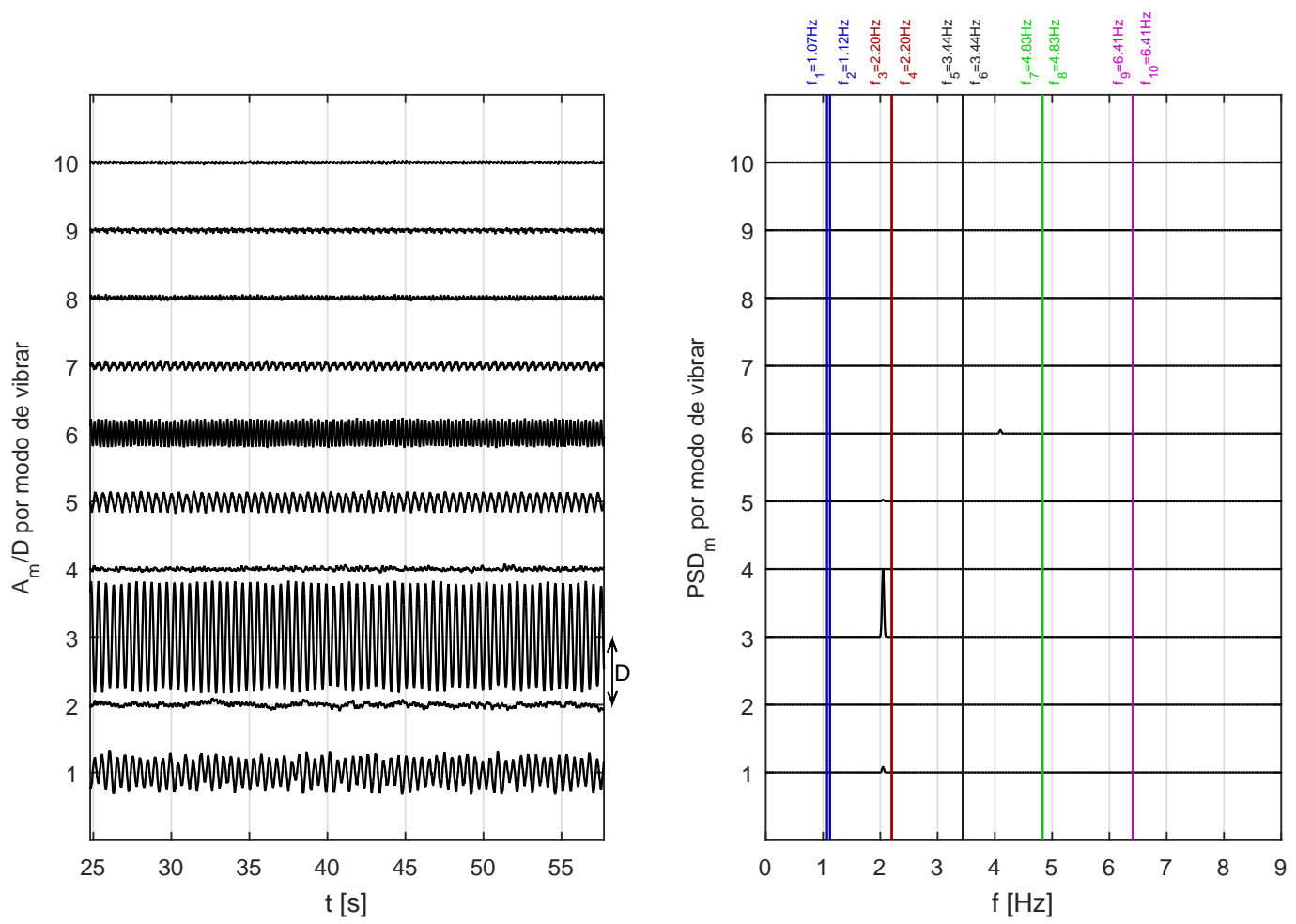

Figura 4.7-Amplitudes Modais e Frequências de Resposta para $V r_{1}=12.11-\theta=10^{\circ} \mathrm{e}$ $\beta=0^{\circ}$.

Nos casos com incidência oblíqua $\left(\beta=45^{\circ}\right.$ e $\beta=135^{\circ}$ ), este comportamento da obtenção de frequências dominantes por patamares quase não é observado. Olhando para o gráfico da frequência para $\theta=10^{\circ} \mathrm{e} \beta=45^{\circ}$, observamos que em praticamente todos os modos a frequência oscilante acompanha a reta da frequência de emissão de vórtices, ou seja, $f_{i} \approx f_{S_{i}}$. Este fato será melhor discutido em um estudo de caso na seção seguinte.

Estes comportamentos observados para as frequências de oscilação estão intrinse-

\footnotetext{
${ }^{2}$ por motivos de concisão utiliza-se a notação, proposta em Rateiro (2014), para facilitar a designação de um modo de vibrar oscilando na frequência de outro.
} 


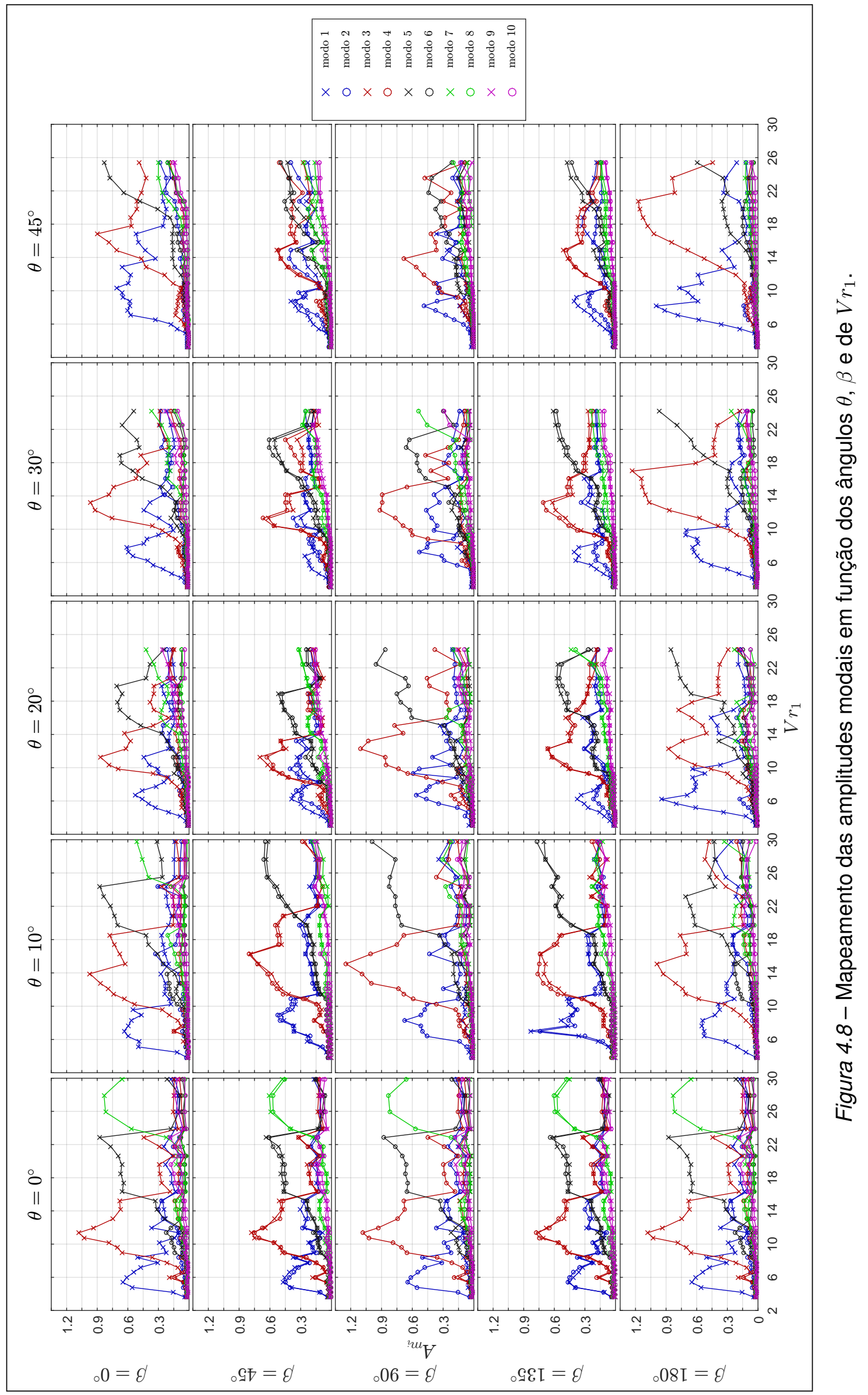


camente ligados ao comportamento multimodal dos cilindros flexíveis. Neste ponto o estudo fica mais claro introduzindo um novo formato de gráfico, apresentado na Figura 4.8, que considera as amplitudes modais em função apenas de $\overline{V r}$, na qual a barra significa que a velocidade reduzida é calculada com base na frequência do primeiro modo e considerando o perfil de correnteza sem descontar as componentes tangenciais, ou seja:

$$
\overline{V r}_{1}=\frac{U}{f_{n_{1}} D}
$$

Assim podemos observar quais modos estão agindo concomitantemente em uma mesma velocidade. Estes gráficos nos dizem que ao passo que a velocidade vai aumentando, independente do azimute ou ângulo de inclinação, vai ocorrendo uma alternância de modos com amplitudes predominantes. Basicamente, em toda faixa de velocidades estudadas foram observadas amplitudes significativas com um modo predominante. Esses gráficos são apresentadas de forma isolada e com mais detalhes no Apêndice C.2.

Nesta região entre a transição de modos ocorrem os chamados "saltos", nos quais há uma alternância repentina de um modo para o outro. Comportamento que pode ser exemplificado na Figura 4.9. No gráfico à esquerda $\left(\overline{V r}_{1}=9.80\right)$, temos uma dominância alternada entre o $1^{\circ} \mathcal{M}$ e $\circ 3^{\circ} \mathcal{M}$. O $1^{\circ} \mathcal{M}$ ainda é sobressalente em termos de amplitude modal, porém observamos que o sistema começa a responder de forma a saltar para o modo $3^{\circ} \mathcal{M}$, ou seja, tem-se uma competição modal. Observando-se as amplitudes para uma velocidade um pouco maior $\left(\overline{V r}_{1}=10.32\right)$, essa alternância já não é mais apresentada. O que ocorre nessa velocidade é uma dominância de oscilação do sistema no $3^{\circ} \mathcal{M}$, ainda que o $1^{\circ} \mathcal{M}$ apresente oscilação, ou seja, tem-se uma coexistência modal.

A Figura 4.10 apresenta um recorte de tempo para as mesmas condições da Figura 4.9, agora do ponto de vista da evolução temporal. Nestes gráficos o eixo vertical é a coordenada curvilínea $s$, o eixo horizontal é o tempo em segundos e as cores representam a amplitude da componente binormal adimensionalizada pelo diâmetro $\boldsymbol{b} / D$.

No gráfico superior é possível observar pelo menos três regiões distintas: região onde prevalece $\circ 1^{\circ} \mathcal{M}$, região onde prevalece o modo $3^{\circ} \mathcal{M}$ e uma região de transição onde não é possível identificar um único modo agindo. $O 1^{\circ} \mathcal{M}$ é identificado por regiões coloridas paralelas que vão alternando do azul pro vermelho. $\mathrm{O} 3^{\circ} \mathcal{M}$ é identificado por apresentar duas regiões coloridas opostas em um mesmo instante de tempo (caracterizando dois "ventres"). Na região de transição esses aspectos nítidos não são observados. 

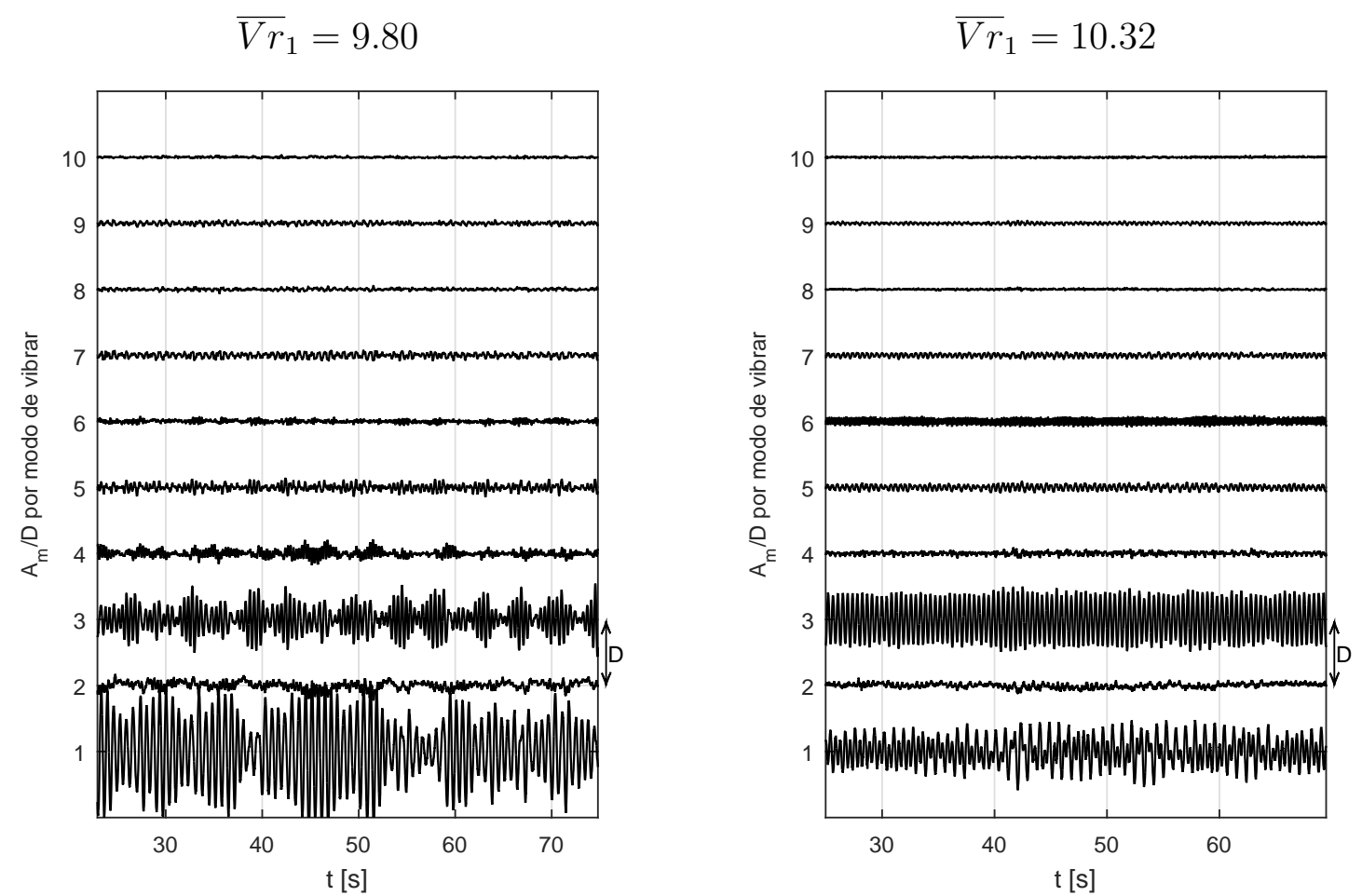

Figura 4.9 - Comparação da avaliação das amplitudes modais para $\overline{V r}_{1}=9.80$ e $\overline{V r}_{1}=10.32$ $-\theta=30^{\circ} \mathrm{e} \beta=180^{\circ}$.
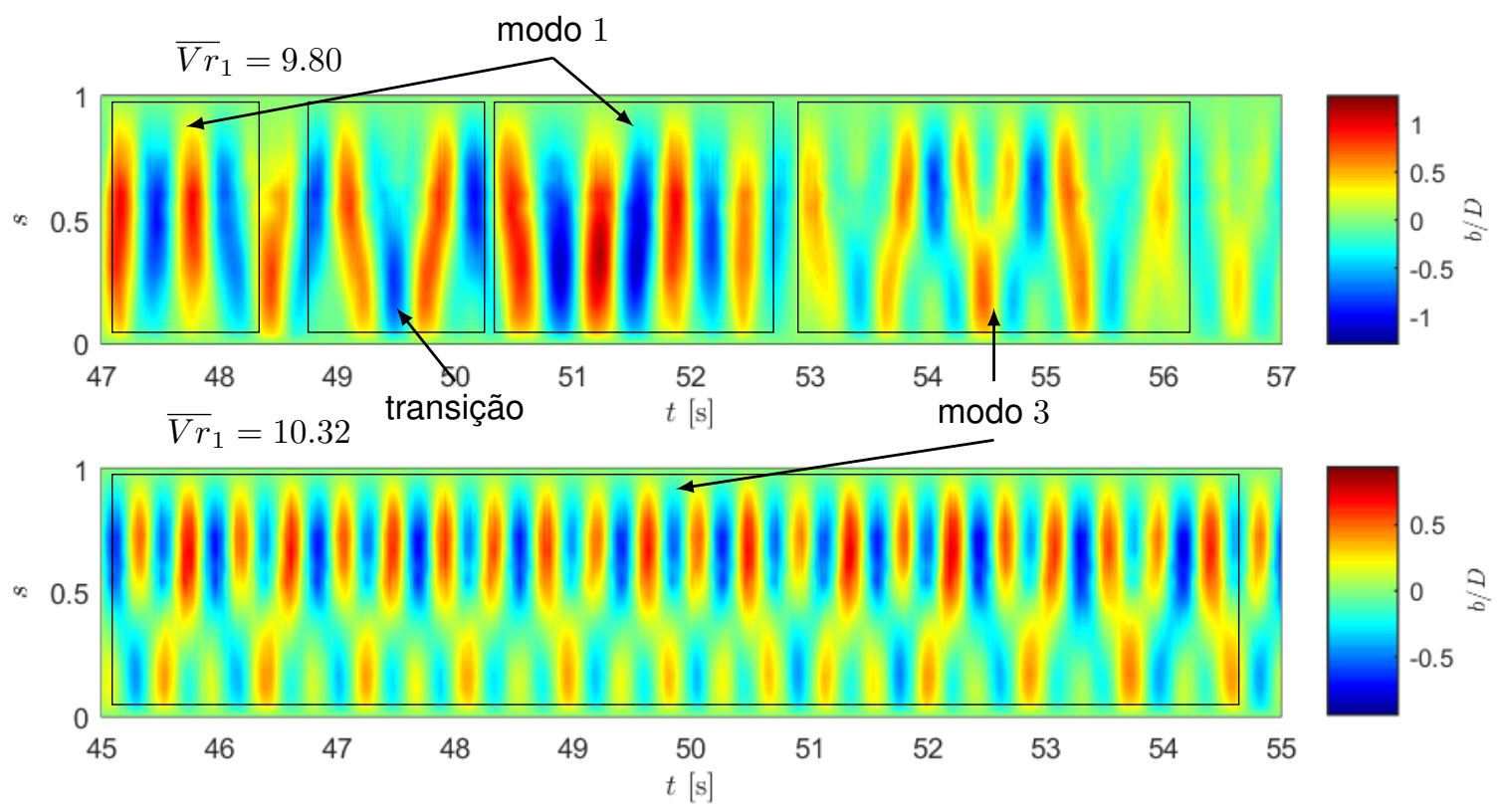

Figura 4.10 - Comparação da evolução temporal da componente binormal entre $\overline{V r}_{1}=9.80 \mathrm{e}$ $\overline{V r}_{1}=10.32-\theta=30^{\circ} \mathrm{e} \beta=180^{\circ}$. 
No gráfico inferior somente $03^{\circ} \mathcal{M}$ prevalece ao longo de todo tempo registrado. Esses comportamentos de transição são típicos dos cilindros flexíveis e foram observados em trabalhos anteriores para sistemas verticais e lançados em catenária, como é o caso de Rateiro (2014). O que se observa aqui é que o mesmo comportamento é obtido em cilindros inclinados em ângulos de até $45^{\circ}$.

Em alguns casos, ocorrem "saltos" permanentes, ou seja, ao invés dos comportamento intermitentes apresentados nas Figuras 4.9 e 4.10, a mudança de modos ocorre uma única vez. Este fato, observado em diversas das velocidades ensaiadas, é apresentado, a partir da série temporal da configuração $\theta=20^{\circ}$ e $\beta=45^{\circ}$, obtida para $\overline{V r}_{1}=14.11$. A Figura 4.11 apresenta a utilização do método da decomposição modal para a análise deste sinal.

O que se vê nesta figura é que o sistema está inicialmente oscilando de maneira concomitante nos $5^{\circ} \mathcal{M}, 6^{\circ} \mathcal{M}, 7^{\circ} \mathcal{M}, 8^{\circ} \mathcal{M}, 9^{\circ} \mathcal{M}$ e $10^{\circ} \mathcal{M}$, sendo o movimento bem evidenciado principalmente para o $5^{\circ} \mathcal{M}$ e o $6^{\circ} \mathcal{M}$. Em torno de 35 s ocorre o "salto" e 0 sistema começa a oscilar principalmente no $3^{\circ} \mathcal{M ~ e ~} 4^{\circ} \mathcal{M}$.

Essa mudança de modos é evidenciada com as evoluções espaço-temporais das componentes normal e binormal apresentadas na Figura 4.12. Em ambas as componentes é nítida a presença de dois nós e três ventres de 20 a $35 \mathrm{~s}$ caracterizando os $5^{\circ} \mathcal{M}$ e $6^{\circ} \mathcal{M}$ e a presença de um nó e dois ventres entre os intervalos de 35 e $50 \mathrm{~s}$, caracterizando o $3^{\circ} \mathcal{M}$ e $04^{\circ} \mathcal{M}$.

Ambos gráficos mostram que as amplitudes modais após o salto são bem maiores que as anteriores, provavelmente porque se tinha a energia distribuída em seis modos distintos e em seguida esta é focalizada em apenas dois. Importante notar a mudança na frequência de oscilação que era $f_{5,6} \approx 2.6 \mathrm{~Hz}$ antes do salto e passou para $f_{3,4}=$ $3.3 \mathrm{~Hz}$ após o mesmo. 

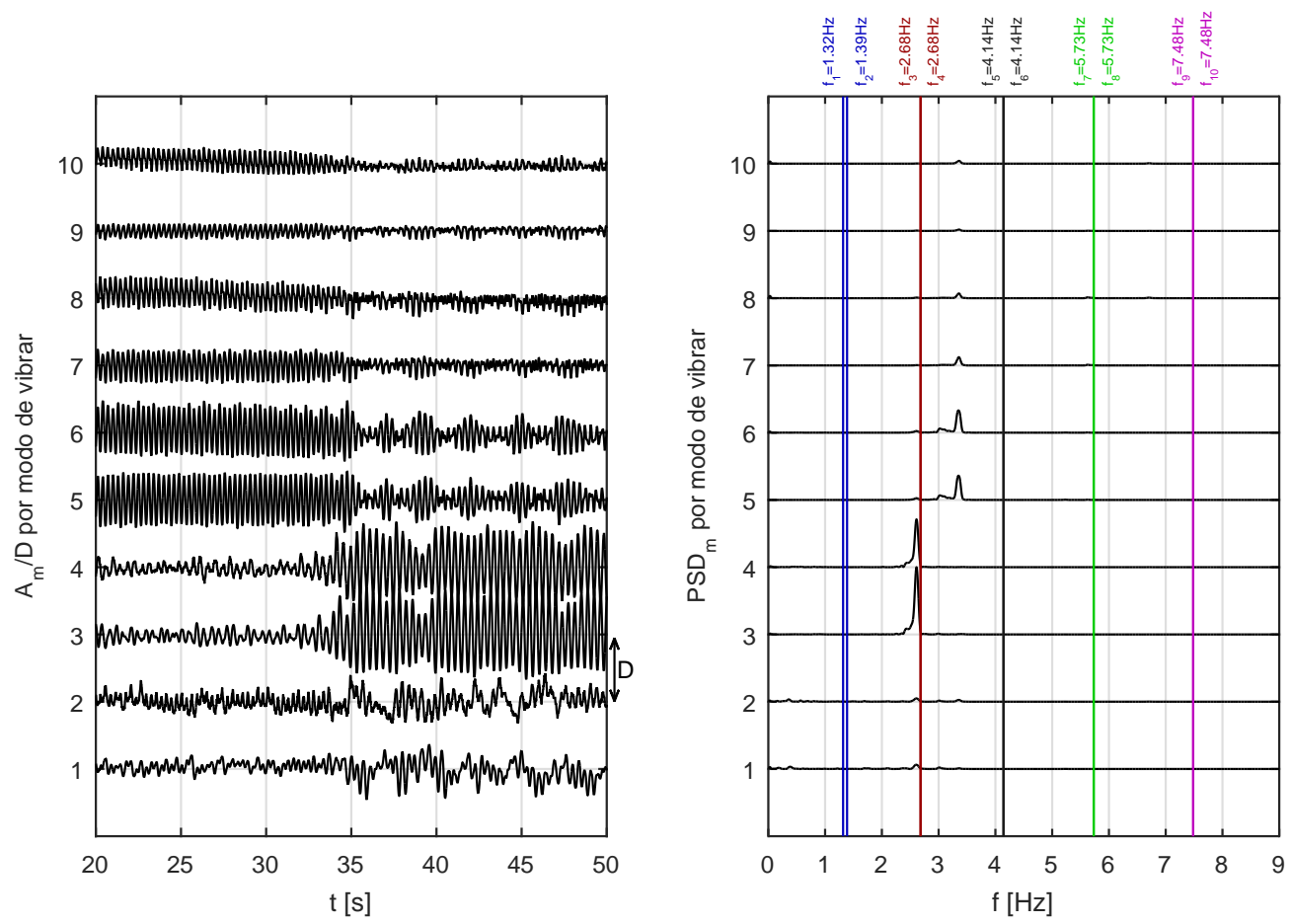

Figura 4.11 - Amplitudes Modais e Frequências de Resposta para $\overline{V r}_{1}=14.11-\theta=20^{\circ} \mathrm{e}$ $\beta=45^{\circ}$.
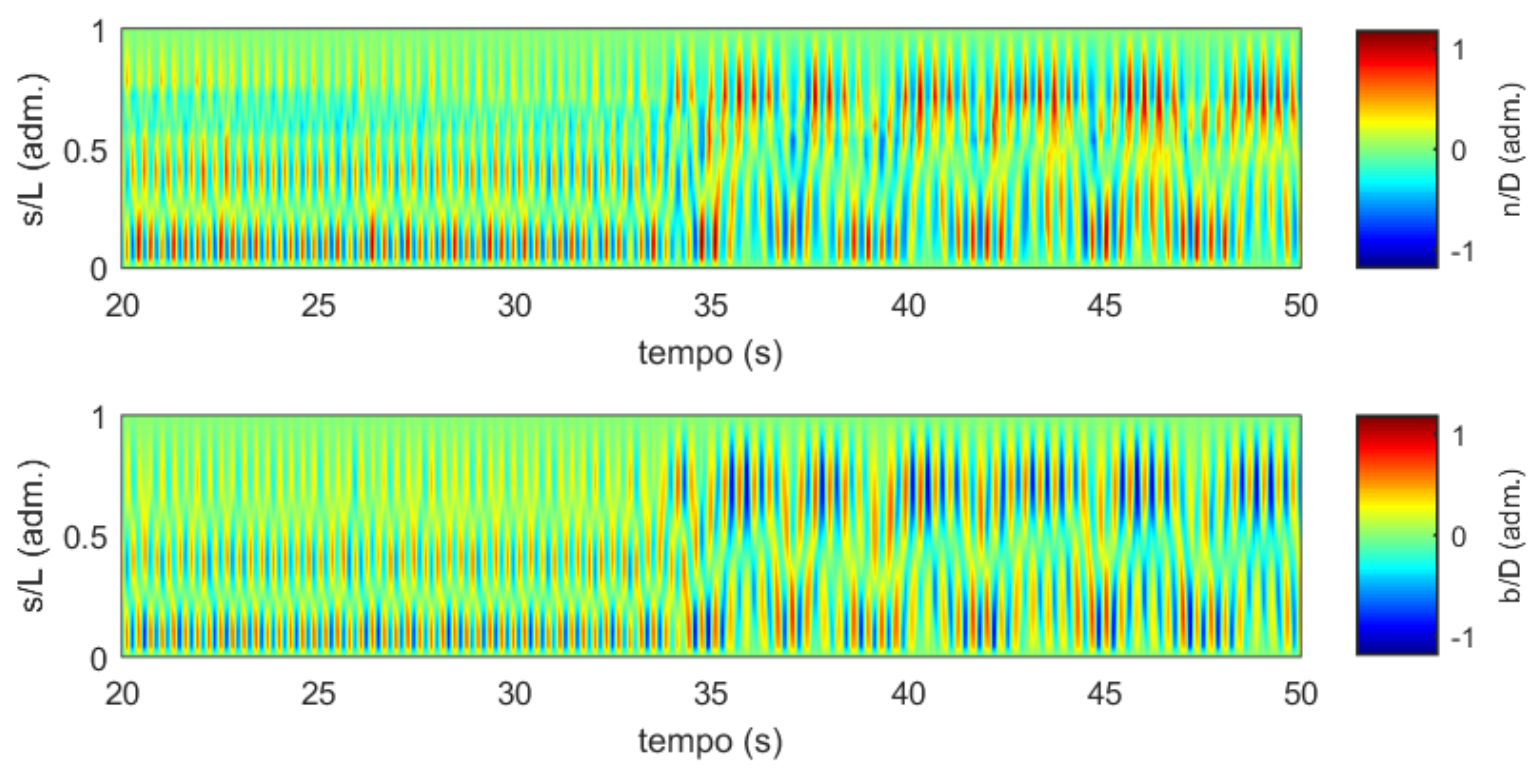

Figura 4.12 - Evolução temporal das componentes normal e binormal para $\overline{V r}_{1}=14.11-$ $\theta=20^{\circ} \mathrm{e} \beta=45^{\circ}$.

Uma análise mais precisa deste fenômeno é possível com a utilização da transformada de Hilbert-Huang, conforme discutido na seção 2.2. Na Figura 4.13 são apresentados os espectros de Hilbert-Huang para as séries temporais do $3^{\circ} \mathcal{M}, 4^{\circ} \mathcal{M}, 5^{\circ} \mathcal{M}$ e $6^{\circ} \mathcal{M}$, 
nos quais é possível observar mais nitidamente o fenômeno de "salto" discutido nos parágrafos anteriores. Um ponto importante é notar que, tanto para o $5^{\circ} \mathcal{M}$ e $06^{\circ} \mathcal{M}$, antes do "salto", como para o $3^{\circ} \mathcal{M}$ e $\circ 4^{\circ} \mathcal{M}$, após este, a frequência apresenta uma correlação maior ao redor dos valores obtidos nos espectro da Figura 4.11. Nos casos em que estes modos não são predominantes, há uma variação muito grande das frequências instantâneas.

Em sistemas como o do presente estudo, no qual as frequências naturais dos modos são bem próximas, o fenômeno de "salto" mais comum é este entre modos, diferente daquele apresentado em Pesce et al. (2006) que é um salto no próprio modo, porém mudando de ramo de resposta.
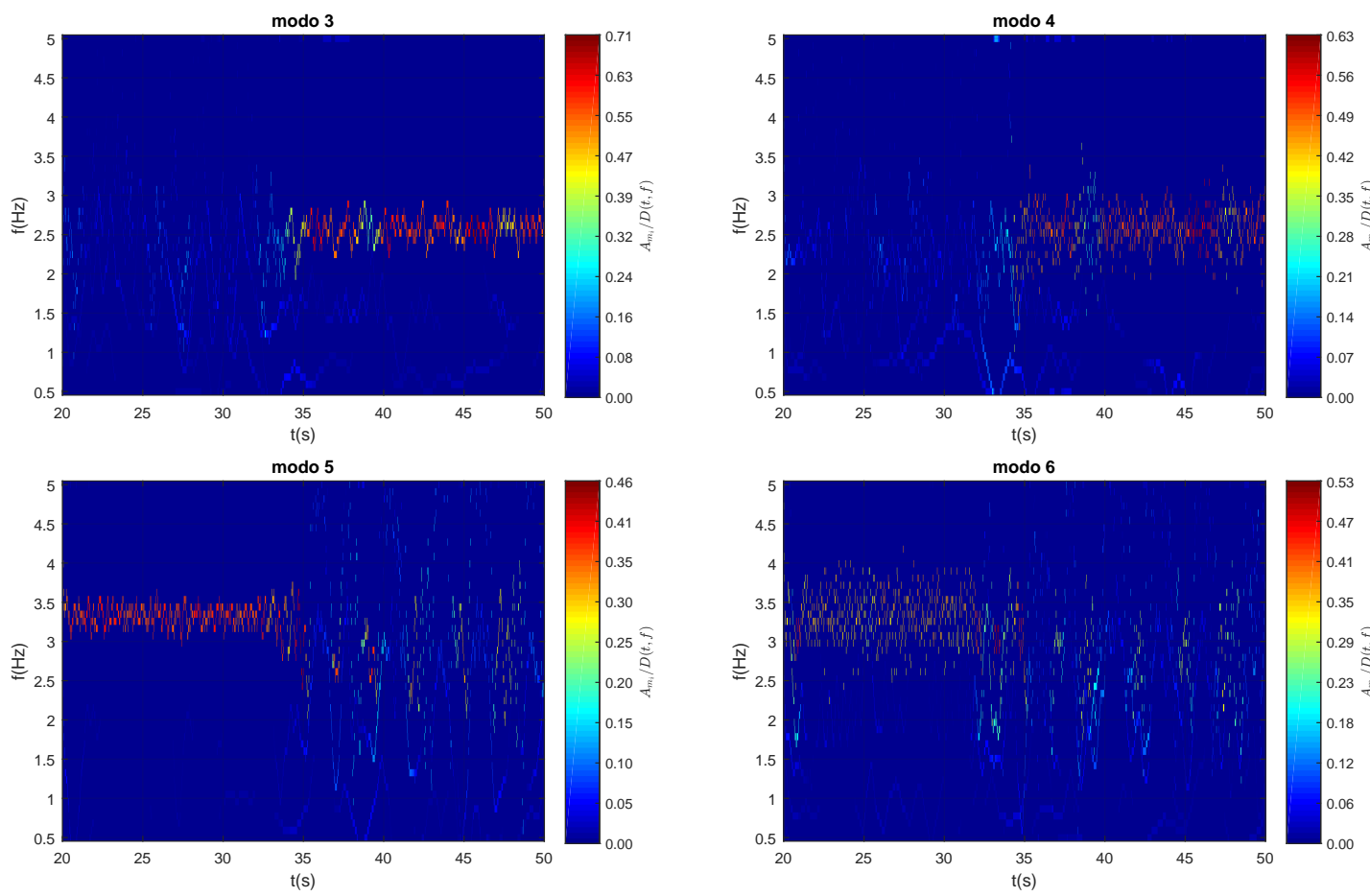

Figura 4.13- Amplitudes modais em função do tempo e da frequência (Espectro de HilbertHuang) para $\overline{V r}_{1}=14.11-\theta=20^{\circ}$ e $\beta=45^{\circ}$.

Retomando a observação das amplitudes, outro ponto interessante, suscitado pelos gráficos da Figura 4.8, diz respeito aos ângulos de azimute oblíquos $\beta=45^{\circ} \mathrm{e}$ $\beta=135^{\circ}$. É possível observar que as curvas de amplitude dos modos ímpares e pares são praticamente idênticas, acompanhando a ordem dos modos, ou seja, $A_{m_{1}}\left(\overline{V r}_{1}\right) \approx$ $A_{m_{2}}\left(\overline{V r}_{1}\right), A_{m_{3}}\left(\overline{V r}_{1}\right) \approx A_{m_{4}}\left(\overline{V r}_{1}\right), A_{m_{5}}\left(\overline{V r}_{1}\right) \approx A_{m_{6}}\left(\overline{V r}_{1}\right), A_{m_{7}}\left(\overline{V r}_{1}\right) \approx A_{m_{8}}\left(\overline{V r}_{1}\right) \mathrm{e}$ $A_{m_{9}}\left(\overline{V r}_{1}\right) \approx A_{m_{10}}\left(\overline{V r}_{1}\right)$, salvo algumas poucas exceções. Este comportamento foi o mesmo obtido por Matsumoto et al. (1990) em túnel de vento e comentado anteriormente na seção 2.3.

Esse é um resultado que implica diretamente na validação do PI se pensado apenas no ângulo de azimute, pois este comportamento ocorre independente do ângulo de in- 
clinação, com a observação que essas relações são mais fracas para o par $1^{\circ} \mathcal{M} / 2^{\circ} \mathcal{M}$ em ângulos à partir de $\theta=20^{\circ}$, provavelmente devido ao fato que as frequências naturais destes modos são distintas. Estudos aprofundados apresentados na seção seguinte irão retomar o assunto e apresentar essas pequenas diferenças.

Para fechar a seção, será introduzida uma outra forma de apresentação gráfica que diz respeito às trajetórias dos alvos fixados ao longo do modelo. Como exemplo, a Figura 4.14 apresenta uma comparação das trajetórias para diferentes valores de $\overline{V r}_{1}$, compreendendo regiões em que $01^{\circ} \mathcal{M}, 3^{\circ} \mathcal{M}, 5^{\circ} \mathcal{M}$ e $7^{\circ} \mathcal{M}$ são praticamente dominantes. O eixo horizontal apresenta movimentação na direção binormal, enquanto o eixo vertical apresenta a movimentação na direção normal. Na vertical as trajetórias de cada alvo foram centradas na coordenada $s \times 10$ para facilitar a visualização espacial, tanto da posição que o alvo ocupa no modelo, quanto da amplitude do movimento. Nestes casos a unidade representa a movimentação de magnitude um diâmetro.

Somente nesse exemplo, que compreende o caso de referência vertical $\left(\theta=0^{\circ} \mathrm{e}\right.$ $\beta=0^{\circ}$ ) já é possível notar uma grande variedade de padrões conhecidos do estudo de VIV, como padrões em "C", em "8", regiões com trajetórias mais definidas, regiões com trajetórias menos definidas e, o mais importante, que padrões diferentes ocorrem simultaneamente para diferentes coordenadas $s$ em uma mesma velocidade reduzida. Este aspecto aponta a já comentada natureza tridimensional intrínseca ao comportamento dinâmico de linhas flexíveis.

\subsection{Análises aprofundada em regiões de interesse}

Nesta seção foram propostas apenas algumas análises mais aprofundadas em regiões de interesse, tais como as regiões onde são obtidas efeitos ressonantes máximos e regiões de comportamento multimodal. Essas regiões foram escolhidas de forma a complementar a análise mais geral apresentada na seção anterior.

\subsubsection{Amplitudes Máximas para $\beta=0^{\circ}$}

Neste primeiro tópico é investigada a influência da inclinação do modelo no comportamento do sistema para cada uma das velocidades em que apresentou máxima amplitude modal de oscilação. As velocidades reduzidas $\overline{V r}_{1}$ estudadas estão apresentadas na Tabela 4.5. A Figura 4.15 mostra o conjunto de séries temporais dos modos de vibrar para cada um dos ângulos de inclinação. 


$$
\overline{V r}_{1}=5.38 \quad \overline{V r}_{1}=11.96 \quad \overline{V r}_{1}=19.58 \quad \overline{V r}_{1}=31.89
$$
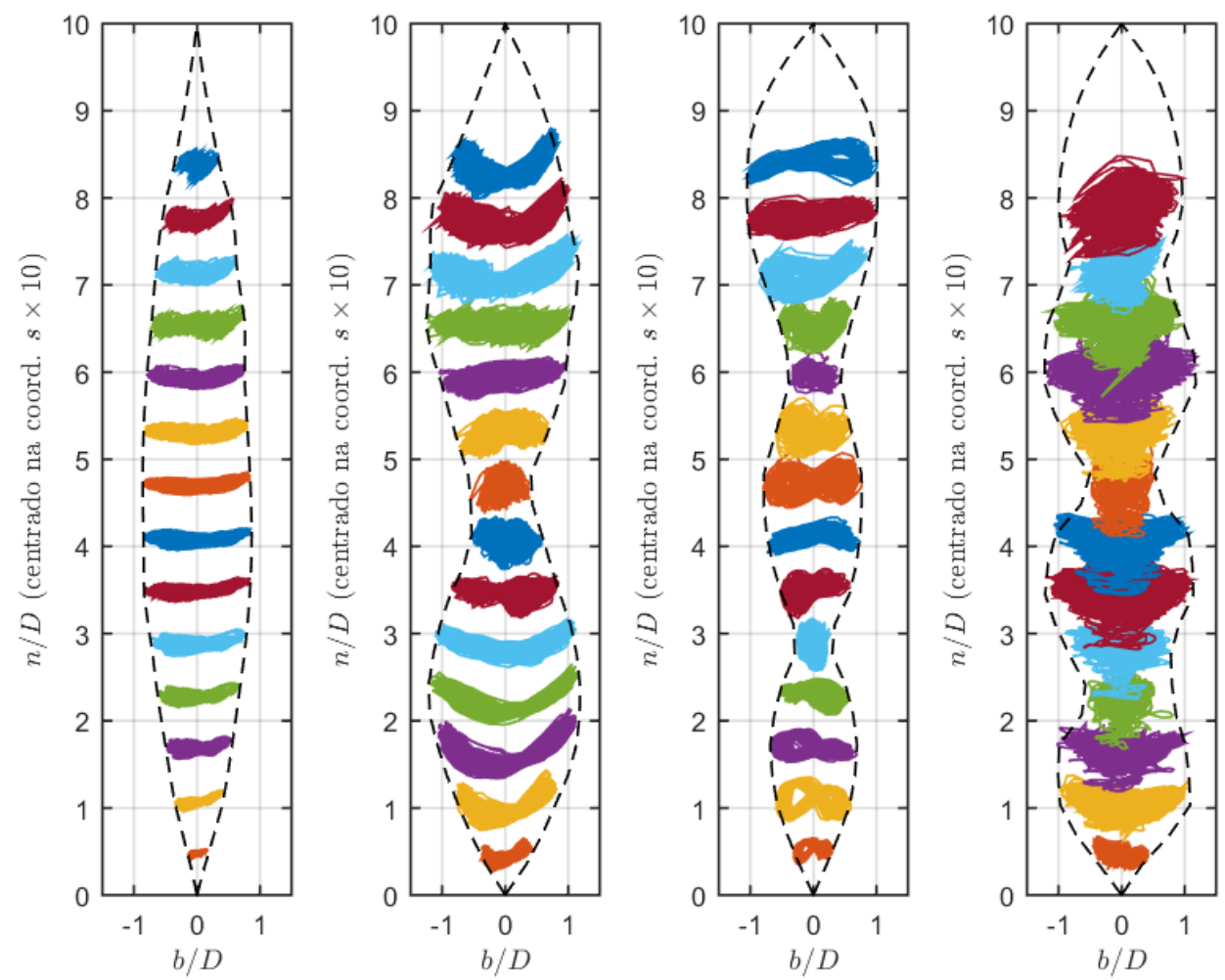

Figura 4.14 - Comparação entre os resultados para diferentes $\overline{V r}_{1}$ das trajetórias obtidas nas velocidades que apresentaram a amplitude máxima de vibração para $01^{\circ} \mathcal{M}$, $3^{\circ} \mathcal{M}, 5^{\circ} \mathcal{M}$ e $7^{\circ} \mathcal{M}-\beta=0^{\circ}$ e $\theta=0^{\circ}$.

Tabela 4.5 - Velocidades reduzidas, $\overline{V r}_{1}$, estudadas na seção $4.3 .1-\beta=0^{\circ}$.

\begin{tabular}{cc}
\hline$\theta$ & $\overline{V r}_{1}\left(A_{m_{i}}^{\max }\right)$ \\
\hline $0^{\circ}$ & 11.36 \\
$10^{\circ}$ & 13.90 \\
$20^{\circ}$ & 11.28 \\
$30^{\circ}$ & 13.21 \\
$45^{\circ}$ & 16.83 \\
\hline
\end{tabular}

Como pode ser notado, o comportamento geral do sistema é bem parecido para estas velocidades: amplitude vibração do modo $3^{\circ} \mathcal{M}$, da ordem de um diâmetro, e a presença de oscilações menores no $1^{\circ} \mathcal{M}, 5^{\circ} \mathcal{M}$ e $6^{\circ} \mathcal{M}$. Ao passo que se aumenta a inclinação a contribuição do $1^{\circ} \mathcal{M}$ torna-se mais significativa. Olhando para a primeira fileira de gráficos da Figura 4.8 pode-se ver que para os ângulos $\theta=20^{\circ}, 30^{\circ} \mathrm{e} 45^{\circ}$, o 
$1^{\circ} \mathcal{M}$ possui um comportamento bem particular: existe uma primeira região onde o sistema oscila predominantemente no $1^{\circ} \mathcal{M}$ e com o aumento da velocidade ele começa a decair dando lugar à predominância do $3^{\circ} \mathcal{M}$. No entanto, nas inclinações apontadas, um novo ramo de ressonância para o $1^{\circ} \mathcal{M}$, com uma amplitude $A_{m_{1}} \approx 0.45 D$, ligeiramente menor do que o primeiro ramo $A_{m_{1}} \approx 0.65 D$, enquanto para $\circ 3^{\circ} \mathcal{M}$ tem-se $A_{m_{3}} \approx 1.0 D$.

A Figura 4.16 apresenta as densidades espectrais para os mesmos casos estudados. A frequência do modo principal atuante em todos os casos está um pouco abaixo da frequência natural, ou seja, na amplitude máxima $f_{3}<f_{n_{3}}$, exceto para $\theta=10^{\circ}$ onde são praticamente coincidentes. Além disso, tem-se $1^{\circ} \mathcal{M}\left\langle f_{3}\right\rangle$ e $5^{\circ} \mathcal{M}\left\langle f_{3}\right\rangle$. Já o $6^{\circ} \mathcal{M}$ apresenta em todos os casos uma frequência aproximadamente duas vezes maior que o $3^{\circ} \mathcal{M}$, ou seja, $f_{6} \approx 2 f_{3}$.

O comportamento do $6^{\circ} \mathcal{M}$ em relação ao $3^{\circ} \mathcal{M}$ é justamente o comportamento clássico observado para cilindros rígidos em dois graus de liberdade, sendo o $3^{\circ} \mathcal{M}$ correspondente à oscilação cross-flow e o $6^{\circ} \mathcal{M}$ à oscilação in-line

A Figura 4.17 apresenta a evolução espaço-temporal da componente binormal para um intervalo de 30 s do sinal de cada um dos casos estudados. Estes gráficos suscitam mais algumas diferenças que não são passíveis de observação com as séries temporais e as densidades espectrais.

Uma das diferenças aparentes é na amplitude ao longo do comprimento do modelo das metades inferiores $(0<s<0.5)$ e superiores $(0.5<s<1.0)$, conforme se aumenta o ângulo de inclinação. No caso vertical, a intensidade das cores é praticamente a mesma nestas duas regiões. Nos casos inclinados, claramente a metade inferior apresenta cores menos intensas, o que representa uma menor amplitude de oscilação. As cores são menos intensas conforme a inclinação aumenta. Já o trecho superior permanece com a mesma intensidade de cores, independente do ângulo de inclinação.

Outro fato é uma ligeira intermitência do modo dominante $\left(3^{\circ} \mathcal{M}\right)$ para ângulos $\theta>0^{\circ}$, representado pelas faixas amarelas inclinadas que ligam dois ventres vermelhos e pelas faixas azul claro que ligam dois ventres azuis. Essas faixas denotam o comportamento semelhantes aos obtidos em sistemas com travelling waves, ou seja, ondas que "viajam" ao longo do comprimento da linha sem apresentar nós fixos, provavelmente relacionado ao fato que $1^{\circ} \mathcal{M}\left\langle f_{3}\right\rangle$ e $5^{\circ} \mathcal{M}\left\langle f_{3}\right\rangle$, já mencionado anteriormente. Como o $1^{\circ} \mathcal{M}$ e $\circ 5^{\circ} \mathcal{M}$ são modos simétricos e $\circ 3^{\circ} \mathcal{M}$ é anti-simétrico a combinação da fase entre esses três modos gera o comportamento descrito acima. 

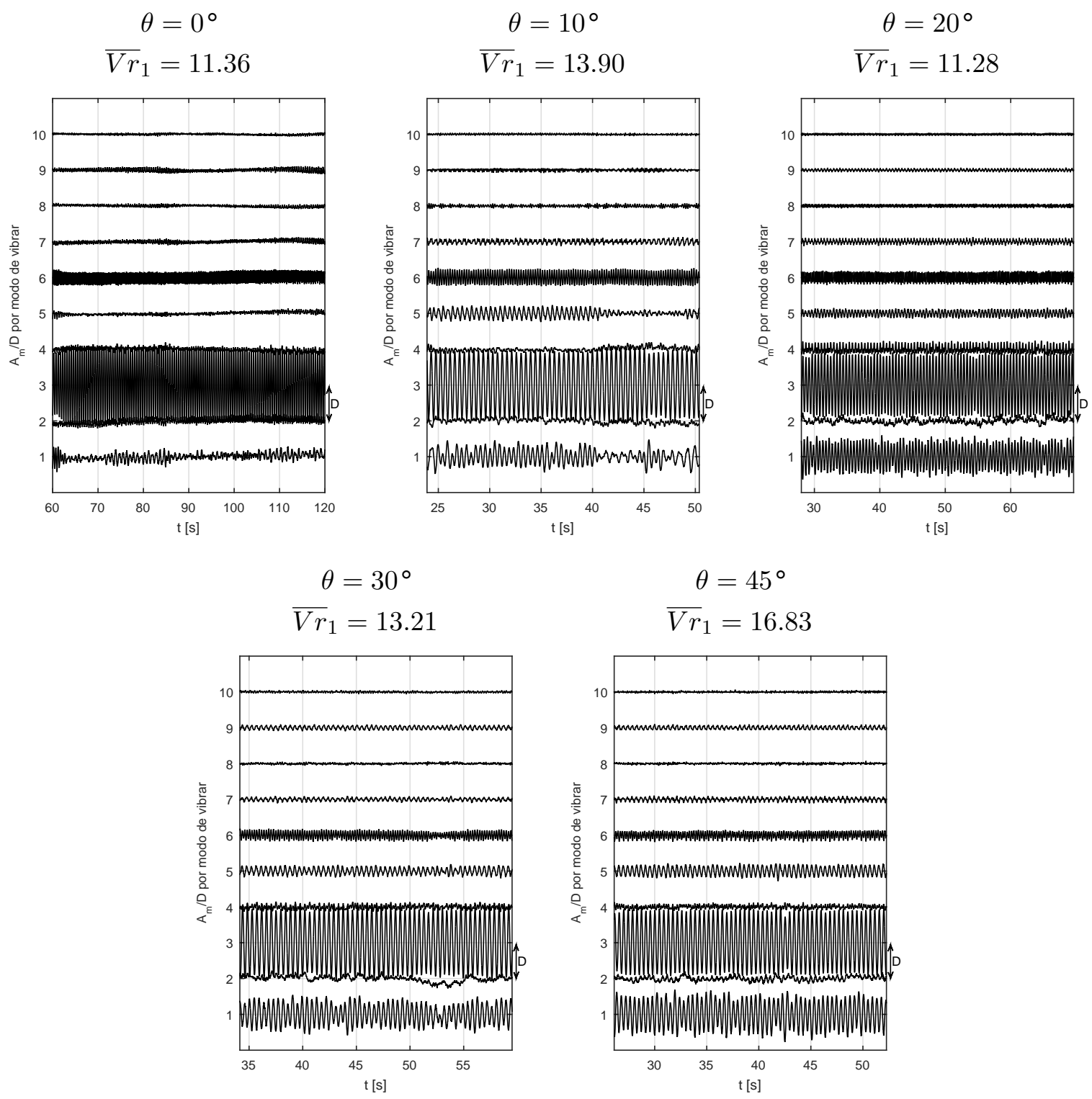

Figura 4.15 - Amplitudes modais referentes aos ângulos de inclinação e velocidades reduzidas apresentados na Tabela $4.5-\beta=0^{\circ}$. 

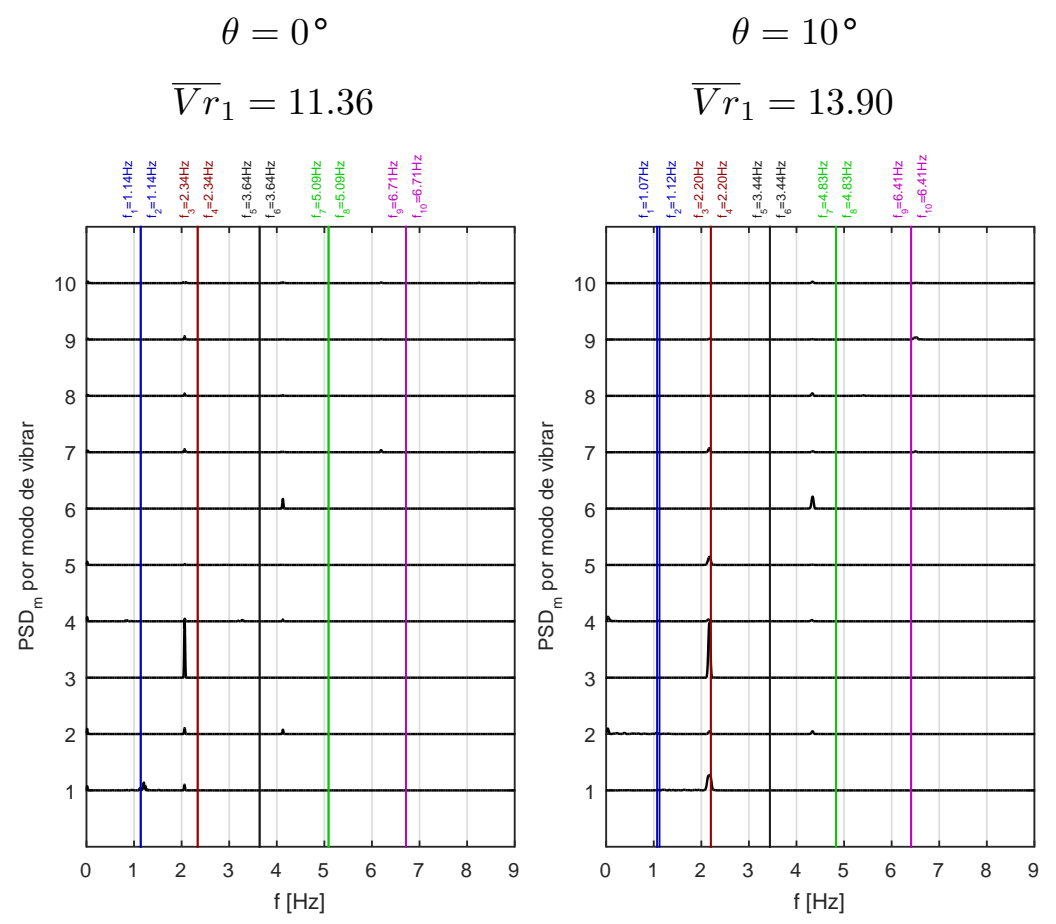

$$
\begin{gathered}
\theta=20^{\circ} \\
\overline{V r}_{1}=11.28
\end{gathered}
$$
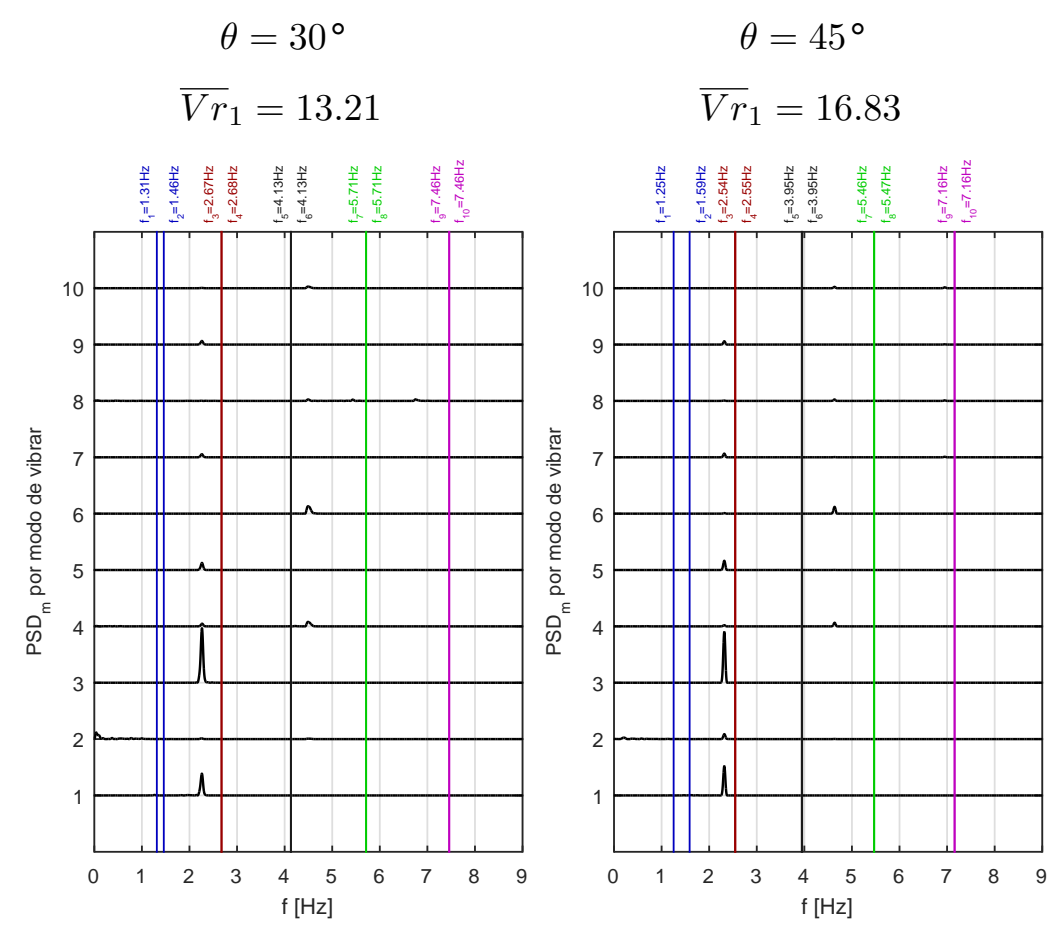

Figura 4.16 - Densidades espectrais referentes aos ângulos de inclinação e velocidades reduzidas apresentados na Tabela $4.5-\beta=0^{\circ}$. 

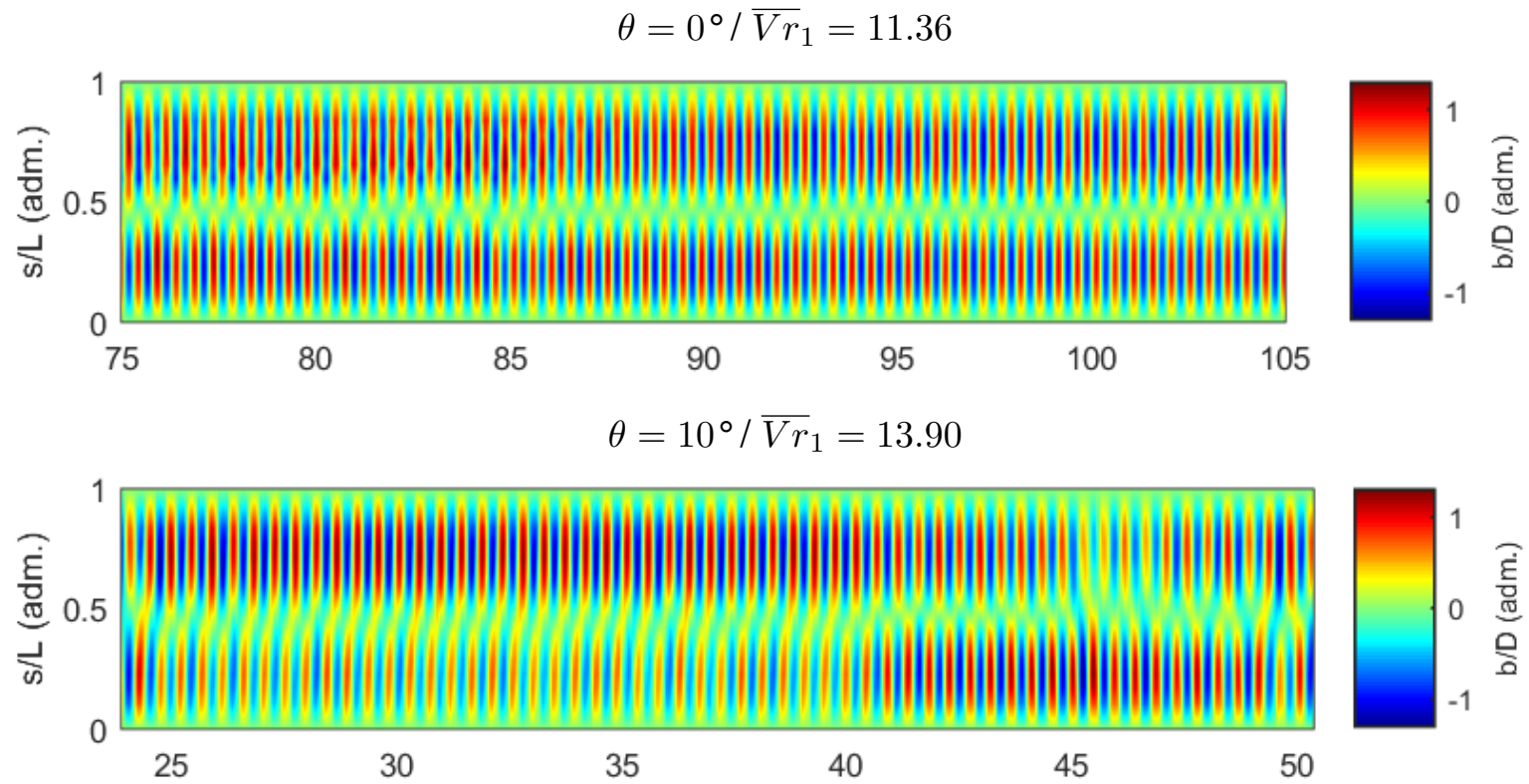

$\theta=20^{\circ} / \overline{V r}_{1}=11.28$

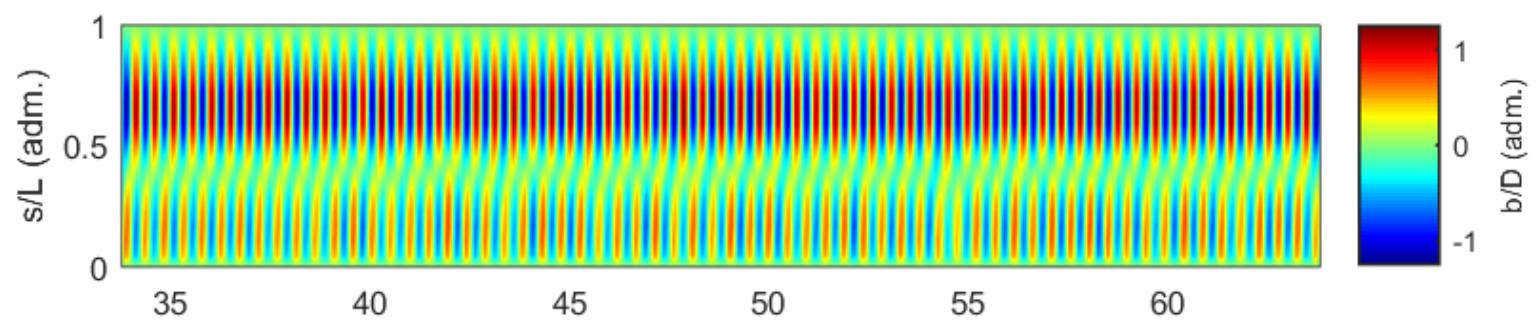

$\theta=30^{\circ} / \overline{V r}_{1}=13.21$
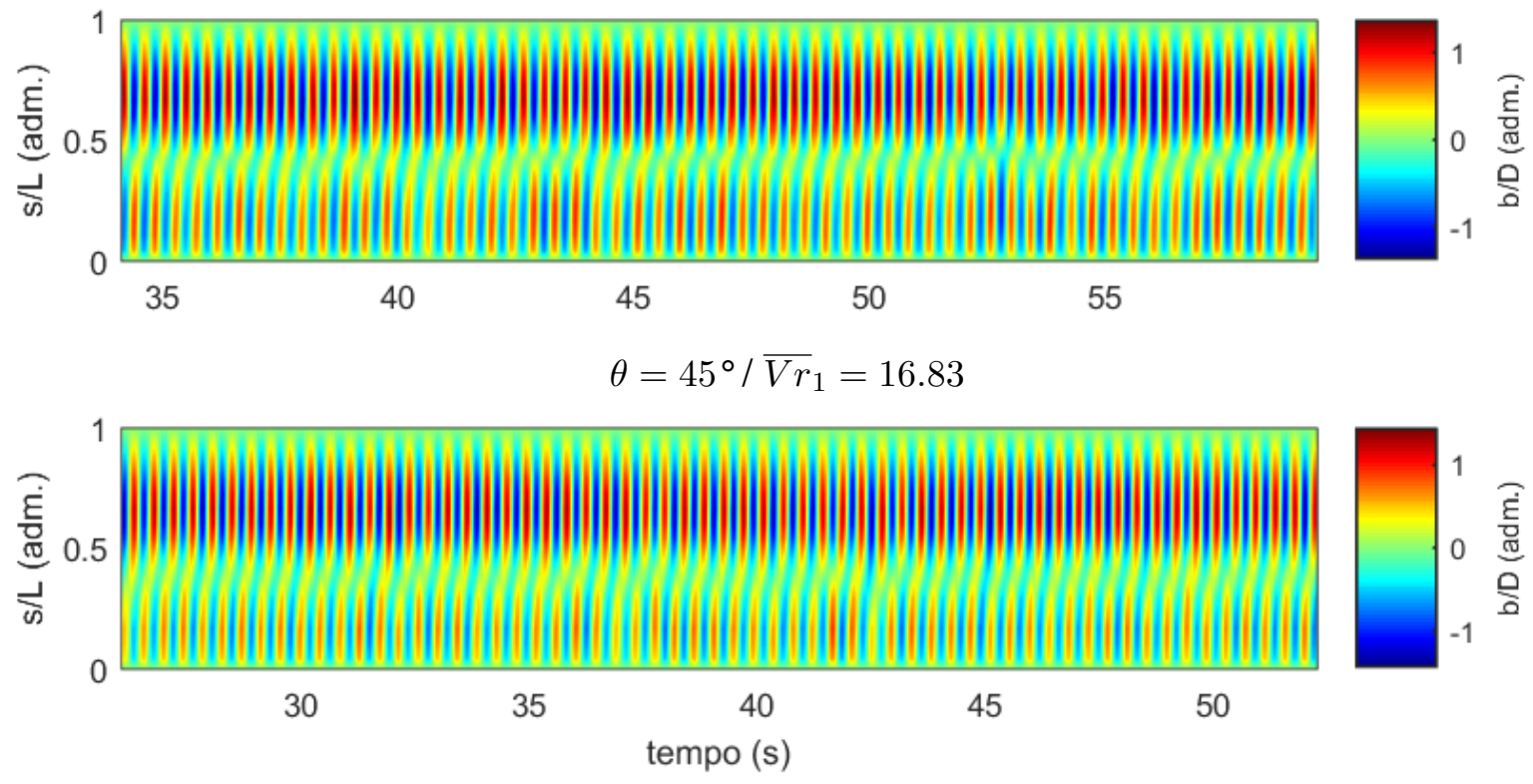

Figura 4.17- Evoluções espaço-temporais referentes aos ângulos de inclinação e velocidades reduzidas apresentados na Tabela $4.5-\beta=0^{\circ}$. 


\subsubsection{Região de transição para $\beta=135^{\circ}$}

Uma segunda região de interesse no presente estudo é a influência da inclinação do modelo à jusante do escoamento na região de transição entre modos, ou seja, na região onde há a troca na dominância dos modos de vibrar. Como estudo de caso, nesta seção são apresentadas algumas velocidades obtidas para as configurações $\operatorname{com} \beta=135^{\circ}$. As velocidades escolhidas (Tabela 4.6) são aquelas logo antes de haver a troca entre a dominância entre $1^{\circ} \mathcal{M}$ e $2^{\circ} \mathcal{M}$ para a dominância entre $3^{\circ} \mathcal{M}$ e $4^{\circ} \mathcal{M}$.

Tabela 4.6 - Velocidades reduzidas, $\overline{V r}_{1}$, estudadas na seção $4.3 .2-\beta=135^{\circ}$.

\begin{tabular}{cc}
\hline$\theta$ & $\overline{V r}_{1}\left(A_{m_{i}}^{\max }\right)$ \\
\hline $0^{\circ}$ & 8.37 \\
$10^{\circ}$ & 10.84 \\
$20^{\circ}$ & 8.28 \\
$30^{\circ}$ & 8.82 \\
$45^{\circ}$ & 9.79 \\
\hline
\end{tabular}

Na Figura 4.18 são apresentadas as séries temporais referentes a estas velocidades. Como dito, em comum os gráficos possuem o fato que a amplitudes médias dos extremos do $1^{\circ} \mathcal{M}$ e $2^{\circ} \mathcal{M}$ são ligeiramente maiores que as amplitudes médias dos extremos do $3^{\circ} \mathcal{M ~ e ~} 4^{\circ} \mathcal{M}$. Por se tratar de uma região de transição, o que se observa é justamente um comportamento de alternância entre os referidos modos. Esse comportamento é notado principalmente em $\theta=0^{\circ} \mathrm{e} \theta=10^{\circ}$.

Um fato um pouco mais interessante decorre se for olhada a série temporal dos modos em duplas: $1^{\circ} \mathcal{M} / 2^{\circ} \mathcal{M}$ e $3^{\circ} \mathcal{M} / 4^{\circ} \mathcal{M}$, como no exemplo da Figura 4.19, que apresenta um recorte de tempo dos sinais para $\theta=10^{\circ}$. O que se observa do conjunto de sinais desses modos é a relação $A_{m_{1}}(t) \approx A_{m_{2}}(t)$ e $A_{m_{3}}(t) \approx A_{m_{4}}(t)$. De fato ao se comparar os diversos sinais o que se observa para outras velocidades é que, para $\beta=135^{\circ}$, tem-se uma relação muito próxima à

$$
A_{m_{i}}(t) \approx A_{m_{i+1}}(t) \text { sendo } i \text { ímpar. }
$$

Este fato está de acordo com o $\mathrm{PI}$, uma vez que pelo princípio, se o caso $\operatorname{com} \beta=0^{\circ}$ possuir amplitude $A_{m_{i}}^{\left(0^{\circ}\right)}(t)$, o caso para $\beta=135^{\circ}$ deverá possuir: 

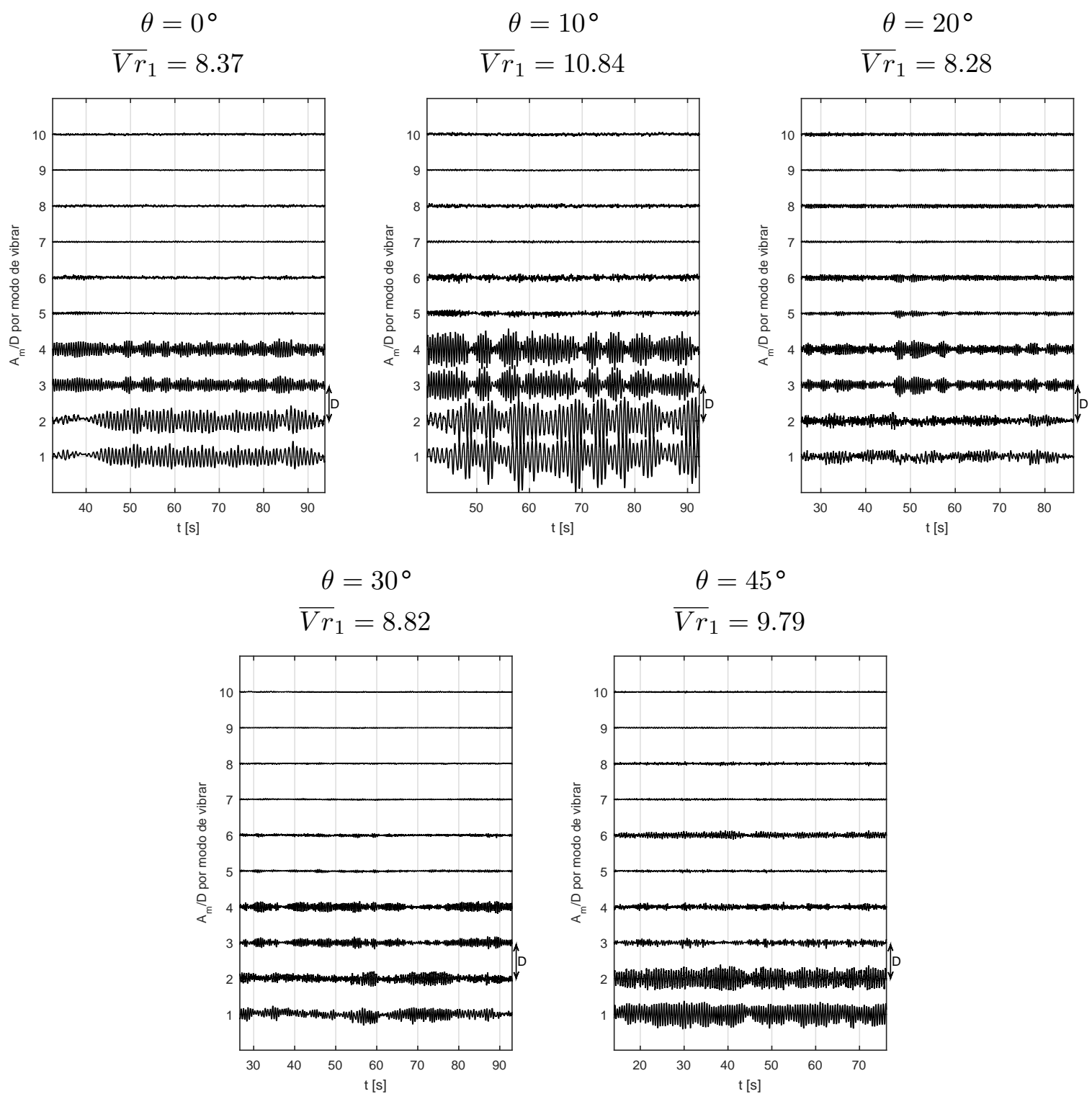

Figura 4.18 - Amplitudes modais referentes aos ângulos de inclinação e velocidades reduzidas apresentados na Tabela $4.6-\beta=135^{\circ}$. 


$$
\begin{gathered}
A_{m_{i}}^{\left(135^{\circ}\right)}(t)=A_{m_{i}}^{\left(0^{\circ}\right)}(t) \cdot \cos \left(135^{\circ}\right) \text { para modos ímpares } \\
A_{m_{i}}^{\left(135^{\circ}\right)}(t)=A_{m_{i}}^{\left(0^{\circ}\right)}(t) \cdot \operatorname{sen}\left(135^{\circ}\right) \text { para modos pares }
\end{gathered}
$$

e no caso para $\beta=135^{\circ}$ tem-se que $\cos \left(135^{\circ}\right)=-\operatorname{sen}\left(135^{\circ}\right)$.
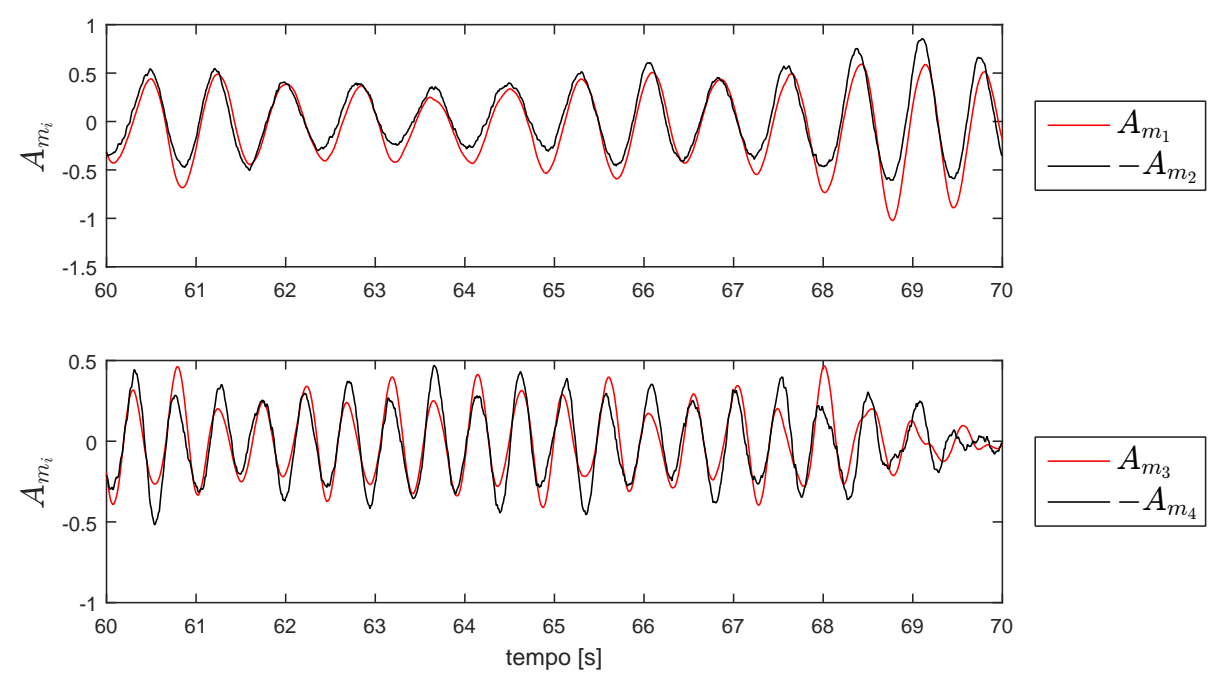

Figura 4.19-Comparação de um trecho das séries temporais de amplitude para os pares: $1^{\circ} \mathcal{M} / 2^{\circ} \mathcal{M}$ e $3^{\circ} \mathcal{M} / 4^{\circ} \mathcal{M}-\beta=135^{\circ}$ e $\theta=10^{\circ}$.

Este último aspecto nos leva a concluir que a vibração ocorre sempre na mesma frequência para os pares de modos, provavelmente na frequência de emissão de vórtices que se dá num plano oblíquo aos dois modos, como já apontado na seção anterior. Sendo assim, independente do azimute a linha apresenta comportamento dinâmico muito próximo de se considerar as direções in-line e cross-flow para cada coordenada $s$. Essa obervação ocorre independente de regiões de transição ou regiões de modos dominantes.

Na Figura 4.18 a amplitude maior do caso $\theta=10^{\circ}$ é atribuído à questão de seu menor tracionamento, como comentado anteriormente, porém sem prejuízo ao comentário tecido no parágrafo anterior.

As maiores diferenças quanto à utilização do PI para a previsão da amplitude de oscilação ocorrem justamente para $01^{\circ} \mathcal{M}$ e $02^{\circ} \mathcal{M}$. Devido à rigidez geométrica, estes modos possuem frequências naturais distintas, que acabam resultando em amplitudes modais distintas. No entanto, estas diferenças são observadas apenas para os ângulos de inclinação mais altos, a partir de $\theta=20^{\circ}$, e serão abordadas no estudo de caso seguinte. 


\subsubsection{Amplitudes máximas do $1^{\circ} \mathcal{M}$ e do $2^{\circ} \mathcal{M}$ para $\beta=135^{\circ}$}

Com base no que foi levantado das observações do estudo de caso anterior, um novo tópico foi proposto para entender melhor como que o $1^{\circ} \mathcal{M}$ e $\circ 2^{\circ} \mathcal{M}$ interagem devido a diferença na frequência natural resultante da rigidez geométrica imposta pelo formato inerente de catenária.

Observando os gráficos para $\beta=135^{\circ}$ apresentados na Figura 4.8 percebe-se que para $\theta=20^{\circ}, 30^{\circ} \mathrm{e} 45^{\circ}$, as amplitudes modais $A_{m_{1}}$ e $A_{m_{2}}$ diferem um pouco, ao contrário do comportamento dos outros modos em que permanecem iguais aos pares, conforme comentário tecido no estudo anterior.

Para entender este fato, serão estudadas as velocidades reduzidas apresentadas na Tabela 4.7.

Tabela 4.7- Velocidades reduzidas, $\overline{V r}_{1}$, estudadas na seção $4.3 .3-\beta=135^{\circ}$.

\begin{tabular}{cc}
\hline$\theta$ & $\overline{V r}_{1}\left(A_{m_{i}}^{\max }\right)$ \\
\hline $0^{\circ}$ & 5.38 \\
$10^{\circ}$ & 7.01 \\
$20^{\circ}$ & 6.21 \\
$30^{\circ}$ & 7.26 \\
$45^{\circ}$ & 8.70 \\
\hline
\end{tabular}

As séries temporais das amplitudes modais para as velocidades reduzidas da Tabela 4.7 estão apresentadas na Figura 4.20. Como esperado, as séries temporais refletem o comportamento típico da região de lock-in: amplitudes ressonantes significativas apenas no $1^{\circ} \mathcal{M}$ e no $2^{\circ} \mathcal{M}$, frequências de oscilação muito próximas das frequências naturais, como pode ser observado nos gráficos de densidade espectral da Figura 4.21.

Um fato interessante observado principalmente para $\theta=45^{\circ}$ é que ambos modos $\left(1^{\circ} \mathcal{M}\right.$ e $\left.2^{\circ} \mathcal{M}\right)$ oscilam com uma frequência coincidente com $f_{2}$ que é justamente $o$ modo que sofre a influência da rigidez geométrica por estar contido no plano da catenária. Justamente para o $2^{\circ} \mathcal{M}$ as amplitudes modais são claramente menores que para o $1^{\circ} \mathcal{M}$, fato que não ocorreu para $\theta=0^{\circ}$ e $\theta=10^{\circ}$.

Pelas linhas azuis verticais dos gráficos da Figura 4.21 e pelos resultados de frequência natural apresentados anteriormente na Tabela 4.3 percebe-se que conforme se aumenta a inclinação do modelo, maior é a diferença entre $f_{n_{1}}$ e $f_{n_{2}}$, sendo que para 
$\theta=0^{\circ} \mathrm{e} \theta=10^{\circ}$,estas frequências são praticamente coincidentes.
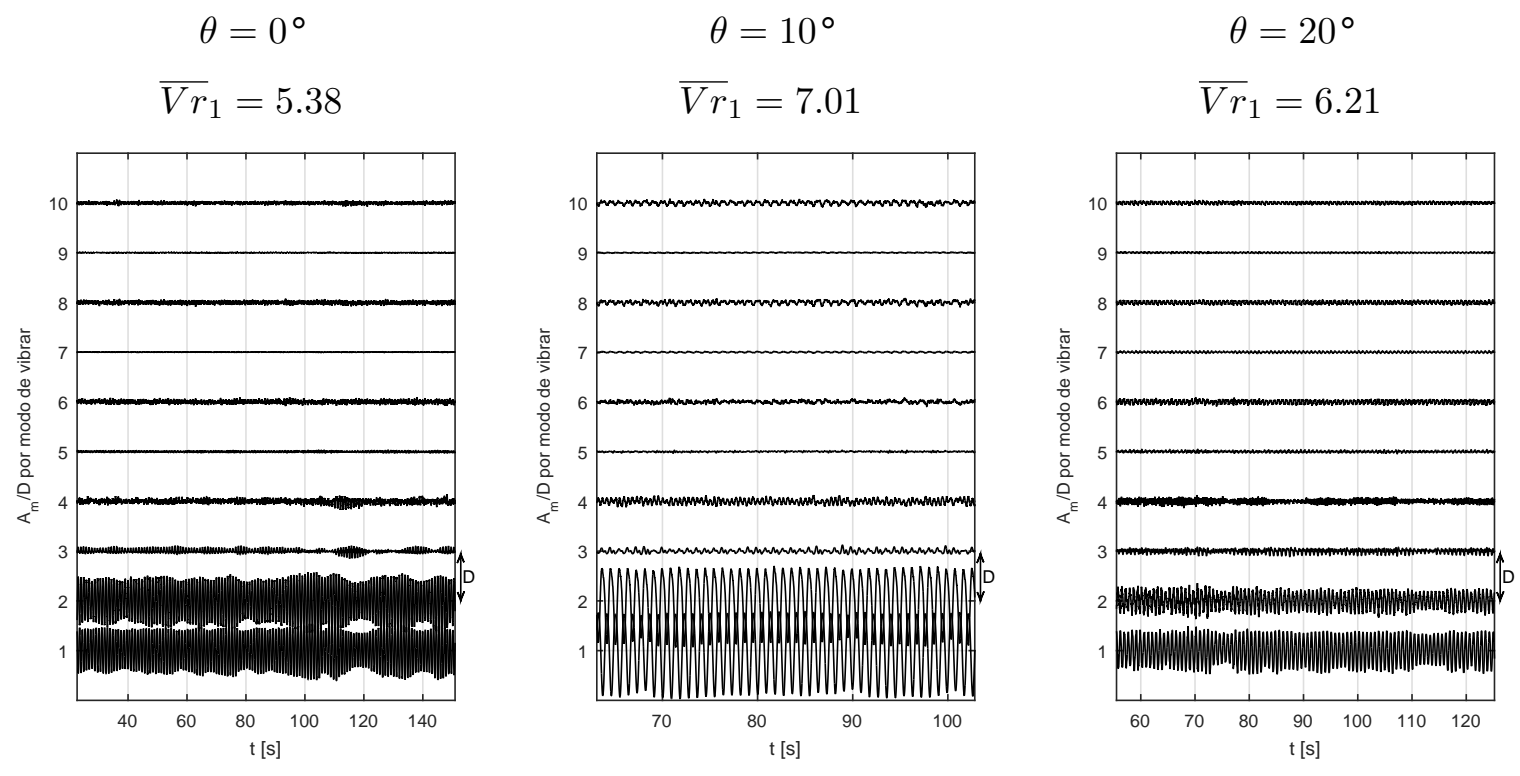

$$
\begin{gathered}
\theta=30^{\circ} \\
\overline{V r}_{1}=7.26
\end{gathered}
$$
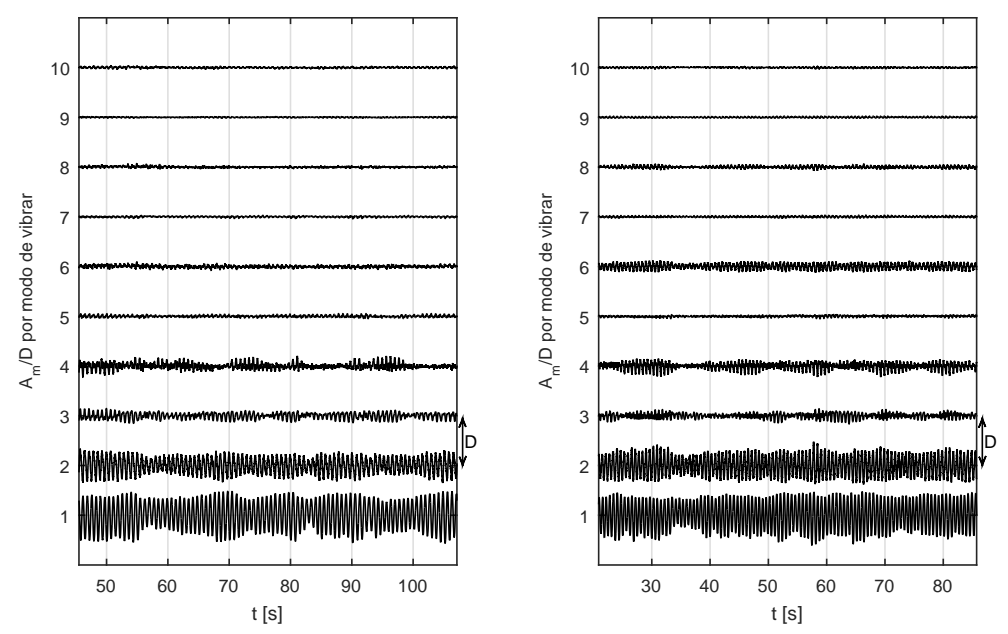

Figura 4.20 - Amplitudes modais referentes aos ângulos de inclinação e velocidades reduzidas apresentados na Tabela $4.7-\beta=135^{\circ}$.

Olhando mais de perto para as amplitudes modais, tem-se um recorte de 10 s das séries do $1^{\circ} \mathcal{M}$ e do $2^{\circ} \mathcal{M}$ apresentados em detalhe na Figura 4.22. O que se percebe nesses gráficos é que, para $\theta=20^{\circ}, 30^{\circ}$ e $45^{\circ}$, além da diferença na amplitude entre os dois modos, há claramente uma defasagem entre eles. Defasagem esta que não é observada para $\theta=0^{\circ}$ e $10^{\circ}$, ainda que neste último já seja possível observar uma pequena diferença da amplitude principalmente nos vales da curva $-A_{m_{2}}$. 


$$
\begin{aligned}
& \theta=0^{\circ} \\
& \theta=10^{\circ} \\
& \theta=20^{\circ} \\
& \overline{V r}_{1}=5.38 \\
& \overline{V r}_{1}=7.01 \\
& \overline{V r}_{1}=6.21
\end{aligned}
$$
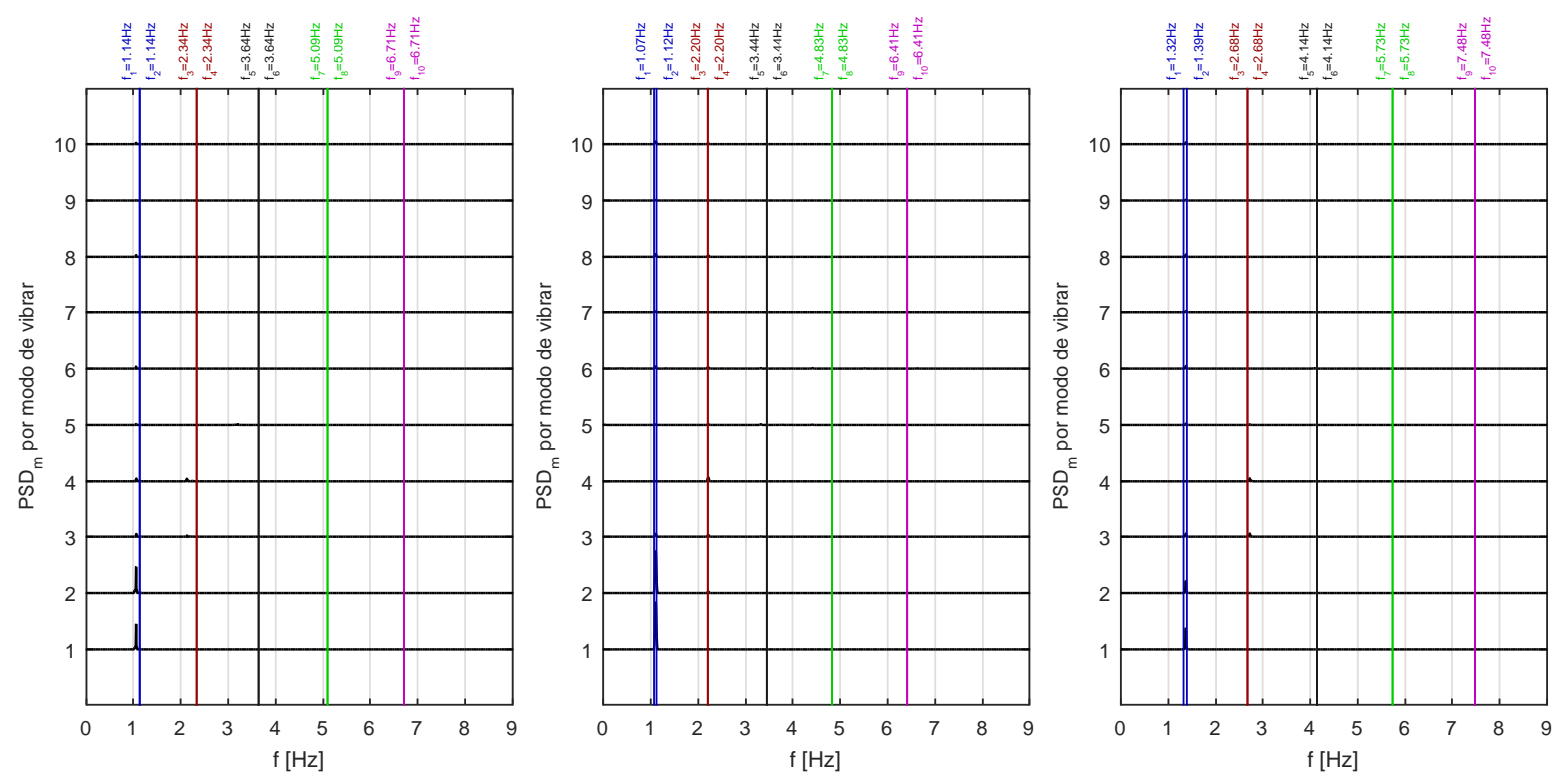

$$
\begin{gathered}
\theta=30^{\circ} \\
\overline{V r}_{1}=7.26
\end{gathered}
$$

$$
\theta=45^{\circ}
$$$$
\overline{V r}_{1}=8.70
$$
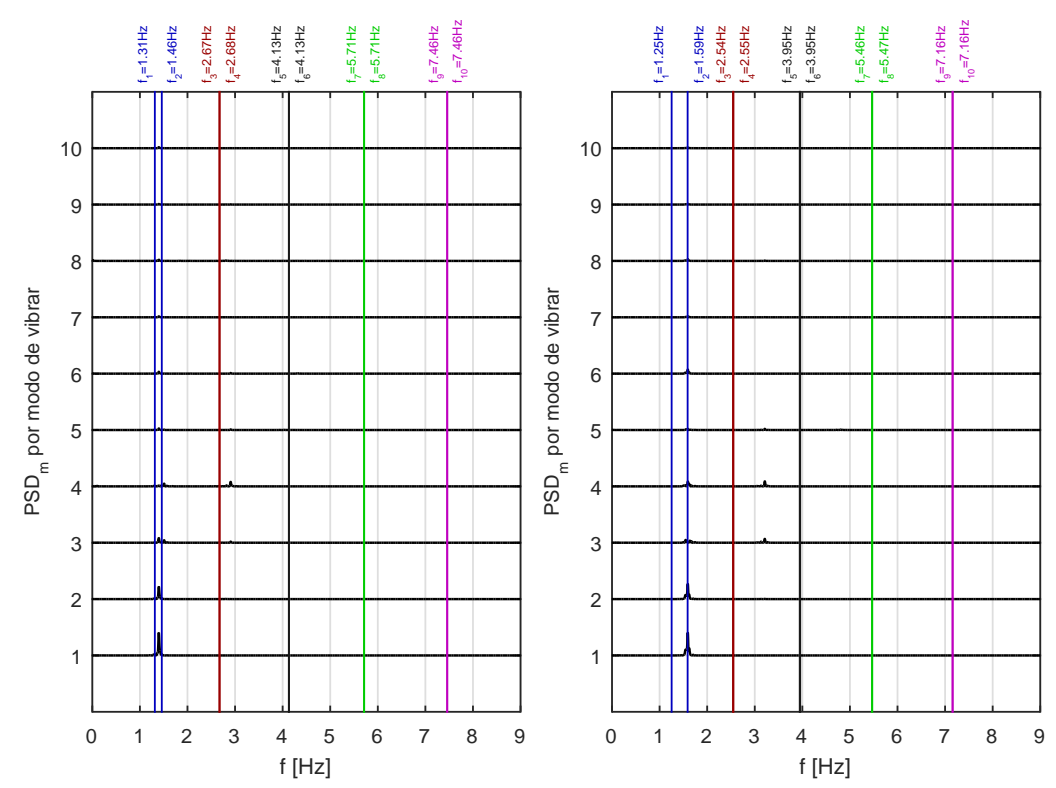

Figura 4.21 - Densidades espectrais referentes aos ângulos de inclinação e velocidades reduzidas apresentados na Tabela $4.7-\beta=135^{\circ}$.

Essa diferença entre picos e vales, para um modo que está contido no plano da catenária, já é um indício de que a curvatura neste plano realmente influencie o comportamento ressonante. 

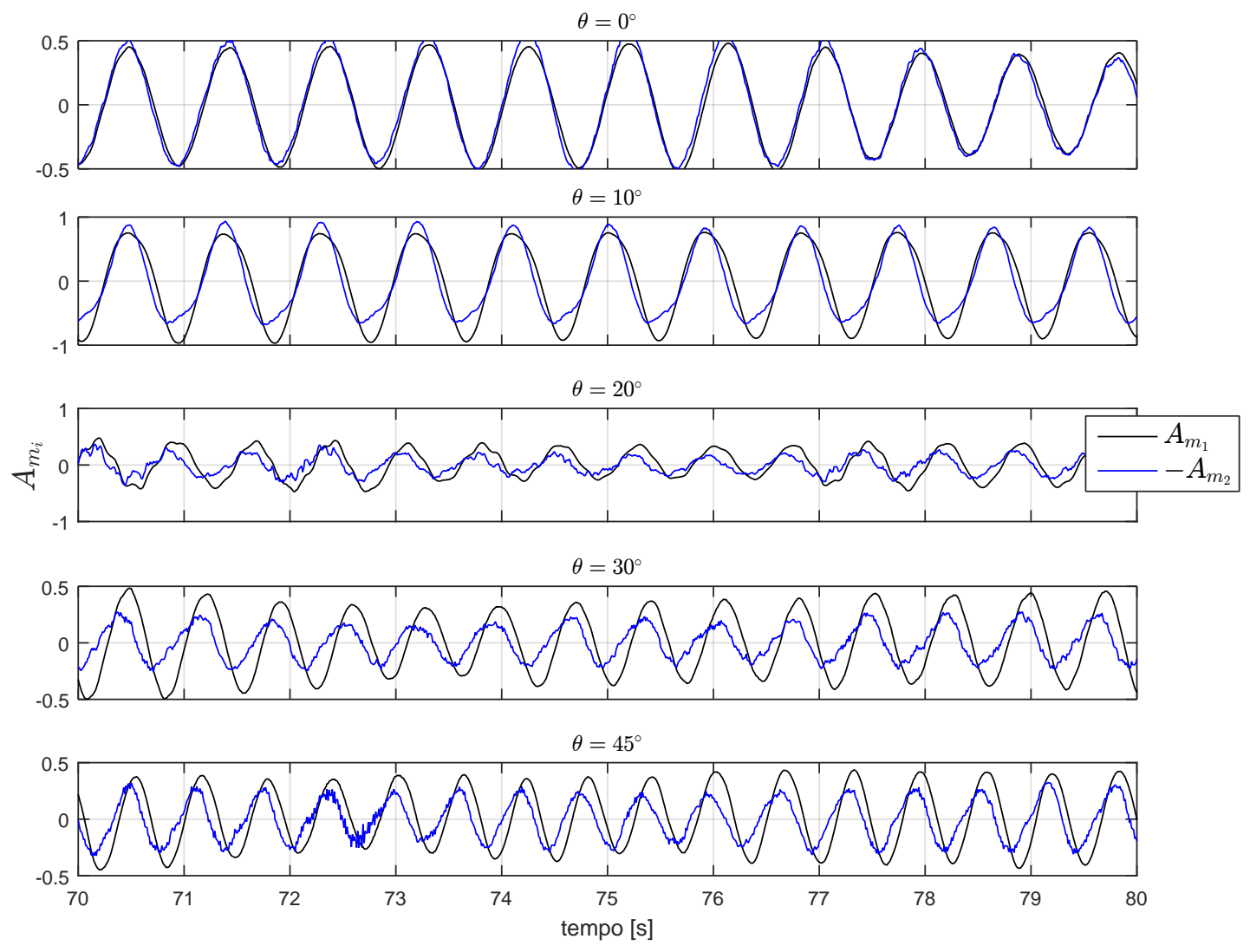

Figura 4.22 - Comparação de um trecho das séries temporais de amplitude para os pares: $1^{\circ} \mathcal{M} / 2^{\circ} \mathcal{M}-\beta=135^{\circ}$.

Alguns dos pontos descritos acima podem ser melhor visualizados com as evoluções espaço-temporais para a componente normal do movimento apresentadas na Figura 4.23. Olhando estes gráficos para $\theta=20^{\circ}, 30^{\circ}$ e $45^{\circ}$ é notável que o comportamento típico da oscilação do $2^{\circ} \mathcal{M}$ não é obtido. Apesar dos ventres serem perfeitamente paralelos, percebe-se uma modulação advinda das diferentes fases, com as amplitudes sendo maiores ora na parte superior do modelo $(s>0.5)$ e ora na parte inferior $(s<0.5)$. Para $\theta=10^{\circ}$ nota-se uma diferença de amplitude em $s \approx 0.65$ somente para $n / D>0$ (cores vermelhas), o que representa exatamente as diferenças observadas nos vales da curva $-A_{m_{2}}$ (Figura 4.22).

As trajetórias dos alvos no plano $O^{\prime} n b$ contidas na Figura 4.24 apresentam as mesmas informações das evoluções espaço-temporais, porém sob uma ótica diferente. Nestes gráficos, quanto maior a correlação entre $A_{m_{1}} \mathrm{e}-A_{m_{2}}$, mais a trajetória se aproxima de uma reta inclinada, parecida com as curvas obtidas para $\theta=0^{\circ}$. As diferenças notadas para $\theta>0^{\circ}$ deformam as trajetórias de maneiras diferentes. No caso de $\theta=10^{\circ}$ formou-se uma trajetória em forma de laço quando $n / D>0$ e $b / D<0$, devido à diferença na região dos vales. Para as outras inclinações, o que se observa 


$$
\theta=0^{\circ} / \overline{V r}_{1}=5.38
$$

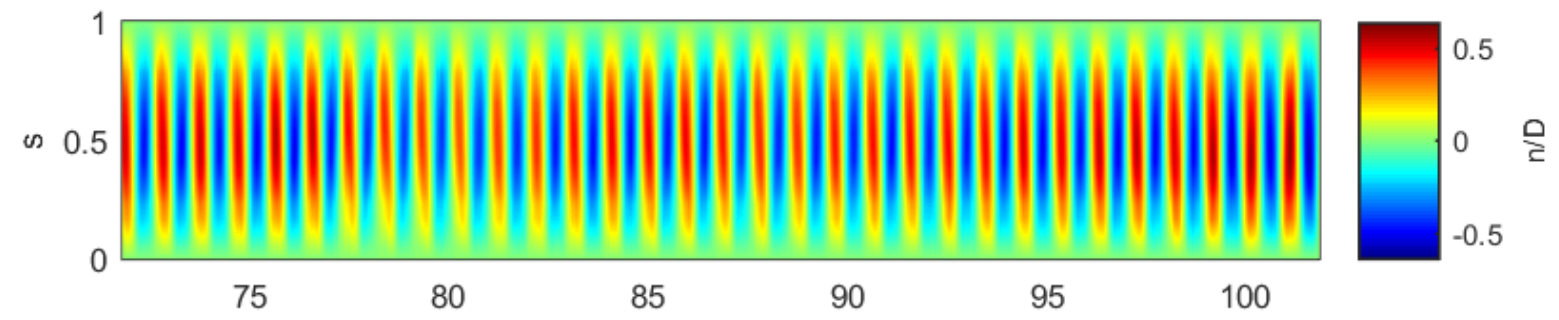

$\theta=10^{\circ} / \overline{V r}_{1}=7.01$

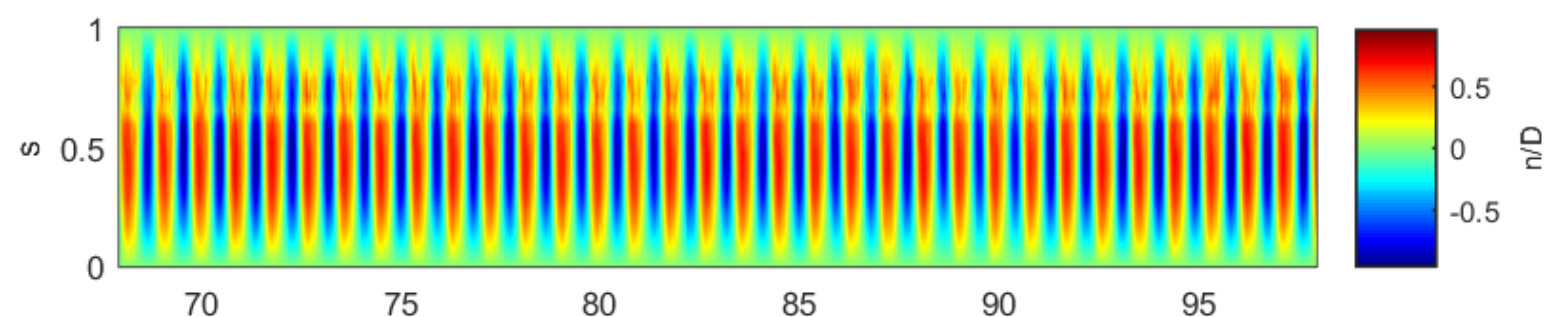

$\theta=20^{\circ} / \overline{V r}_{1}=6.21$

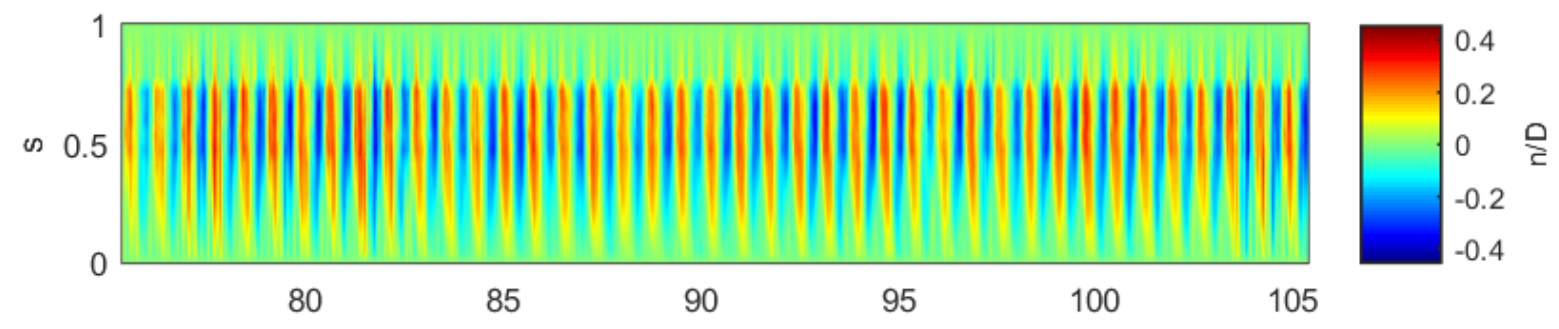

$\theta=30^{\circ} / \overline{V r}_{1}=7.26$

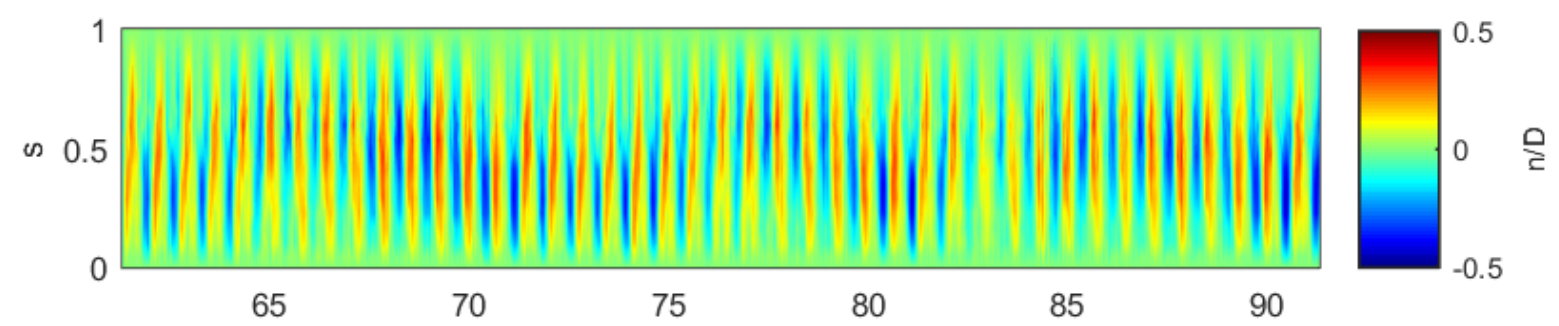

$\theta=45^{\circ} / \overline{V r}_{1}=8.70$

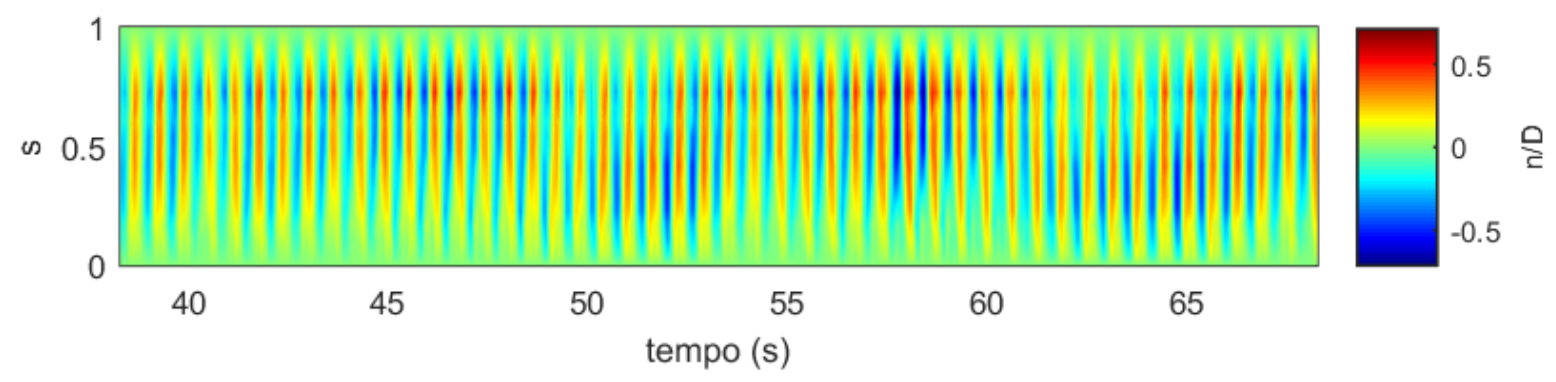

Figura 4.23 - Evoluções espaço-temporais referentes aos ângulos de inclinação e velocidades reduzidas apresentados na Tabela $4.7-\beta=135^{\circ}$. 
é que a defasagem apontada, a diferença de amplitude e o fato de $1^{\circ} \mathcal{M}\left\langle f_{2}\right\rangle$ e $2^{\circ} \mathcal{M}\left\langle f_{2}\right\rangle$ formaram trajetória elípticas, sendo que o semieixo de menor dimensão está alinhado à direção da correnteza, representada no gráfico pela seta na cor preta.

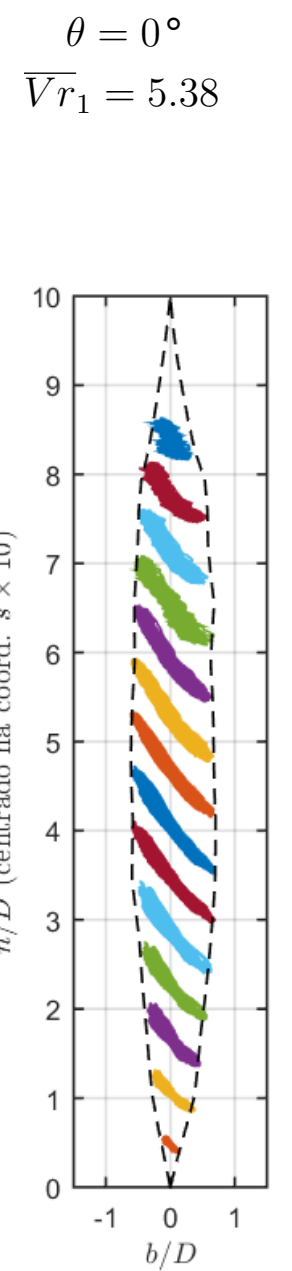

$$
\begin{gathered}
\theta=10^{\circ} \\
\overline{V r}_{1}=7.01
\end{gathered}
$$$$
\theta=20^{\circ}
$$$$
\theta=30^{\circ}
$$$$
\theta=45^{\circ}
$$

$\overline{V r}_{1}=6.21$

$\overline{V r}_{1}=7.26$

$\overline{V r}_{1}=8.70$

\section{Direção da correnteza}
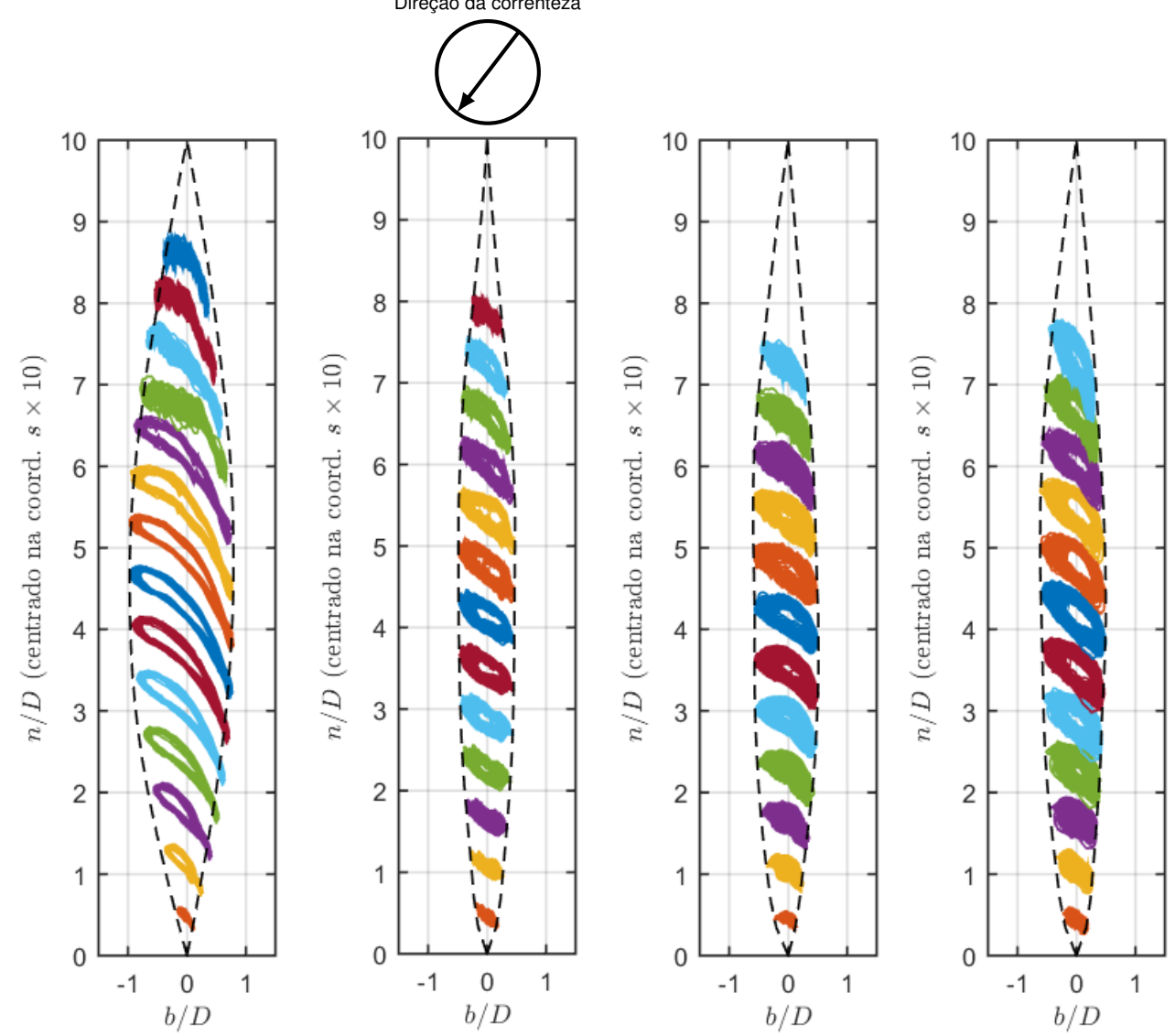

Figura 4.24 - Trajetórias dos alvos fixados no modelo referentes aos ângulos de inclinação e velocidades reduzidas apresentados na Tabela $4.7-\beta=135^{\circ}$.

Uma vez descritos e apresentados alguns dos principais pontos obtidos nos resultados do experimento de VIV e feita uma descrição mais aprofundada de certas regiões de interesse ao estudo do fenômeno é possível encaminhar o texto para sua conclusão e considerações finais apresentadas no capítulo seguinte. 


\section{Capítulo 5}

\section{Conclusões e Considerações Finais}

O problema das vibrações induzidas pela emissão de vórtices em cilindros flexíveis inclinados em relação à correnteza foi estudado do ponto de vista experimental. A inclinação foi parametrizada principalmente quanto ao ângulo $\theta$ com a vertical e quanto a mudança de azimute $\beta$. Paralelos quanto à recorrência destas configurações em situações de aplicação na engenharia oceânica foram inicialmente traçados e exemplificados.

Além do objetivo central do estudo que é investigar experimentalmente a influência da inclinação com a vertical e a mudança de azimute no comportamento dinâmico de cilindros flexíveis suscetíveis às vibrações induzidas pela emissão de vórtices, diversos objetivos secundários foram traçados com o intuito de se obter, com a maior precisão possível, a base de dados necessária ao levantamento de discussões técnicocientíficas.

A revisão bibliográfica foi pautada pela caracterização dos fenômenos envolvidos, pela sua aplicação quanto aos cilindros flexíveis e pelas questões inerentes à inclinação. A leitura e entendimento dos mais variados trabalhos referenciados forneceram uma base concisa de onde partiram a composição de uma metodologia adequada e as diferentes análises adotadas.

Diversas lacunas foram identificadas como, por exemplo, a reduzida base de dados experimentais para flexíveis inclinados, sendo que os poucos experimentos estudados em sua maioria foram executados em escoamentos em ar e são geralmente voltados a problemas da construção civil. Outra lacuna foi a falta de estudos em que o azimute fosse considerado. Quase em sua totalidade, os problemas de inclinação são tratados sempre no plano da correnteza.

A metodologia apresentada compreendeu processos e técnicas comprovadamente eficazes na abordagem do problema de VIV em cilindros flexíveis, originalmente propos- 
tos pelo grupo de pesquisa no qual este trabalho também foi desenvolvido, o que facilitou a adaptação dessas técnicas ao estudo dos sistemas inclinados. Para a abordagem experimental, um modelo em escala reduzida constituído por um tubo de silicone preenchido com microesferas de aço foi ensaiado em tanque de reboque com o auxílio de sistemas de medição de tração no topo e de medição da posição de alvos refletivos fixados ao longo do comprimento do modelo. Este último foi realizado com a utilização de um sistema comercial que realiza a medição com o uso de câmeras submersas.

Foram ensaiadas 21 combinações de ângulos obtidas a partir de $\theta=0^{\circ}, 10^{\circ}, 20^{\circ}, 30^{\circ}$ e $45^{\circ}$; bem como $\beta=0^{\circ}, 45^{\circ}, 90^{\circ}, 135^{\circ}$ e $180^{\circ}$. Além disso, mais 4 configurações foram obtidas para o modelo vertical rotacionando, no plano $O^{\prime} b n$, as funções $\phi_{i}$ que descrevem dos modos naturais de vibrar, obtendo a resposta para os azimutes $\beta=$ $45^{\circ}, 90^{\circ}, 135^{\circ}$ e $180^{\circ}$.

Em cada configuração teve-se o cuidado da realização de ensaios de caracterização tanto em ar com em água, a fim de se determinar as frequências naturais e coeficientes de amortecimento do sistema. Esses parâmetros foram utilizados com sucesso para situar o presente experimento perante outros apresentados na literatura, através da avaliação dos parâmetros de "Skop-Griffin", $S_{G}$ e $\alpha$. As comparações foram apresentadas nas Figuras 4.4 e 4.5 e mostraram que os ensaios apresentaram resultados coerentes com as estimativas teóricas propostas na literatura.

O princípio da independência foi inicialmente tomado como ponto de partida para a definição de uma base de cálculo das velocidades reduzidas, avaliadas para cada modo de vibrar $V r_{i}\left(U, D, f_{n_{i}}, \theta, \beta\right)$. Essa base se mostrou muito eficaz na identificação dos padrões fenomenológicos do problema.

Os resultados apresentados na pesquisa cumpriram dois objetivos: primeiramente fornecer ao leitor um panorama geral do fenômeno de VIV agindo sobre o sistema inclinado nas suas mais diversas configurações, combinando ângulos de inclinação com ângulos de azimute. Esse panorama é dado principalmente pelos mapas de amplitude modal adimensionalizada apresentados nas Figuras 4.1, 4.3 e 4.8 e pelo mapa de frequência da Figura 4.6.

Em segundo lugar, forneceram ao leitor alguns exemplos de análises em regiões de interesse, tais como nos pontos onde as amplitudes máximas foram obtidas e regiões de transição, caracterizadas pelo comportamento multimodal.

O método da decomposição modal foi aplicado com sucesso, de modo a caracterizar esses comportamentos multimodais, efeitos de transição, fenômenos não lineares, entre outros. A base gráfica utilizada para apresentação dos dados de cada velocidade reduzida compreendeu: 
- Séries temporais das oscilação em cada modo de vibrar $A_{m_{i}}(t)$, avaliadas até o $10^{\circ} \mathcal{M}$

- Respectivas curvas de densidade espectral de potência que caracterizam as frequências de oscilação $f_{i}$,

- Gráficos de evolução espaço-temporal da componente normal, binormal e tangencial,

- Gráficos da trajetória de pontos posicionados ao longo do modelo,

que, de modo geral, serviram para corroborar a efetividade do método e complementar a análise com uma visão mais geral do sistema.

Além das curvas de densidade espectral de potência, em casos mais complexos, foi utilizada a análise através da obtenção do espectro de Hilbert-Huang que fornece uma quantidade maior de informações sobre o padrão de oscilação do sistema.

Mediante esta abordagem investigativa foi possível concluir que a aplicação do princípio da independência, nos cilindros flexíveis inclinados, é válida com algumas ressalvas. De maneira geral, o sistema se comportou conforme a metodologia clássica de VIV, apresentando sucessivas regiões de lock-in, onde foram verificadas as ressonâncias modais presentes geralmente em $3<V r_{i}<8$.

Os principais pontos identificados foram que para $01^{\circ} \mathcal{M}$ ou $2^{\circ} \mathcal{M}$ a ressonância ocorre de maneira unimodal. Do $3^{\circ} \mathcal{M}$ em diante os fenômenos ressonantes foram observados sempre com dois ou mais modos agindo concomitantemente. Em todas configurações a amplitude máxima de oscilação foi obtida no $3^{\circ} \mathcal{M}$ ou $4^{\circ} \mathcal{M}$.

As diferenças nos comportamentos das configurações com $\beta=0^{\circ}$ e $45^{\circ}$ ou com $\beta=180^{\circ}$ e $135^{\circ}$ foram atribuídas à diferença na tração média resultante da direção de atuação da força de arrasto média. Os azimutes $\beta=180^{\circ}$ e $135^{\circ}$ apresentaram amplitudes maiores na ressonância. As diferenças aumentaram com o aumento do ângulo de inclinação $\theta$.

Das análises mais aprofundadas nas regiões de interesse foi identificada a diferença nas amplitudes modais do $1^{\circ} \mathcal{M}$ e do $2^{\circ} \mathcal{M}$ para $\theta>20^{\circ}$, sendo que tanto para $\beta=45^{\circ}$ como para $\beta=135^{\circ}$ tem-se $A_{m_{1}}>A_{m_{2}}$. Além disso, uma defasagem entre as curvas $A_{m_{1}}(t)$ e $A_{m_{2}}(t)$ foi observada, o que impactou diretamente no formato das trajetórias de oscilação. Essas diferenças foram atribuídas ao efeito causado pela rigidez geométrica que só diferencia a coexistência do $1^{\circ} \mathcal{M} / 2^{\circ} \mathcal{M}$, sendo que a frequência do modo no plano da catenária é sempre maior que no plano transversal $\left(f_{n_{1}}<f_{n_{2}}\right)$, e que a distância entre essa frequências aumenta com a incrementação na inclinação. 
Para os outros pares de modos $\left(3^{\circ} \mathcal{M} / 4^{\circ} \mathcal{M}, 5^{\circ} \mathcal{M} / 6^{\circ} \mathcal{M}, 7^{\circ} \mathcal{M} / 8^{\circ} \mathcal{M}\right.$ e $9^{\circ} \mathcal{M} / 10^{\circ} \mathcal{M}$, ) estudados, vale a aplicação do $\mathrm{PI}$ apenas do ponto de vista das amplitudes e frequências observadas.

As análises e comparações passíveis de serem realizadas são muitas e dada a envergadura da matriz de ensaios realizada, e consequente volume de resultados, não era de se esperar o esgotamento das mesmas. Ao final desta etapa, é intenção do autor que os dados provenientes deste experimento e os pontos interessantes que surgem com o desdobramento das análises devam ser publicados em periódicos e congressos pertinentes ao tema.

Desde já, no entanto, acredita-se ser possível afirmar que a consecução de um ensaio com cilindro flexível variando inclinação e azimute em tanque de reboque, por si só já confere ao presente trabalho a originalidade necessária à elaboração da tese como aqui feita. A base de dados obtida, juntamente com as análises que corroboram a validade do PI para o sistema estudado, naturalmente dadas as limitações discutidas, fornecem resultados importantes que suscitam a continuidade do estudo em temas correlatos, ficando como sugestão o estudo:

- das frequências e padrões de emissão de vórtices;

- do impacto da tração média no comportamento dinâmico;

- do impacto de ângulos de inclinação maiores que $\theta=45^{\circ}$;

- estudo de ângulos de azimute intermediários e tais que $|\operatorname{sen} \beta| \neq|\cos \beta|$;

- estudos em perfis de correnteza variáveis e/ou estratificados.

Para finalizar, é importante ressaltar que, além do resultado inédito, a base de dados foi obtida de forma independente da iniciativa privada em uma parceria entre a Universidade de São Paulo e o Instituto de Pesquisas Tecnológicas do Estado de São Paulo, o que resultou em dados que futuramente podem ser abertos à comunidade científica, contribuindo sobremaneira para mais avanços na compreensão do fenômeno de VIV agindo nas estruturas flexíveis muito longas. 


\section{Bibliografia}

Alfosail, F. K., Nayfeh, A. H., \& Younis, M. I. (2016). Natural frequencies and mode shapes of statically deformed inclined risers. International Journal of NonLinear Mechanics.

Amarante, R. A. (2015). Compressão Dinâmica em Risers. Tese de Doutorado, Escola Politécnica da Universidade de São Paulo, São Paulo.

ASsI, G. R. S. (2009). Mechanisms for flow-induced vibration of interfering bluff bodies. Tese de Doutorado, Imperial College London, London, United Kingdom.

ATI INDUSTRIAL AUTOMATION (2010). Six-axis force/torque sensor system. Installation and Operation Manual.

BAtHe, K. (1996). Finite element procedures. Prentice hall Englewood Cliffs, NJ.

Bearman, P. W. (1984). Vortex shedding from oscillating bluff bodies. Annual Reviews of Fluid Mechanics, 16, 195-222.

Benaroya, H. \& Gabbal, R. (2008). Modelling vortex-induced fluid-structure interaction. Philosophical Transactions of the Royal Society A: Mathematical, Physical and Engineering Sciences, 366(1868), 1231-1274.

BLEVINS, R. D. (1990). Flow-induced vibration. Van Nostrand Reinhold.

Bourguet, R., Karniadakis, G. E., \& Triantafyllou, M. S. (2015). On the validity of the independence principle applied to the vortex-induced vibrations of a flexible cylinder inclined at $60^{\circ}$. Journal of Fluids and Structures, 53, 58-69. Special Issue on Unsteady Separation in Fluid-Structure Interaction-II.

Bowman, F. (1958). Introduction to Bessel functions. Dover.

Chakrabarti, S. K. (2005). Handbook of Offshore Engineering, volume I. Elsevier.

Chaplin, J. R., Bearman, P. W., Huera Huarte, F. J., \& Pattenden, R. J. (2005). Laboratory measurements of vortex-induced vibrations of a vertical tension riser in a stepped current. Journal of Fluids and Structures, 21(1), 3-24. 
CHEN, W.-L., ZHANG, Q.-Q., LI, H., \& HU, H. (2015). An experimental investigation on vortex induced vibration of a flexible inclined cable under a shear flow. Journal of Fluids and Structures, 54, 297-311.

CHUNG, T.-Y. (1987). Vortex-induced vibration of flexible cylinders in sheared flows. Tese de Doutorado, Massachusetts Institute of Technology.

CUNHA, L. D. (2005). Vibração induzida por vórtices: Análise crítica de modelos fenomenológicos. Dissertação de Mestrado, Escola Politécnica da Universidade de São Paulo, São Paulo.

Dale, J., Menzel, H., \& McCandless, J. (1966). Dynamic characteristics of wire rope: Flow-induced transverse vibrations. US Naval Ak Development Center Report NADC-AE-6620.

de Mello, P. C., Rateiro, F., Fujarra, A. L., Oshiro, A. T., Neves, C. R., dos SANTOS, M. F., \& TANNURI, E. A. (2011). Experimental set-up for analysis of subsea equipment installation. In ASME 2011 30th International Conference on Ocean, Offshore and Arctic Engineering OMAE2011 (pp. 763-772).: American Society of Mechanical Engineers.

Facchinetti, M. L., De Langre, E., \& Biolley, F. (2004). Coupling of structure and wake oscillators in vortex-induced vibrations. Journal of Fluids and Structures, 19(2), 123-140.

FRANÇA, L. N. F. \& SOTELO JR., J. (2006). Introdução às vibrações mecânicas. Editora Edgard Blucher.

FRANZINI, G. R. (2013). Investigação experimental do escoamento ao redor de cilindros inclinados, sujeitos a condições de contorno assinmétricas nas extremidades. Tese de Doutorado, Escola Politécnica da Universidade de São Paulo, São Paulo.

Franzini, G. R., Fujarra, A. L. C., \& Pesce, C. P. (2009). Numerical studies of a flexible structure subject to vortex-induced vibrations. In Proceedings of the 20th International Congress of Mechanical Engineering. Gramado, RS, Brazil.

Franzini, G. R., Pesce, C. P., Salles, R., Gonçalves, R. T., Fujarra, A. L., \& MENDES, P. (2015). Experimental analysis of a vertical and flexible cylinder in water: Response to top motion excitation and parametric resonance. Journal of Vibration and Acoustics, 137(3), 031010. 
Fujarra, A., Gonçalves, R., Fonseca, R., Siewert, K., \& Martins, J. (2009). Optical motion capture as a techinique for measuring the water wave elevation. In 4th International Workshop pn Applied Offshore Hydrodynamics (IWAOH).

FUJARRA, A. L. C. (2002). Estudos experimentais e analíticos das vibrações induzidas pela emissão de vórtices em cilindros flexíveis e rígidos. Tese de Doutorado, Escola Politécnica da Universidade de São Paulo, São Paulo.

Fujarra, A. L. C. \& Pesce, C. P. (2002). Added mass variation and van der Pol models applied to Vortex-Induced vibrations. Proceedings of 5th International Symposium on Fluid Structure Interaction, Aeroelasticity, and Flow Induced Vibration and Noise, In: ASME International Mechanical Engineering Congress and Exposition (IMECE2002). New Orleans, Louisiana, USA.

Fujarra, A. L. C., Pesce, C. P., Flemming, F., \& Williamson, C. H. K. (2001). Vortex-induced vibration of a flexible cantilever. Journal of Fluids and Structures, 15(3), 651-658.

GerRARD, J. H. (1966). The mechanics of the formation region of vortices behind bluff bodies. J. Fluid Mech, 25(2), 401-413.

Griffin, O., Skop, R., \& KoopmanN, G. (1973). The vortex-excited resonant vibrations of circular cylinders. Journal of Sound and Vibration, 31(2), 235-IN3.

HARTLEN, R. \& CURRIE, I. (1970). Lift-oscillator model of vortex-induced vibration. Journal of the Engineering Mechanics Division, 96(5), 577-591.

Hartlen, R. T., Baines, W., \& CurRiE, I. (1968). Vortex-excited oscillations of a circular cylinder. University of Toronto, Department of Mechanical Engineering.

Huang, N. E., Shen, Z., Long, S. R., Wu, M. C., Shih, H. H., Zheng, Q., Yen, N.-C., TUNG, C. C., \& LIU, H. H. (1998). The empirical mode decomposition and the hilbert spectrum for nonlinear and non-stationary time series analysis. In Proceedings of the Royal Society of London A: Mathematical, Physical and Engineering Sciences, volume 454 (pp. 903-995).: The Royal Society.

Huera Huarte, F. J. (2006). Multi-mode vortex-induced vibrations of a flexible circular cylinder. Tese de Doutorado, Imperial College London (University of London). IRVine, H. M. \& Caughey, T. K. (1974). The linear theory of free vibrations of a suspended cable. Proceedings of the Royal Society of London. A. Mathematical and Physical Sciences, 341(1626), 299-315.

IWAN, W. D. \& BLEVINS, R. D. (1974). A model for vortex-induced oscillations of structures. Journal of Applied Mechanics, 41, 581-586. 
Jauvtis, N. \& Williamson, C. H. K. (2004). The effect of two degrees of freedom on vortex-induced vibration at low mass and damping. Journal of Fluid Mechanics, $509,23-62$.

KHALAK, A. \& WILLIAMSON, C. (1999). Motions, forces and mode transitions in vortexinduced vibrations at low mass-damping. Journal of fluids and Structures, 13(7), 813-851.

KING, R. (1977). Vortex excited oscillations of yawed circular cylinders. Journal of Fluids Engineering, 99(3), 495-501.

Kumarasena, S., Jones, N. P., IRWin, P., \& TayloR, P. (2005). Wind induced vibration of stay cables. Technical report, HNTB Corporation.

LUCOR, D. \& KARNIADAKIS, G. E. (2003). Effects of oblique inflow in vortex-induced vibrations. Flow, Turbulence and Combustion, 71(1-4), 375-389.

LYONS, G. \& PATEL, M. (1986). A prediction technique for vortex induced transverse response of marine risers and tethers. Journal of Sound and Vibration, 111(3), 467487.

MALTA, E. B. (2014). Investigação Experimental Das Vibrações Induzidas Pela Emissão De Vórtices Em Catenárias Sujeitas A Perfis De Correnteza Variável Ortogonais Ao Plano De Lançamento. Tese de Doutorado, Escola Politécnica da Universidade de São Paulo, São Paulo.

MARSHALL, J. (2003). Wake dynamics of a yawed cylinder. Journal of fluids engineering, 125(1), 97-103.

Matsumoto, M., Daito, Y., Kanamura, T., Shigemura, Y., Sakuma, S., \& IShiZAKI, H. (1998). Wind-induced vibration of cables of cable-stayed bridges. Journal of Wind Engineering and Industrial Aerodynamics, 74, 1015-1027.

Matsumoto, M., Shiraishi, N., Kitazawa, M., Knisely, C., Shirato, H., Kim, Y., \& TSUJII, M. (1990). Aerodynamic behavior of inclined circular cylinders-cable aerodynamics. Journal of Wind Engineering and Industrial Aerodynamics, 33(12), 63-72.

Matsumoto, M., Shirato, H., Yagl, T., Goto, M., Sakal, S., \& Ohya, J. (2003). Field observation of the full-scale wind-induced cable vibration. Journal of Wind Engineering and Industrial Aerodynamics, 91(1), 13-26.

Matsumoto, M., Yagi, T., Shigemura, Y., \& Tsushima, D. (2001). Vortex-induced cable vibration of cable-stayed bridges at high reduced wind velocity. Journal of Wind Engineering and Industrial Aerodynamics, 89(7), 633-647. 
MenEGHINI, J. R. (1993). Numerical Simulation of Bluff Body Flow: Control Using a Discrete Vortex Method. Tese de Doutorado, Imperial College of Technology and Medicine, London, United Kingdom.

ParRa, P. H. C. C. (1996). Modelo semi-empírico para vortex-induced vibrations: Análise teórica e experimental. Dissertação de Mestrado, Escola Politécnica da Universidade de São Paulo, São Paulo.

Pesce, C., Fujarra, A., Simos, A., Tannuri, E., et al. (1999). Analytical and closed form solutions for deep water riser-like eigenvalue problem. In The Ninth International Offshore and Polar Engineering Conference: International Society of Offshore and Polar Engineers.

Pesce, C. P. \& FujarRA, A. L. C. (2000). Vortex-induced vibrations and jump phenomenon: experiments with a clamped flexible cylinder in water. International Journal of Offshore and Polar Engineering, 10(1).

Pesce, C. P., Fujarra, A. L. C., \& KubotA, L. K. (2006). The Hilbert-Huang spectral analysis method applied to VIV. Proceedings of 25th International Conference on Offshore Mechanics and Arctic Engineering (OMAE2006). Hamburg, Germany.

QUIGGIN, P. P. (2015). Orcaflex quality assurance, testing and validation. Document 99/005:7.

RAMBERG, S. (1983). The effects of yaw and finite length upon the vortex wakes of stationary and vibrating circular cylinders. Journal of Fluid Mechanics, 128, 81-107.

RAMBERG, S. \& GRIFFIN, O. (1974). Vortex formation in the wake of a vibrating, flexible cable. Journal of Fluids Engineering, 96(4), 317-322.

RAMBeRG, S. E. \& GRIFFIN, O. (1976). Velocity correlation and vortex spacing in the wake of a vibrating cable. Journal of Fluids Engineering, 98(1), 10-18.

Rateiro, F., Pesce, C. P., Gonçalves, R. T., Franzini, G. R., Fujarra, A. L. C., SALLES, R., \& MENDES, P. (2012). Risers model tests: Scaling methodology and dynamic similarity. Proceedings of 22th International Offshore and Polar Engineering Conference (ISOPE2012). Rhodes, Greece.

RATEIRO, F. P. (2014). Investigação Das Vibrações Induzidas Pela Emissão De Vórtices Em Modelos Reduzidos De Riser Lançados Em Catenária. Tese de Doutorado, Escola Politécnica da Universidade de São Paulo, São Paulo.

RAYLEIGH, J. W. S. B. (1896). The theory of sound, volume 1 e 2 . Macmillan. 
Routh, E. J. (1909). A Treatise on Analytical Statics: With Numerous Examples, volume I. Cambridge University Press.

SARPKAYA, T. (2004). A critical review of the intrinsic nature of vortex-induced vibrations. Journal of Fluids and Structures, 19, 389-447.

SCRUTON, C. (1963). On the wind-excited oscillations of stacks, towers and masts. In Proceedings of the Symposium on Wind Effects on Structures Teddington.

SILVEIRA, L. M. Y. D. (2009). Modelo hidro-elástico para simular as vibrações induzidas por vórtices em cabos submersos. Tese de Doutorado, Escola Politécnica da Universidade de São Paulo, São Paulo.

Silveira, L. M. Y. D., Martins, C. D. A., Cunha, L. D., \& Pesce, C. P. (2007). An investigation on the effect of tension variation on VIV of risers. Proceedings of 26th International Conference on Offshore Mechanics and Arctic Engineering (OMAE2007). San Diego, USA.

SKOP, R. \& GRIFFIN, O. (1973). A model for the vortex-excited resonant response of bluff cylinders. Journal of Sound and Vibration, 27(2), 225-233.

SKOP, R. \& GRIFFIN, O. (1975). On a theory for the vortex-excited oscillations of flexible cylindrical structures. Journal of Sound and Vibration, 41(3), 263-274.

SKoP, R. A. \& BALASUbRAmANiAn, S. (1997). A new twist on an old model for vortexexcited vibrations. Journal of Fluids and Structures, 11(4), 395-412.

Skop, R. A., Griffin, O. M., ET AL. (1973). An heuristic model for determining flow-induced vibration of offshore structure. In Offshore Technology Conference: Offshore Technology Conference.

Strouhal, V. (1878). Über eine besondere art der tonerregung. Annalen der Physik, 241(10), 216-251.

Triantafyllou, M. (1984). The dynamics of taut inclined cables. The Quarterly Journal of Mechanics and Applied Mathematics, 37(3), 421-440.

Triantafyllou, M. \& Grinfogel, L. (1986). Natural frequencies and modes of inclined cables. Journal of Structural Engineering, 112(1), 139-148.

VANDIVER, J. K. (1993). Dimensionless parameters important to the prediction of vortex-induced vibration of long, flexible cylinders in ocean currents. Journal of Fluids and Structures. 
VICKERY, B. \& WATKINS, R. (1964). Flow-induced vibrations of cylindrical structures. In Proceedings of the 1st Australian Conference on Hydraulics and Fluid Mechanics, Crawley, Australia (pp. 213-241).

Williamson, C. \& Govardhan, R. (2004). Vortex-induced vibrations. Annual Reviews of Fluid Mechanics, 13(5), 413-455.

YEO, D. \& JONES, N. P. (2008). Investigation on 3-D characteristics of flow around a yawed and inclined circular cylinder. Journal of Wind Engineering and Industrial Aerodynamics, 96(10), 1947-1960.

YEO, D. \& JONES, N. P. (2011). Computational Study on 3-D Aerodynamic Characteristics of Flow around a Yawed, Inclined, Circular Cylinder. Technical report, Newmark Structural Engineering Laboratory. University of Illinois at UrbanaChampaign. 
Apêndices 


\section{Apêndice A}

\section{Subsídios Teóricos}

Apesar de o trabalho estudar as linhas flexíveis inclinadas em relação ao perfil de correnteza, a configuração geométrica obtida é a que chamamos de catenária. A diferença de nomenclatura aqui se deve ao fato que em engenharia naval e oceânica, geralmente, a denominação catenária se refere ao cabo que possui um trecho suspenso com uma extremidade fixada na embarcação e a outra extremidade no ponto de contato com o solo conhecido pelo nome em inglês TDP, o outro trecho se encontra apoiado no solo desde o TDP até o ponto de ancoragem.

Já por configuração inclinada entendemos o sistema que só possui o trecho suspenso da linha e o TDP é coincidente com o ponto de ancoragem. Do ponto prático a presente pesquisa tende a estudar o cilindro flexível o mais próximo possível da posição inclinada, que seria a reta que liga o ponto de conexão na embarcação e o TDP, no entanto, devido ao peso próprio e a elasticidade axial do material, a posição estática de equilíbrio é uma posição deformada desta reta e o equacionamento para a sua obtenção recai nas equações clássicas de catenária com a simplificação de não existir o trecho de contato com o solo que matematicamente se traduz em não continuidades no equacionamento.

O presente apêndice tem o intuito de oferecer ao leitor os alguns subsídios teóricos que foram utilizados previamente, antes da implementação do modelo numérico. Estes subsídios tratam basicamente da obtenção da configuração estática de catenária, considerando o efeito da rigidez flexional, a apresentação das equações dinâmicas que regem o problema e o modelo inicial utilizado para a estimativa das frequências naturais.

Como foi visto nos capítulos anteriores, a importância da rigidez geométrica (rigidez imposta pela posição curvada da no plano da catenária) é significativa apenas na determinação dos dois primeiros modos, para os modos mais altos apenas a rigidez imposta pela tração do modelo é necessária para uma boa aproximação do problema. 
Este efeito nos dois primeiros modos foi o que suscitou a utilização do modelo numérico em detrimento das aproximações teóricas aqui apresentadas.

\section{A.1 Configuração Estática da Catenária Elástica}

Para a determinação da posição estática das linhas inclinadas conforme as configurações que serão apresentadas adiante, foi utilizada uma formulação simplificada para representação do problema no plano (Routh, 1909). Deste modo, o equacionamento que se segue assume as seguintes hipóteses:

- Rigidez flexional desprezível $\left(E I /\left(\gamma L^{3}\right) \ll 1\right)$

- O material sofre apenas deformação elástica de acordo com a Lei de Hooke

Dado um elemento infinitesimal cujo comprimento deformado é $s$, sob a ação de uma tração $T$, o comprimento indeformado $\bar{s}$ fica:

$$
d \bar{s}=\left(1+\frac{T}{E A}\right) d s
$$

que pode ser reescreito como:

$$
\frac{d \bar{s}}{d s}=1+\frac{T}{E A}
$$

As componentes horizontal e vertical da tração são dadas por:

$$
\begin{aligned}
& T_{H}=T \cos \varphi \\
& \gamma s=T \operatorname{sen} \varphi
\end{aligned}
$$

Deste modo a inclinação é dada pela relação:

$$
\frac{d z}{d x}=\tan \varphi=\frac{\gamma s}{T_{H}}
$$

e a tração dada por:

$$
T=\sqrt{T_{H}^{2}+(\gamma s)^{2}}
$$


Definindo o parâmetro $a$ como

$$
a=\frac{T_{H}}{\gamma}
$$

é possível reescrever a inclinação e a tração, respectivamente, como

$$
\begin{aligned}
& \frac{d z}{d x}=\tan \varphi=\frac{s}{a} \\
& T=\frac{T_{H}}{a} \sqrt{a^{2}+s^{2}}
\end{aligned}
$$

Assim:

$$
\begin{gathered}
\frac{d x}{d \bar{s}}=\frac{T_{H}}{T} \\
\frac{d z}{d \bar{s}}=\frac{\gamma s}{T}
\end{gathered}
$$

Fazendo a mudança de variável de $\bar{s}$ para $s$, tem-se

$$
\begin{aligned}
& \frac{d x}{d s}=\frac{T_{H}}{T} \frac{d \bar{s}}{d s}=\frac{a}{\sqrt{a^{2}+s^{2}}}+\frac{T_{H}}{E A} \\
& \frac{d z}{d s}=\frac{\gamma s}{T} \frac{d \bar{s}}{d s}=\frac{s}{\sqrt{a^{2}+s^{2}}}+\frac{T_{H} s}{E A a}
\end{aligned}
$$

Integrando (A.12) e (A.13) obtém-se as seguintes equações paramétricas para a catenária elástica:

$$
\begin{gathered}
x(s)=a \operatorname{arcsenh}\left(\frac{s}{a}\right)+\frac{T_{H} s}{E A}+C_{1} \\
z(s)=\sqrt{a^{2}+s^{2}}+\frac{T_{H} s^{2}}{2 E A a}+C_{2}
\end{gathered}
$$

A determinação de $C_{1}$ e $C_{2}$ depende das condições de contorno do problema, que para o caso em questão são:

$$
x(0)=0 ;
$$

$$
x(L)=L \sin (\theta) ;
$$




$$
\begin{gathered}
z(0)=0 ; \\
z(L)=L \cos (\theta) ;
\end{gathered}
$$

Dados os parâmetros $L, E A$ e $\gamma$, a determinação das constantes e de $T_{H}$ foi realizada de forma iterativa através de uma rotina computacional.

Importante ressaltar que o modelo estático de catenária elástica foi utilizado nesta tese com o único intuito de recuperar com precisão as trações e posições iniciais do modelo em suas diversas configurações.

\section{A.2 Cálculo das frequências naturais}

Dadas as configurações de lançamento do modelo, é interessante separar o estudo analítico em duas partes, sendo a primeira delas para o modelo lançado verticalmente, cuja solução para os modos naturais é obtida, por exemplo, por meio de funções de Bessel; e a segunda delas com a consideração de linha retesada. Nesse sentido, cumpre destacar que uma abordagem por catenária direta implicaria em incompatibilidade das condições de contorno no fundo, já que, stricto sensu, não existe um TDP com ângulo de saída nulo.

\section{A.2.1 Configuração Vertical}

Dada a natureza linear da variação da tração em cabos posicionados verticalmente, aliado ao fato que o caso aqui estudado possui $T_{0}>0$ e rigidez flexional desprezível $E I<<1$, pode-se aplicar uma solução analítica, através da utilização das funções de Bessel, para obtenção das frequências naturais, conforme apresentado em Pesce et al. (1999).

Para o caso aqui estudado, no qual o peso linear e a massa linear são constantes ao longo do comprimento a equação do movimento é:

$$
\left(m+m_{a}\right) \frac{\partial^{2} y}{\partial t}=\frac{\partial}{\partial x}\left(T(z) \frac{\partial y}{\partial z}\right)
$$

onde $T(z)=T_{0}+\gamma z$. Realizando a separação de variáveis, tal que $y(z, t)=\phi(z) e^{i \omega t}$, temos: 


$$
\left(T_{0}+\gamma z\right) \frac{d^{2} \phi}{d z^{2}}+\gamma \frac{d \phi}{d z}+\left(m+m_{a}\right) \omega^{2} \phi
$$

realizando as mudanças de variáveis $\xi=T_{0} / \gamma+z \mathrm{e} \kappa^{2}=\left(m+m_{a}\right) \omega^{2} / \gamma$, obtém-se:

$$
\xi \frac{d^{2} \phi}{d \xi^{2}}+\frac{d \phi}{d \xi}+\kappa^{2} \phi=0
$$

definindo uma nova variável tal que $\xi=\varsigma^{2}$ e, após uma manipulação algébrica, chegase à seguinte equação:

$$
\varsigma^{2} \frac{d^{2} \phi}{d \varsigma^{2}}+\frac{d \phi}{d \varsigma}+4 \kappa^{2} \varsigma^{2} \phi=0
$$

Esta equação tem solução analítica dada através das funções de Bessel como apresentado em Bowman (1958), tal qual:

$$
\phi(\varsigma)=C_{1} J_{0}(2 \kappa \varsigma)+C_{2} Y_{0}(2 \kappa \varsigma)
$$

onde $J_{0}$ e $Y_{0}$ são as funções de Bessel de ordem 0 . Assumindo as condições de contorno $\phi(0)=\phi(L)=0$ e realizando a substituição de variáveis chegamos à equação característica:

$\operatorname{det}\left[\begin{array}{cc}J_{0}\left(2 \omega_{n}\left(\frac{m+m_{a}}{\gamma}\right)^{1 / 2}\left(\frac{T_{0}}{\gamma}\right)^{1 / 2}\right) & Y_{0}\left(2 \omega_{n}\left(\frac{m+m_{a}}{\gamma}\right)^{1 / 2}\left(\frac{T_{0}}{\gamma}\right)^{1 / 2}\right) \\ J_{0}\left(2 \omega_{n}\left(\frac{m+m_{a}}{\gamma}\right)^{1 / 2}\left(\frac{T_{0}}{\gamma}+L\right)^{1 / 2}\right) & Y_{0}\left(2 \omega_{n}\left(\frac{m+m_{a}}{\gamma}\right)^{1 / 2}\left(\frac{T_{0}}{\gamma}+L\right)^{1 / 2}\right)\end{array}\right] \equiv 0$

As raízes da equação (A.25) são as frequências naturais do sistema na configuração vertical.

\section{A.2.2 Configuração Inclinada}

Irvine \& Caughey (1974) desenvolveram uma formulação analítica simples para vibrações livres de um cabo uniforme suspenso, com razões flecha-vão menores ou aproximadamente iguais a $1 / 8$. Foram avaliadas os modos e frequências de vibrar dentro e fora do plano da linha com resultados bastante acurados, quando comparados com experimentos.

Desde então, outros trabalhos de grande importância foram desenvolvidos nesse âmbito, como o de Triantafyllou \& Grinfogel (1986), que tratou, com todo rigor, das fre- 
quências e modos de vibrar de cabos inclinados, a partir de soluções assintóticas, considerando a elasticidade do cabo e efeitos decorrentes da variação da tração dinâmica e avaliando a ocorrência de crossing-over.

Em Alfosail et al. (2016) abordam o problema de uma viga de Euler-Bernoulli para a determinação dos modos e frequências naturais de vibrar, considerando as rijezas axial e flexional, e a influência de fluxo interno (incluindo o efeito inercial de Coriolis), coeficiente de amortecimento viscoso e inércia adicional, promovendo um estudo mais aprofundado e geral da dinâmica de risers, sob o ponto de vista do problema de autovalor. A solução obtida foi auferida a partir do implementação do Método de Galerkin, com resultados excepcionalmente acurados.

Para os objetivos desta tese, utilizou-se as formulações desenvolvidas e apresentadas por Irvine \& Caughey (1974), por serem suficientemente adequadas para as finalidades desejadas. A modelagem analítica de cabos retesados, da teoria linear (sem a consideração da deformação axial), também foram implementados numericamente, sem que diferenças substanciais fossem identificadas, a ponto de serem aqui descritas.

Os estudos desenvolvidos em Irvine \& Caughey (1974) iniciam com a clássica consideração de um cabo uniforme em um plano vertical, biapoiado em suportes localizados em uma mesma cota.

$$
\begin{gathered}
\frac{d}{d s}\left(T \frac{d x}{d s}\right)=0 \\
\frac{d}{d s}\left(T \frac{d z}{d s}\right)=-m g
\end{gathered}
$$

É importante notar que a solução de conjunto de equações A.26 é uma catenária; entretanto, para relações flecha-vão menores ou iguais a 1/8 os autores utilizaram uma aproximação parabólica, cuja solução é dada pela equação A.28.

$$
z=\frac{m g L^{2}}{2 H}\left[\frac{x}{L}-\left(\frac{x}{L}\right)^{2}\right]
$$

onde $L$ é o vão (distância entre os apoios) e $H$ é a componente horizontal da tração no cabo (que é sabidamente constante em um cabo em catenária direta), cuja aproximação para o caso parabólico é dada pela equação A.29.

$$
H=\frac{m g L^{2}}{8 d}
$$


onde $d$ é a flecha.

Nos casos aqui estudados, a maior razão $d / L$ é da ordem de $1 / 25$, ou seja, muito menor do que o valor requisitado para a aplicação do método.

Incorporando os efeitos da rigidez axial e, portanto, da extensibilidade do cabo, foram feitas aproximações de primeira ordem até que o problema pudesse ser apresentado por meio da equação transcendental A.30, de fundamental importância para a teoria linear de vibrações em cabos, cuja solução permite determinar as frequências naturais de um cabos, sob as condições apresentadas anteriormente.

$$
\tan \left(\frac{\omega_{n}}{2}\right)=\left(\frac{\omega_{n}}{2}\right)-\frac{4}{\lambda^{2}}\left(\frac{\omega_{n}}{2}\right)^{3}
$$

onde

$$
\lambda^{2}=\left[\frac{m g L \cos (\theta)}{H}\right]^{2} \frac{E A L}{H L_{e}}
$$

e

$$
L_{e}=L\left\{1+\frac{1}{8}\left[\frac{m g L \cos (\theta)}{H}\right]^{2}\right\}
$$

Essa formulação leva em consideração um possível desnível vertical entre os apoios, como é o caso dos experimentos realizados no âmbito desta tese. A fim de permitir a determinação das frequências naturais para relações flecha-vão $(d / L)$ maiores que 1/8, Kumarasena et al. (2005) propuseram uma extensão à formulação de Irvine \& Caughey (1974), bastante elegante e simples, mas que não possui aplicação prática para os ensaios desta tese, mas que podem ser de interesse do leitor. 


\section{Apêndice B}

\section{Frequências, modos naturais e coeficientes de amortecimento}

\section{B.1 Ensaios de decaimento no ar}

Nas Tabelas B.1 até B.5 estão apresentadas as frequências naturais medidas em ar para os ângulos de inclinação $\theta=0^{\circ}, 10^{\circ}, 20^{\circ}, 30^{\circ} \mathrm{e} 45^{\circ}$, respectivamente. Em conjunto com as medidas realizadas para cada uma das cinco repetições do ensaio estão os valores obtidos para o amortecimento estrutural $\zeta$.

Como pode ser observado em todos os casos, os valores experimentais ficaram muito próximos dos valores teóricos obtidos com o Orcaflex®. Isso reforça a metodologia de se utilizar os modos naturais obtidos numericamente para a realização da decomposição modal.

Além de caracterizar bem a frequência natural dos dez primeiros modos de vibrar das condições ensaiadas, foram obtidos os coeficientes de amortecimento estruturais, apresentados na última coluna das referidas tabelas.

Quanto ao amortecimento um resultado interessante surgiu das avaliações: a configuração de referência (vertical) apresentou valores ligeiramente menores que os casos inclinados. Para esta configuração temos $\zeta=2.5 \%$ ao passo que para as outras inclinações este valor varia de $3.0 \%$ a $3.6 \%$. Este fato deve-se principalmente à curvatura imposta pela campo gravitacional nos casos inclinados.

Nas Figuras B.1 até B.5 são apresentadas as avaliações dos dez primeiros modos de vibrar do modelo estudado nas inclinações $\theta=0^{\circ}, 10^{\circ}, 20^{\circ}, 30^{\circ} \mathrm{e} 45^{\circ}$, respectivamente. Nestas figuras são apresentadas as frequências naturais obtidas $\left(f_{n_{i}}\right)$ bem como a descrição das funções $\phi_{i}$ através do gráfico das componentes normal $(\boldsymbol{n})$, bi-normal (b) e tangencial $(\boldsymbol{t})$ também em função da coordenada $s$. 
Tabela B.1 - Frequências naturais dos modos de vibrar obtidas através de ensaios de decaimento realizados em $\mathrm{ar}-f_{n_{i}}^{a r}(\mathrm{~Hz})$ - e Coeficiente de Amortecimento - $\zeta_{s}\left(\theta=0^{\circ}\right)$

\begin{tabular}{ccccccccccc|c}
\hline \multirow{2}{*}{ Repetição } & \multicolumn{10}{c|}{ Modos } & \multirow{8}{c}{$\zeta_{s}$} \\
\cline { 2 - 12 } & 1 & 2 & 3 & 4 & 5 & 6 & 7 & 8 & 9 & 10 & \\
\hline 1 & 1.62 & 1.60 & 3.29 & 3.16 & 4.81 & 4.76 & 6.48 & 6.46 & 8.82 & 8.54 & $2.5 \%$ \\
2 & 1.58 & 1.59 & 3.21 & 3.22 & 4.86 & 4.87 & 6.42 & 6.54 & 9.20 & 9.21 & $2.0 \%$ \\
3 & 1.63 & 1.59 & 3.22 & 3.13 & 4.82 & 4.90 & 6.59 & 6.85 & 9.42 & 9.13 & $2.3 \%$ \\
4 & 1.56 & 1.58 & 3.17 & 3.20 & 4.82 & 4.87 & 6.62 & 6.67 & 8.99 & 8.93 & $2.8 \%$ \\
5 & 1.63 & 1.57 & 3.25 & 3.20 & 4.87 & 4.83 & 6.50 & 6.49 & 8.61 & 8.51 & $2.7 \%$ \\
\hline Média & 1.60 & 1.59 & 3.23 & 3.18 & 4.84 & 4.85 & 6.52 & 6.60 & 9.01 & 8.86 & $2.5 \%$ \\
\hline Teórica & 1.60 & 1.60 & 3.25 & 3.25 & 5.00 & 5.00 & 6.88 & 6.88 & 8.93 & 8.93 & - \\
\hline Diferença & $0.4 \%$ & $0.8 \%$ & $0.7 \%$ & $2.1 \%$ & $3.2 \%$ & $3.0 \%$ & $5.2 \%$ & $4.0 \%$ & $0.8 \%$ & $0.8 \%$ & - \\
\hline
\end{tabular}
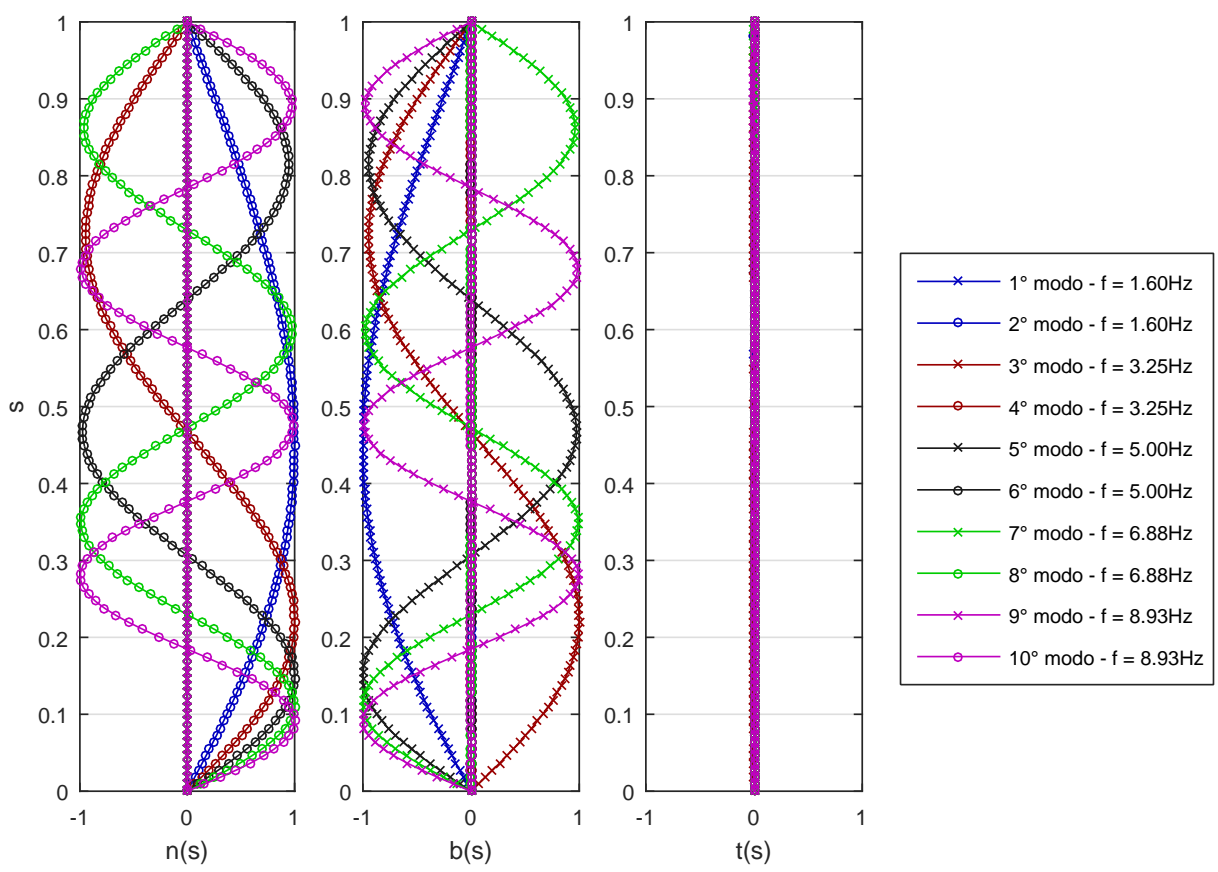

Figura B.1 - Componentes locais dos modos de vibrar do modelo em ar - Inclin. $\theta=0$ graus. 
Tabela B.2 - Frequências naturais dos modos de vibrar obtidas através de ensaios de decaimento realizados em ar - $f_{n_{i}}^{a r}(\mathrm{~Hz})$ - e Coeficiente de Amortecimento - $\zeta_{s}\left(\theta=10^{\circ}\right)$

\begin{tabular}{ccccccccccc|c}
\hline \multirow{2}{*}{ Repetição } & \multicolumn{10}{c|}{ Modos } & \multicolumn{1}{c}{$\zeta_{s}$} \\
\cline { 2 - 12 } & 1 & 2 & 3 & 4 & 5 & 6 & 7 & 8 & 9 & 10 & \\
\hline 1 & 1.57 & 1.65 & 3.30 & 3.27 & 4.93 & 4.95 & 6.73 & 6.52 & 8.93 & 8.23 & $2.9 \%$ \\
2 & 1.62 & 1.61 & 3.25 & 3.23 & 4.85 & 4.82 & 6.45 & 6.35 & 8.44 & 9.45 & $2.9 \%$ \\
3 & 1.60 & 1.63 & 3.24 & 3.24 & 4.91 & 4.91 & 6.60 & 6.55 & 8.53 & 8.53 & $3.0 \%$ \\
4 & 1.63 & 1.65 & 3.28 & 3.32 & 4.94 & 4.91 & 6.45 & 6.61 & 8.21 & 8.25 & $3.1 \%$ \\
5 & 1.61 & 1.62 & 3.21 & 3.20 & 4.89 & 4.85 & 6.52 & 6.62 & 8.53 & 9.36 & $3.2 \%$ \\
\hline Média & 1.61 & 1.63 & 3.26 & 3.25 & 4.90 & 4.89 & 6.55 & 6.53 & 8.53 & 8.76 & $3.0 \%$ \\
\hline Teórica & 1.60 & 1.64 & 3.24 & 3.24 & 4.99 & 4.99 & 6.86 & 6.87 & 8.92 & 8.92 & - \\
\hline Diferença & $0.7 \%$ & $0.2 \%$ & $0.5 \%$ & $0.3 \%$ & $1.6 \%$ & $2.0 \%$ & $4.6 \%$ & $4.9 \%$ & $4.4 \%$ & $1.7 \%$ & - \\
\hline
\end{tabular}
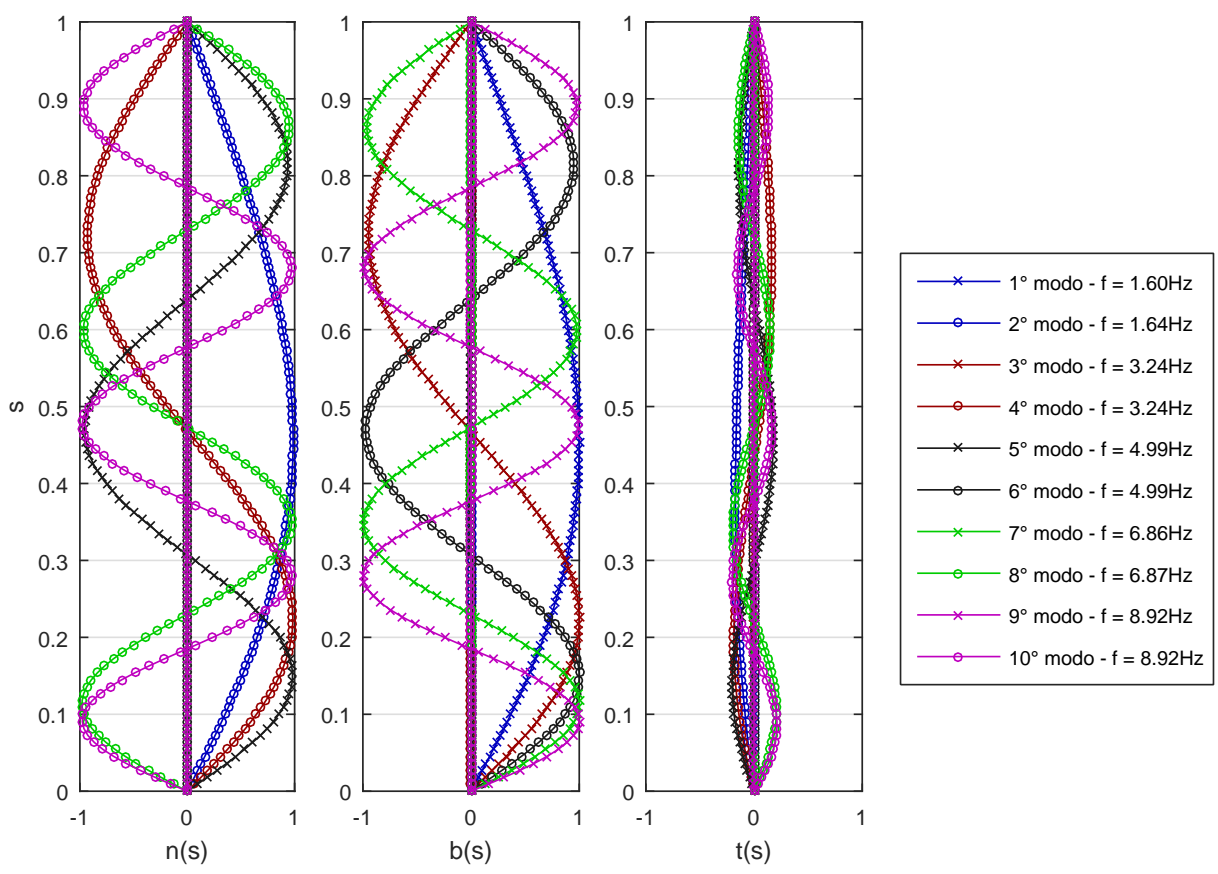

Figura B.2 - Componentes locais dos modos de vibrar do modelo em ar - Inclin. $\theta=10$ graus. 
Tabela B.3 - Frequências naturais dos modos de vibrar obtidas através de ensaios de decaimento realizados em ar - $f_{n_{i}}^{a r}(\mathrm{~Hz})$ - e Coeficiente de Amortecimento - $\zeta_{s}\left(\theta=20^{\circ}\right)$

\begin{tabular}{ccccccccccc|c}
\hline \multirow{2}{*}{ Repetição } & \multicolumn{10}{c|}{ Modos } & \multicolumn{1}{c}{$\zeta$} \\
\cline { 2 - 12 } & 1 & 2 & 3 & 4 & 5 & 6 & 7 & 8 & 9 & 10 & \\
\hline 1 & 1.67 & 1.74 & 3.23 & 3.28 & 4.93 & 5.03 & 6.73 & 6.74 & 8.84 & 8.75 & $3.7 \%$ \\
2 & 1.62 & 1.63 & 3.28 & 3.50 & 4.89 & 5.10 & 6.54 & 6.59 & 9.48 & 8.72 & $3.0 \%$ \\
3 & 1.70 & 1.72 & 3.38 & 3.32 & 5.15 & 4.93 & 6.89 & 6.77 & 8.50 & 8.65 & $3.7 \%$ \\
4 & 1.60 & 1.72 & 3.25 & 3.23 & 4.90 & 5.01 & 6.58 & 6.55 & 8.65 & 9.55 & $3.4 \%$ \\
5 & 1.60 & 1.72 & 3.22 & 3.23 & 4.89 & 4.98 & 6.50 & 6.63 & 8.75 & 8.84 & $3.5 \%$ \\
\hline Média & 1.64 & 1.71 & 3.27 & 3.31 & 4.95 & 5.01 & 6.65 & 6.65 & 8.84 & 8.90 & $3.4 \%$ \\
\hline Teórica & 1.63 & 1.77 & 3.31 & 3.31 & 5.08 & 5.09 & 6.99 & 6.99 & 9.06 & 9.07 & - \\
\hline Diferença & $0.5 \%$ & $3.4 \%$ & $1.1 \%$ & $0.0 \%$ & $2.6 \%$ & $1.5 \%$ & $4.9 \%$ & $4.8 \%$ & $2.4 \%$ & $1.8 \%$ & - \\
\hline
\end{tabular}
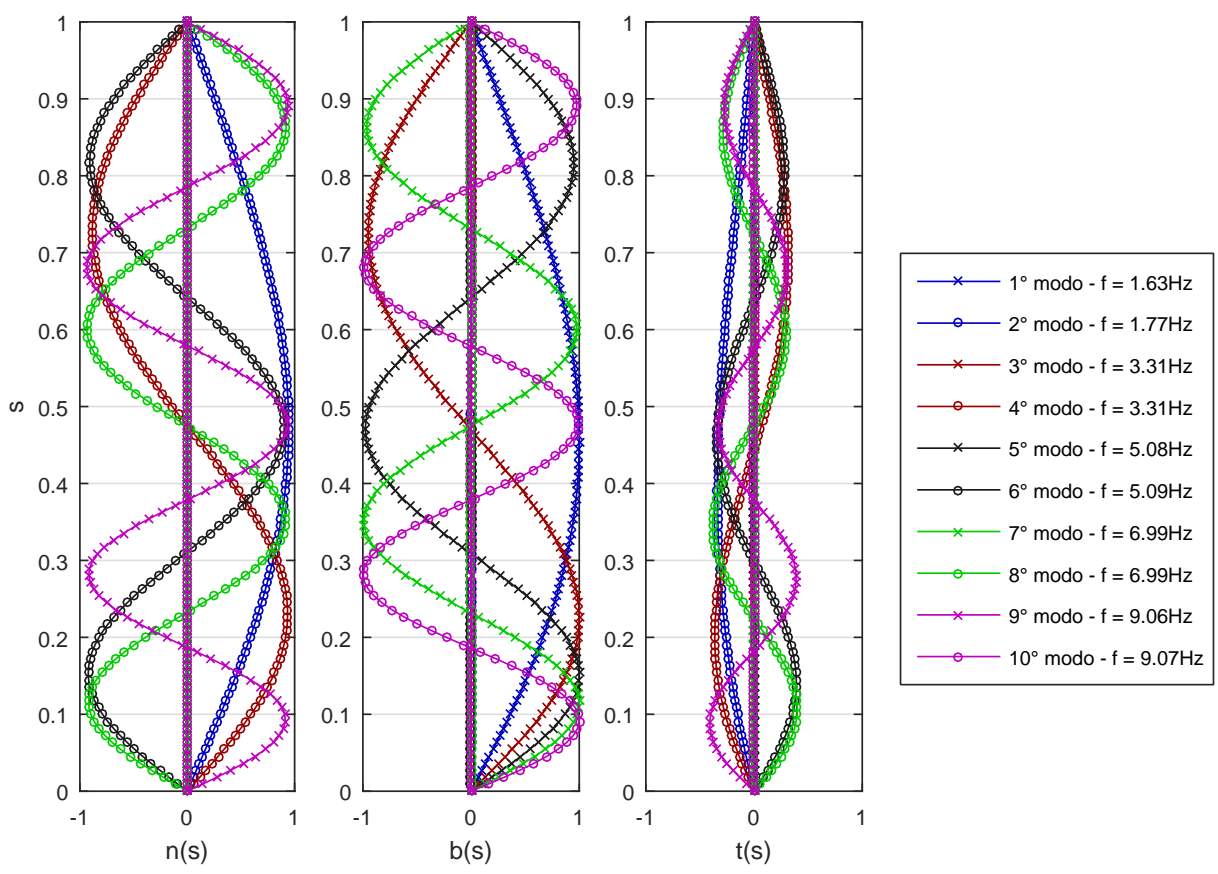

Figura B.3 - Componentes locais dos modos de vibrar do modelo em ar - Inclin. $\theta=20$ graus. 
Tabela B.4 - Frequências naturais dos modos de vibrar obtidas através de ensaios de decaimento realizados em ar - $f_{n_{i}}^{a r}(\mathrm{~Hz})$ - e Coeficiente de Amortecimento - $\zeta_{s}\left(\theta=30^{\circ}\right)$

\begin{tabular}{ccccccccccc|c}
\hline \multirow{2}{*}{ Repetição } & \multicolumn{10}{c|}{ Modos } & \multirow{8}{c}{$\zeta_{s}$} \\
\cline { 2 - 12 } & 1 & 2 & 3 & 4 & 5 & 6 & 7 & 8 & 9 & 10 & \\
\hline 1 & 1.81 & 1.97 & 3.35 & 3.55 & 5.21 & 5.03 & 7.19 & 7.29 & 8.82 & 8.82 & $3.7 \%$ \\
2 & 1.68 & 1.65 & 3.20 & 3.28 & 4.86 & 4.90 & 6.77 & 6.61 & 8.66 & 9.52 & $2.9 \%$ \\
3 & 1.64 & 1.93 & 3.38 & 3.49 & 5.27 & 5.35 & 6.88 & 7.16 & 9.27 & 8.88 & $3.8 \%$ \\
4 & 1.61 & 1.93 & 3.39 & 3.49 & 5.26 & 5.37 & 6.86 & 7.16 & 8.80 & 8.69 & $3.9 \%$ \\
5 & 1.63 & 1.91 & 3.37 & 3.46 & 4.89 & 5.23 & 6.67 & 7.18 & 8.73 & 8.71 & $3.3 \%$ \\
\hline Média & 1.67 & 1.88 & 3.34 & 3.45 & 5.10 & 5.18 & 6.87 & 7.08 & 8.85 & 8.92 & $3.5 \%$ \\
\hline Teórica & 1.64 & 1.91 & 3.32 & 3.33 & 5.12 & 5.12 & 7.02 & 7.03 & 9.11 & 9.11 & - \\
\hline Diferença & $1.7 \%$ & $1.6 \%$ & $0.4 \%$ & $3.5 \%$ & $0.4 \%$ & $1.1 \%$ & $2.2 \%$ & $0.7 \%$ & $2.8 \%$ & $2.0 \%$ & - \\
\hline
\end{tabular}
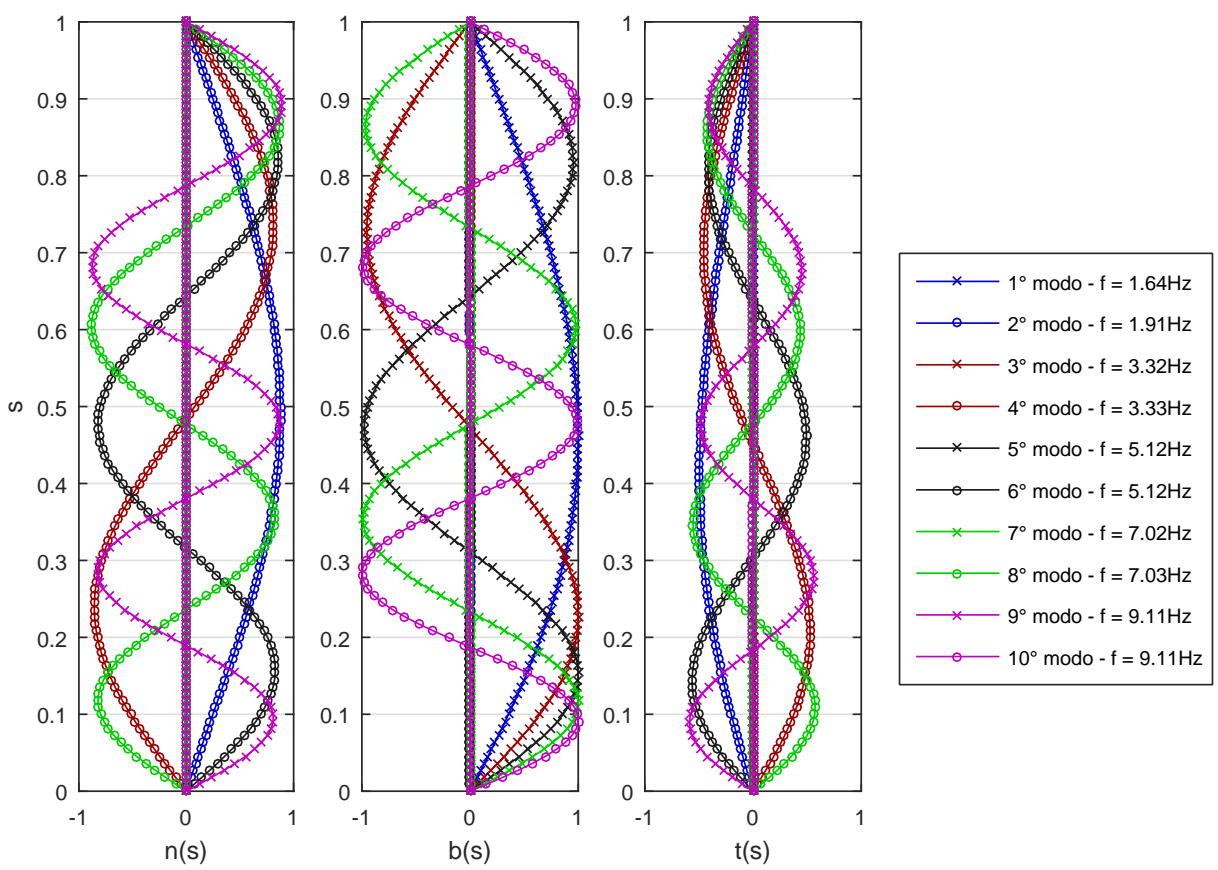

Figura B.4 - Componentes locais dos modos de vibrar do modelo em ar - Inclin. $\theta=30$ graus. 
Tabela B.5 - Frequências naturais dos modos de vibrar obtidas através de ensaios de decaimento realizados em ar - $f_{n_{i}}^{a r}(\mathrm{~Hz})$ - e Coeficiente de Amortecimento - $\zeta_{s}\left(\theta=45^{\circ}\right)$

\begin{tabular}{ccccccccccc|c}
\hline \multirow{2}{*}{ Repetição } & \multicolumn{10}{c|}{ Modos } & \multicolumn{1}{c}{$\zeta_{s}$} \\
\cline { 2 - 13 } & 1 & 2 & 3 & 4 & 5 & 6 & 7 & 8 & 9 & 10 & \\
\hline 1 & 1.59 & 2.27 & 3.15 & 3.26 & 4.69 & 4.80 & 6.57 & 6.57 & 8.96 & 9.29 & $4.4 \%$ \\
2 & 1.55 & 2.19 & 3.14 & 3.23 & 4.80 & 4.86 & 6.51 & 6.52 & 9.21 & 9.15 & $3.1 \%$ \\
3 & 1.59 & 2.26 & 3.15 & 3.24 & 4.65 & 4.82 & 6.55 & 6.96 & 9.17 & 8.88 & $3.8 \%$ \\
4 & 1.56 & 2.16 & 3.11 & 3.12 & 4.67 & 4.74 & 6.51 & 6.59 & 8.51 & 8.53 & $3.4 \%$ \\
5 & 1.55 & 2.16 & 3.11 & 3.12 & 4.67 & 4.75 & 6.41 & 6.69 & 8.53 & 8.61 & $3.2 \%$ \\
\hline Média & 1.57 & 2.21 & 3.13 & 3.19 & 4.70 & 4.80 & 6.51 & 6.67 & 8.87 & 8.89 & $3.6 \%$ \\
\hline Teórica & 1.63 & 2.13 & 3.28 & 3.30 & 5.07 & 5.07 & 6.95 & 6.96 & 9.02 & 9.02 & - \\
\hline Diferença & $3.9 \%$ & $3.4 \%$ & $4.5 \%$ & $3.4 \%$ & $7.3 \%$ & $5.5 \%$ & $6.3 \%$ & $4.3 \%$ & $1.6 \%$ & $1.4 \%$ & - \\
\hline
\end{tabular}
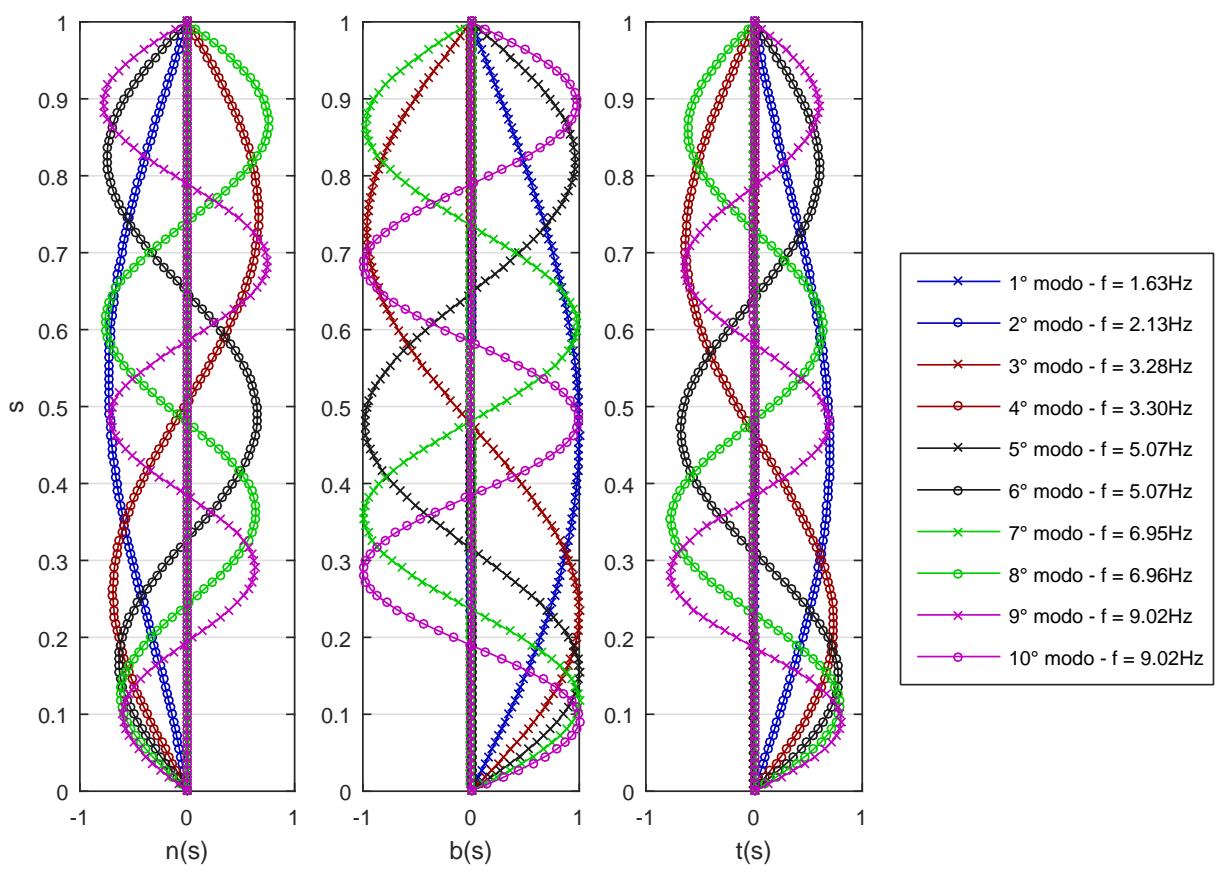

Figura B.5-Componentes locais dos modos de vibrar do modelo em ar - Inclin. $\theta=45$ graus. 


\section{B.2 Ensaios de decaimento em água}

As Tabelas B.6 até B.10 frequências naturais obtidas através de ensaios de decaimento com o modelo submerso em água para os ângulos de inclinação $\theta=0^{\circ}, 10^{\circ}$, $20^{\circ}, 30^{\circ} \mathrm{e} 45^{\circ}$, respectivamente. Em conjunto com as medidas realizadas para cada uma das cinco repetições do ensaio estão os valores obtidos para o amortecimento $\bar{\zeta}$.

Nas Figuras B.6 até B.10 são apresentadas as avaliações dos dez primeiros modos de vibrar do modelo estudado nas inclinações $\theta=0^{\circ}, 10^{\circ}, 20^{\circ}, 30^{\circ} \mathrm{e} 45^{\circ}$, respectivamente. Nestas figuras são apresentadas as frequências naturais obtidas $\left(f_{n_{i}}\right)$ bem como a descrição das funções $\phi_{i}$ através do gráfico das componentes normal $(n)$, bi-normal (b) e tangencial $(t)$ também em função da coordenada $s$.

Apesar de para alguns modos naturais as frequências possuírem uma diferença maior do que os modelos em ar, novamente é possível observar a boa correlação entre os valores obtidos numérico e experimentalmente.

Com relação ao valores de amortecimento foi obtida uma tendência diferente daquela observada nos ensaios em ar. O modo vertical apresentou o maior valor de amortecimento $(\bar{\zeta}=8.0 \%)$ ao passo que as outras configurações apresentaram amortecimentos entre $5.1 \%$ e $7.4 \%$. 
Tabela B.6 - Frequências naturais dos modos de vibrar obtidas através de ensaios de decaimento realizados em água - $f_{n_{i}}(\mathrm{~Hz})$ - e Coeficiente de Amortecimento $-\bar{\zeta}\left(\theta=0^{\circ}\right)$

\begin{tabular}{ccccccccccc|c}
\hline \multirow{2}{*}{ Repetição } & \multicolumn{10}{c|}{ Modos } & \multirow{\zeta}{*}{$\bar{\zeta}$} \\
\cline { 2 - 11 } & 1 & 2 & 3 & 4 & 5 & 6 & 7 & 8 & 9 & 10 & \\
\hline 1 & 1.18 & 1.18 & 2.54 & 2.24 & 3.47 & 3.32 & 4.72 & 4.75 & 6.55 & 6.68 & $7.0 \%$ \\
2 & 1.18 & 1.05 & 2.09 & 2.23 & 3.42 & 3.42 & 4.88 & 4.82 & 6.93 & 6.27 & $8.4 \%$ \\
3 & 1.14 & 1.02 & 2.28 & 2.16 & 3.37 & 3.30 & 4.84 & 4.81 & 6.25 & 6.40 & $8.7 \%$ \\
4 & 1.06 & 1.04 & 2.12 & 2.16 & 3.80 & 3.50 & 5.03 & 4.76 & 6.60 & 6.37 & $8.1 \%$ \\
\hline Média & 1.14 & 1.07 & 2.26 & 2.20 & 3.52 & 3.39 & 4.87 & 4.79 & 6.58 & 6.43 & $8.0 \%$ \\
\hline Teórica & 1.14 & 1.14 & 2.34 & 2.34 & 3.64 & 3.64 & 5.09 & 5.09 & 6.71 & 6.71 & - \\
\hline Diferença & $0.0 \%$ & $5.9 \%$ & $3.4 \%$ & $6.0 \%$ & $3.4 \%$ & $7.0 \%$ & $4.3 \%$ & $6.0 \%$ & $2.0 \%$ & $4.2 \%$ & - \\
\hline
\end{tabular}
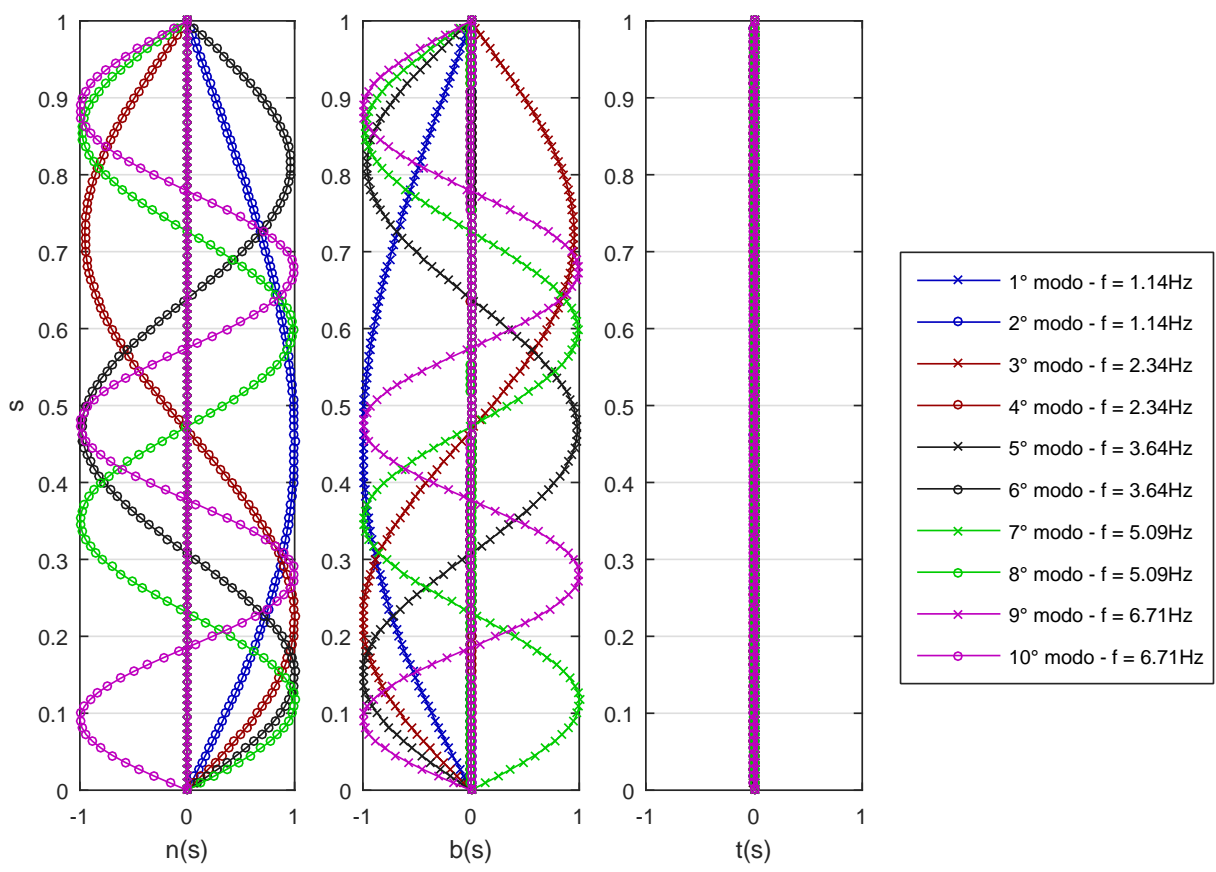

Figura B.6 - Componentes locais dos modos de vibrar do modelo em água - Inclin. $\theta=0$ graus. 
Tabela B.7-Frequências naturais dos modos de vibrar obtidas através de ensaios de decaimento realizados em água - $f_{n_{i}}(\mathrm{~Hz})$ - e Coeficiente de Amortecimento $-\bar{\zeta}$ $\left(\theta=10^{\circ}\right)$

\begin{tabular}{ccccccccccc|c}
\hline \multirow{2}{*}{ Repetição } & \multicolumn{10}{c|}{ Modos } & \multicolumn{1}{c}{} \\
\cline { 2 - 12 } & 1 & 2 & 3 & 4 & 5 & 6 & 7 & 8 & 9 & 10 & \\
\hline 1 & 1.09 & 1.15 & 2.26 & 2.45 & 3.40 & 3.52 & 4.54 & 5.14 & 6.07 & 6.13 & $7.5 \%$ \\
2 & 1.06 & 1.14 & 2.12 & 2.05 & 3.46 & 3.67 & 5.24 & 4.84 & 6.56 & 6.49 & $7.7 \%$ \\
3 & 1.02 & 1.14 & 2.17 & 2.18 & 3.39 & 3.41 & 4.75 & 4.93 & 6.41 & 6.23 & $6.6 \%$ \\
4 & 1.03 & 1.21 & 2.29 & 2.26 & 3.29 & 3.39 & 4.49 & 4.49 & 6.66 & 6.65 & $7.8 \%$ \\
5 & 1.15 & 1.17 & 2.24 & 2.26 & 3.58 & 3.50 & 4.65 & 5.00 & 6.37 & 6.71 & $7.6 \%$ \\
\hline Média & 1.07 & 1.16 & 2.22 & 2.24 & 3.42 & 3.50 & 4.73 & 4.88 & 6.41 & 6.44 & $7.4 \%$ \\
\hline Teórica & 1.07 & 1.12 & 2.20 & 2.20 & 3.44 & 3.44 & 4.83 & 4.83 & 6.41 & 6.41 & - \\
\hline Diferença & $0.0 \%$ & $3.6 \%$ & $0.8 \%$ & $1.8 \%$ & $0.5 \%$ & $1.7 \%$ & $2.0 \%$ & $1.0 \%$ & $0.1 \%$ & $0.5 \%$ & - \\
\hline
\end{tabular}
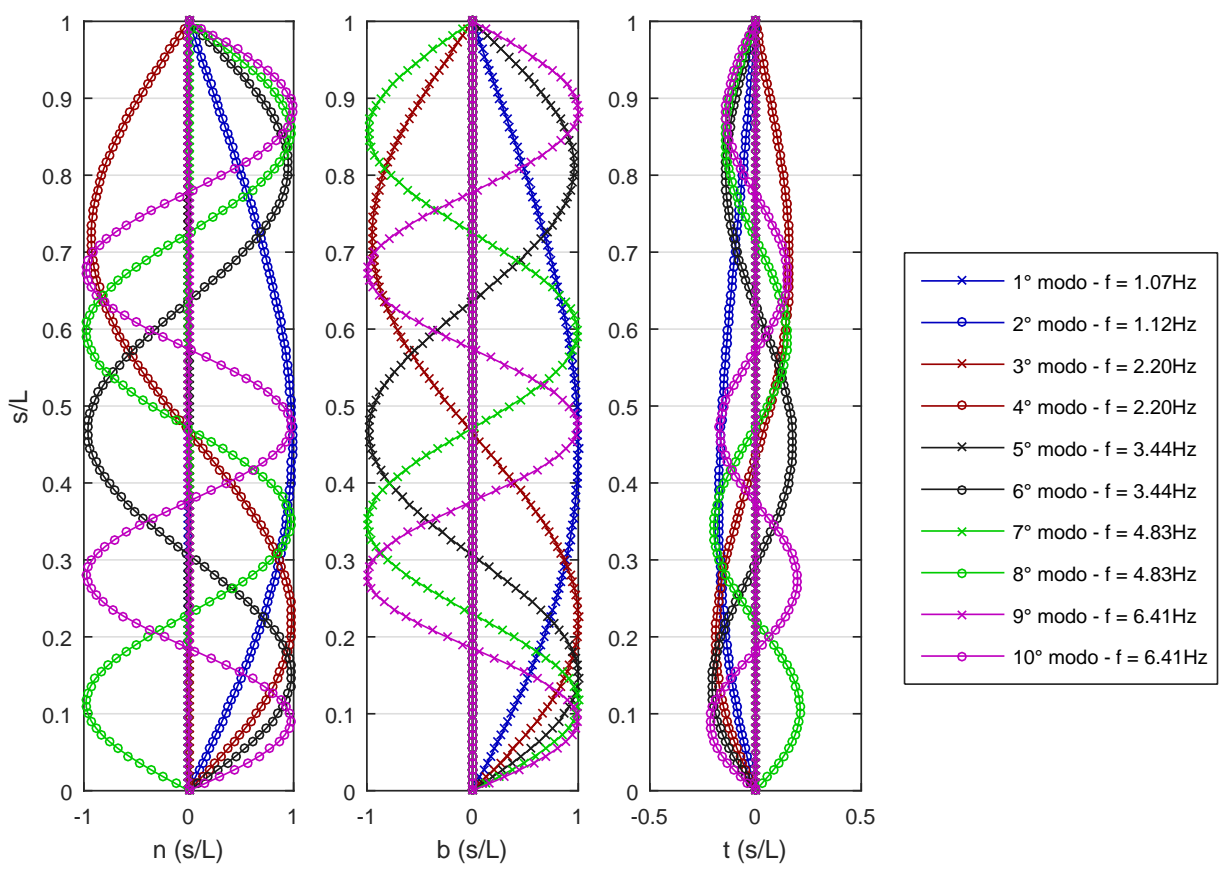

Figura B.7-Componentes locais dos modos de vibrar do modelo em água - Inclin. $\theta=10$ graus. 
Tabela B.8 - Frequências naturais dos modos de vibrar obtidas através de ensaios de decaimento realizados em água - $f_{n_{i}}(\mathrm{~Hz})$ - e Coeficiente de Amortecimento $-\bar{\zeta}$ $\left(\theta=20^{\circ}\right)$

\begin{tabular}{ccccccccccc|c}
\hline \multirow{2}{*}{ Repetição } & \multicolumn{10}{c|}{ Modos } & \multirow{8}{c}{$\bar{\zeta}$} \\
\cline { 2 - 11 } & 1 & 2 & 3 & 4 & 5 & 6 & 7 & 8 & 9 & 10 & \\
\hline 1 & 1.31 & 1.30 & 2.58 & 2.82 & 4.14 & 4.16 & 5.38 & 5.35 & 7.09 & 7.85 & $5.1 \%$ \\
2 & 1.35 & 1.29 & 2.68 & 2.89 & 4.10 & 4.06 & 5.35 & 5.35 & 7.35 & 7.35 & $3.5 \%$ \\
3 & 1.32 & 1.34 & 2.70 & 2.77 & 3.78 & 4.34 & 5.71 & 6.08 & 7.80 & 7.80 & $6.8 \%$ \\
4 & 1.35 & 1.66 & 2.65 & 2.80 & 3.82 & 3.93 & 5.36 & 5.32 & 7.81 & 7.76 & $6.3 \%$ \\
5 & 1.22 & 1.22 & 2.51 & 2.88 & 4.12 & 4.11 & 5.69 & 5.22 & 7.34 & 7.60 & $7.1 \%$ \\
\hline Média & 1.31 & 1.36 & 2.62 & 2.83 & 3.99 & 4.12 & 5.50 & 5.46 & 7.48 & 7.67 & $5.8 \%$ \\
\hline Teórica & 1.32 & 1.39 & 2.68 & 2.68 & 4.14 & 4.14 & 5.73 & 5.73 & 7.48 & 7.48 & - \\
\hline Diferença & $0.5 \%$ & $1.8 \%$ & $2.1 \%$ & $5.5 \%$ & $3.6 \%$ & $0.6 \%$ & $4.1 \%$ & $4.7 \%$ & $0.1 \%$ & $2.5 \%$ & - \\
\hline
\end{tabular}
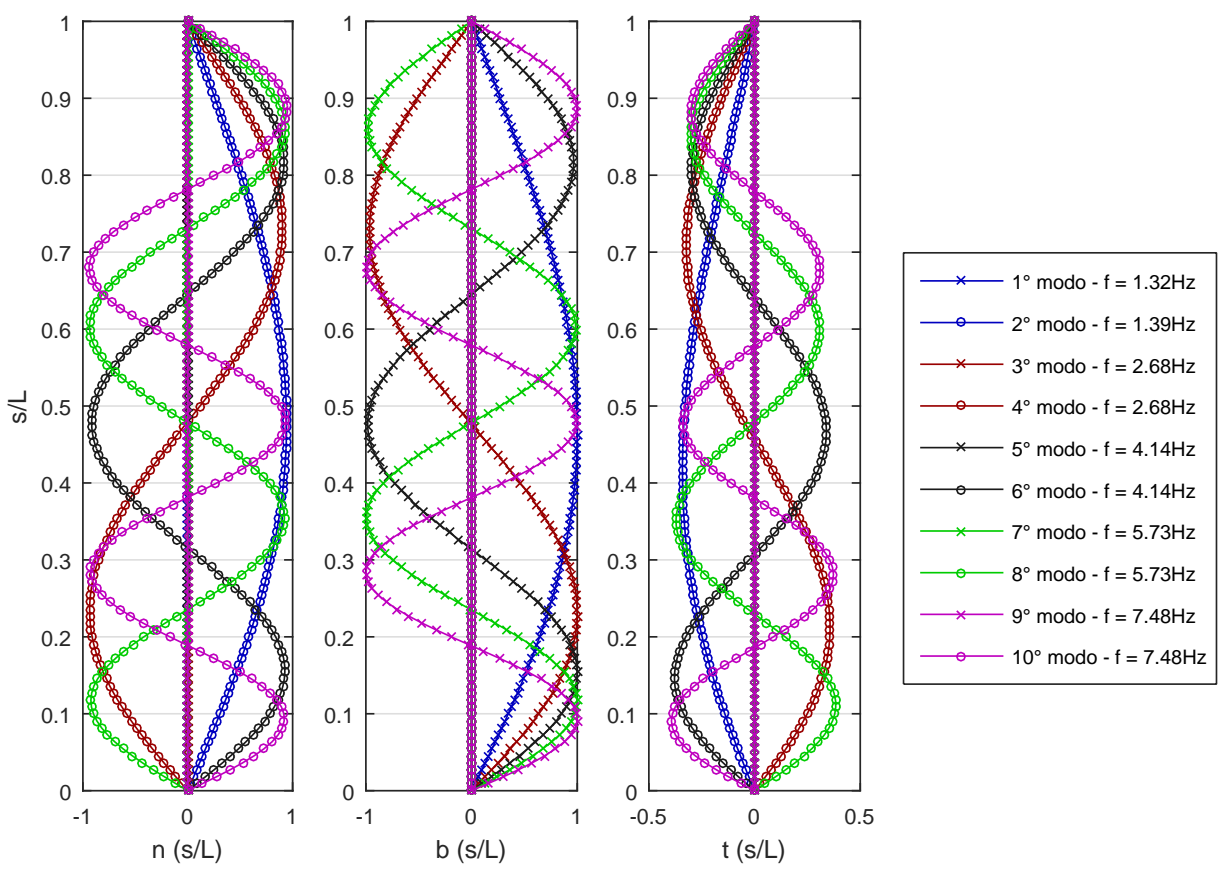

Figura B.8-Componentes locais dos modos de vibrar do modelo em água - Inclin. $\theta=20$ graus. 
Tabela B.9- Frequências naturais dos modos de vibrar obtidas através de ensaios de decaimento realizados em água - $f_{n_{i}}(\mathrm{~Hz})$ - e Coeficiente de Amortecimento $-\bar{\zeta}$ $\left(\theta=30^{\circ}\right)$

\begin{tabular}{ccccccccccc|c}
\hline \multirow{2}{*}{ Repetição } & \multicolumn{10}{c|}{ Modos } & \multirow{8}{c}{$\bar{\zeta}$} \\
\cline { 2 - 11 } & 1 & 2 & 3 & 4 & 5 & 6 & 7 & 8 & 9 & 10 & \\
\hline 1 & 1.32 & 1.29 & 2.60 & 2.87 & 4.03 & 3.95 & 6.10 & 5.90 & 7.68 & 7.45 & $4.7 \%$ \\
2 & 1.35 & 1.32 & 2.67 & 2.87 & 4.17 & 4.36 & 5.17 & 5.66 & 7.00 & 7.07 & $3.4 \%$ \\
3 & 1.40 & 1.68 & 2.86 & 2.74 & 4.25 & 4.26 & 5.79 & 5.93 & 7.02 & 7.51 & $7.0 \%$ \\
4 & 1.32 & 1.64 & 2.75 & 2.78 & 4.39 & 3.76 & 5.98 & 5.49 & 7.37 & 7.77 & $3.6 \%$ \\
5 & 1.34 & 1.65 & 2.75 & 2.76 & 4.29 & 4.24 & 5.78 & 5.99 & 7.66 & 7.15 & $7.0 \%$ \\
\hline Média & 1.35 & 1.52 & 2.73 & 2.80 & 4.23 & 4.11 & 5.76 & 5.79 & 7.35 & 7.39 & $5.1 \%$ \\
\hline Teórica & 1.31 & 1.46 & 2.67 & 2.68 & 4.13 & 4.13 & 5.71 & 5.71 & 7.46 & 7.46 & - \\
\hline Diferença & $2.4 \%$ & $3.8 \%$ & $2.0 \%$ & $4.8 \%$ & $2.3 \%$ & $0.5 \%$ & $0.9 \%$ & $1.4 \%$ & $1.5 \%$ & $0.9 \%$ & - \\
\hline
\end{tabular}
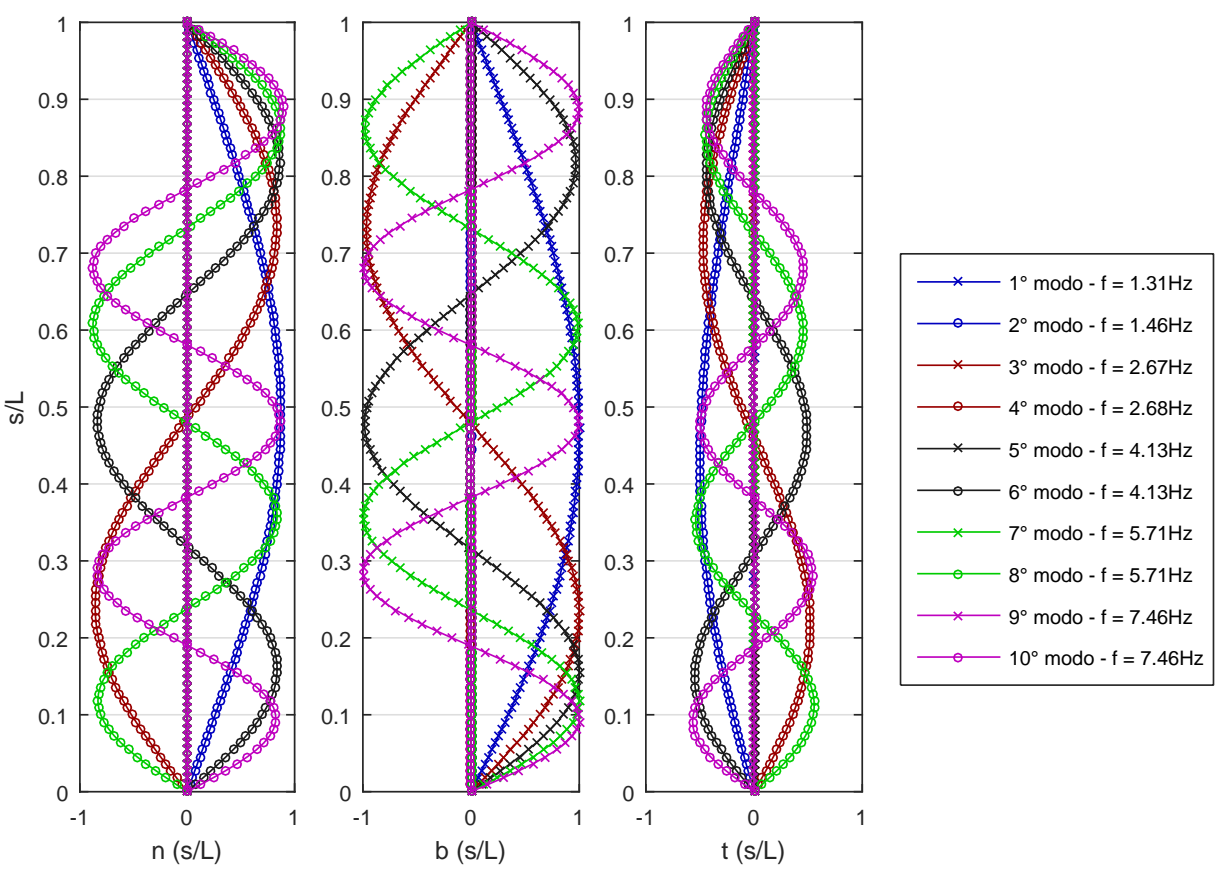

Figura B.9 - Componentes locais dos modos de vibrar do modelo em água - Inclin. $\theta=30$ graus. 
Tabela B.10 - Frequências naturais dos modos de vibrar obtidas através de ensaios de decaimento realizados em água - $f_{n_{i}}(\mathrm{~Hz})$ - e Coeficiente de Amortecimento $-\bar{\zeta}$ $\left(\theta=45^{\circ}\right)$

\begin{tabular}{ccccccccccc|c}
\hline \multirow{2}{*}{ Repetição } & \multicolumn{10}{c|}{ Modos } & \multirow{10}{c}{$\bar{\zeta}$} \\
\cline { 2 - 11 } & 1 & 2 & 3 & 4 & 5 & 6 & 7 & 8 & 9 & 10 & \\
\hline 1 & 1.29 & 1.42 & 2.61 & 2.86 & 4.27 & 4.02 & 5.26 & 5.30 & 6.84 & 7.03 & $6.3 \%$ \\
2 & 1.24 & 1.72 & 2.67 & 2.24 & 3.91 & 4.07 & 5.52 & 5.53 & 7.28 & 6.82 & $6.1 \%$ \\
3 & 1.24 & 1.64 & 2.22 & 2.67 & 3.91 & 4.06 & 5.52 & 5.54 & 6.92 & 7.29 & $5.5 \%$ \\
4 & 1.28 & 1.51 & 2.61 & 2.92 & 4.00 & 3.80 & 5.11 & 5.12 & 6.79 & 6.93 & $6.8 \%$ \\
\hline Média & 1.26 & 1.57 & 2.53 & 2.67 & 4.02 & 3.99 & 5.35 & 5.37 & 6.96 & 7.02 & $6.2 \%$ \\
\hline Teórica & 1.25 & 1.59 & 2.54 & 2.55 & 3.95 & 3.95 & 5.46 & 5.47 & 7.16 & 7.16 & - \\
\hline Diferença & $0.8 \%$ & $1.0 \%$ & $0.6 \%$ & $4.7 \%$ & $2.0 \%$ & $0.8 \%$ & $2.1 \%$ & $1.8 \%$ & $2.8 \%$ & $2.0 \%$ & - \\
\hline
\end{tabular}
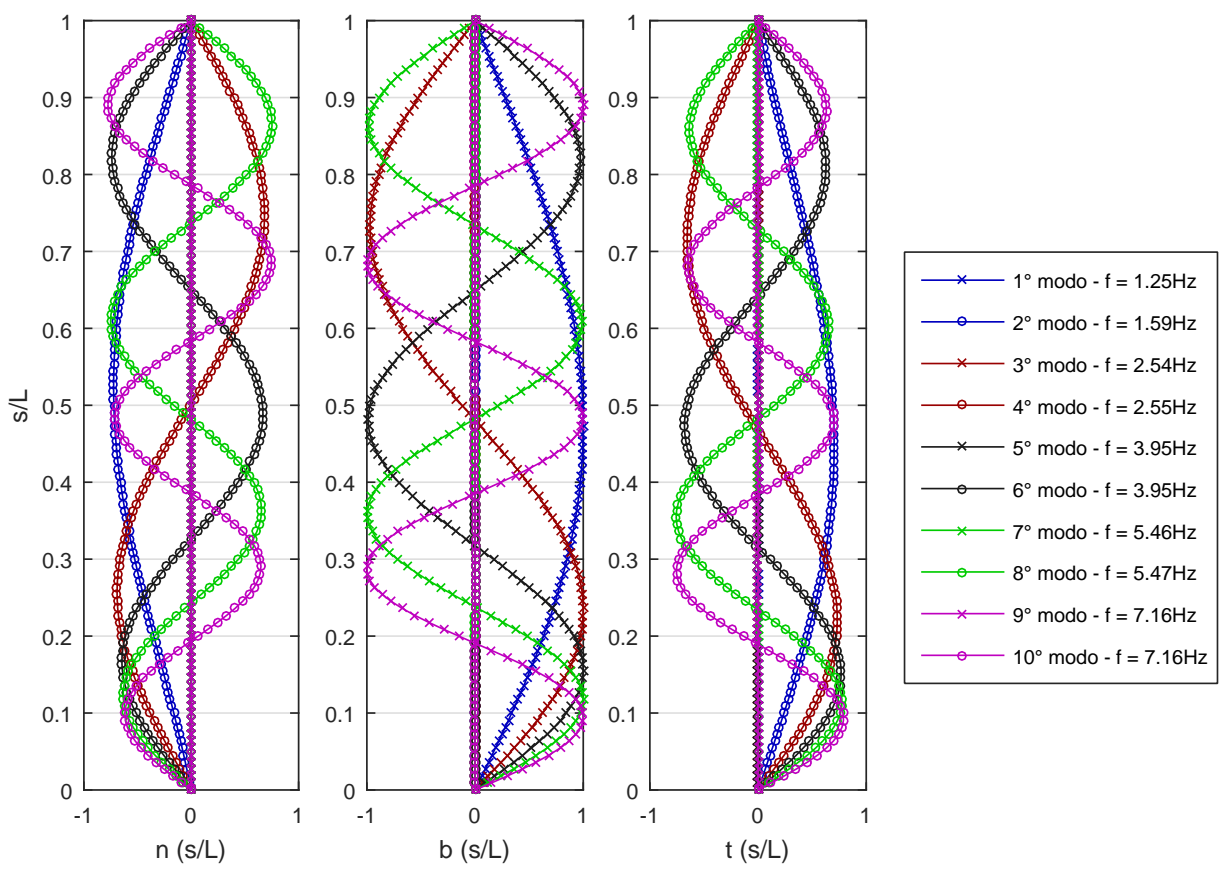

Figura B.10 - Componentes locais dos modos de vibrar do modelo em água - Inclin. $\theta=45$ graus. 


\section{Apêndice C}

\section{Resultados complementares do ensaio de VIV}

Este apêndice é dedicado à apresentação de resultados complementares aqueles obtidos a partir do ensaios de VIV. Os resultados estão divididos em duas seções: a primeira que apresenta as amplitudes modais em função de $V r_{i}$ e a segunda que apresenta as amplitudes modais em função de $\overline{V r}_{1}$.

\section{C.1 Amplitudes modais em função de $V r_{i}$}

Nas Figuras C.1 e C.2 estão apresentados os mapeamentos de amplitude modal considerando a análise da média dos extremos entre zeros ascendentes e da média dos $10 \%$ maiores extremos entre zeros ascendentes do sinal, respectivamente. Esses resultados são complementares aos apresentados na Figura 4.1 que apresenta a análise de $\sqrt{2} \sigma$. 


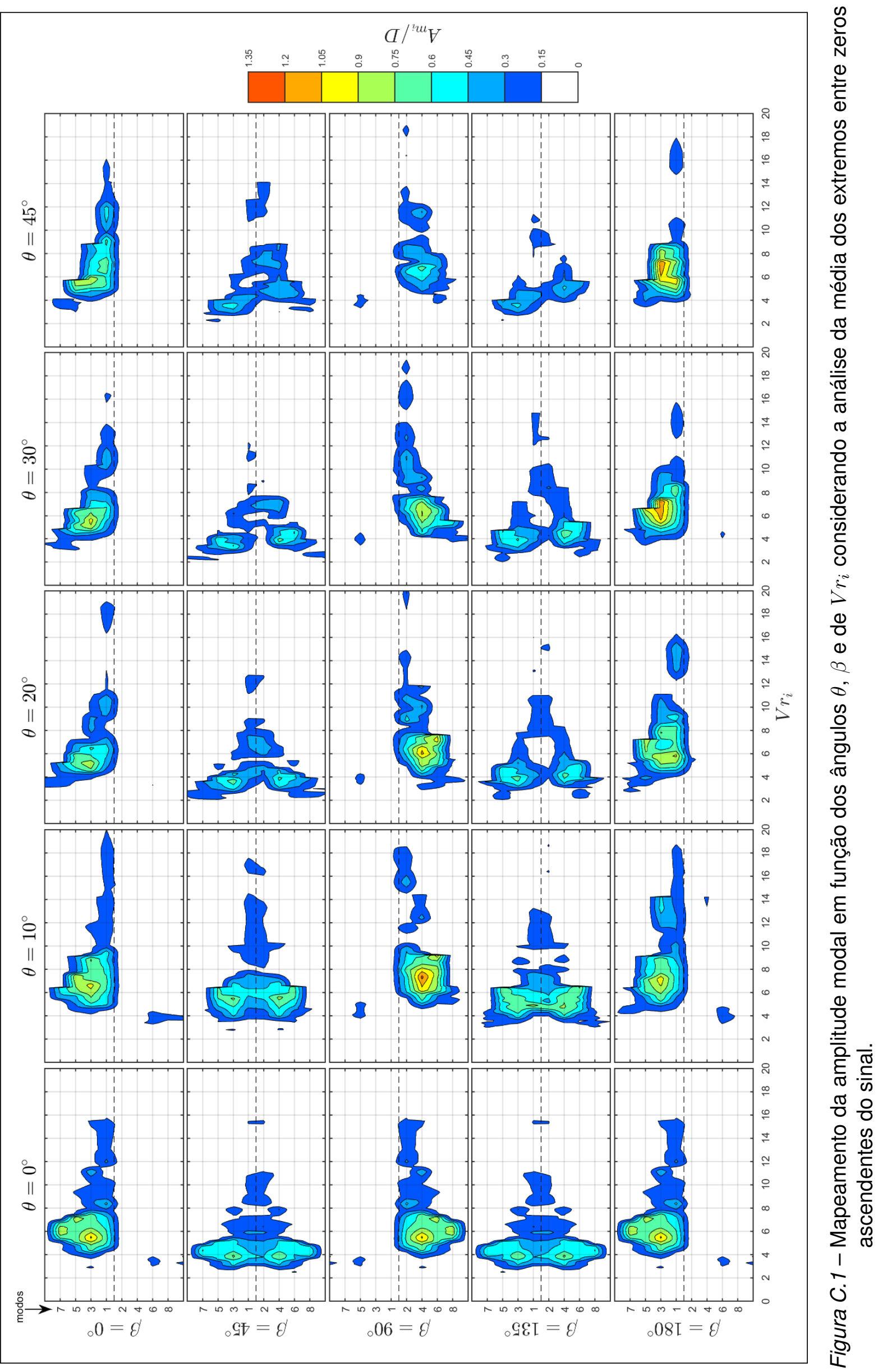




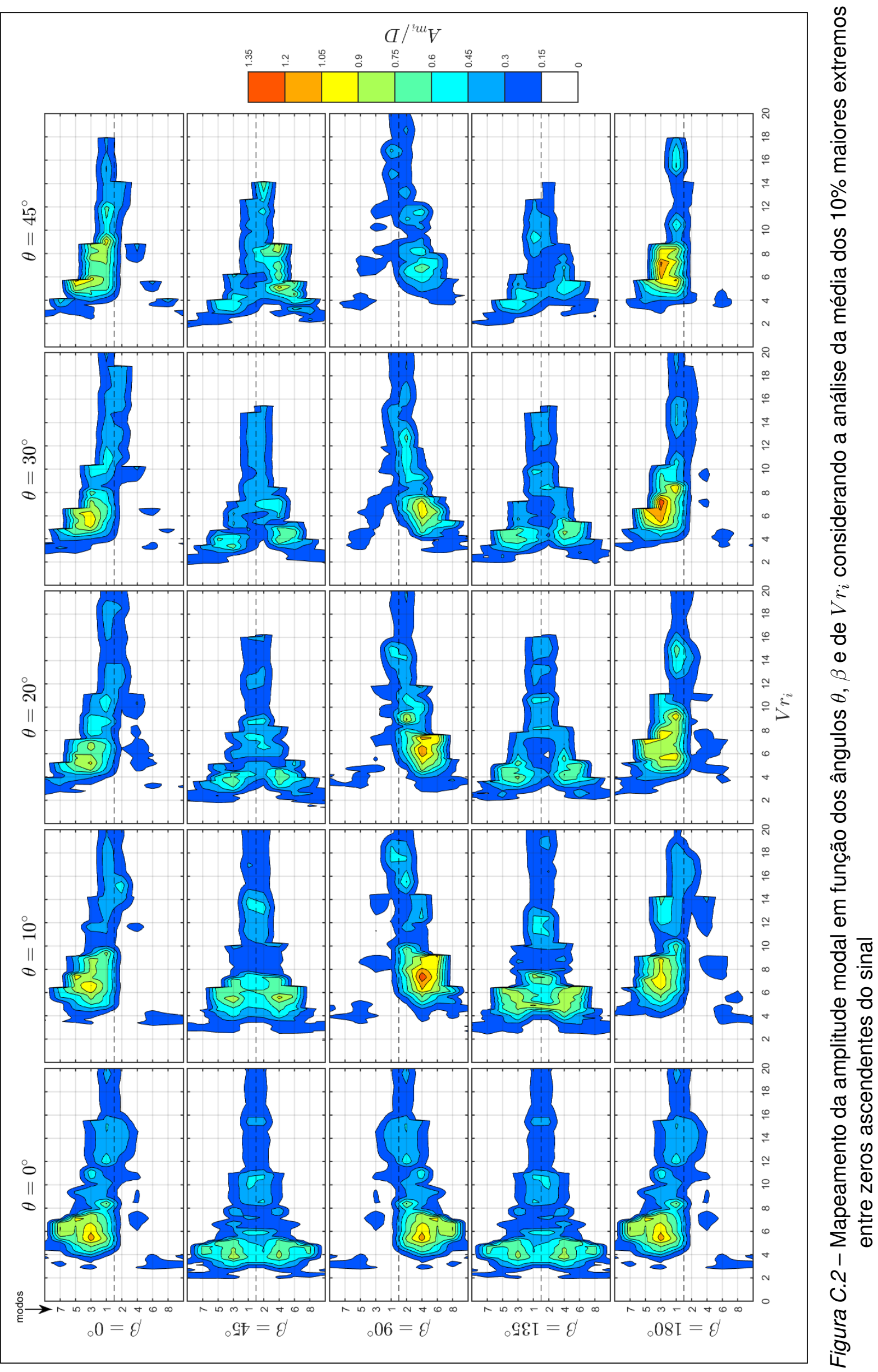




\section{C.2 Amplitudes modais em função de $\overline{V r} 1$}

As seções C.2.1 até C.2.5 apresentam os resultados das amplitudes modais em função de $\overline{V r}_{1}$ para as inclinações $\theta=0^{\circ}, 10^{\circ}, 20^{\circ}, 30^{\circ}$ e $45^{\circ}$, respectivamente. Ao invés de apresentar as curvas em formato de mapeamento como no corpo do texto e na seção anterior, optou-se por apresentar gráficos separados por $\theta$ e $\beta$ para facilitar a visualização dos dados.

\section{C.2.1 Inclinação 0 graus}

As Figuras C.3 até C.7 apresentam as amplitudes modais em função de $\overline{V r}_{1}$ para $\theta=0^{\circ}$ e $\beta=0^{\circ}, 45^{\circ}, 90^{\circ}, 135^{\circ}$ e $180^{\circ}$, respectivamente.

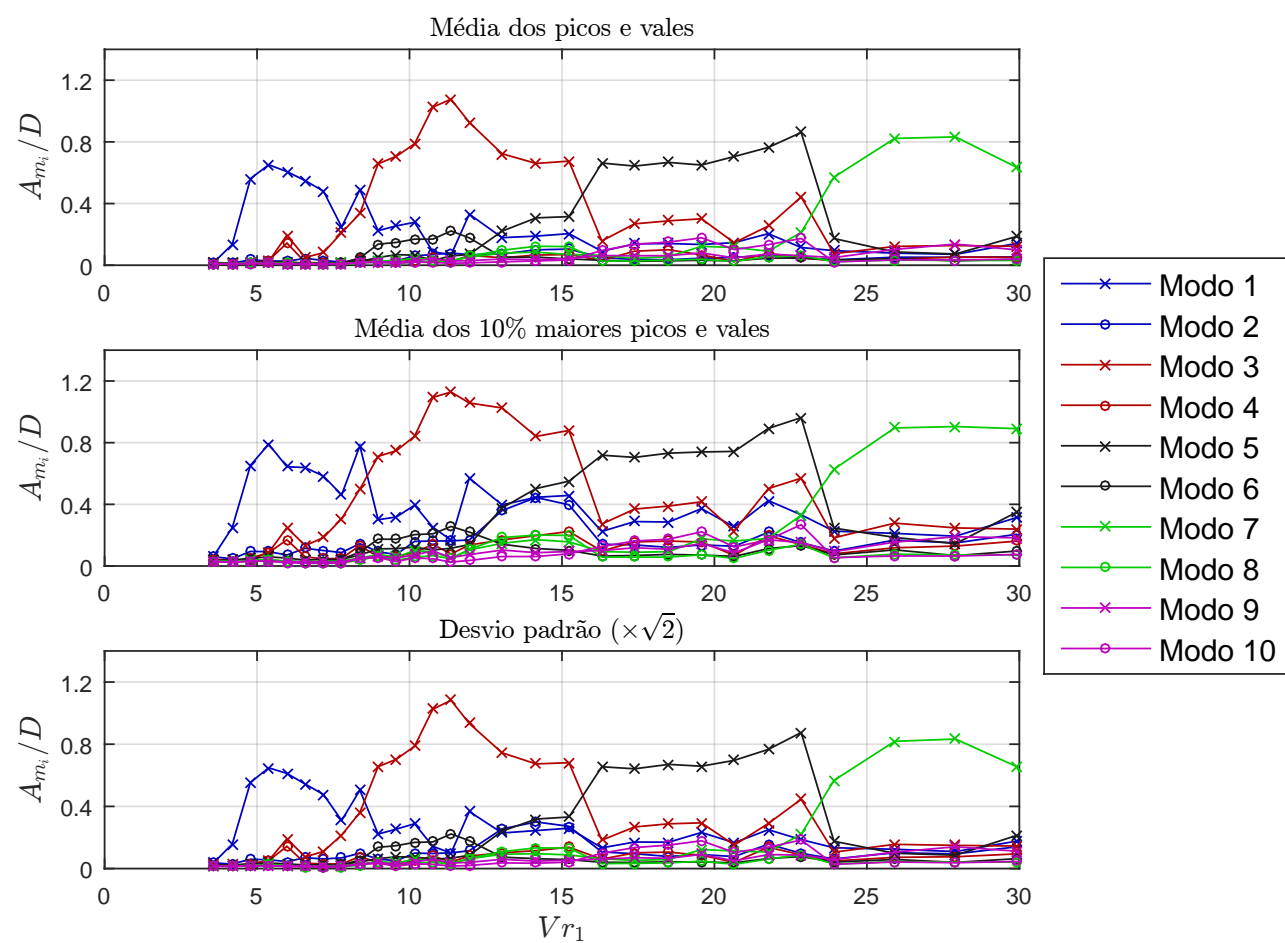

Figura C.3-Amplitudes Modais em função de $\overline{V r}_{1}-\theta=0^{\circ}$ e $\beta=0^{\circ}$. 

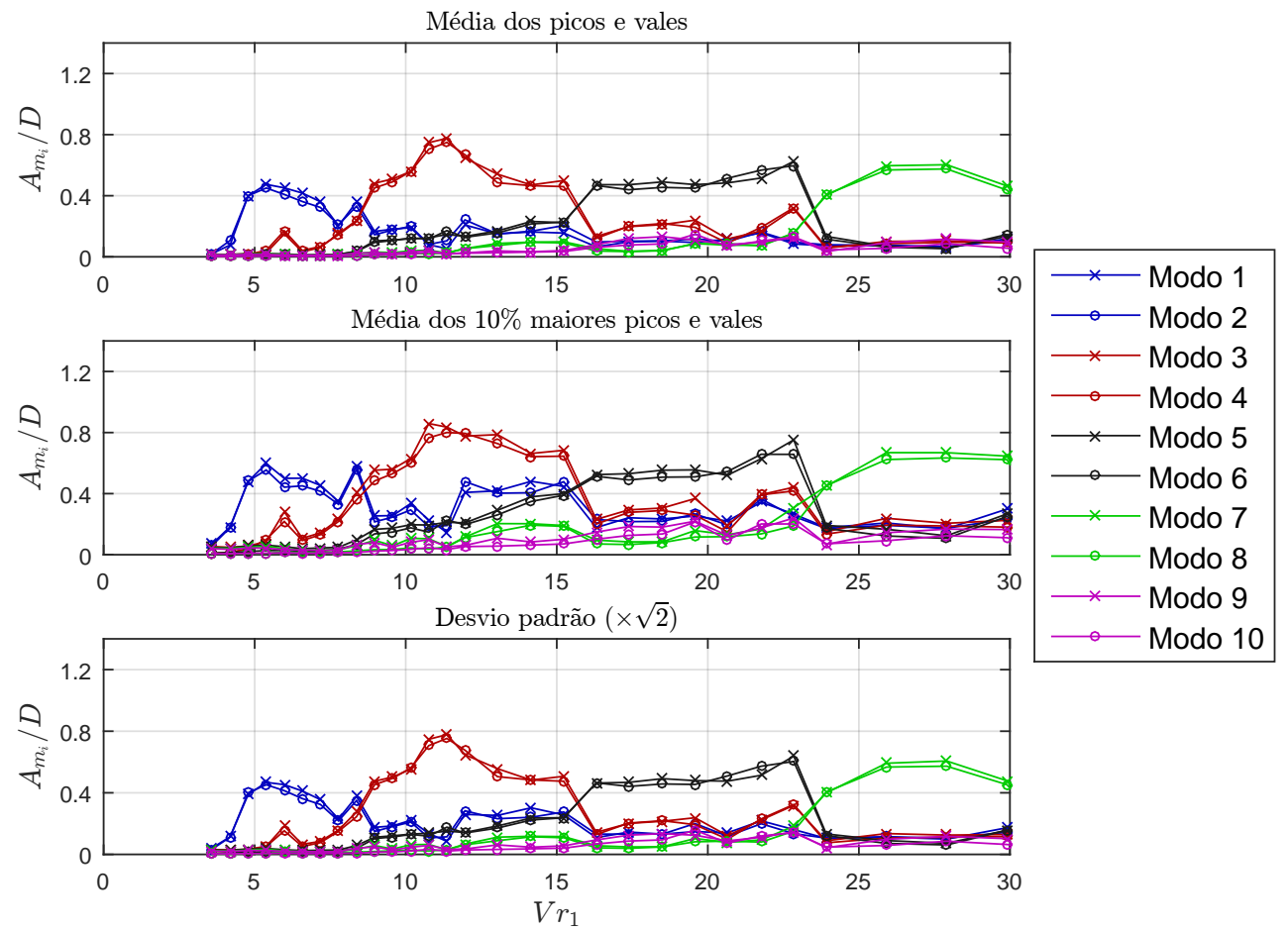

Figura C.4 - Amplitudes Modais em função de $\overline{V r}_{1}-\theta=0^{\circ} \mathrm{e} \beta=45^{\circ}$.
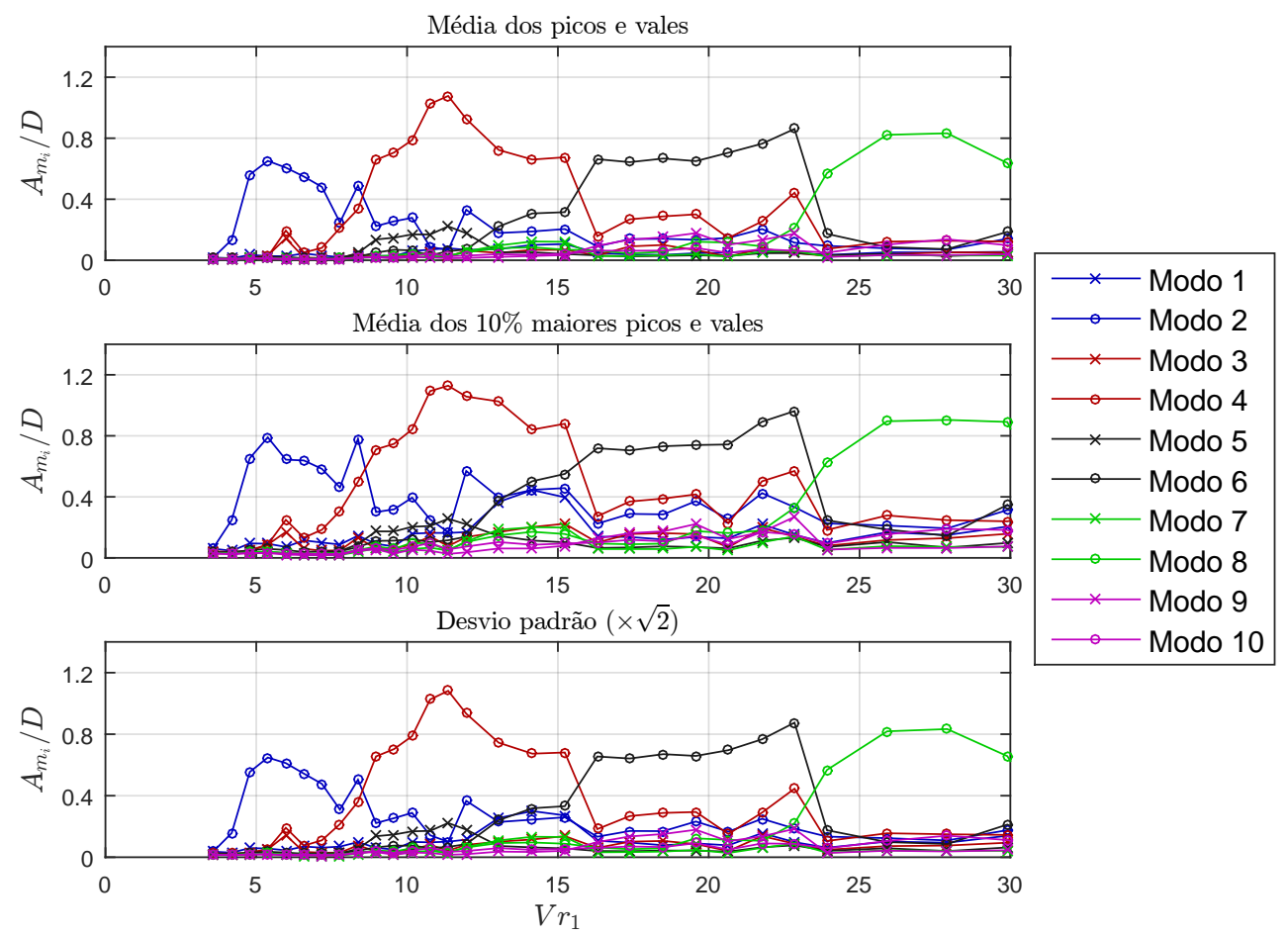

Figura C.5 - Amplitudes Modais em função de $\overline{V r}_{1}-\theta=0^{\circ}$ e $\beta=90^{\circ}$. 


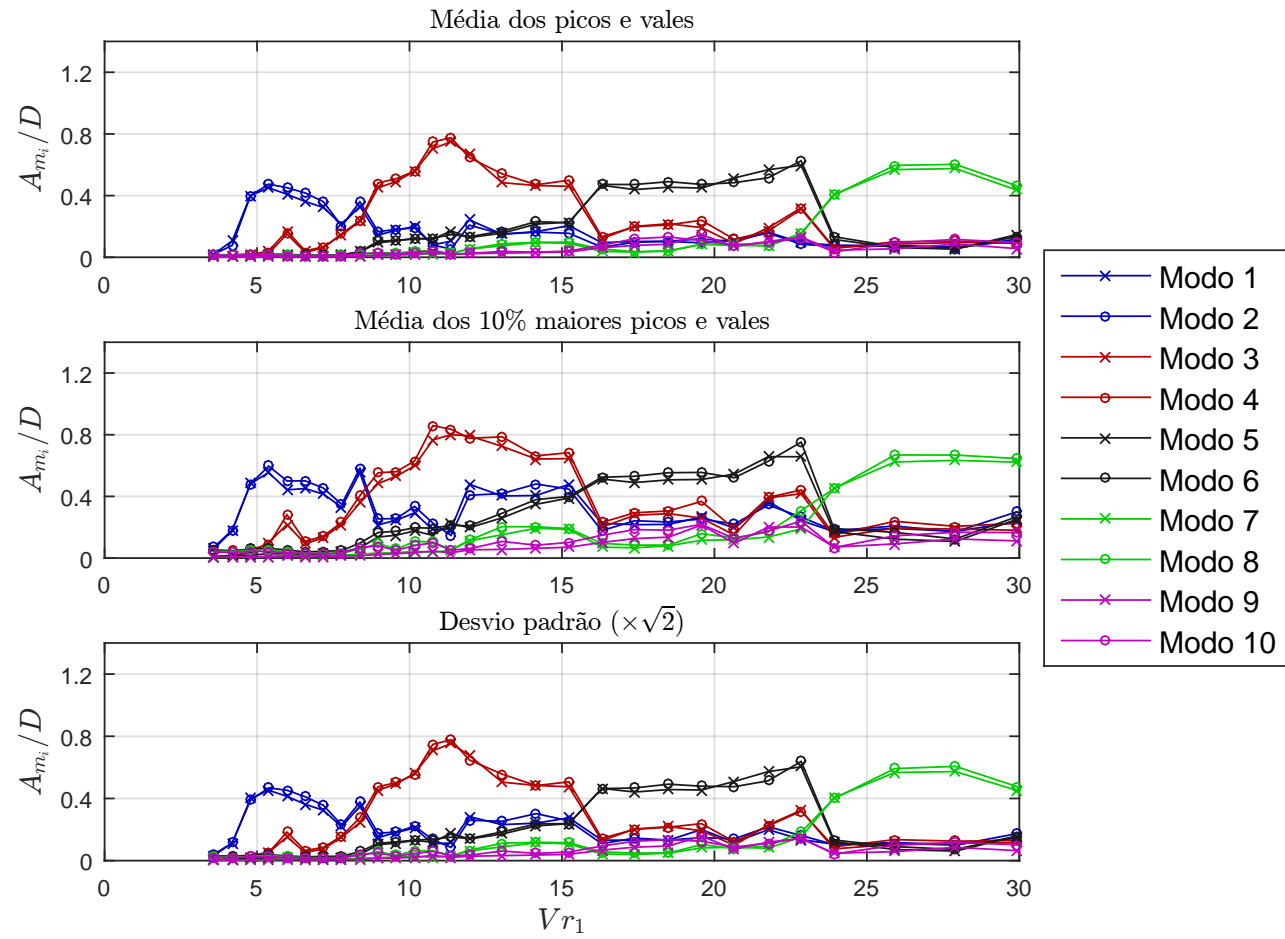

Figura C.6 - Amplitudes Modais em função de $\overline{V r}_{1}-\theta=0^{\circ}$ e $\beta=135^{\circ}$.
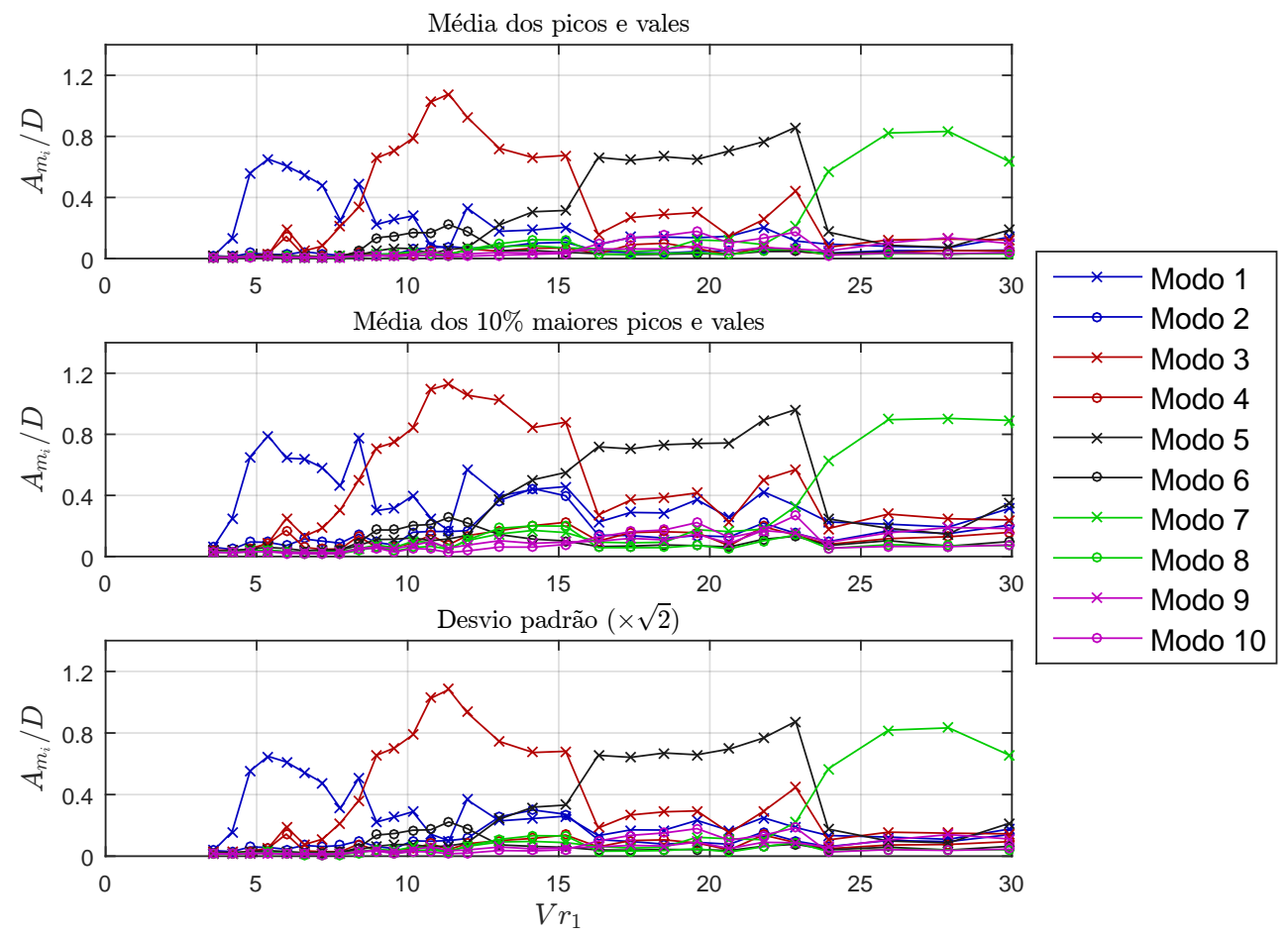

Figura C.7-Amplitudes Modais em função de $\overline{V r}_{1}-\theta=0^{\circ}$ e $\beta=180^{\circ}$. 


\section{C.2.2 Inclinação 10 graus}

As Figuras C.8 até C.12 apresentam as amplitudes modais em função de $\overline{V r}_{1}$ para $\theta=10^{\circ}$ e $\beta=0^{\circ}, 45^{\circ}, 90^{\circ}, 135^{\circ}$ e $180^{\circ}$, respectivamente.

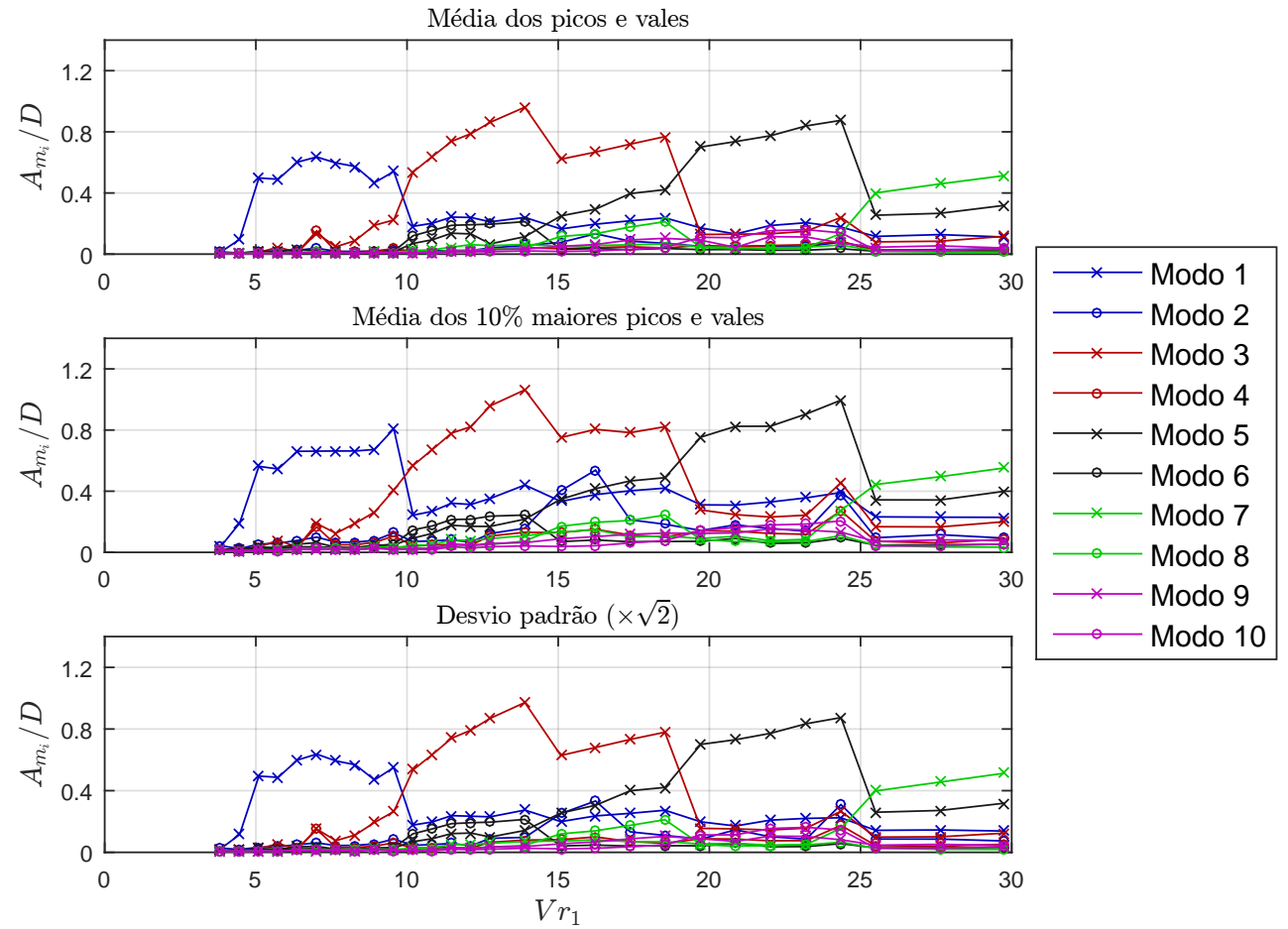

Figura C.8-Amplitudes Modais em função de $\overline{V r}_{1}-\theta=10^{\circ}$ e $\beta=0^{\circ}$. 


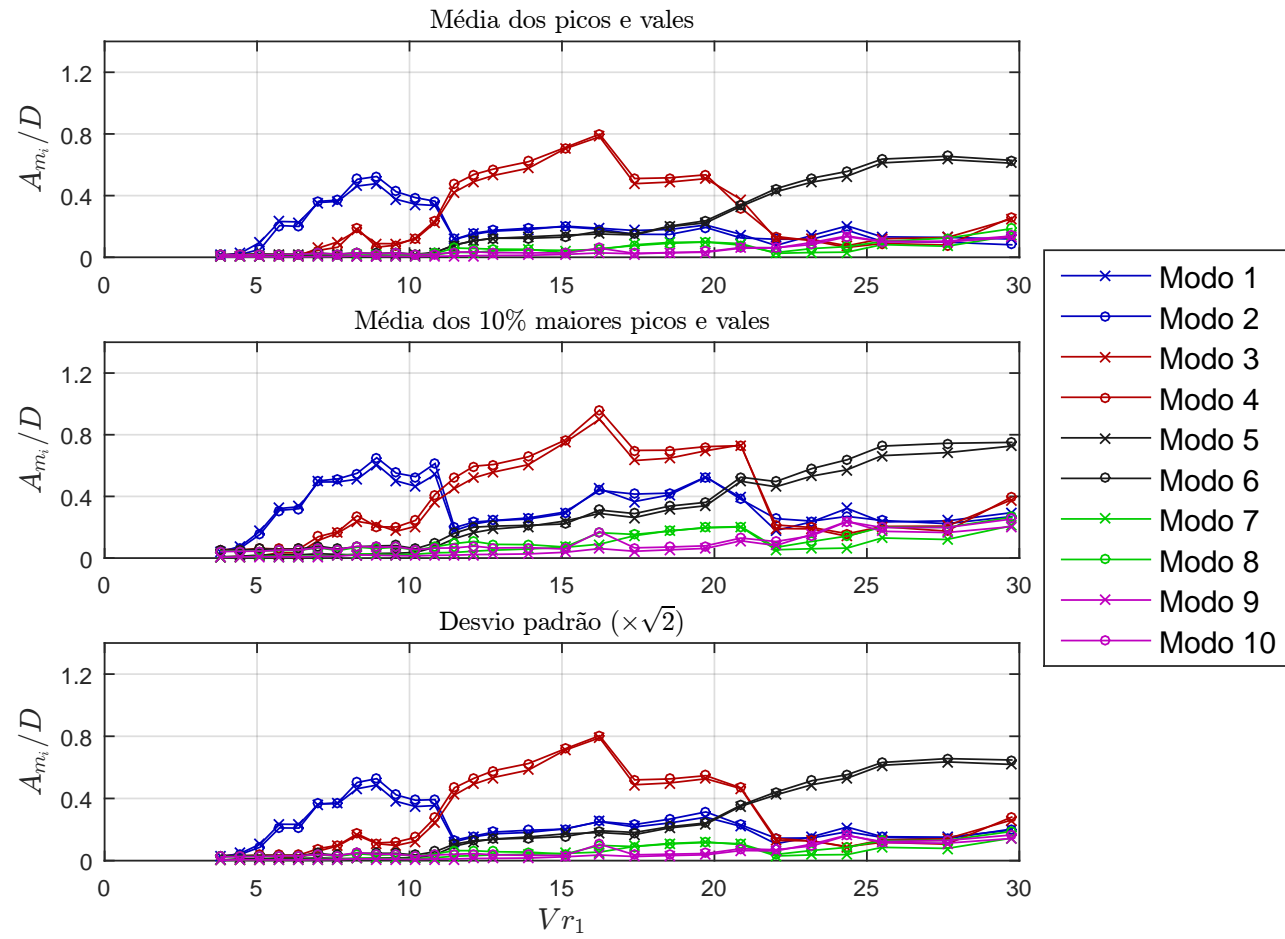

Figura C.9- Amplitudes Modais em função de $\overline{V r}_{1}-\theta=10^{\circ} \mathrm{e} \beta=45^{\circ}$.
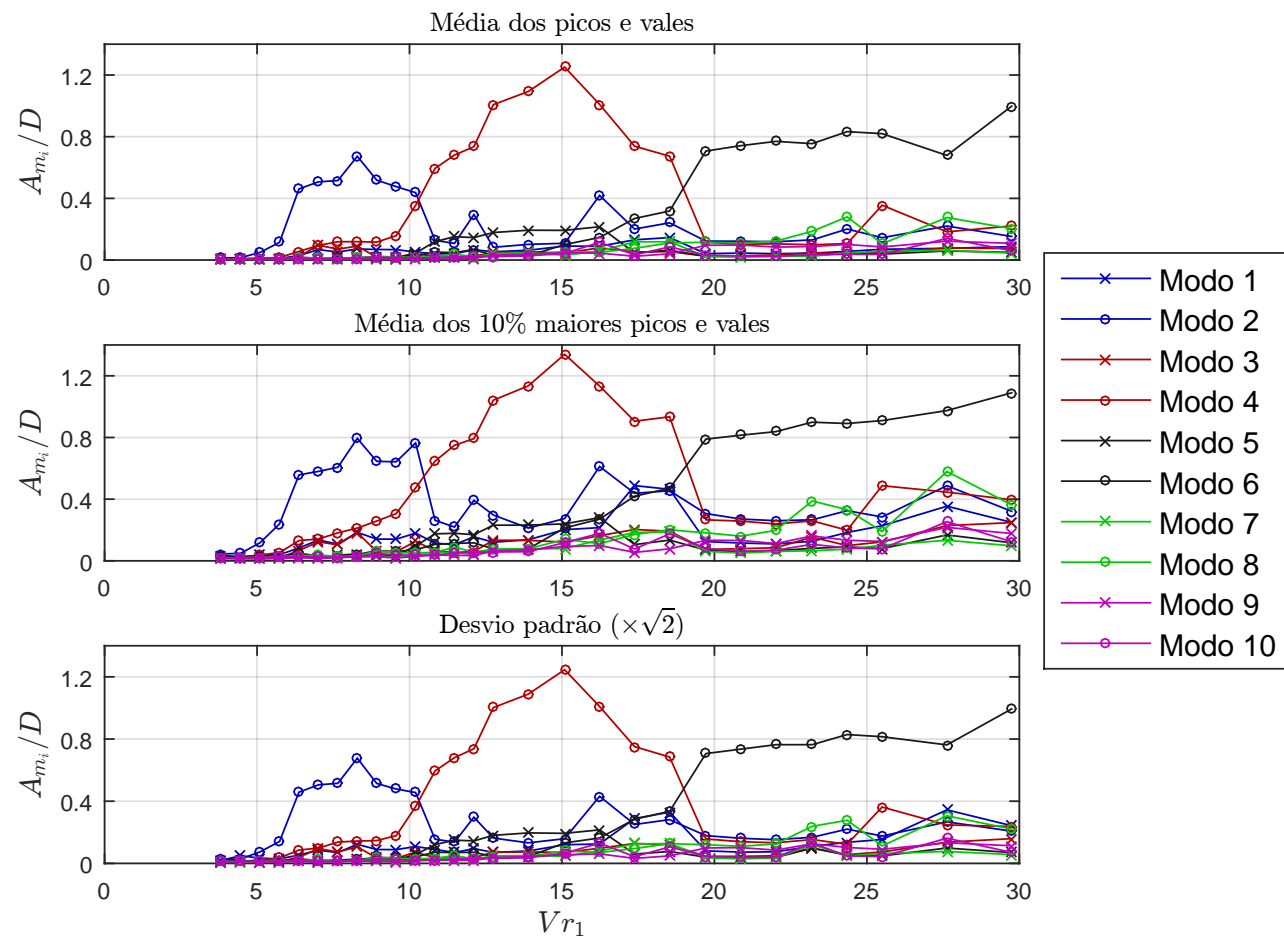

Figura C.10 - Amplitudes Modais em função de $\overline{V r}_{1}-\theta=10^{\circ}$ e $\beta=90^{\circ}$. 

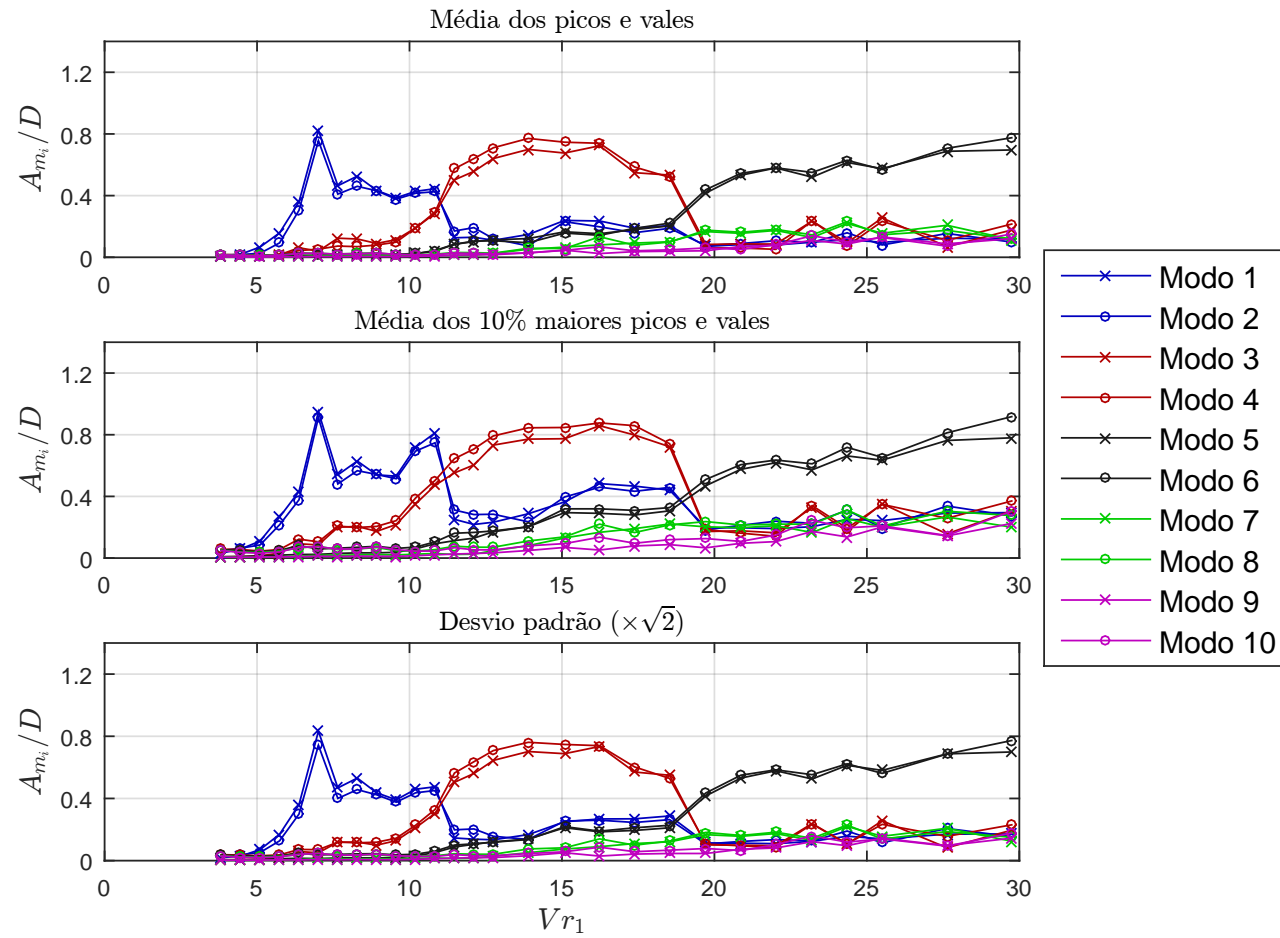

Figura C.11 - Amplitudes Modais em função de $\overline{V r}_{1}-\theta=10^{\circ} \mathrm{e} \beta=135^{\circ}$.
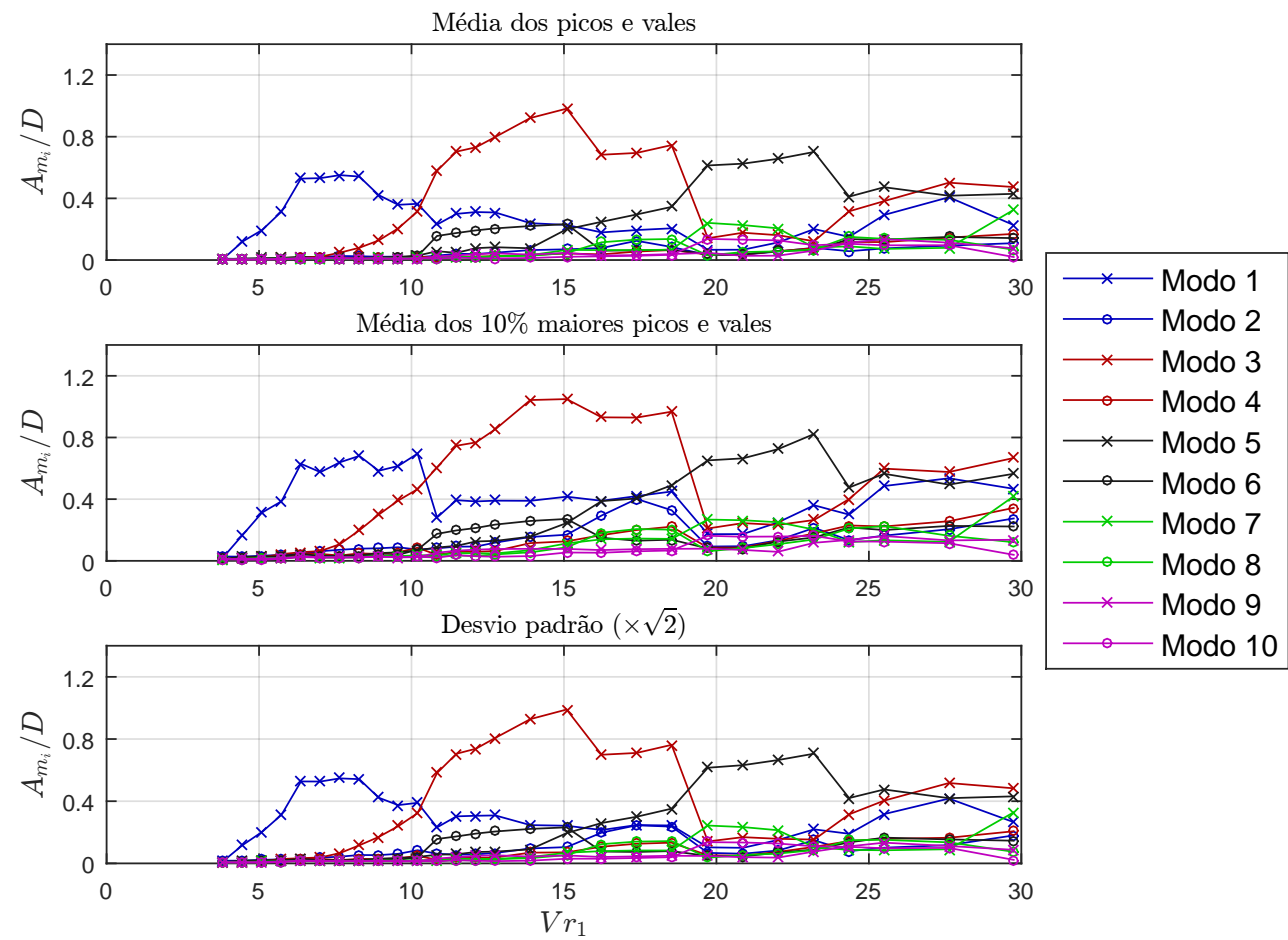

Figura C.12 - Amplitudes Modais em função de $\overline{V r}_{1}-\theta=10^{\circ}$ e $\beta=180^{\circ}$. 


\section{C.2.3 Inclinação 20 graus}

As Figuras C.13 até C.17 apresentam as amplitudes modais em função de $\overline{V r}_{1}$ para $\theta=20^{\circ}$ e $\beta=0^{\circ}, 45^{\circ}, 90^{\circ}, 135^{\circ}$ e $180^{\circ}$, respectivamente.
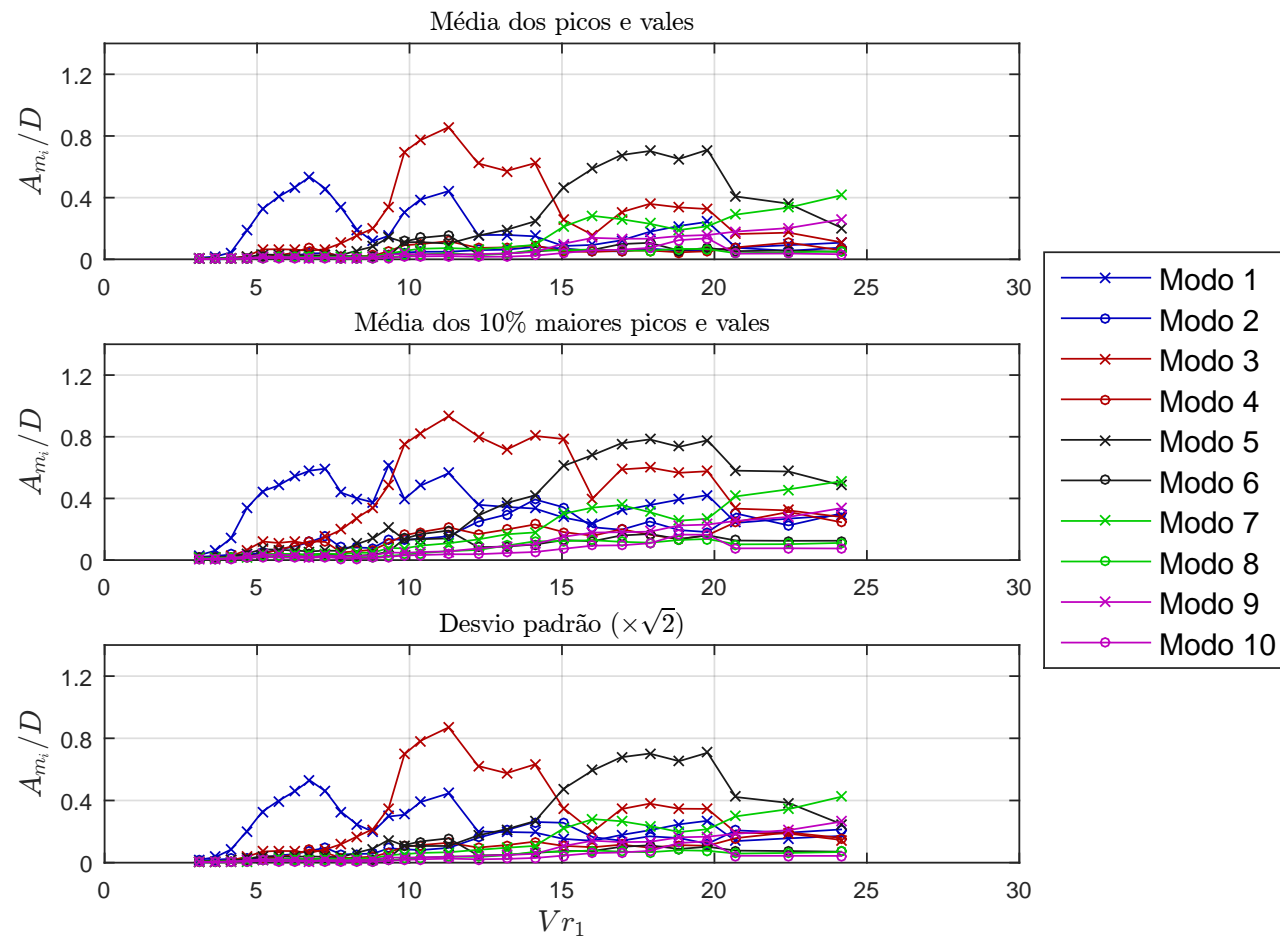

Figura C.13-Amplitudes Modais em função de $\overline{V r}_{1}-\theta=20^{\circ}$ e $\beta=0^{\circ}$. 


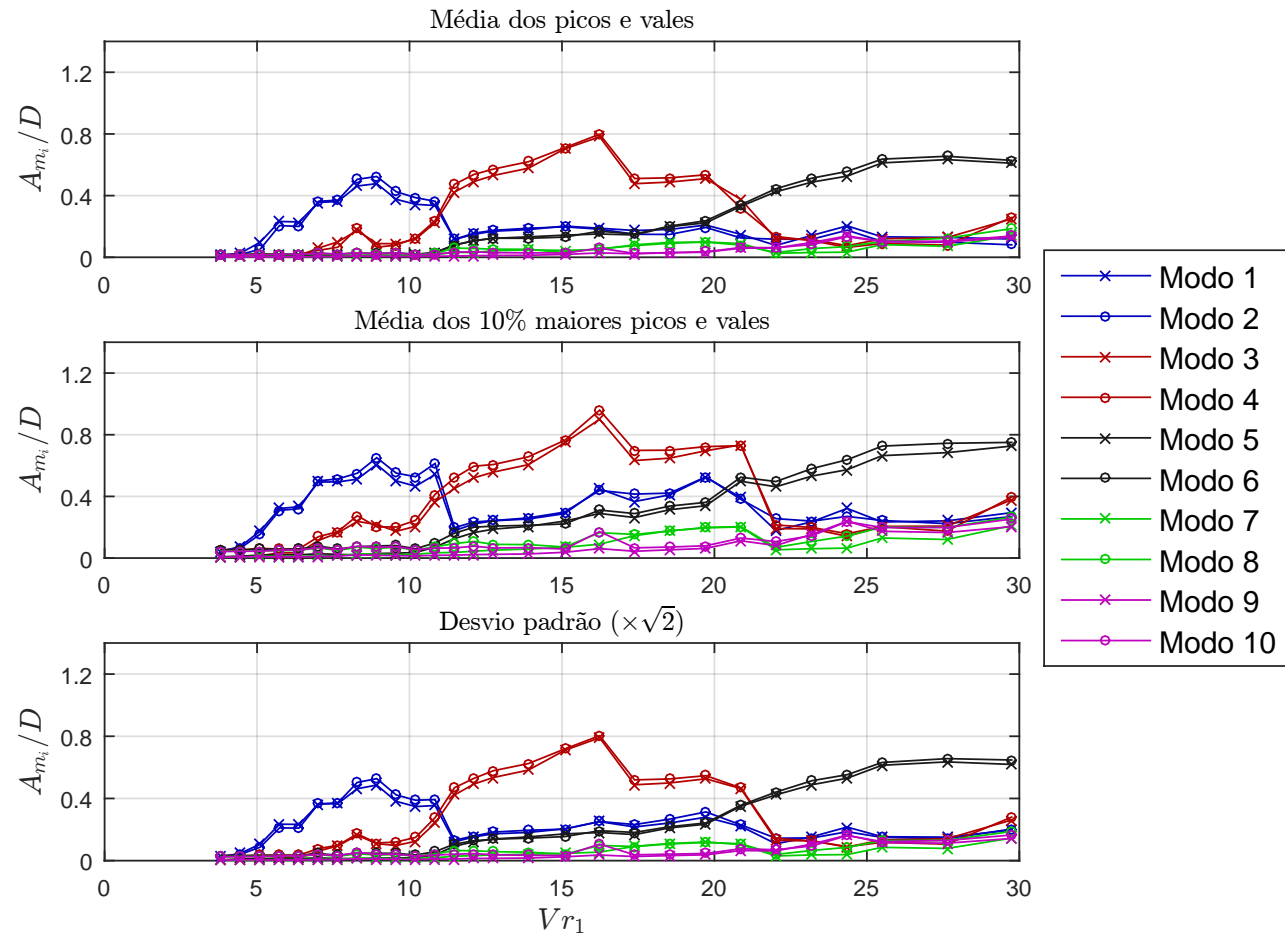

Figura C.14 - Amplitudes Modais em função de $\overline{V r}_{1}-\theta=20^{\circ}$ e $\beta=45^{\circ}$.
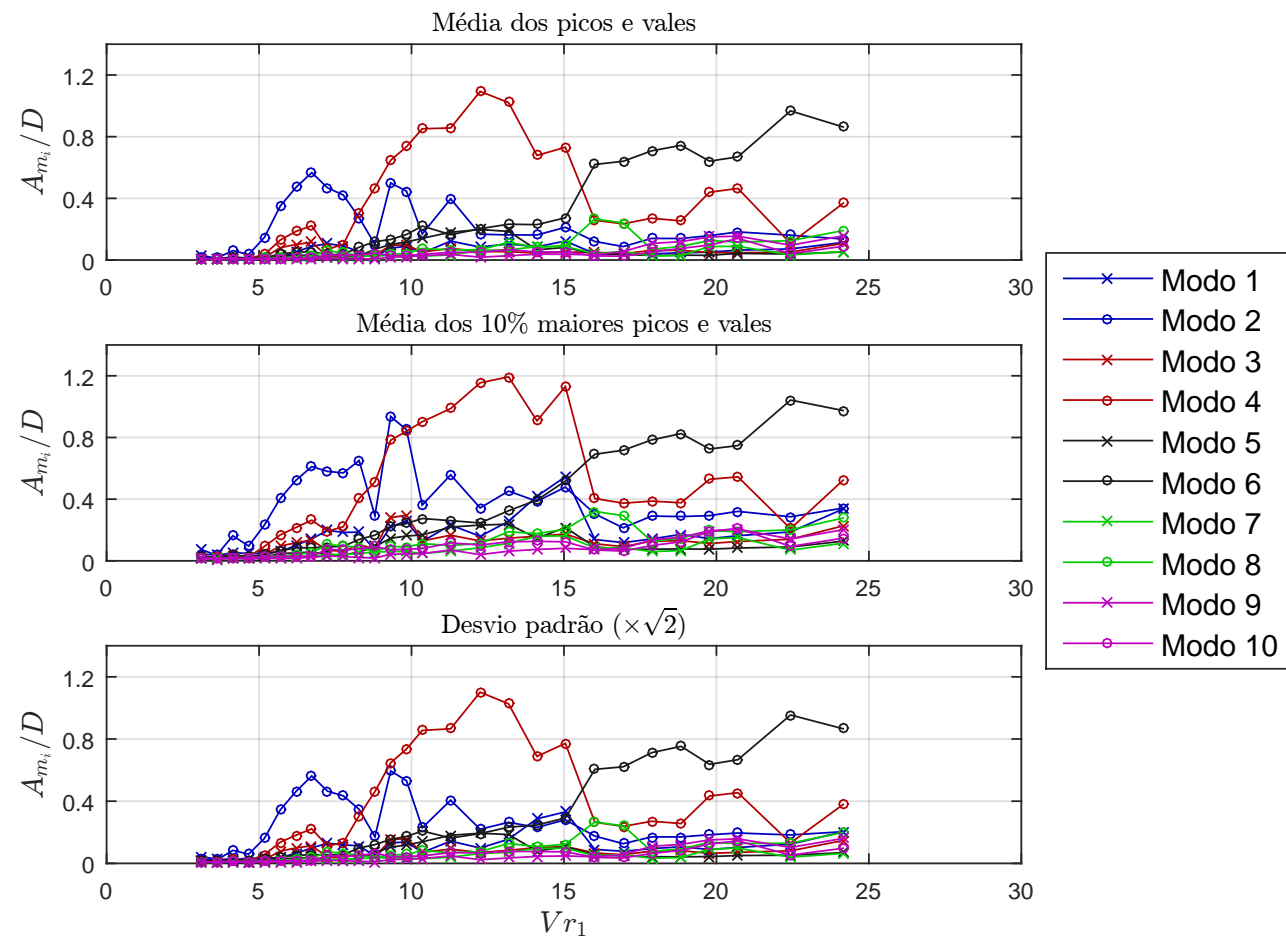

Figura C.15-Amplitudes Modais em função de $\overline{V r}_{1}-\theta=20^{\circ}$ e $\beta=90^{\circ}$. 


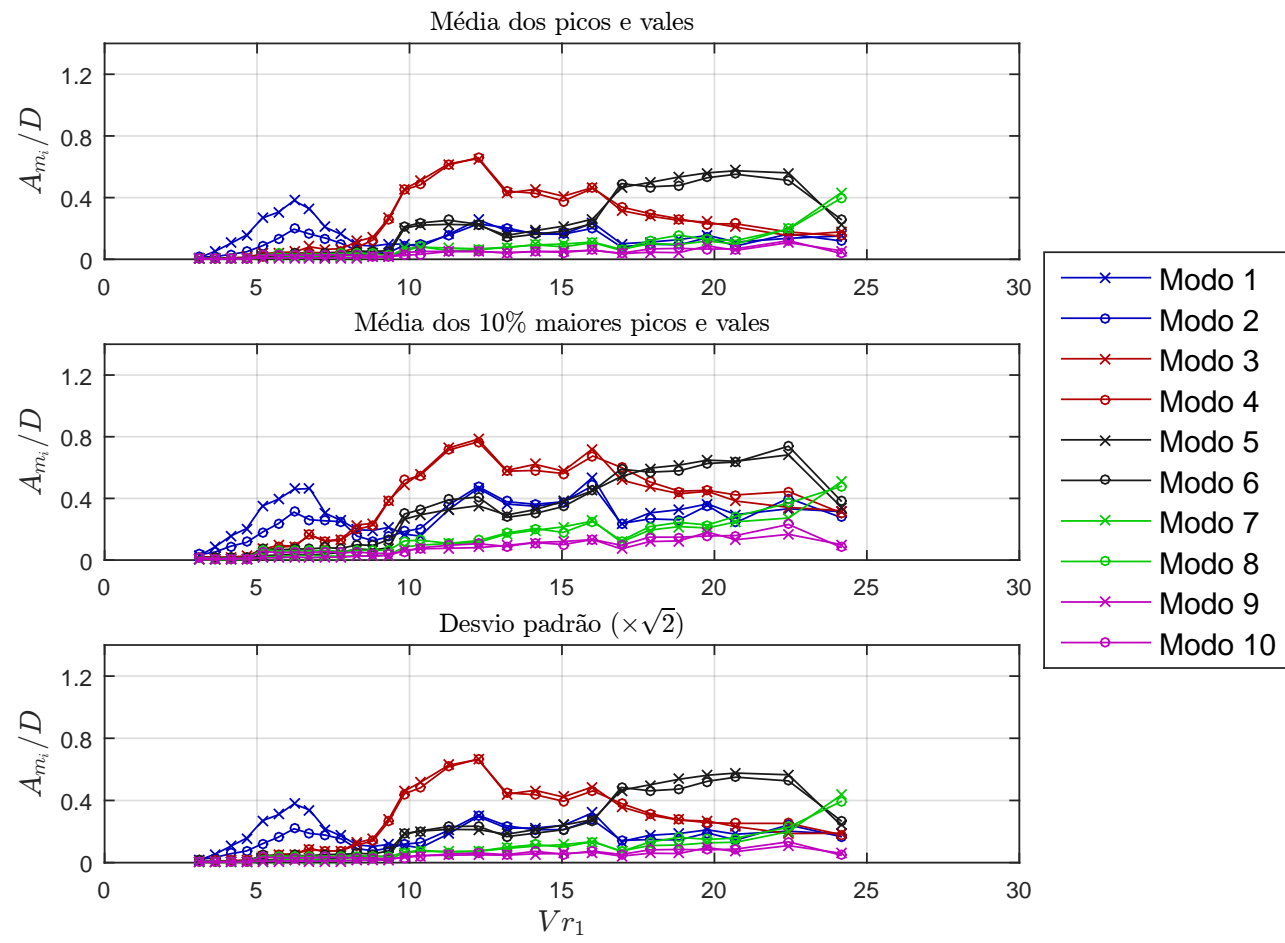

Figura C.16 - Amplitudes Modais em função de $\overline{V r}_{1}-\theta=20^{\circ}$ e $\beta=135^{\circ}$.
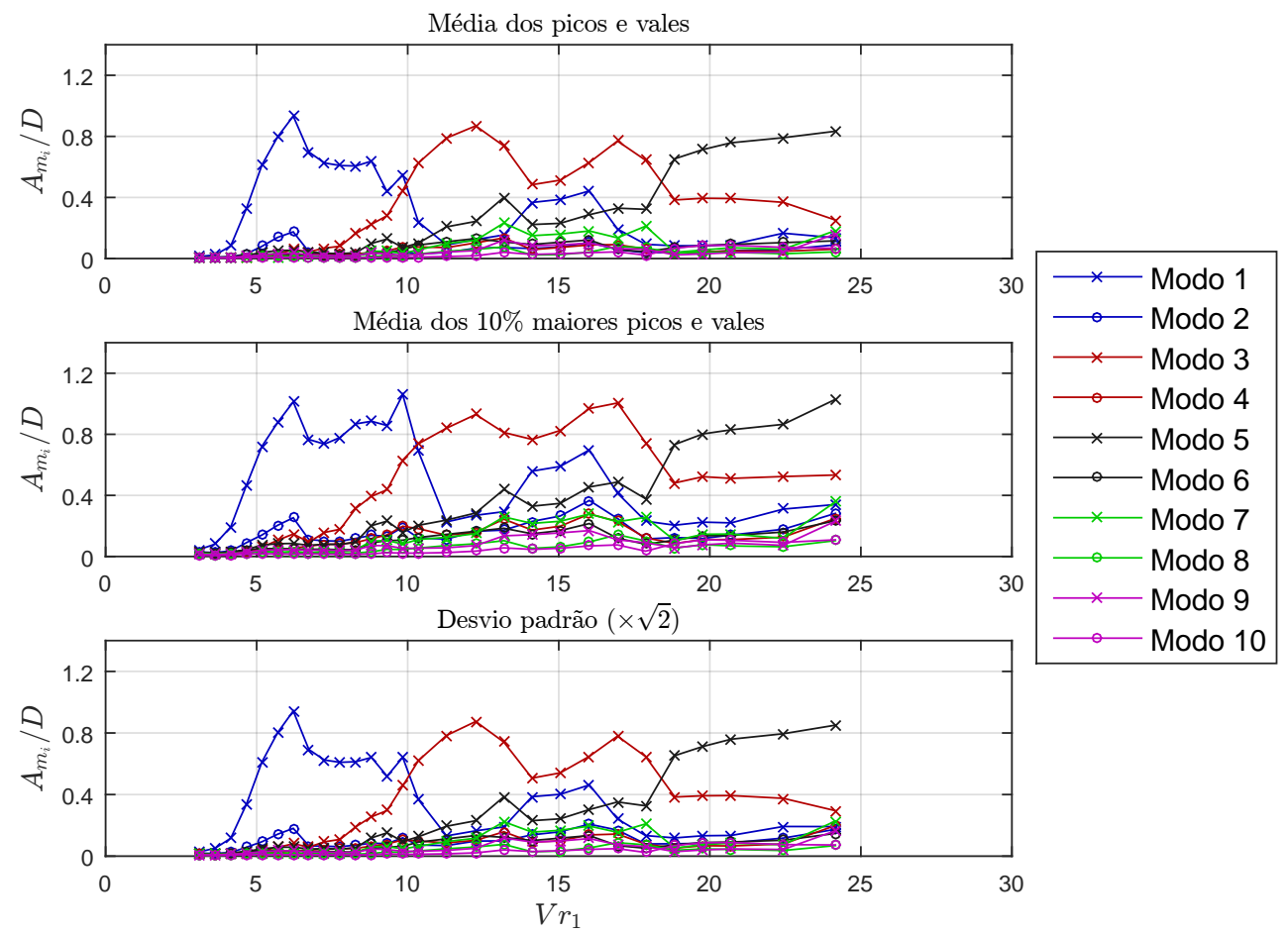

Figura C.17- Amplitudes Modais em função de $\overline{V r}_{1}-\theta=20^{\circ}$ e $\beta=180^{\circ}$. 


\section{C.2.4 Inclinação 30 graus}

As Figuras C.18 até C.22 apresentam as amplitudes modais em função de $\overline{V r}_{1}$ para $\theta=30^{\circ}$ e $\beta=0^{\circ}, 45^{\circ}, 90^{\circ}, 135^{\circ}$ e $180^{\circ}$, respectivamente.
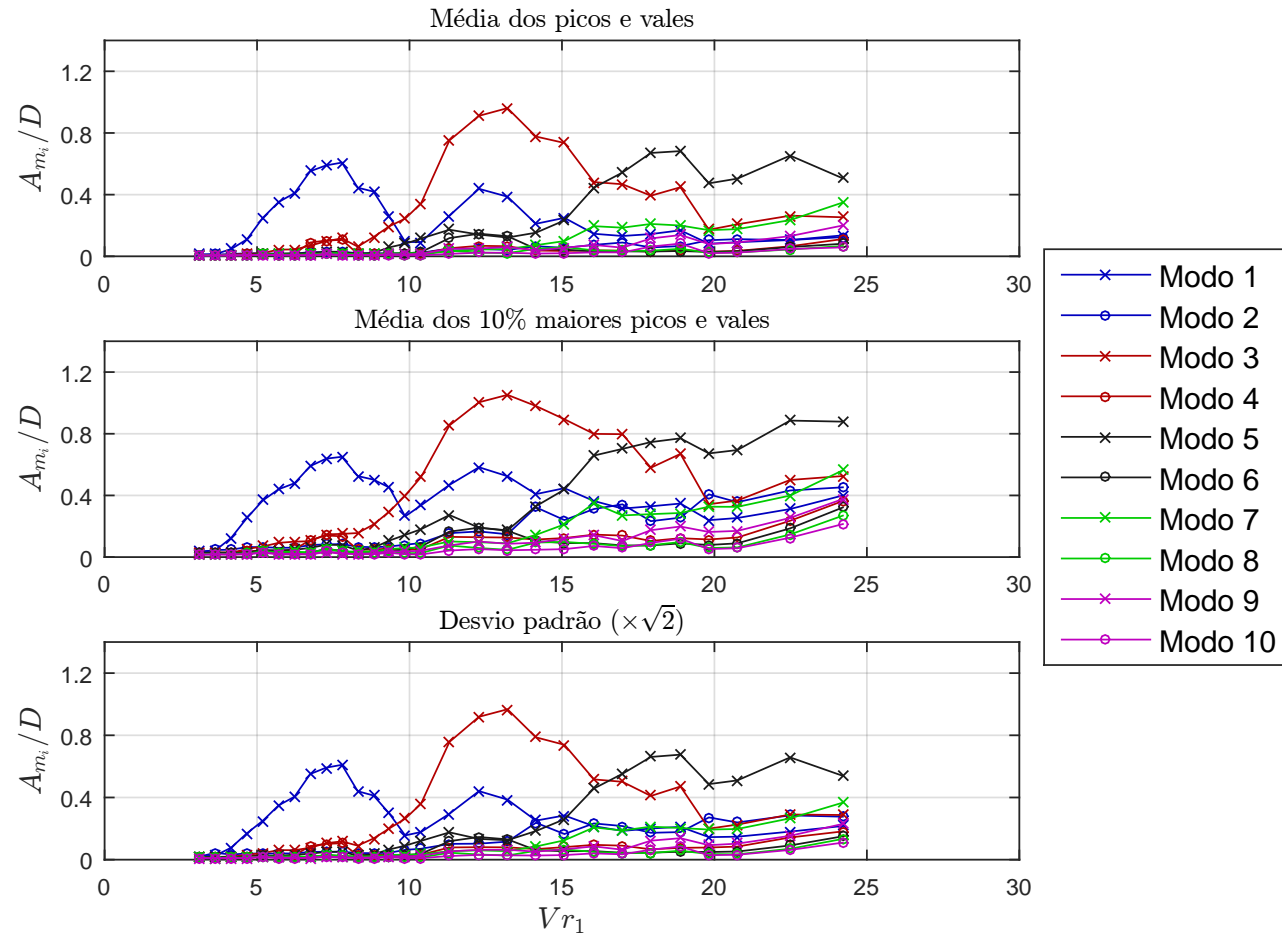

Figura C.18-Amplitudes Modais em função de $\overline{V r}_{1}-\theta=30^{\circ}$ e $\beta=0^{\circ}$. 


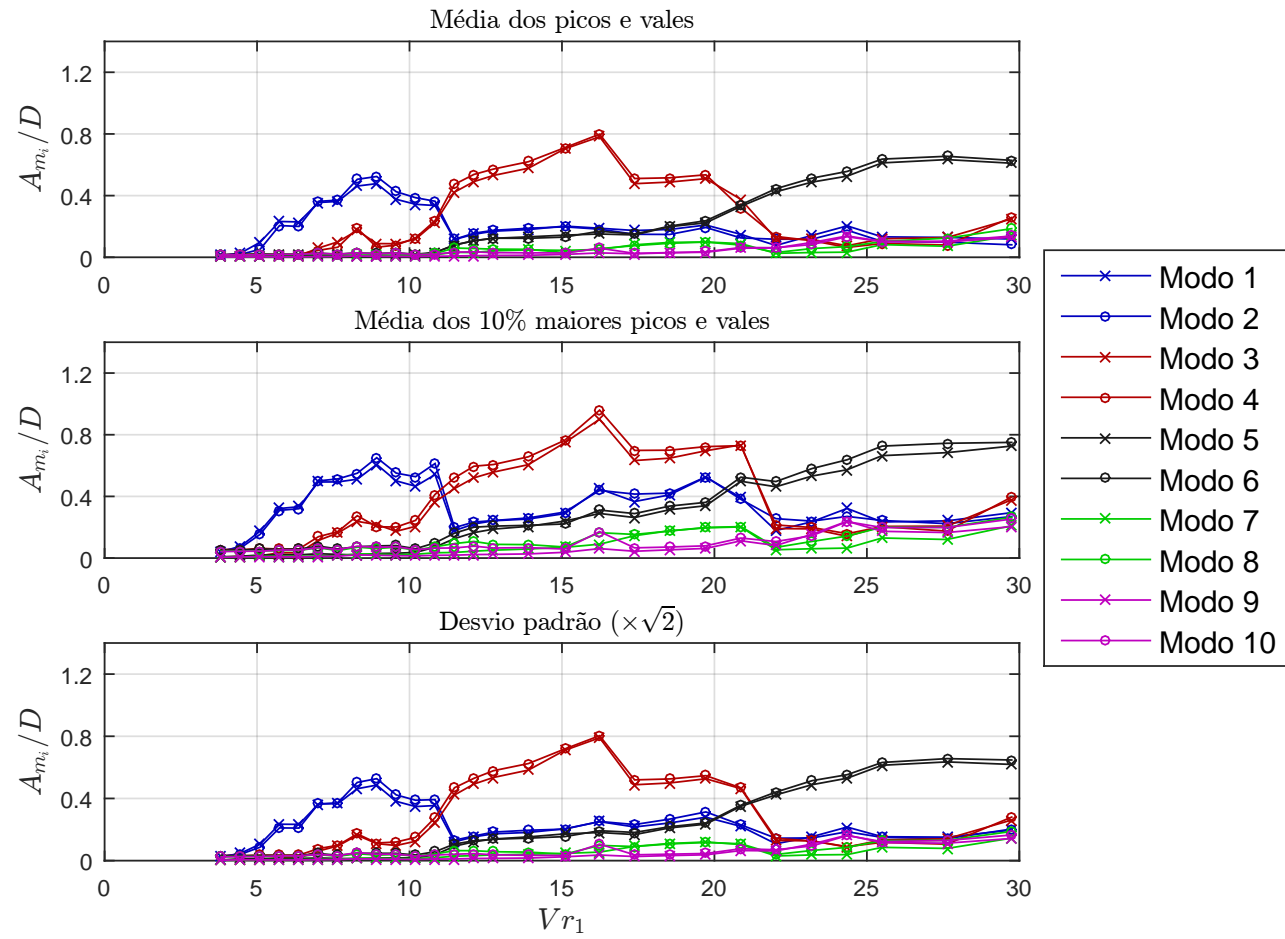

Figura C.19- Amplitudes Modais em função de $\overline{V r}_{1}-\theta=30^{\circ}$ e $\beta=45^{\circ}$.
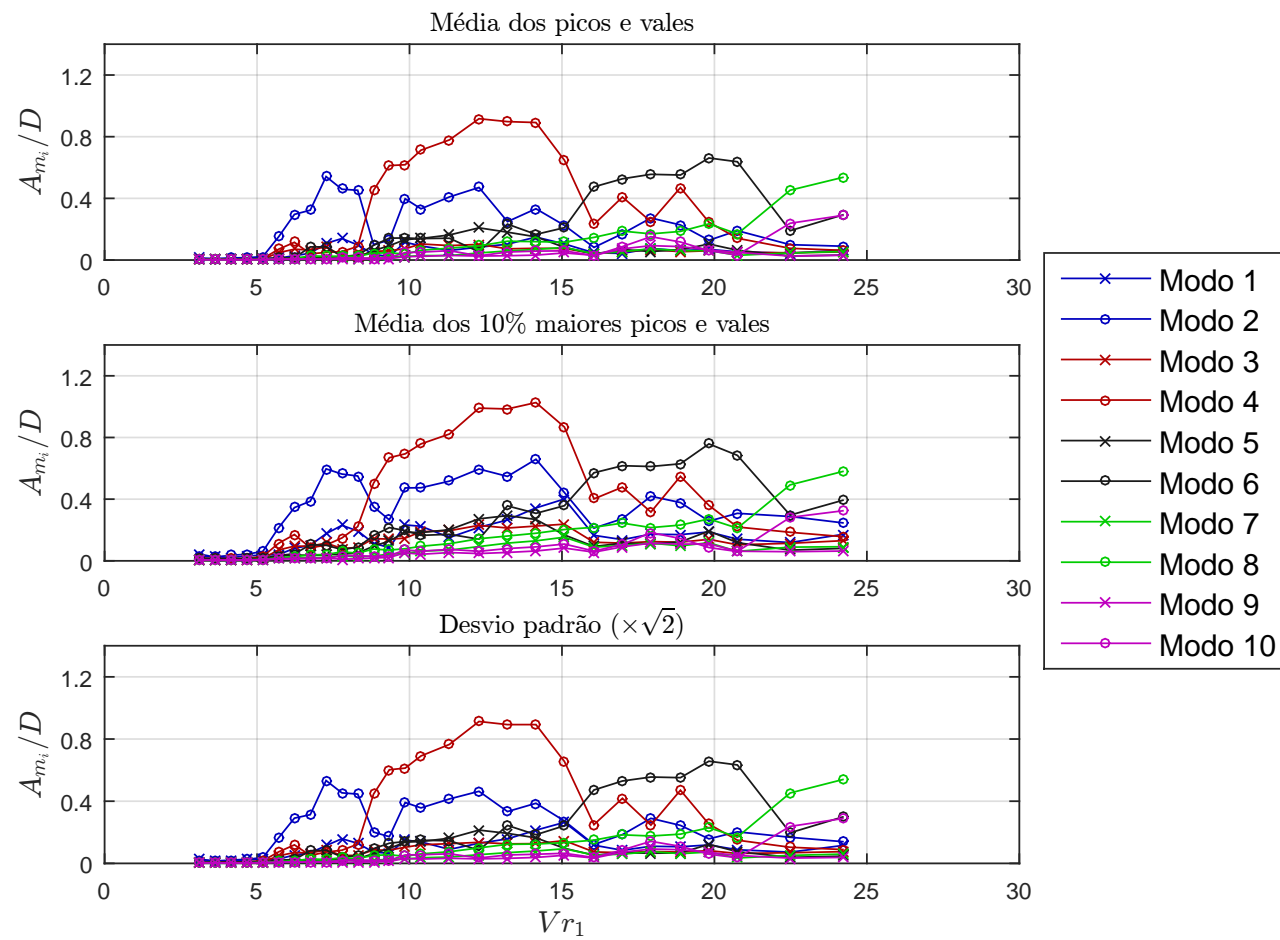

- Modo 10

Figura C.20 - Amplitudes Modais em função de $\overline{V r}_{1}-\theta=30^{\circ}$ e $\beta=90^{\circ}$. 


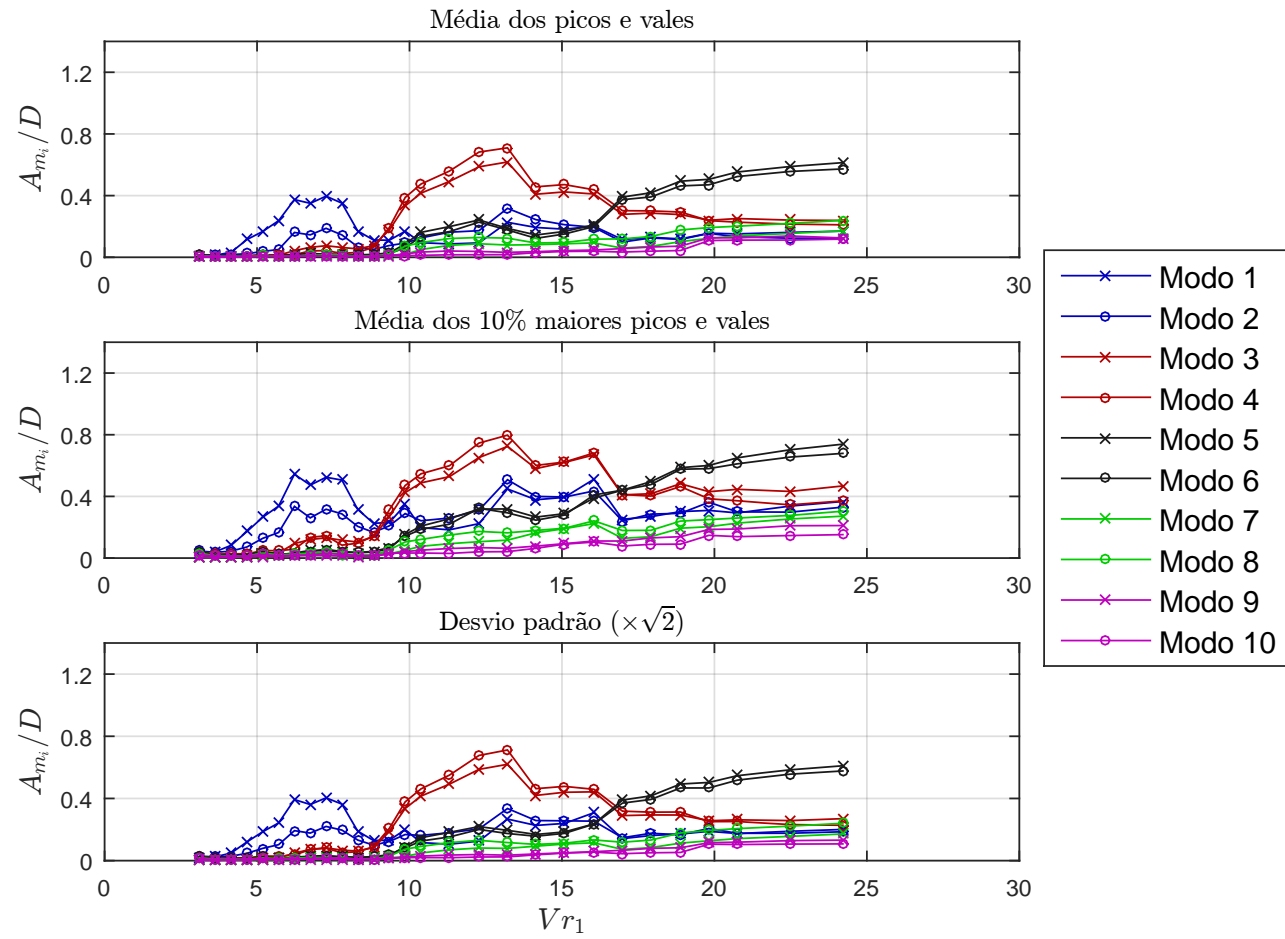

Figura C.21 - Amplitudes Modais em função de $\overline{V r}_{1}-\theta=30^{\circ}$ e $\beta=135^{\circ}$.
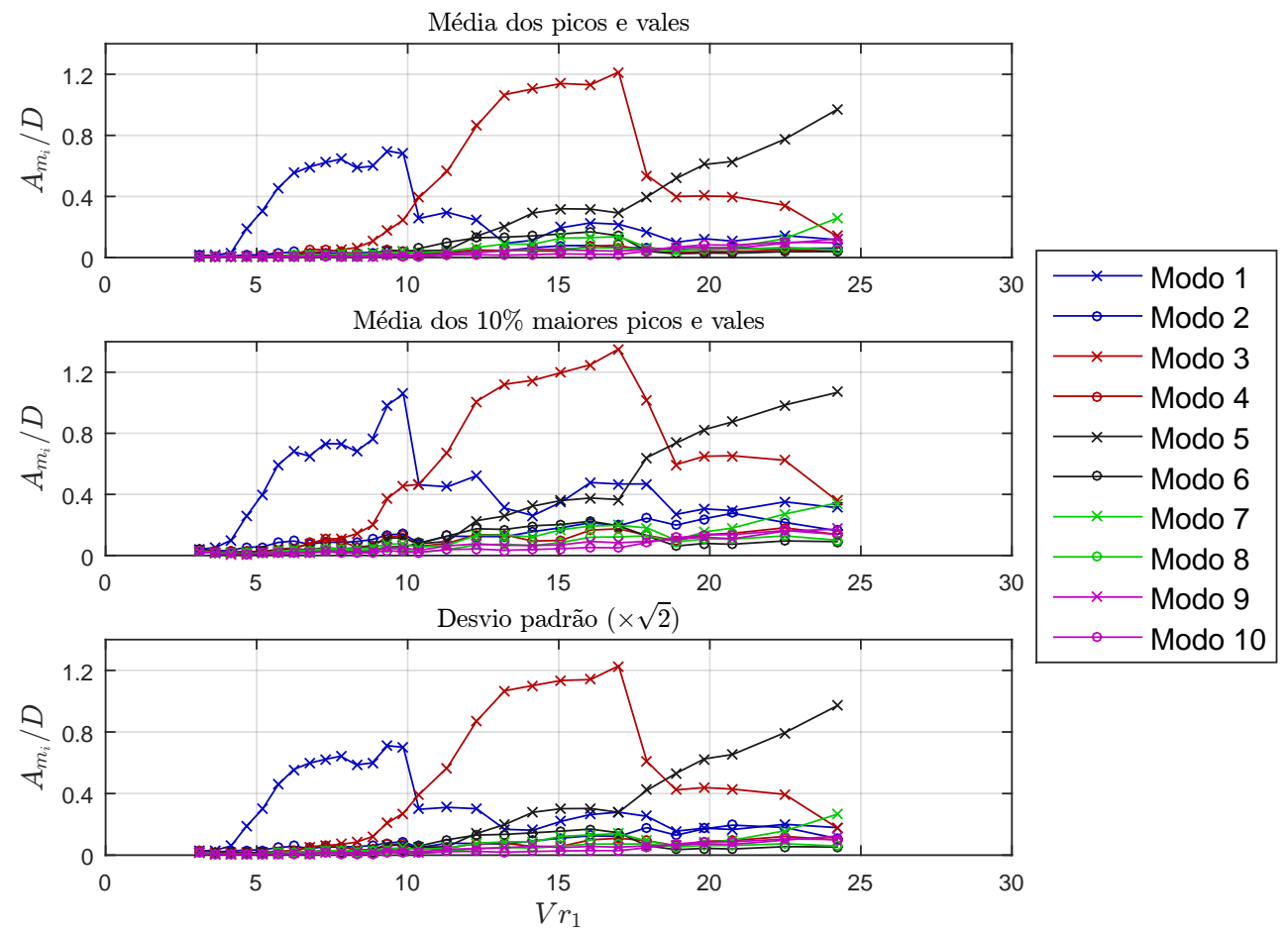

Figura C.22 - Amplitudes Modais em função de $\overline{V r}_{1}-\theta=30^{\circ}$ e $\beta=180^{\circ}$. 


\section{C.2.5 Inclinação 45 graus}

As Figuras C.23 até C.27 apresentam as amplitudes modais em função de $\overline{V r}_{1}$ para $\theta=10^{\circ}$ e $\beta=0^{\circ}, 45^{\circ}, 90^{\circ}, 135^{\circ}$ e $180^{\circ}$, respectivamente.
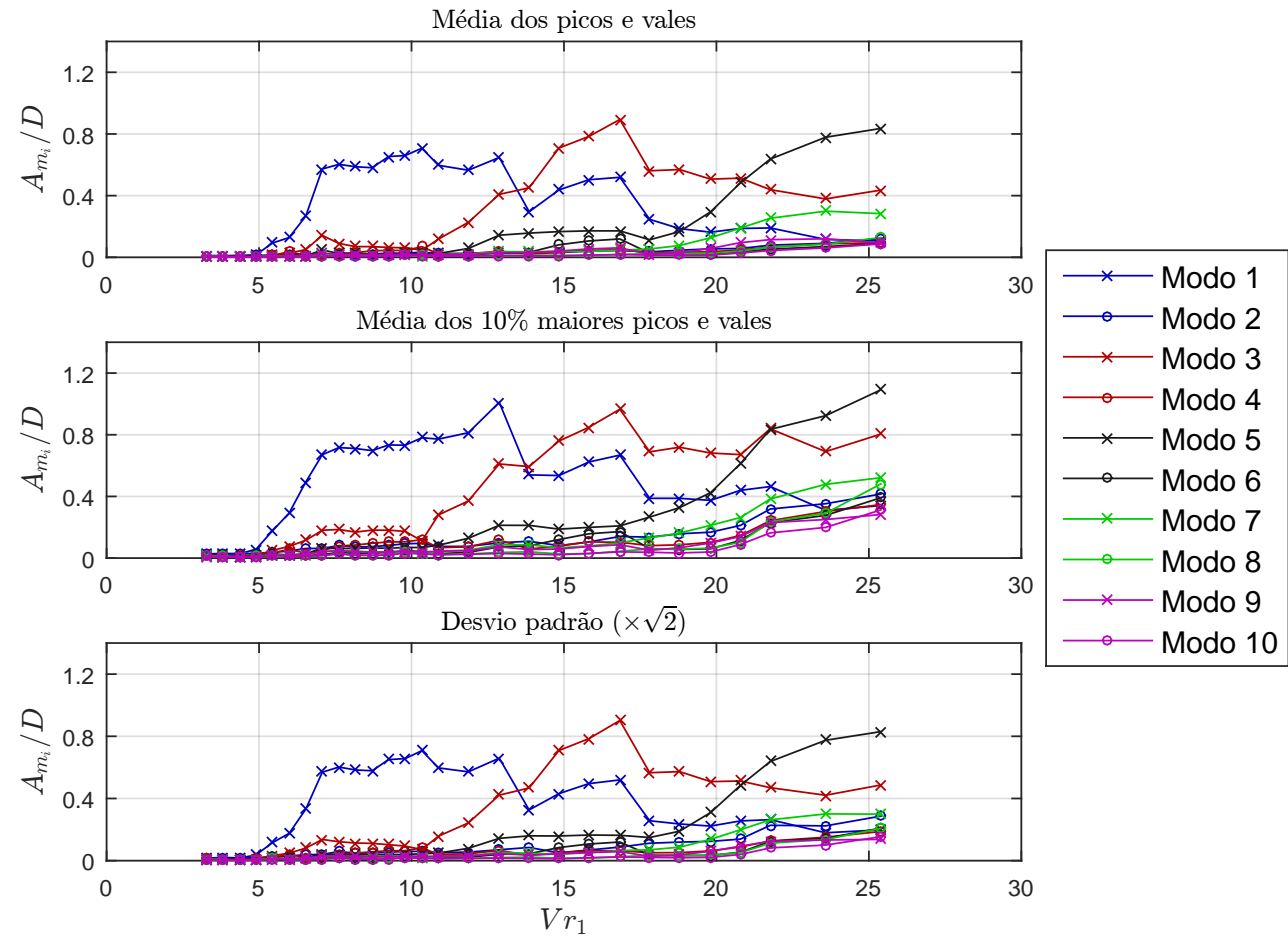

Figura C.23 - Amplitudes Modais em função de $\overline{V r}_{1}-\theta=45^{\circ}$ e $\beta=0^{\circ}$. 


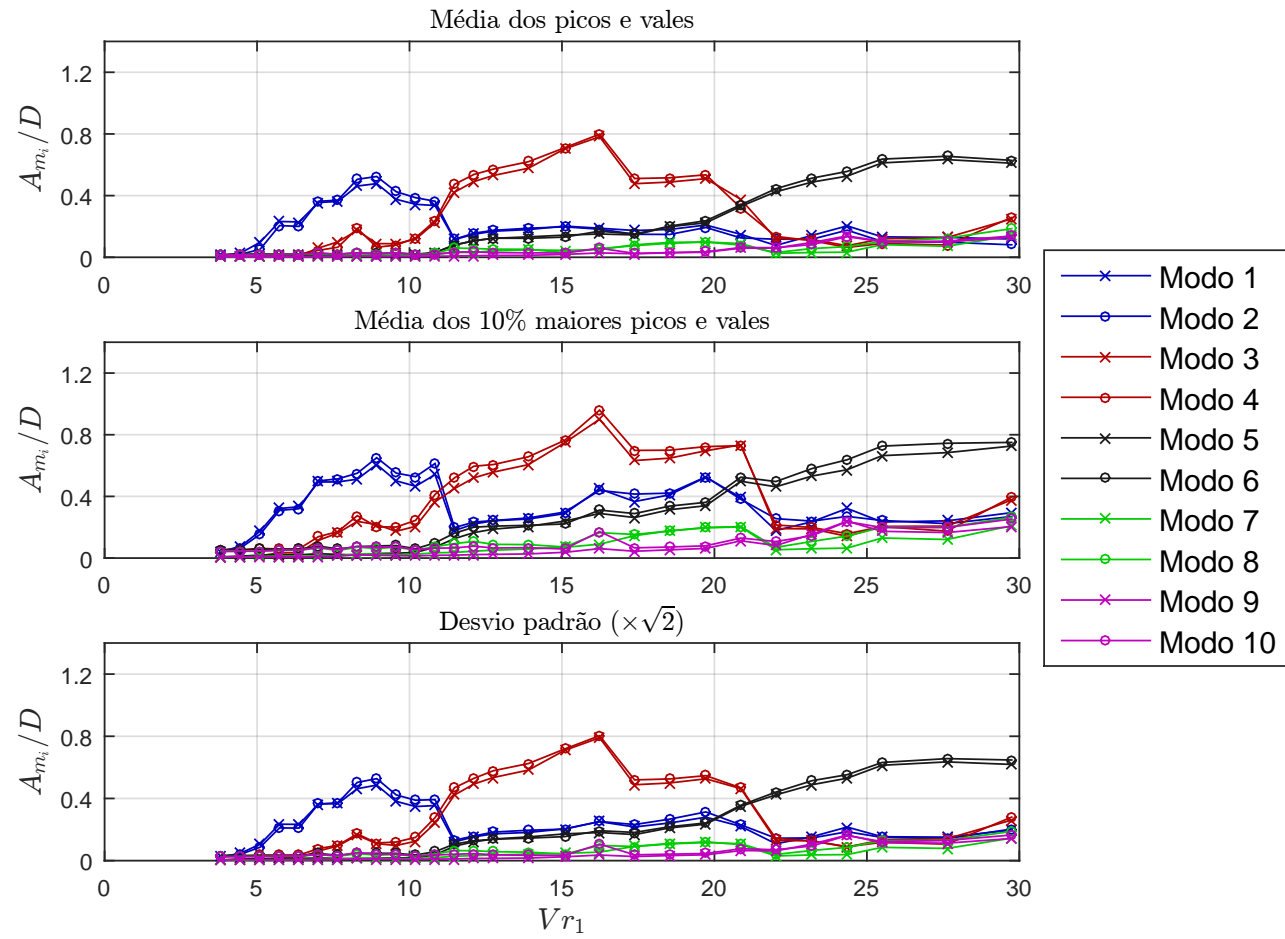

Figura C.24 - Amplitudes Modais em função de $\overline{V r}_{1}-\theta=45^{\circ}$ e $\beta=45^{\circ}$.
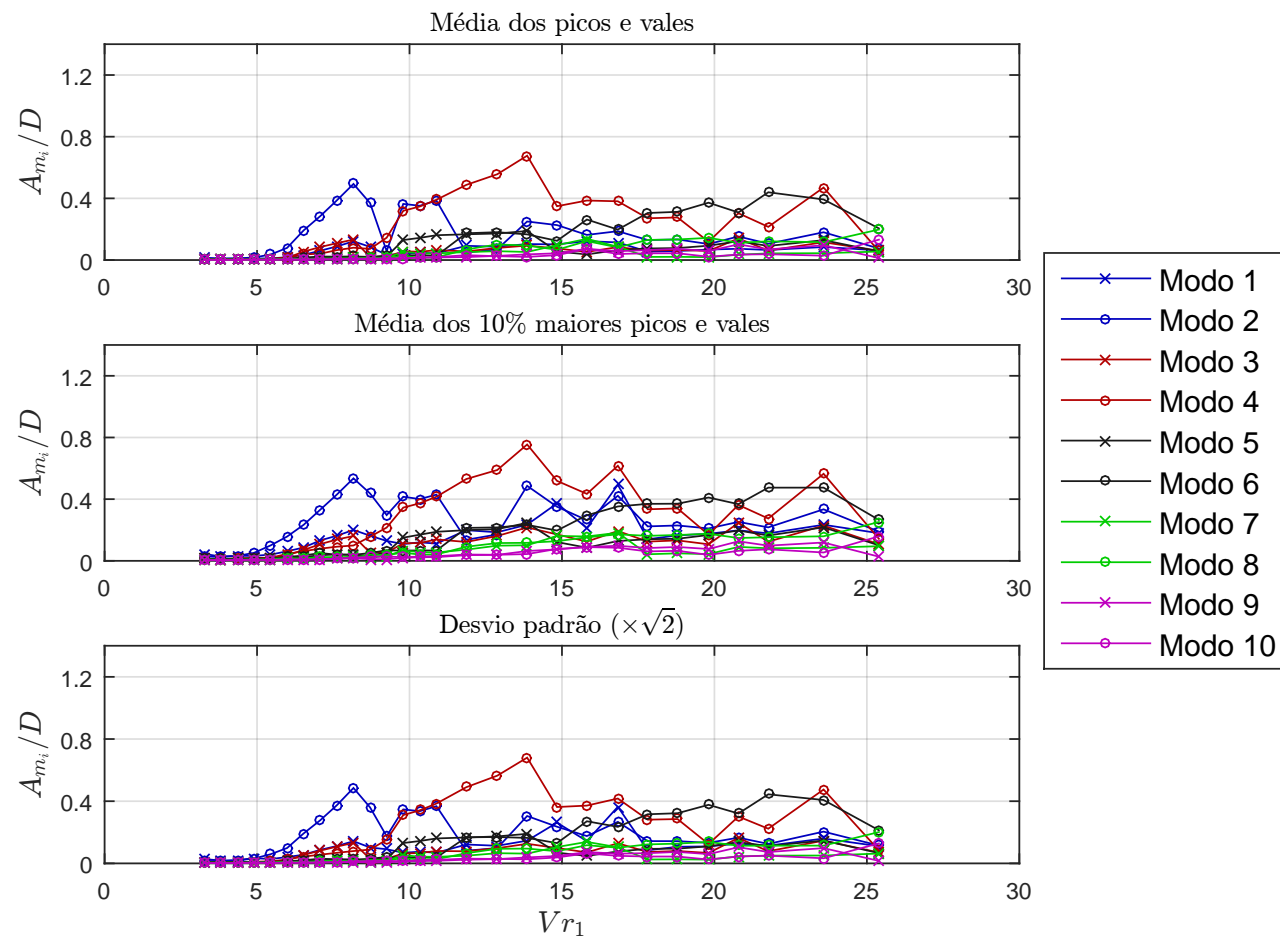

Figura C.25 - Amplitudes Modais em função de $\overline{V r}_{1}-\theta=45^{\circ}$ e $\beta=90^{\circ}$. 


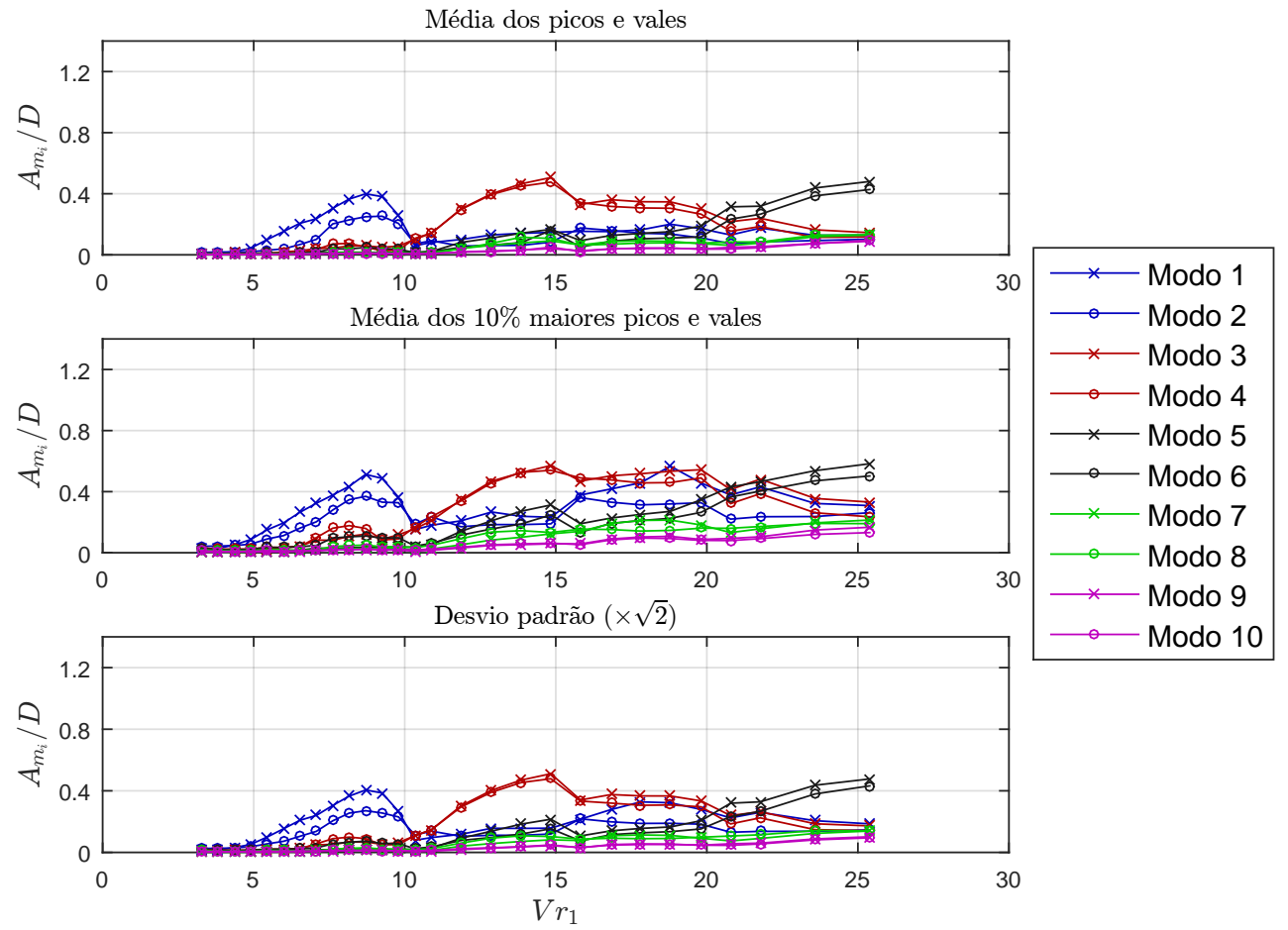

Figura C.26 - Amplitudes Modais em função de $\overline{V r}_{1}-\theta=45^{\circ}$ e $\beta=135^{\circ}$.
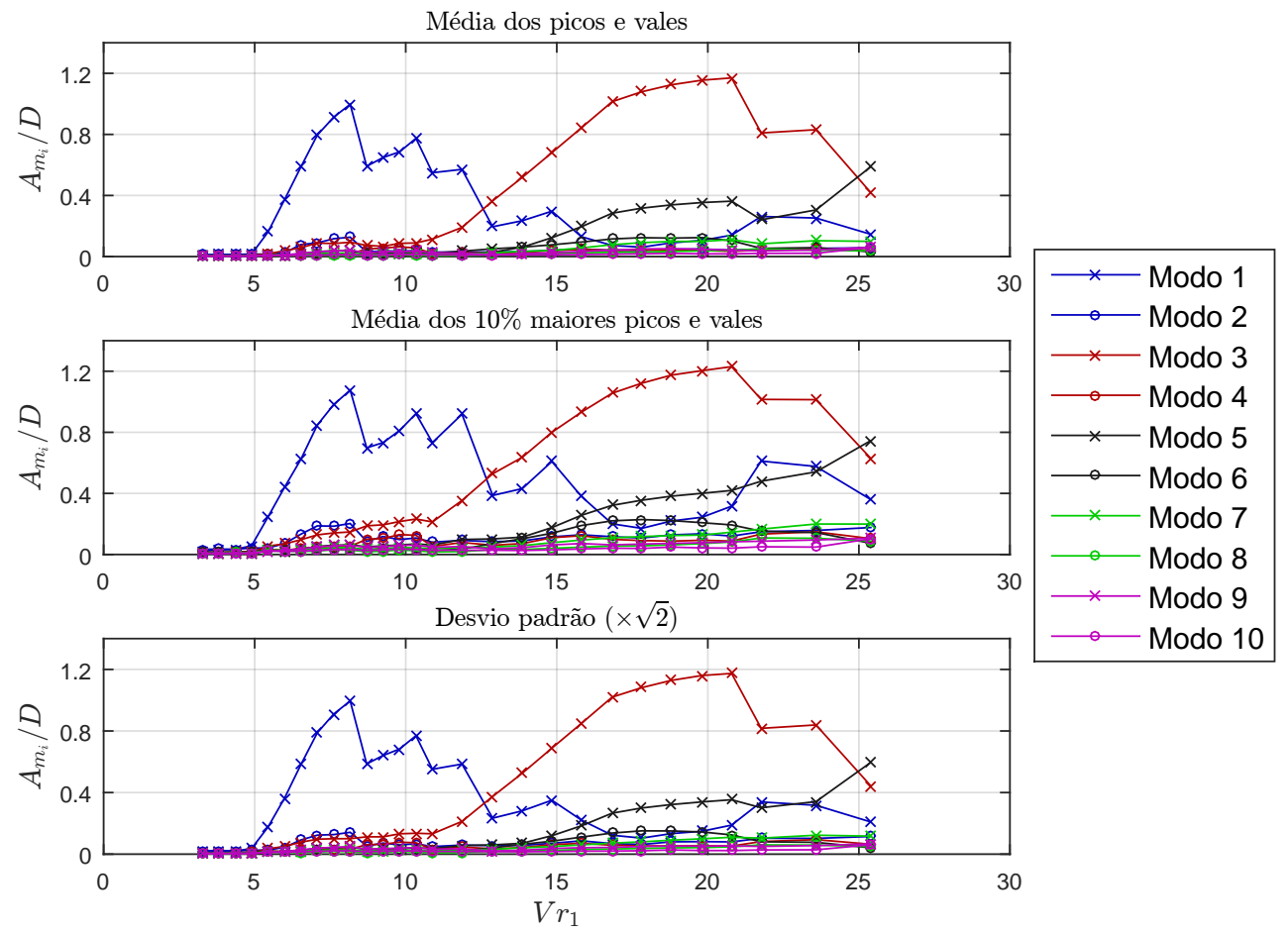

Figura C.27-Amplitudes Modais em função de $\overline{V r}_{1}-\theta=45^{\circ}$ e $\beta=180^{\circ}$. 